\title{
Spezielle Virologie
}




\section{EINLEITUNG}

Picorna-Viren sind kleine RNS-haltige Viren (pico=klein, rna =Ribonukleinsäure) mit einem Durchmesser von etwa $30 \mathrm{~nm}$. Sie sind weltweit verbreitet und rufen die gefürchtete Kinderlähmung, Meningitis, Herz- und Skelettmuskelerkrankungen, Exantheme und Hepatitis hervor. Sie haben sich aus einem gemeinsamen Vorfahren entwickelt und weisen viele Gemeinsamkeiten, aber auch viele Unterschiede auf.

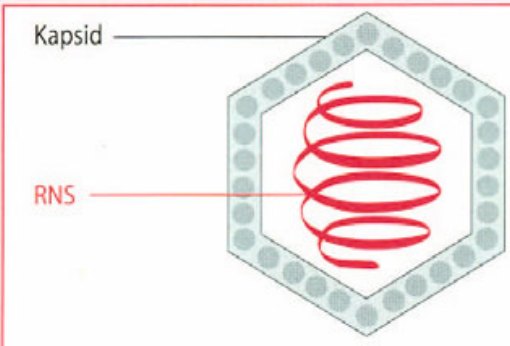

Picorna - Virus
$30 \mathrm{~nm}$

\section{Genom}

Die RNS liegt im Virion als (+)-Strang-RNS vor, sie besteht aus einer nicht-kodierenden Region am 5 '-Ende, einer kodierenden Region für Strukturund Nichtstruktur-Proteine sowie am 3'-Ende des Moleküls eine poly-Adenosin-Sequenz. Sie enthält etwa 7,5 Kb. Am 5'-Ende der (+)- und (-)-RNSStränge sitzt jeweils ein kovalent gebundenes Protein, das als Primer für die Replikation erforderlich ist.

\section{Morphologie}

Alle Picorna-Viren bestehen aus einem Kapsid in Ikosaederform und einem zentral gelegenen RNSKnäuel. Bei der Translation entsteht zunächst ein Vorläufer-Protein; es wird für den Aufbau des Kapsids in vier Virusproteine (VP 1-4) sowie Nichtstruktur-Proteine durch Virusproteasen gespalten. Die VP 1, 2 und 3 sind die wichtigsten immunisierenden Proteine, das VP 1 dient als Ligand für den

Rezeptor auf der Wirtszelle. Das VP 4 liegt im Inneren des Kapsids. Die Kapsomeren bilden ein Ikosaeder-Kapsid mit einem Durchmesser von etwa $30 \mathrm{~nm}$.

\section{Züchtung}

Polio-Virus läßt sich gut auf Affennieren-Zellen züchten, ebenso ECHO- und Entero-Viren. Coxsackie-Viren werden auf Baby-Mäusen isoliert und auf Zellkulturen passagiert. ECHO-Viren sind zytopathogen, aber nicht pathogen für Mäuse.

\section{Resistenz}

Die Entero-Viren sind empfindlich gegen Austrocknen, gegen UV-Strahlen und gegen mäßiges Erhitzen $\left(50^{\circ} \mathrm{C}\right)$, sie sind jedoch sehr säurestabil (Magenpassage) und ätherresistent. In den Abwässern lassen sie sich lange Zeit nachweisen, v.a. bei Anwesenheit von organischen Stoffen. Na-Hypochloritlösung ist ein gutes Inaktivierungsmittel. Durch Formalin kann Polio-Virus unter Erhaltung der Kapsid-Antigenität inaktiviert werden.

Rhino-Viren sind im Gegensatz zu den EnteroViren nur bei pH 6,0-7,5 stabil und sehr temperaturempfindlich.

\section{Einteilung}

Man unterscheidet bei den menschenpathogenen Picorna-Viren vier Genera:

- Entero-Viren,

- Rhino-Viren,

- Hepato-Viren (s. S. 657)

- Parecho-Viren. 
$\mathrm{Zu}$ den Entero-Viren gehören die Spezies:

- Virus der Poliomyelitis (Polio-Virus) mit drei Typen,

- Coxsackie-Viren mit den Untergruppen A und B,

- Entero-Viren 68-71.

Die Viren dieser Gruppe vermehren sich vorzugsweise in den Zellen des Dünndarms und werden mit den Fäzes ausgeschieden. Der natürliche Wirt für die Entero-Viren ist der Mensch.

\subsection{Polio-Viren}

Das Polio-Virus ist der Erreger der spinalen Kinderlähmung oder Poliomyelitis (Polio); in den Entwicklungsländern ist sie nach wie vor häufig. Viele Infektionen verlaufen inapparent. Es gibt zwei Impfstoffe: IPV und OPV (s.u.), die die Ausrottung des Virus ermöglichen sollen.
- ECHO-Viren,

ihre Kinder im Sommer nicht in die Schwimmbäder gehen ließen, oder sie aus Furcht vor einer Ansteckung sogar ganz zu Hause hielten. Inzwischen ist in den Industrieländern das voll pathogene Wildvirus vom attenuierten Impfvirus weitgehend verdrängt worden. Ziel der WHO ist die Ausrottung des Virus.

Maßgebend für die Motivation zur Bekämpfung sind die schwerwiegenden Folgen der zerebrospinalen Komplikation für den betroffenen Einzelnen: Die Lähmungen können zum Tode oder zum Krüppeltum führen. Patienten mit Atemlähmung durch Polio überleben u.U. die Krankheit als Dauergäste der Eisernen Lunge; ihr trauriges Schicksal macht die Poliomyelitis (jetzt nur noch in den Entwicklungsländern) $\mathrm{zu}$ einer gefürchteten Krankheit.

\subsubsection{Beschreibung}

Das Polio-Virus kommt in drei serologisch distinkten Typen vor. Die als Prototypen dienenden Stämme tragen die Namen

- „Brunhilde“ für Typ 1,

- „Lansing“ für Typ 2 und

- „Leon“ für Typ 3.

\subsubsection{Rolle als Krankheitserreger}

Die Kinderlähmung wurde 1840 als Heine-Medin'sche Krankheit beschrieben. 1909 wurde von Landsteiner und Popper das Virus auf Affen übertragen. 1920 erkrankte der frühere Präsident der USA, Franklin D. Roosevelt, an einer Polio. Ihm ist die Gründung einer Stiftung zu verdanken, die für die Bekämpfung der Polio und darüber hinaus für die Entwicklung der Virologie entscheidende Bedeutung erlangt hat.

1949 gelang es den späteren Nobelpreisträgern Enders, Weller und Robbins, Polio-Virus in nichtneuralen Zellen zu züchten und erstmals den „zytopathischen Effekt" (ZPE) nachzuweisen. Erst diese Entdeckung machte die Züchtung der Viren in vitro und die Entwicklung von Impfstoffen möglich.

Vor der Einführung der Schluckimpfung war das Polio-Virus in der Bevölkerung weit verbreitet. Die Furcht vor der Polio war so groß, daß Mütter

\section{Vorkommen}

Virusreservoir und alleinige Infektionsquelle sind der Nasenrachenraum und der Darmkanal von Menschen. Entsprechend der Ausscheidung des Virus in Fäkalien findet sich das Virus in Abwässern und gelegentlich in Freibädern.

\section{Epidemiologie}

Sommer und Frühherbst sind bei der Ausbreitung des Polio-Virus die bevorzugten Jahreszeiten. Die Polio ist das Musterbeispiel einer Krankheit mit einer hohen Quote an stiller Durchseuchung.

Wegen des großen Anteils an klinisch inapparenten Infektionen sind Infektketten nur schwer nachzuweisen. Die hohe Verbreitungspotenz ist v.a. durch Isolierungsversuche an solchen Familien er- 
kannt worden, in welchen ein Mitglied mit der Lebendvakzine geimpft worden war. In Ländern mit niedrigem Hygienestandard und ohne Schutzimpfung werden bereits die Kleinkinder voll durchseucht. Bei besseren Lebensverhältnissen verschiebt sich das Lebensalter der Erstbekanntschaft mit dem Virus zur Adoleszenz hin; die Durchseuchung der Kinder ist nicht mehr vollständig, und die von der Infektion verschonten Kinder können als Erwachsene erkranken. - Diese Tatsache gilt für viele virusbedingte Infektionskrankheiten. Bei den Röteln steigt damit das Risiko der Embryopathie.

Durch die Anwendung des Salk-Impfstoffes sank die Inzidenz in den Jahren 1955-1960 von 13,9 auf 0,5 Fälle pro 100000 Einwohner. Die Epidemiologie der Polio hat sich dann in den Industrieländern durch die Einführung der Schluckimpfung grundsätzlich gewandelt. Bei dem Rückgang der Polio hat auch die Tatsache mitgewirkt, daß der Anteil der Kinder an der Bevölkerung kleiner geworden ist. 1992 hat es auf der Welt 150000,1999 noch 7000 Erkrankungen gegeben.

\section{Übertragung}

Die Übertragung erfolgt direkt von Mensch zu Mensch durch Schmierinfektion fäkal-oral. Als Vehikel dienen verunreinigte Hände, Gebrauchsgegenstände, Wasser und Fliegen. Die Verbreitungspotenz des Virus ist sehr groß: Auch bei strengster Sauberkeit und guten hygienischen Verhältnissen ist eine Übertragung im Familienmilieu praktisch unvermeidbar. Neben der Übertragung durch Fäkalmaterial spielt die Infektion durch Speichel im Sinne der Schmierinfektion und der Tröpfcheninfektion eine wichtige Rolle. Die Ausscheidung des Virus im Stuhl dauert nach apparenter und inapparenter Infektion etwa 6-8 Wochen, gelegentlich auch mehrere Monate, Dauerausscheider gibt es jedoch nicht.

\section{Pathogenese}

Die Polio ist das Musterbeispiel für die Entstehung einer Viruskrankheit durch einen direkten virusbedingten Zellschaden: Die Immunreaktion des befallenen Organismus spielt für die Zellschädigung keine Rolle.

Das Polio-Virus ist primär enterotrop, es infiziert nur selten das ZNS. Seine Rezeptoren auf der Zellmembran hat man als Moleküle der Immunglobulinsuperfamilie der Zellen identifiziert. Der Host-shut-off (s. S. 474) wird durch eine virusko- dierte Protease ausgelöst, die einen Initiationsfaktor für die Translation zerstört, die Zelle stirbt durch Apoptose.

Hinsichtlich der Virusausbreitung im Organismus kann man fünf Stadien des Infektionsverlaufes unterscheiden:

- Lokale Ansiedelung und Vermehrung des Virus in den Zellen der Rachen- und Darmschleimhaut sowie in den Tonsillen und den Peyerschen Plaques. Es wird von den Schleimhäuten ausgeschieden.

- Invasion durch Einbruch des Virus in die Lymphknoten und dann in die Blutbahn (primäre Virämie): „Vorkrankheit“. Hierbei werden viele Viren vom RES abgefangen und abgebaut. Das Virus gelangt auf diesem Weg in die Lymphknoten und das braune Fett und vermehrt sich dort. In einem zweiten Schub gelangt es erneut in die Blutbahn (sekundäre Virämie) und besiedelt die entsprechenden Organe.

- Befall des „Erfolgsorgans“ mit erneuter Vermehrung. Das Virus gelangt durch die Blut-Liquorschranke (Plexus chorioideus?) in den Meningealraum. Über die Endothelien kleiner Gefäße infiziert es die motorischen Vorderhornzellen des Rückenmarkes und vermehrt sich darin. Dies kann zur Schädigung oder zum Untergang der Zellen („Neuronophagie“) und damit zu schlaffen Lähmungen führen. Eine Besonderheit ist das Wandern des Virus entlang der Axone von Nerven. Wunden im Rachenraum (Tonsillektomie) ermöglichen den Eintritt in die Nervenfasern und können die gefürchteten Bulbärparalysen hervorrufen. In seltenen Fällen kann das Hinterhorn der grauen Rückenmarkssubstanz und aszendierend das Gehirn befallen werden. Auch hat man eine Beteiligung des Myokards bei der Polio beobachtet.

- Elimination des Virus in der Rekonvaleszenz. Dies geschieht bei der Polio und den übrigen Picorna-Infektionen vollständig. Hierfür sind neben dem Interferon v.a. humorale Antikörper verantwortlich. Ihre Bedeutung geht aus dem mangelhaften Impfschutz bei Agammaglobulinämie hervor.

- Persistierende Infektionen (Polio-, Coxsackie-, ECHO-Viren) hat man bei Patienten mit und ohne Defekt des humoralen Immunsystems festgestellt. - Pathohistologisch findet man in den befallenen Bezirken des ZNS perivaskuläre Infiltrate. Die nekrotischen Ganglien-Zellen sind von Infiltraten monozytärer Zellen umgeben. 
Sehr selten ist das Post-Polio-Syndrom, d.h. fortschreitende Lähmungen viele Jahre nach der Erstlähmung (s. Anhang).

\section{Klinik}

Die Inkubationszeit beträgt für die klinisch manifesten Fälle 5-10 Tage.

Nach dem Schweregrad des Krankheitsbildes unterscheidet man vier Verlaufsformen:

- Inapparenter Verlauf: Weitaus am häufigsten (99\%).

- Abortiver Verlauf: Katarrhalische Symptome („minor illness"). Hier finden sich leichte, uncharakteristische Symptome einer „Indisposition“.

- Meningitis ohne Lähmungen: Im klaren Liquor findet sich eine lymphozytäre Zellvermehrung („aseptische Meningitis“); meningitische Erscheinungen treten relativ selten auf.

- Paralytische Form: Charakteristisch sind schlaffe Lähmungen, vornehmlich an der Extremitätenmuskulatur, aber auch den Atemmuskeln. In schweren Fällen verläuft die Polio als MeningoEnzephalo-Myelitis. Der Kortex wird dabei nicht befallen. Der Tod kann durch Atemlähmung oder Herzversagen eintreten. Die Lähmungen bilden sich, sofern der Patient überlebt, häufig zurück. Primäre Infektionen verlaufen bei Erwachsenen schwerer als bei Kindern (Abb. 1.1).

- Post-Polio-Syndrom: Nach Jahrzehnten tritt eine Verstärkung der Lähmungen auf (selten).

\section{Immunität}

Die im Gefolge einer natürlichen Infektion auftretende Immunität gegen Poliomyelitis ist humoral und typenspezifisch. Humorale Antikörper werden vorwiegend gegen das Kapsid, aber auch gegen Nichtstrukturproteine gebildet. Vor Einführung der Schutzimpfung hat in Mitteleuropa ein großer Teil der Bevölkerung eine inapparente Infektion mit Wildstämmen durchgemacht und dadurch eine „stille Feiung" erworben.

Im ersten Lebenshalbjahr schützt mütterliches IgG gegen eine Erkrankung. Die durch Infektion mit Wildstämmen erworbene Immunität kann auf zweierlei Weise wirksam werden:

- IgA: Lokal. Im Idealfalle wird bereits die Besiedelung der Schleimhaut verhindert. Hierfür sind Antikörper der Klasse IgA verantwortlich.

- IgG: Systemisch. Bei schwächer ausgeprägter Immunität wird die Schleimhaut zwar besiedelt, die Invasion des ZNS wird aber durch Neutralisation des Virus verhindert. Dies geschieht in der Blutbahn durch IgG-Antikörper. Die lange Dauer der Polio-Immunität beruht vermutlich darauf, daß beim Nachlassen der Immunität unbemerkt verlaufende Neuinfektionen als „Booster" wirken. Über die Beteiligung zellulärer Effektoren bei der Immunität (T-Zellen) ist kaum etwas bekannt.

\section{Labordiagnose}

Die Laboratoriumsdiagnose der Poliomyelitis erfolgt

- durch Isolierung und Identifizierung des Virus aus Patientenmaterial (ggf. durch PCR) sowie

- durch Nachweis der spezifischen Antikörper im Patientenserum mit Anstieg.

Isolierung. Aus Fäzes oder Rachenspülwasser macht man einen NaCl-Extrakt. Die begleitenden Bakterien werden abzentrifugiert und das Material auf eine Affennieren-Zellkultur verimpft. Dann beobachtet man, ob sich ein zytopathischer Effekt in Form von Abkugelung und Ablösung zeigt. Ist dies der Fall, so legt man von der positiven Kultur eine Passage an. Die Isolierung des Polio-Virus aus dem Blut oder dem Liquor gelingt nur selten.

Identifizierung. Der so gezüchtete Stamm muß sich anschließend durch ein typenspezifisches Anti-Polio-Serum 1, 2 oder 3 neutralisieren lassen.

Nachweis von Polio-spezifischen Antikörpern im Patienten-Serum. Zwei im Abstand von 14 Tagen entnommene Serumproben werden mit dem Neutralisationstest oder der KBR gleichzeitig getestet. Ein Titeranstieg um das Vierfache oder mehr spricht für eine akute Polio-Infektion. Die KBR liefert bei Polio nicht sehr aussagekräftige Resultate, weil sie relativ unempfindlich ist. Ein ELISA ist noch nicht verfügbar.

\section{Prävention}

Impfstoffe. Für die Schutzimpfung stehen zwei Impfstoffe zur Verfügung, die Salk-Vakzine und die Sabin-Vakzine. In Deutschland wird in Zukunft vorzugsweise der Salk-Impfstoff angewendet.

Salk-Impfstoff. Die Salk-Vakzine ist ein Totimpfstoff. Der Impfstoff besteht aus Formalin-inaktiviertem Polio-Virus der drei Typen (IPV, inakti- 

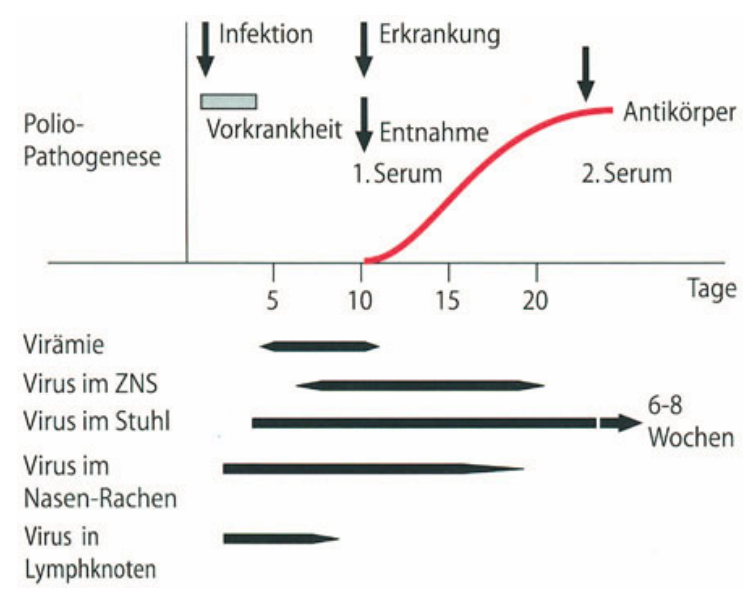

Abb. 1.1. Ablauf einer Polio-Infektion

vierte Polio-Vakzine). Die Viren werden jeweils in der Zellkultur gezüchtet und vor der Inaktivierung gereinigt.

Die Anwendung der Salk-Vakzine erfolgt durch Injektion des trivalenten Totimpfstoffes. Die Impflinge sollen 3-6 Monate alt sein und erhalten die Impfung $3 \times \mathrm{i} . \mathrm{m}$. in Abständen von mehreren Wochen. Die Salk-Impfung wird in Kombination mit anderen Totimpfstoffen angewendet. Sie muß später in größeren Zeitabständen wiederholt werden.

Die Salk-Vakzine war drei Jahrzehnte lang zugunsten der Sabin-Vakzine in den Hintergrund getreten. Neue Herstellungsverfahren haben ihre Antigenität gesteigert, so daß nach der Impfung IgM-, IgGund auch IgA-Antikörper entstehen. Die Salk-Vakzine wird seit langem mit gutem Erfolg angewendet. Auch in Deutschland wird sie jetzt zur Primär- und Auffrischungsimpfung ausschließlich eingesetzt (s. Impftabelle).

Sabin-Impfstoff. Der Sabin'sche Lebendimpfstoff ist seit 1961 als „Schluckimpfung“ in Gebrauch. Er besteht aus lebenden, durch Mutation und Selektion abgeschwächten („,attenuierten“) Polio-Viren (OPV, orale Polio-Vakzine). Die Abschwächung erfolgt für jeden der drei Typen durch Passagen in geeigneten Wirtszellen. Bei den so selektionierten Varianten ist die Neurovirulenz stark reduziert, wäh- rend die Infektiosität und die Antigenität erhalten bleiben. Die Viren des Impfstammes werden vom Impfling über den Magen-Darm-Kanal aufgenommen. Sie führen zu einer inapparenten Infektion.

Die Sabin'sche Impfung wird mit trivalenten Impfstoffen vorgenommen. Die Applikation erfolgt oral. In der Zukunft soll sie reserviert bleiben für Polio-Ausbrüche als Abriegelungsimpfung.

Die WHO hofft, die Polio ausrotten zu können. Eine Gefahr erwächst aus der Impfmüdigkeit der Eltern und der Einschleppung von neuem Wildvirus, etwa durch Gastarbeiter oder Auslandsreisende. Die Infektion mit dem Wildvirus führt zu dessen Ausscheidung im Stuhl und damit ggf. zur Infektion nicht geimpfter Personen.

\section{Therapie}

Die Therapie ist symptomatisch. Es wird künstlich beatmet, früher: Eiserne Lunge. Notwendig sind langdauernde Rehabilitationsmaßnahmen.

Meldepflicht. Bei Verdacht, Erkrankung oder Tod an Poliomyelitis. Erregernachweis, alle Erkrankungen mit schlaffen Lähmungen.

\section{Anhang}

Post-Polio-Syndrom (PPS). In den USA traten bis 1960 große Polioepidemien auf, dank der „Eisernen Lunge" überlebten viele Patienten. Ab 1980 klagten viele von ihnen über Müdigkeit, Muskelschwäche, Erschöpfung u.a. Symptome. In Deutschland schätzt man 10-50000 solcher Patienten.

Die Entstehung des PPS stellt man sich folgendermaßen vor: Die Funktion der abgestorbenen Motoneuronen wurde durch die verbliebenen Zellen übernommen. Offenbar sind die neuen Nervenverbindungen nicht so stabil. Auch muß jedes erhaltene Motoneuron 5-10 mal so viel Muskelzellen versorgen; dies führte auf die Dauer zu einer Überlastung und dadurch $\mathrm{zu}$ den beschriebenen Symptomen. 


\section{ZUSAMMENFASSUNG: Polio-Viren}

Virus. Genus Entero-Virus, Spezies Polio-Virus. (+)-Strang-RNS-Virus, Typ 1, 2 und 3. Ikosaeder mit $30 \mathrm{~nm}$ Durchmesser. Ätherresistent. Virus in Umwelt sehr stabil, transportstabil.

Vorkommen. Virusreservoir ist der Nasenrachenraum und der Darmkanal. Ausscheidung als Aerosol sowie im Stuhl und Urin. Virus in Abwässern und Badegewässern. Meist nur im Sommerhalbjahr.

Epidemiologie. Jetzt Einschleppung aus Entwicklungsländern, Ausbreitung wegen Impfmüdigkeit.

Übertragung. Schmutz- und Schmierinfektion, Aerosolübertragung, Virus in Abwässern.

Pathogenese. Virusbedingte Zellschäden an den motorischen Vorderhornzellen. Ausbreitung von Magen- und Darmschleimhaut über Lymph- und Blutgefäße mit dem Blut, Eindringen ins und Replikation im Rückenmark und Gehirn (zwei Virämiephasen). Inkubationsperiode 5-10 Tage. Weniger als 1\% erkranken mit Lähmungen, Infektionen meist inapparent.

Klinik. Abortive Verläufe, Meningitis und schlaffe Lähmungen mit Meningitis, Atemlähmungen. Post-Polio-Syndrom.

Immunität. IgM-, IgG-, Humoral- und IgASchleimhaut-Antikörper. Keine Kreuzimmunität zwischen den Typen. Zelluläre Immunität?

Diagnose. Virusisolierung aus Liquor, RSW, Stuhl, Urin (und Blut) in Zellkulturen. Antikörperbestimmung im Neutralisationstest.

Therapie. Keine spezifische Therapie, symptomatisch, künstliche Beatmung, Rehabilitationsmaßnahmen.

Prävention. Basisimmunisierung mit SalkImpfstoff, alle späteren Auffrischungen jetzt auch nur noch mit Salk- (IPV-) Impfstoff.

Meldepflicht. Verdacht, Erkrankung, Tod. Erregernachweis, schlaffe Lähmungen!

\subsection{Coxsackie-Viren}

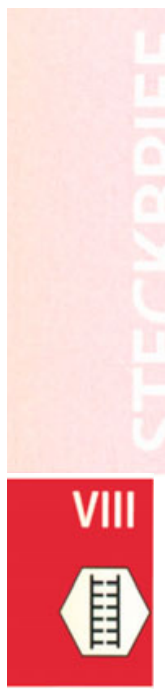

Coxsackie ist der Ort im US-Staat New York, in dem die Erstisolierung erfolgte. Das Spektrum der Virus-Wirt-Beziehungen reicht von asymptomatischen Verläufen bis zu tödlichen Erkrankungen: Erkältungskrankheiten, Meningitis, Myo-Perikarditis, Myositis und Exantheme. Insulin-abhängiger Diabetes mellitus (wahrscheinlich).

\subsubsection{Beschreibung}

Die Coxsackie-Viren (CV) sind serologisch nicht mit den Polio-Viren verwandt; ihre Struktur, der Modus ihrer Replikation und ihr Verhalten in der Umwelt sind jedoch weitgehend identisch.

Man unterscheidet nach den typischen Läsionen im Babymaus-Versuch:

- Die Untergruppe A mit 23 Serotypen. Diese erzeugen bei der Babymaus eine diffuse Myositis.

- Die Untergruppe B mit sechs Typen erzeugt eine herdförmige Myositis, daneben aber auch noch zahlreiche Organ- und Gewebsschädigungen: Eine Enzephalomyelitis mit spastischen Lähmungen, eine nekrotisierende Fettgewebsentzündung sowie Pankreatitis, Myokarditis und Endokarditis. 


\subsubsection{Rolle als Krankheitserreger}

\section{Epidemiologie}

Coxsackie-Viren (CV) sind in der ganzen Welt verbreitet und kommen nur beim Menschen vor.

Innerhalb eines Haushaltes ist eine Ausbreitung unvermeidlich, sobald sich ein Familienmitglied infiziert. Bei nicht-immunen Kindern zirkulieren mehrere Typen gleichzeitig. Diese Gruppe stellt das Hauptreservoir für Coxsackie-Viren dar.

\section{Übertragung}

Die Viren werden mit dem Stuhl ausgeschieden, ihre Übertragung erfolgt von Mensch zu Mensch auf $f \ddot{a}-$ kal-oralem Wege oder durch Tröpfcheninfektion.

\section{Pathogenese}

Eintrittspforte der Coxsackie-Viren sind der NasenRachenraum und der Dünndarm. Es kommt hier wie bei der Polio zur lokalen Vermehrung, anschlieBend zur Generalisation und zur sekundären Ansiedelung und Vermehrung in den Zielorganen (Muskeln, Meningen, Pankreas, Herz und Haut). Coxsackie-Virusinfektionen sind für die Entstehung einer Kardiomyopathie bedeutsam. Mehrere Regionen der CV-RNS sind für die Kardiovirulenz verantwortlich. Durch Hybridisierung hat man persistierende RNS des Coxsackie-Virus in Herzmuskelzellen des Menschen nachgewiesen. TNF- $\alpha$, IFN- $\gamma$, NO sowie CD4- und CD8-Zellen limitieren die Infektion. Die Persistenz der Coxsackie-Viren in Herzmuskelzellen ist wahrscheinlich durch eine Verschiebung der Relation der (+)- zu den (-)-RNSSträngen bei der Replikation bedingt. Die kardiale Persistenz der RNS bleibt über längere Zeit nach Abklingen der akuten Infektion bestehen. CV replizieren sich auch im Glomerulum der Niere.

\section{Klinik}

Die Mehrzahl der Erkrankungsfälle verläuft symptomlos oder wird nicht diagnostiziert. Die Inkubationsperiode variiert von einem Tag bis zu 2-3 Wochen. Die klinisch wahrnehmbare Infektion mit Coxsackie-Viren verläuft stets fieberhaft und manchmal mit Exanthem. Folgende Symptomenkomplexe sollten den Verdacht auf eine CoxsackieInfektion entstehen lassen (Tabelle 1.1):
Tabelle 1.1. Krankheiten durch Coxsackie-, ECHO- und Entero-Viren

\begin{tabular}{|c|c|}
\hline Symptom & Virustyp \\
\hline \multicolumn{2}{|l|}{ Zentralnervensystem } \\
\hline Meningitis & Coxsackie-, ECHO-, Entero-Viren \\
\hline Lähmung & $\begin{array}{l}\text { Entero-Virus } 70,71 \text {; ECHO } \\
\text { Coxsackie A7, A9, B2-5 }\end{array}$ \\
\hline Enzephalitis & Entero 71 und andere \\
\hline Chron. Meningo-Enzephalitis & ECHO-Viren u.a. \\
\hline \multicolumn{2}{|l|}{ Skelett- und Herzmuskel } \\
\hline Myokarditis und Perikarditis & Coxsackie B, einige Coxs. A, ECHO \\
\hline $\begin{array}{l}\text { Pleurodynie (Bornholm'sche } \\
\text { Krankheit) }\end{array}$ & Coxsackie B \\
\hline \multicolumn{2}{|l|}{ Haut und Schleimhaut } \\
\hline Herpangina & Coxsackie A 1-10, 16, 22, B1-5 \\
\hline $\begin{array}{l}\text { Hand-Fuß- } \\
\text { u. Mundkrankheit }\end{array}$ & $\begin{array}{l}\text { Coxsackie A4, } 5,9 \text { u. 16, B 2, } 5 \text {, } \\
\text { Entero-71, andere }\end{array}$ \\
\hline Makulo-papulöses Exanthem & ECHO 9 u. 16, u.v.a., Coxs. A \\
\hline \multicolumn{2}{|l|}{ Obere Luftwege } \\
\hline Schnupfen & Coxsackie A 21 u. 24 , \\
\hline Sommergrippe & ECHO 11,20 , Coxs. B 1-5 \\
\hline \multicolumn{2}{|l|}{ Auge } \\
\hline Akute hämorrh. Konjunktivitis & Entero 70, Coxs. A 24 \\
\hline \multicolumn{2}{|l|}{ Perinatal } \\
\hline $\begin{array}{l}\text { Myokarditis, Hepatitis, } \\
\text { Enzephalitis }\end{array}$ & $\begin{array}{l}\text { Coxsackie A und B, ECHO 11, } \\
\text { u.a. }\end{array}$ \\
\hline
\end{tabular}

Herpangina. Eine mit Bläschen einhergehende fieberhafte Rachenentzündung. Der Patient hat Schluckbeschwerden. Die Herpangina wird vornehmlich durch die Viren der Untergruppe A verursacht (Abb. S. 687).

Schnupfen und Pharyngitis. Einige CoxsackieViren, z. B. A21, erzeugen ein Krankheitsbild, welches als banaler Schnupfen oder als fieberhafte Pharyngitis auftritt.

"Sommergrippe“. Eine unter dem Bilde einer Erkältungskrankheit verlaufende fieberhafte Infektion im Frühjahr, Sommer und Frühherbst. Hier kommen alle Typen in Betracht.

Pleurodynie. (Synonyme: Bornholm'sche Erkrankung, epidemische Myalgie). Die Patienten klagen über plötzlich auftretendes Unwohlsein mit Fieber und heftigen Thoraxschmerzen, z.T. auch über Leibschmerzen. Dieses Krankheitsbild wird v.a. durch Viren der Untergruppe B hervorgerufen. 
Abakterielle Meningitis. Es kommt zu Meningismus mit Fieber, Nackensteifheit, Kopfschmerzen, Erbrechen, geringgradiger Zellvermehrung (Lymphozyten) im Liquor; gelegentlich beobachtet man lokale Pseudoparesen aufgrund von myalgischer Muskelschwäche. Die „Paresen“ bilden sich vollkommen zurück. Bei der Meningitis sind vornehmlich die Viren der Untergruppe B beteiligt; Viren der Untergruppe A findet man seltener.

Das myokarditische Bild. Beim Neugeborenen und bei Säuglingen verursachen die Viren der Gruppe B eine Myokarditis mit hoher Letalität (sog. Säuglingsmyokarditis). Tritt der Tod nicht ein, so erholen sich die Kinder vollständig. Die Symptome sind Zyanose, Dyspnoe und Tachykardie.

Beim Erwachsenen kommt es durch Viren der Untergruppe A und B zu einer akuten Myokarditis bzw. Myo-Perikarditis, deren Bild manchmal an einen Herzinfarkt erinnert. Man schätzt, daß $5 \%$ aller apparent verlaufenden Infektionen durch Coxsackie-Viren mit Beteiligung des Herzens einhergehen. Die Prognose der Erkrankung beim Erwachsenen ist besser als beim Neugeborenen. Pro Jahr beobachtet man in der Bundesrepublik etwa 10000 neue Fälle mit einer dilatativen Kardiomyopathie, davon 1/4 durch Coxsackie-Viren; auch Adeno-Viren und das ZMV sind beteiligt. Man vermutet auch die Auslösung von Aborten (bei Primärinfekten).

Exantheme. Generalisiert, Röteln-ähnlich und das sog. „hand-foot-and-mouth-disease“ (Bläschen auf Handinnenfläche, Fußsohle und Mundschleimhaut) (Abb. s. S. 687).

Akuter IDDM. Coxsackie B4- und B5-Infektionen sind in Beziehung zur Entstehung eines „insulinabhängigen Diabetes mellitus" (IDDM) gebracht worden. In einigen Fällen ist tatsächlich dieses Virus in den Inselzellen nachgewiesen worden. Die Serokonversion von Autoantikörpern gegen Inselzellantigene ist mit Coxsackie-Virusinfektionen korreliert; die PCR erlaubt jetzt häufig bei diesen Fällen den Nachweis von Coxsackie-Viren im Blut.

Für die Entstehung des Diabetes vom Typ 1 macht man Autoimmunprozesse in Verbindung mit bestimmten MHC-Konstellationen (DR1, 3, 4 sowie selten 2 und 5) verantwortlich. Die epidemiologischen Daten sprechen für einen Infektionsprozess nach dem Hit und Run-Prinzip, dem sich immunpathologische Vorgänge infolge Molekularmi- mikry (Glutaminsäuredecarboxylase und Inselzellen mit dem Virus) anschließen. Aus Monozyten wird dabei TNF $a$, IFN $a$ sowie IL-1 freigesetzt, die ZTL aktivieren und den Prozeß unterhalten. In den Inselzellen steigt dadurch auch die MHC-Expression. Im Tiermodell (EMC-Virus in der Maus) ist ein primärer Virusschaden mit einem sekundären Autoimmunprozeß verknüpft.

Hämorrhagische Konjunktivitis. Das Coxsackie A24-Virus erzeugt ausgedehnte Epidemien von akuter, hämorrhagischer Konjunktivitis ohne neurologische Symptome.

\section{Immunität}

Die durch Überstehen der Krankheit erworbene Immunität ist relativ dauerhaft, so daß ältere Personen seltener infiziert werden.

Es gibt innerhalb der Coxsackie-Gruppe eine Vielzahl von serologischen Kreuzreaktionen, die sich im Neutralisationstest und in der KBR nachweisen lassen. Die Aussagefähigkeit der Seroreaktionen ist deshalb beschränkt; die Typendiagnose gelingt im Neutralisationstest.

\section{Labordiagnose}

Züchtung. In der akuten Phase der Coxsackie-Infektionen werden Stuhl, Rachenspülwasser und Liquor untersucht. In der Rekonvaleszenz ist nur die Stuhluntersuchung sinnvoll. Die primäre Verimpfung des infektiösen Materials erfolgt auf Babymäuse und auf Affennieren-Zellkulturen. Mit der PCR lassen sich jetzt bei unklaren Fällen mit Meningitis und Fieber viel häufiger Entero-Viren nachweisen. Biopsien erfolgen bei unklarer Herzbeteiligung.

Nachweis von Antikörpern. Typenspezifische Antikörper lassen sich durch den Neutralisationstest bestimmen. Die KBR ist wenig empfindlich; neuerdings wird ein ELISA (IgG und IgM) mit Gruppenreaktivität angeboten.

\section{Therapie, Schutzimpfung, allgemeine Maßnahmen}

Es gibt weder eine spezifische Therapie noch eine Schutzimpfung. Allgemeine Maßnahmen sind nicht erforderlich. Meldepflichtig sind Erkrankung und Tod an Meningitis/Enzephalitis. 
Virus. Entero-Virus, Genus der Picorna-Viren. (+)-RNS-Virus wie Polio; Gruppe A mit 23 und Gruppe B mit sechs Serotypen. Transportstabiles Virus.

Vorkommen. Virusreservoir ist der Nasen-Rachenraum und der Darmkanal des Menschen. Ausscheidung als Aerosol sowie im Stuhl und Urin. Virus in Abwässern und Freibädern. Meist im Sommerhalbjahr.

Epidemiologie. Weltweite Verbreitung und frühzeitige Durchseuchung. Virusreservoir ist nur der Mensch.

Übertragung. Ausscheidung mit dem Stuhl, fäkal-orale Übertragung sowie Tröpfcheninfektion.

Pathogenese. Ausbreitung im Organismus wie Polio. Gruppe A erzeugt in der Babymaus eine diffuse, Gruppe B eine herdförmi- ge Myositis. Myokardbefall kann zu Kardiomyopathie führen.

Klinik. Inkubationsperiode 6-12 Tage. Herpangina, Schnupfen, Pharyngitis, "Sommergrippe", Bornholm'sche Erkrankung, Myo-Perikarditis, dilatative Kardiomyopathie, Meningitis, Exantheme, Konjunktivitis, Säuglingsmyokarditis, IDDM. DD: Herzinfarkt.

Immunität. Relativ dauerhafte Immunität, serologische Kreuzreaktionen.

Diagnose. Isolierung in der Babymaus und Zellkulturen aus Rachenspülwasser, Stuhl, Liquor. Typisierung im Neutralisationstest. Herzmuskelbiopsie.

Therapie. Symptomatisch.

Prävention. Keine. Cave: Nosokomiale Infektion (Säuglinge).

Meldepflicht. Meningitis, Lähmungen.

\subsection{ECHO-Viren}

ECHO-Viren kommen nur beim Menschen vor, sie erzeugen eine Vielzahl von Krankheitsformen. Sie wurden erst nach und nach bekannt, als die Viren bereits lange Zeit als ECHO-(Enteric, Cytopathogenic, Human, Orphan [engl. Waisen])-Viren isoliert und typisiert worden waren.

\subsubsection{Beschreibung}

ECHO-Viren werden zur Familie der Picorna-Viren gezählt. Innerhalb der ECHO-Gruppe gibt es 32 verschiedene Serotypen. Im Unterschied $\mathrm{zu}$ den
Coxsackie-Viren sind die ECHO-Viren nicht infektiös für Säuglingsmäuse. ECHO-Viren kommen nur beim Menschen vor und werden wie die anderen Entero-Viren übertragen, ihre Epidemiologie gleicht derjenigen der Coxsackie-Viren.

\subsubsection{Rolle als Krankheitserreger}

\section{Pathogenese}

Die Ausbreitung im Organismus erfolgt wie die der Coxsackie-Viren lymphogen-hämatogen. ECHO-Viren befallen viele verschiedene Zellspezies.

\section{Klinik}

Die Inkubationszeit beträgt von 12 Stunden bis $\mathrm{zu}$ einem Monat, meistens 6-12 Tage. Die Infektion mit ECHO-Viren verläuft in der überwiegenden Mehrzahl der Fälle inapparent. In relativ wenigen Fällen kommt es zu fieberhaften Erkrankungen 
mit einem gelegentlichen Ausbruch von papulomakulösen Exanthemen. Es können sich dabei die folgenden Symptome herausbilden: Meningitis, Myalgie, Pharyngitis, Schnupfen, fieberhaftes Exanthem („Boston“-Exanthem), übertragbare hämorrhagische Konjunktivitis, „hand-foot-andmouth-disease“. Perinatale Infektionen bewirken lebensbedrohende Allgemeinerkrankungen (Blutungen, Apnoe, Hepatosplenomegalie, Hypothermie; s. a. Tabelle 1.1, S. 537).

\section{Immunität}

Die Humoralimmunität wird durch IgM- und IgGAntikörper hervorgerufen, IgA-Antikörper schützen die Schleimhäute. Während bei Erstinfektionen typenspezifische Antikörper entstehen, bilden sich bei Reinfektionen zunehmend kreuzreagierende Antikörper. ZTL bewirken die Elimination des Virus, bei neonatalen Infektionen sind sie häufiger als Antikörper zu finden.

\section{Labordiagnose}

Während der akuten Phase untersucht man Rachenspülwasser, Liquor und Stuhl (Analabstriche) auf die Anwesenheit des Virus. In der Rekonvaleszenz ist nur die Stuhluntersuchung aussichtsreich. Die Züchtung gelingt auf Zellkulturen von Mensch und Affe.

Die Identifizierung erfolgt nach Angehen des Virus durch Neutralisation mit bekannten Seren. Nicht selten werden Virusgemische isoliert. Hier ist eine Klonierung durch Abimpfung einzelner Plaques notwendig (s. S. 526).

Die serologische Untersuchung der Kranken ist wegen der stillen Durchseuchung und der Typenvielfalt ohne diagnostischen Wert. In Zweifelsfällen wird die RT-PCR eingesetzt

\subsection{Parecho-Viren (ECHO 22 und 23)}

Sie lassen sich durch ihre RNS-Sequenz abgrenzen, das „cleavage“ des Vorläuferproteins ist unvollständig. Prototyp ist das ECHO 22-Virus. Ein naher Verwandter (Ljunga-Virus) wurde von Wühlmäusen in Nordschweden isoliert. Dort korreliert die Zahl der Nagetiere (Maximum alle 3-4 Jahre) mit der Häufigkeit des Auftretens von GBS, IDDM und Myokarditis beim Menschen. Diese Viren sind außerdem für Gastroenteritis, Erkältungen, Myokarditis und Enzephalitis verantwortlich.

\subsection{Entero-Viren 68, 69, 70, 71 und 72}

Diese Viren sind erst im letzten Jahrzehnt isoliert worden. Das Entero-Virus 70 ruft eine akute, hämorrhagische Konjunktivitis sowie Paralysen und Meningoenzephalitis hervor. Die Erkrankungen treten pandemisch-epidemisch vorzugsweise in übervölkerten tropischen Städten (Nord- und Südamerika, Japan, Indien und südpazifische Inselwelt) auf. Die Konjunktiven sezernieren ein seromuköses Sekret. Kurzfristige Titer von IgM-Antikörpern sind im Serum festgestellt worden. Während die Infektionen bei Kindern häufig asymptomatisch sind, führt die Infektion der Erwachsenen zur akuten hämorrhagischen Konjunktivitis (Tabelle 1.1, S. 537).

Der Typ 71 ruft Fieber, Meningoenzephalitis, schlaffe Paralysen und das Hand-Fuß-Mund-Syndrom hervor. Schwere Fälle verlaufen lokal-epidemisch zusätzlich mit einem neurogenen Lungenödem bzw. -hämorrhagien sowie Myokarditis. Pathohistologisch bieten die ZNS-Erkrankungen das Bild einer Hirnstammenzephalitis (ggs. Polio: Bulbärparalyse!).

Die Typen 68 und 69 erzeugen Infektionen der oberen und unteren Luftwege, einschließlich Bronchiolitis und Pneumonie. Das Entero-Virus 72 ist mit dem Hepatitis A-Virus identisch (s. S. 657), gehört jetzt zum Genus Hepato-Virus. 
ZUSAMMENFASSUNG: ECHO-, Parecho- und Entero-Viren

Virus. Entero-Virus, Genus der Picorna-Viren. (+)-RNS-Virus, wie Polio. Mehr als 30 Typen, sowie Entero-Viren 68-71, Parecho-Viren. Transportstabil.

Vorkommen. Virusreservoir ist der Nasenrachenraum und der Darmkanal. Ausscheidung als Aerosol sowie im Stuhl und Urin. Virus in Abwässern und Freibädern. Meist im Sommerhalbjahr.

Epidemiologie. Weltweite Verbreitung und frühzeitige oder auch spätere Durchseuchung.

Übertragung. Ausscheidung und Übertragung wie Polio- und Coxsackie-Viren.

Pathogenese. Keine Babymaus-Pathogenität. Ausbreitung im Organismus lympho-hämatogen.
Klinik. Inkubationsperiode 6-12 Tage. ECHOViren: Fieberhafte Infekte der oberen und unteren Luftwege, makulo-papulöse Exantheme, Meningitis, Myalgie, Myokarditis, Pharyngitis, hämorrhagische Konjunktivitis (Entero-Virus Typ 70), hand-foot-and-mouth-disease (Typ 71), Pneumonie, z.T. schlaffe Paralysen und Enzephalitis (Typ 70 und 71) G.B.S. und IDDM.

Immunität. Die Immunität ist humoral bedingt. Hinzu kommt Schleimhautimmunität durch sekretorisches $\lg$ A.

Diagnose. Rachenspülwasser, Liquor, Stuhl zur Isolierung auf Zellkulturen; Identifizierung im Neutralisationstest. PCR.

Antikörpernachweis ist ungebräuchlich.

Therapie. Symptomatisch.

Prävention. Keine.

Meldepflicht. Enzephalitis, Meningitis, Lähmungen, Erregernachweis.

\subsection{Rhino-Viren}

Die Rhino-Viren sind neben anderen Viren die Haupterreger des Schnupfens (" common cold") mit etwa $30-50 \%$. Sie sind trotz ihrer Harmlosigkeit für einen hohen Anteil an Arbeitsausfällen verantwortlich. Die Replikation erfolgt bei $33^{\circ} \mathrm{C}$ im Epithel. Das Sekret ist sero-mukös mit vielen Granulozyten.

\subsubsection{Beschreibung}

Sie gleichen im Aufbau den anderen Picorna-Viren, besiedeln jedoch vorwiegend den Nasenrachenraum; ihre Virulenzeigenschaften differieren beträchtlich. Es gibt über 100 Serotypen; sie lassen sich im Hinblick auf ihre Bindung an bestimmte Zellrezeptoren (interzelluläres Adhäsionsmolekül „ICAM") in zwei Gruppen einteilen; nur eine Gruppe (90 Rhino-Viren) bindet sich an ICAM's.

\subsubsection{Rolle als Krankheitserreger \\ Vorkommen, Übertragung und Epidemiologie}

Sie kommen nur beim Menschen vor, und zwar während des ganzen Jahres. Die Übertragung erfolgt überwiegend indirekt durch virusverunreinigte Hände oder Gegenstände, aber nur zu einem kleinen Teil durch Aerosol-Infektion. Rhino-Viren treten epidemisch im Frühjahr und Herbst auf, die Durchseuchung ist hoch.

\section{Pathogenese}

Rhino-Viren befallen nur die Epithelzellen des Nasenrachenraumes. Sie rufen i.allg. nur begrenzte Schädigungen hervor. Im Elektronenmikroskop er- 
kennt man einzelne, abgestoßene Zellen. Es kommt fast nie $\mathrm{zu}$ einer Generalisation; andere Schleimhäute werden nicht befallen. Dies ist u.U. für die klinische Differentialdiagnose gegenüber Adeno-, Coxsackie- und ECHO-Viren wichtig. Schnupfen durch Rhino-Viren und durch CoronaViren läuft in der gleichen Weise ab. Man nimmt daher an, daß ihnen ein gleichartiger Entzündungsmechanismus zugrunde liegt (vasoaktive Amine, Vasokine). Die Symptome beruhen auf einer Hyperämie mit Hypersekretion von sero-mukösem Schleim sowie einer akuten Entzündung der Schleimhaut. Die größte Menge an Virus läßt sich immer dann feststellen, wenn die wäßrige Sekretion am größten ist. Bei Rhino-Virusinfektionen wird IL-1 freigesetzt, das die Adhärenz der Granulozyten erhöht und diese wie auch T-Lymphozyten anlockt. Infolge der gesteigerten Gefäßdurchlässigkeit treten Albumin und andere Serumbestandteile in das Sekret über. Histamin wird nicht gefunden. Mit einiger Sicherheit werden auch die Nebenhöhlen in die "Erkältung“ einbezogen; dies bedeutet aber noch keineswegs eine mit Antibiotika behandlungsbedürftige Sinusitis!

\section{Klinik}

Nach einer Inkubationsperiode von 1-3 Tagen entwickeln sich typische Symptome: Ausfluß aus der Nase, Niesen, Husten, Kopfdruck, verstopfte Nase und rauher Hals. Die Beteiligung von pharyngealen und bronchitischen Symptomen wechselt mit dem Serotyp und von Person zu Person. Innerhalb von 2-3 Tagen werden die Symptome ausgeprägter, sie bleiben dann 2-3 Tage im Maximum und gehen im Anschluß daran schnell zurück. Fieber fehlt meistens. Häufig werden die Nebenhöhlen einbezogen. Bei Rauchern treten Rhino-Virusinfektionen nicht gehäuft auf; die Krankheit dauert aber durchschnittlich länger und verläuft schwerer.
Bei Rauchern ist die Phagozytosefähigkeit der Makrophagen herabgesetzt. Komplikationen: Otitis media und Sinusitis.

\section{Immunität}

Die Antigenität der Rhino-Viren ist gering, so daß keine dauerhafte Immunität entsteht. IgG- und IgA-Antikörper bewirken den Immunschutz; es gibt zwischen den Typen keine Kreuzimmunität. Auch spezifisch sensibilisierte TH1-Lymphozyten treten auf und produzieren IL-2 und IFN- $\gamma$.

\section{Labordiagnose}

Rhino-Viren können in menschlichen embryonalen Zellen bei $32^{\circ} \mathrm{C}$ gezüchtet werden. Die Züchtung gelingt nur, wenn man die Temperatur und den $\mathrm{pH}$-Wert der Kultur den Verhältnissen der Nasenschleimhaut beim Lebenden angleicht. Die zahlreichen Typen lassen sich durch den Neutralisationstest unterscheiden. Eine Routinediagnostik gibt es nicht.

\section{Therapie}

Rhino-Virusinfektionen sind eher unangenehm als bedrohlich. Man hat mit Erfolg versucht, ihr Angehen durch Gaben von $a$-Interferon zu hindern. Eine Dauerbehandlung mit Interferon verbietet sich, da Nebenwirkungen (Nasenbluten und Verstopfung der Nase) auftreten. Eine kausale Therapie gibt es noch nicht.

\section{Prävention}

Die beste Präventivmaßnahme ist die Befolgung allgemeiner Hygieneregeln, oftmaliges Händewaschen und die Benutzung von Einmaltaschentüchern. 
ZUSAMMENFASSUNG: Rhino-Viren

Virus. Picorna-Virus. Mehr als 100 Typen von (+)-RNS-haltigen Viren, relativ temperaturempfindlich.

Vorkommen. Ganzjährig, nur beim Menschen.

Übertragung. Durch virushaltige Hände (Nasensekret), seltener Tröpfcheninfektion.

Epidemiologie. Mehrere Infektionen pro Jahr (4-6), gehäuft im Herbst und Frühjahr.

Pathogenese. ICAM's dienen z.T. als Rezeptoren auf der Zelle. Lokale Schleimhautinfektio- nen, kaum Generalisierung. Zerstörung einzelner Schleimhautzellen.

Klinik. Banaler Schnupfen, 1-3 Tage nach Ansteckung. Komplikationen.

Immunität. Kurzdauernde Immunität durch IgA-Antikörper. Keine Kreuzimmunität.

Diagnose. Züchtung in Zellkulturen bei $32^{\circ} \mathrm{C}$ (nicht gebräuchlich).

Therapie. Symptomatisch.

Prävention. Händewaschen. Hygienisches Verhalten bei Schnupfen. 
D. FALKE

\section{EINLEITUNG}

Orthomyxo-Viren rufen beim Menschen die Influenza ("Grippe") hervor, das als Hauptvertreter dieser Virusfamilie gilt, 3 Genera (Influenza A, B und C). 1918 hat die Pandemie der „Spanischen Grippe" 20 Mio Todesopfer gefordert. Das Influenza-Virus bewirkt bei Pan- und Epidemien Übersterblichkeit. Bei diesem Virus hat man als Grund seines besonderen epidemiologischen Verhaltens den Antigendrift und -shift entdeckt und als Ursache Punktmutationen und Reassortment festgestellt. Orthomyxo-Viren besitzen die Eigenschaft der Hämagglutination.

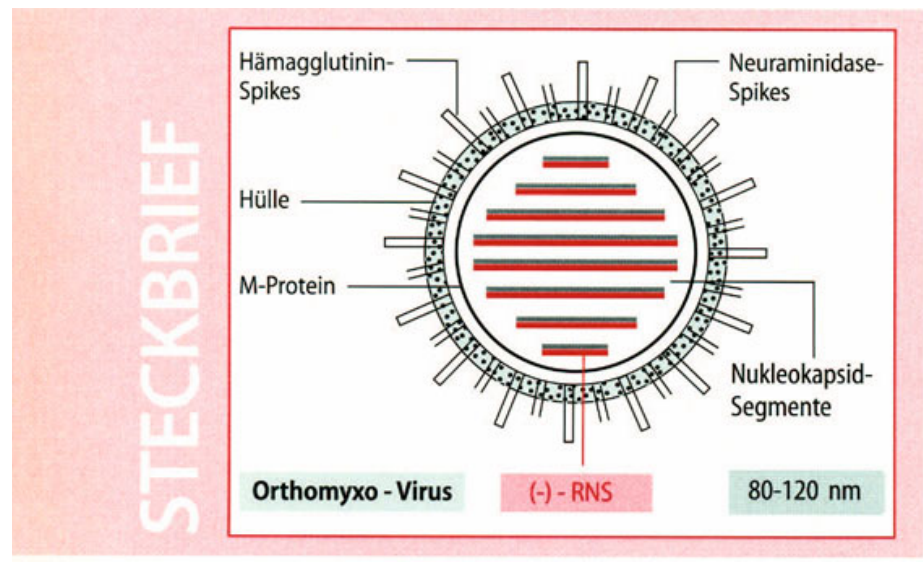

\subsection{Beschreibung}

\section{Genom}

Die RNS der Orthomyxo-Viren besteht aus (-)Strang-RNS; sie kann sich deshalb nicht mit den Ribosomen verbinden. Ein (+)-Strang dieser RNS wird gleich zu Beginn der Replikation durch eine im Virion enthaltene Replikase synthetisiert. Erst dann kann die Synthese von RNS und Proteinen beginnen. Das Genom enthält 13,0 Kb.

Die RNS der Influenza-Viren ist segmentiert. Beim Influenza-Virus A und B gibt es jeweils acht Segmente, bei Influenza $C$ sieben Segmente. Im Kern erfolgt die RNS-Replikation, die Montage erfolgt an der Zellmembran.

\section{Morphologie}

Das $80-120 \mathrm{~nm}$ große Influenza-Virus besteht aus einem helikalen, segmentierten Ribonukleokapsid, das von einer Hülle mit Spikes umgeben ist. Diese sitzen auf der Außenseite der lipidhaltigen Hülle. Sie entstehen aus dem als HA bezeichneten Hämagglutinin. Durch enzymatische Spaltung des Gesamtmoleküls $\mathrm{HAO}$ entstehen zwei getrennte $\mathrm{Ab}$ schnitte der Proteinkette, nämlich HA1 und HA2; ihr Zusammenhalt wird aber noch durch eine S-SBrücke gesichert. Durch die Spaltung gewinnt das Molekül eine neue, pathogenetisch wirksame Eigenschaft - es wird infektiös.

Außerdem gibt es kleinere, Spikes-ähnliche Strukturen, die aus Neuraminidase bestehen. Unter der Lipid-Hülle befindet sich das sog. Matrixprotein (M-Protein).

Schüttelt man intakte Partikel des Influenza-Virus mit Äther, so kann man elektronenoptisch und serologisch folgende Partikelfragmente nachweisen:

Hämagglutininpartikel. Sie sind ca. $30 \mathrm{~nm}$ groß und entstehen durch Zusammenlagerung einzelner Hüllenteile, auch der Neuraminidase. Diese Partikelbestandteile haben die gleiche Antigenspezifität wie im intakten Virion.

Nukleokapsid. Es sind fädige Bruchstücke von 10 nm Durchmesser und $60 \mathrm{~nm}$ Länge. Die Nukleokapsid-Fragmente bestehen aus einer „RNS-Seele“ und einem diese „Seele“ einhüllenden „Kapsidschlauch". 
Aus der Ätherphase lassen sich Lipide gewinnen, die beim intakten Viruspartikel das Hämagglutinin und die Nukleokapsid-Segmente zusammenhalten.

Die Bauelemente des Influenza-Virus sind biologisch in verschiedener Hinsicht wirksam:

- Die hämagglutinierenden Strukturen (H) mit den Antigendeterminanten, die für die Neutralisation und für die Hämagglutinationshemmung maßgebend sind. Sie bestimmen die serologische Spezifität der Subtypen und deren Varianten (V-Ag).

- Die Neuraminidase-Aktivität (N). Sie ist in der Hülle des Virions neben den HämagglutininSpikes in Form kleinerer Spikes lokalisiert. Sie ist für die Immunität nur von untergeordneter Bedeutung.

- Das Nukleokapsid ist der Sitz der typenspezifischen Kapsid-Antigene. Diese haben keine Beziehung zur Neutralisation und auch nicht zur Hämagglutinationshemmung (S-Antigen).

Das M-Protein wird weder in der diagnostischen KBR noch im Hämagglutinationstest erfaßt. Es ist ein typenspezifisches Antigen.

Eine Zusammenstellung der Eigenschaften des Virus findet sich in Tabelle 3.1 (s. S. 552).

\section{Typen und Subtypen des Influenza-Virus}

Man bezeichnet die Virusstämme, welche das gleiche Kapsid-Antigen haben, als Typ (A, B oder C). Nur der Typ A weist bei konstantem Kapsid-Antigen hinsichtlich seiner Hülle wesentliche Strukturverschiedenheiten auf: Die Spikes der Hülle kommen in Form mehrerer, serologisch distinkter Subtypen vor (z. B. H1, H2 oder H3).

Das Hüllmaterial wird mit Hilfe bekannter, subtypenspezifischer Antikörper charakterisiert. Man verwendet dazu den Hämagglutinations-Hemmungstest. Das Kapsidmaterial wird mit Hilfe von bekannten typenspezifischen Antikörpern in der Komplementbindungsreaktion bestimmt.

Die Bezeichnung eines Influenza-Virus ergibt sich aus einer Formel, z.B. A/Hongkong/1/68 (H3N2). Dabei ist A die Typenbezeichnung; der Ortsname bezieht sich auf den Fundort. Die Ziffer 1 gibt die Nummer des jeweils isolierten Stammes an; die Zahl 68 bezieht sich auf das Isolierungsjahr. H3N2 gibt die Nummern von $\mathrm{H}$ oder $\mathrm{N}$ an.

\section{Antigenwandel}

Der Typ $A$ des Influenza-Virus zeigt das Phänomen des Antigenwandels. Dieser Antigenwandel führt $\mathrm{zu}$ einem periodischen, alle 10-20 Jahre $\mathrm{zu}$ beobachtenden Auftauchen von neuen Subtypen, was sich im Auftreten einer neuen Pandemie zeigt. Die dabei auftretenden Veränderungen des Genoms werden als ,antigenic shift" bezeichnet. Unabhängig von dem in langen Zeitabständen erfolgenden "großen" Antigenwandel kommen zwischenzeitlich kleinere Antigenveränderungen vor; sie führen nicht zu neuen Subtypen, sondern nur zu Abwandlungen des alten Subtyps (Subtypenvarianten). Die Tendenz zur Entstehung der Subtypenvarianten wird "antigenic drift" genannt. Ihr Auftauchen ist für die Herstellung der InfluenzaTotimpfstoffe von großer Bedeutung.

Der Antigenshift ist die Folge eines „reassortment": Es erfolgt zwischen zwei Genomen verschiedener Subtypen ein Austausch von funktionell homologen RNS-Segmenten. So ist 1968 das Reassortment zwischen einem Asia-Virus der Antigenformel H2N2 und einem tierischen Virus der Formel H3Nx erfolgt. Das Ergebnis dieser Rekombination war das Hongkong-Virus, das eine Pandemie auslöste; es entsprach der Formel H3N2. Wegen des neuen $\mathrm{H} 3$ besaß das Hongkong-Virus einen starken Selektionsvorteil gegenüber dem AsiaVirus. Viren mit der Antigenformel $\mathrm{H} 3 \mathrm{Nx}$ hatte man bereits Jahre vorher z. B. bei Puten und Enten isoliert. Wahrscheinlich erfolgte diese Rekombination im Schwein, da sich in dieser Spezies sowohl tierische als auch menschliche Influenza-Viren replizieren können.

Der Antigendrift ist die Folge von Punktmutationen in den Epitopen; das Hämagglutinin und die Neuraminidase werden dadurch so verändert, daß sich der "neuen" Variante im Sinne der Selektion neue Überlebenschancen bieten. Die „Entwicklungsgeschichte" eines Subtyps mit seinen Varianten läßt sich anhand der Punktmutationen rekonstruieren. Der Typ B zeigt nur Antigendrift.

\section{Züchtung}

Das Influenza-Virus läßt sich im bebrüteten Hühnerei isolieren und züchten, ebenso wie auch in Affennierenzellen. Experimentell läßt es sich auf Frettchen übertragen. Es besitzt kein Hämolysin, Zellfusion wird nicht hervorgerufen und läßt sich durch Hämadsorption im Zellrasen nach Zugabe von Erythrozyten nachweisen.

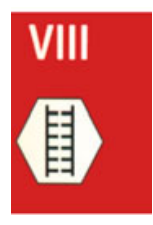




\subsection{Rolle als Krankheitserreger}

\section{Epidemiologie}

Die Influenza ist eine hochkontagiöse Krankheit. Die Virusquellen sind in Epidemiezeiten der Kranke und der subklinisch infizierte Mensch, vorzugsweise Kinder und Jugendliche. Die Übertragung erfolgt durch Tröpfcheninfektion. Haupterkrankungszeit ist der Winter. Die Hälfte der Infizierten macht die Krankheit symptomlos durch. Kontagiosität: 6-10.

Der Aufenthaltsort des Influenza-Virus zwischen den großen Pandemien ist im einzelnen nicht bekannt; jedoch weiß man, daß das in Ostasien gehaltene Hausschwein sowie Pferde, Enten, Puter und Seevögel Influenza-Virus aufnehmen, über längere Zeitspannen beherbergen und ausscheiden können. Als erwiesen gilt inzwischen, daß das Influenza-Virus vom Schwein auf den Menschen und Vogelspezies und umgekehrt übertragen werden kann.

Für den Subtypenwandel spielt das Schwein eine wichtige Rolle: Als Träger von Doppelinfektionen dient es quasi als „Mischgefäß“ für die rekombinierenden RNS-Segmente von aviären und/oder humanen Influenza-Viren.

Die Virulenz des Influenza-Virus ist polygenisch bestimmt, d.h. durch die 8 Segmente. Bestimmte Nukleoproteine des Influenza-Virus bestimmen das pathogene Wirtsspektrum. Sie entscheiden darüber, ob sich das Virus beim Menschen oder in den Zellen bestimmter Tierspezies vermehren kann oder nicht. Alle existierenden Hämagglutinine und Neuraminidasen können in die menschenpathogenen Influenza-Viren eingebaut werden. Man kennt 15 verschiedene Hämagglutinine und 9 Neuraminidasen (H 1-15, N 1-9). Die Antigenformeln der Pandemie-Stämme sind in Tabelle 2.1 aufgeführt. Ein H5N1-Virus vom Geflügel infizierte zwar den Menschen, breitete sich aber nicht weiter aus.

Epidemiologisch unterscheiden sich die InfluenzaTypen A, B und C in dreierlei Hinsicht:

- Der Typ A breitet sich typischerweise pandemisch und epidemisch aus, während

- die Typen B und C vornehmlich epidemisch oder sporadisch auftreten.

In den letzten 100 Jahren haben drei Subtypen der A-Influenza fünf Pandemien verursacht; der Ausgangspunkt lag häufig in China. Die Antigenfor- mel der Subtypen wird durch die serologische Spezifität des Hämagglutinins $(\mathrm{H})$ und der Neuraminidase $(\mathrm{N})$ bestimmt.

Aus Tabelle 2.1 und Abb. 2.1 läßt sich entnehmen, daß in längeren Zeiträumen Influenza-Viren oder einige ihrer Komponenten wiederkehren.

Die Subtypen der Influenza kommen zeitlich gesehen in einem typischen Nacheinander vor: Sie lösen sich gewissermaßen ab. Hat ein gegebener Subtyp in einem bestimmten Jahr eine Pandemie verursacht, so folgen periodisch, und zwar im $\mathrm{Ab}$ stand von 1-3 Jahren, Epidemien mit wesentlich geringerer Erkrankungszahl („Nachwellen“). Hierbei erkranken solche Personen, die während der Pandemie nicht oder nur schwach immunisiert worden sind. Die Nachwellen erfassen sukzessive immer weniger Personen; sie treten zunächst als Seuchenherd und schließlich nur noch in Gestalt von sporadischen Fällen auf. Ein Subtyp erfaßt im Laufe seiner 15-20 Jahre währenden "Amtszeit“ bis zu $70 \%$ der Weltbevölkerung; bei dieser Durchseuchungsquote ist die Immunität so weit verbreitet, daß der Subtyp praktisch verschwindet: Die Seuche ist damit als Pandemie erloschen.

Die von kleineren Epidemien ausgefüllte Zeitspanne währt so lange, bis ein neuer Subtyp entsteht (Antigenshift, s.o.). Dieser "debütiert" dann mit einer Pandemie, da er in der Lage ist, die Massenimmunität, wie sie durch den vorigen Subtyp hervorgerufen worden ist, zu unterlaufen.

\section{Pathogenese}

Eintrittspforte und zugleich Ansiedlungsort ist der Respirationstrakt, insbesondere die Bronchialschleimhaut. Die im Virion enthaltene Neuraminidase kann den Bronchialschleim verflüssigen. Auf diese Weise dringt das Viruspartikel leichter zu den Bronchialepithelzellen vor; es kann dort nach seiner Adsorption an die Membranrezeptoren den Vermehrungszyklus einleiten.

Tabelle 2.1. Pandemien durch Influenza-Viren

\begin{tabular}{llll}
\hline Virussubtyp & $\begin{array}{l}\text { Pandemie- } \\
\text { beginn }\end{array}$ & $\begin{array}{l}\text { Antigen- Bemerkungen } \\
\text { formel }\end{array}$ & \\
\hline A3 Hongkong-ähnlich & 1889 & H3N8 & \\
A1 Swine-ähnlich & 1918 & H1N1 & "Spanische Grippe" \\
A2 Asia & 1957 & H2N2 & "Asiatische Grippe" \\
A3 Hongkong & 1968 & H3N2 & kommen seit 1977 \\
A1 UdSSR & 1977 & H1N1 & gleichzeitig vor \\
\hline
\end{tabular}




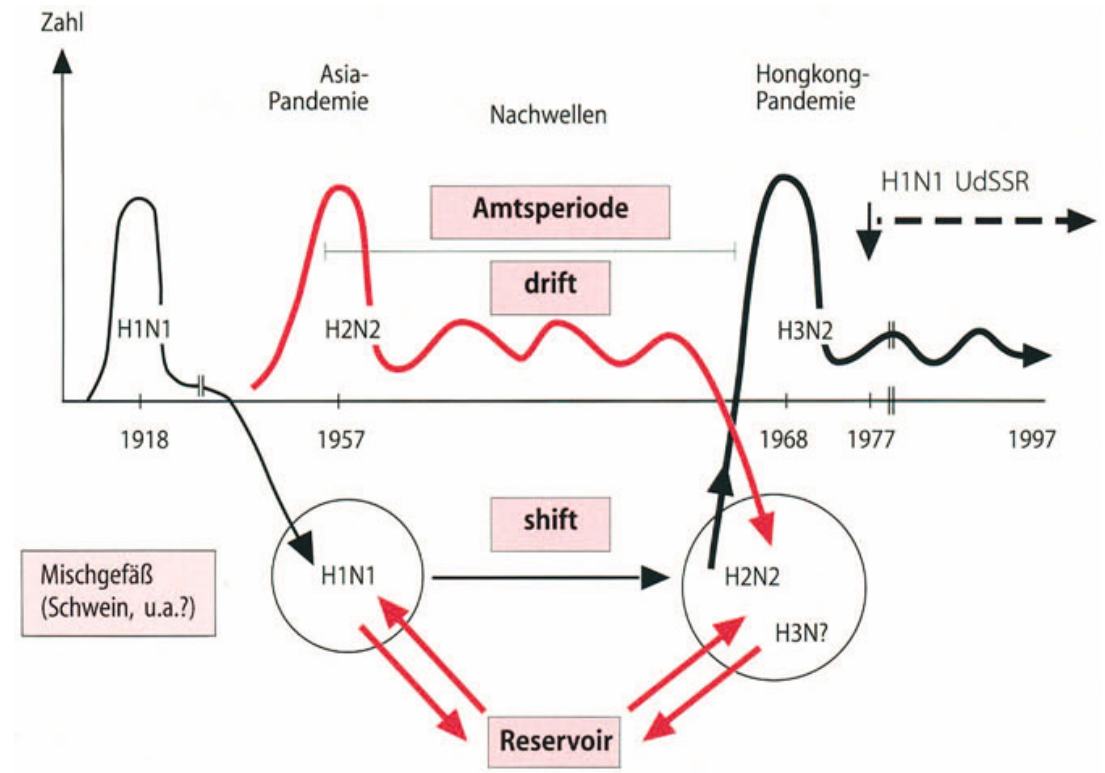

Abb. 2.1. Die Epidemiologie der Influenza. Die "Amtsperiode" beginnt mit einer Pandemie infolge Rekombination (",shift") im "Mischgefäß"; es folgen Punktmutationen ("drift") des Hämagglutinins.

Bei der Adsorption bindet sich das enzymatisch gespaltene Hämagglutinin mit dem Anteil HA1 an den Neuraminsäure-haltigen ersten Rezeptor der Zellmembran und spaltet diesen ab (Hemmung durch Zanamivir). Dann erfolgt die Bindung des Virions über den HA2-Teil an den zweiten Rezeptor der Zelle. Dabei stülpt sich das virusbesetzte Membranstück ein; es bildet zunächst ein endozytotisches Bläschen, in dem sich das Virion befindet. Erst anschließend verschmilzt die Hülle des Virions mit der Bläschenmembran. Das auf diese Weise freigelegte Nukleokapsid wird dann vom $\mathrm{Zy}$ toplasma aufgenommen.

Die Influenza-Viren bleiben während der Krankheit vorwiegend im Bronchialbaum lokalisiert. Sie führen zu einer Epithelschädigung mit Transsudation, Nekrose und Desquamation; hierdurch wird die örtliche Resistenz gegenüber bakteriellen Infektionen vermindert. Dementsprechend wird die Influenza oft durch sekundäre Infektionen in Form von bakteriellen Bronchopneumonien kompliziert. Diese sind häufig die Todesursache.

Erreger der Bronchopneumonie sind Häm. influenzae, Staph. aureus und Str. pyogenes. Der Häm. influenzae wurde so bezeichnet, weil man diese Bakterienspezies in zahlreichen Fällen von
Als Mischgefäß dient das Schwein, das Influenza-Viren vom Menschen und aus dem Reservoir (Vogelspezies) aufnimmt

Influenza nachweisen konnte und damals für den Erreger der Grundkrankheit hielt.

Beim Studium der Vorgänge im Bronchialepithel haben sich wichtige Befunde ergeben. Als erstes Zytokin wird aus Schleimhautzellen und Makrophagen $\alpha / \beta$-Interferon, IL- $1,-6,-10$ sowie MIP- $1 \alpha / \beta$ und TNF- $a$ gebildet, die natürliche Killerzellen stimulieren. Diese bilden Interferon- $\gamma$ und bewirken hierdurch ein Überwiegen des TH1-Lymphozyten-Kompartments. Influenza-Viren vermindern die Phagozytose-Kapazität der Makrophagen gegenüber Staph. aureus; die gleiche Wirkung wird in späteren Phasen der Infektion durch Virus-Antikörperkomplexe hervorgerufen. Systemisch wird eine Minderung der zellulären Immunität beobachtet.

Von besonderem Interesse ist die Tatsache, daß sich zwischen Influenza-Viren und gewissen Proteasen des Staph. aureus eine Kooperation herausbilden kann. Influenza-Virus ist nur dann „pathogen“, wenn das Vorläufer-Hämagglutinin (HA) in die Fragmente HA1 und HA2 gespalten wird. Dann kann der oben geschilderte Mechanismus der Adsorption/Penetration ablaufen. Die Besiedlung des Bronchialbaumes mit Staph. aureus kann eine Protease liefern, die zu dieser Spaltung befähigt ist. Hierdurch läßt sich der besonders schwere 
Verlauf der Influenza-Erkrankung beim Vorhandensein von Staph. aureus erklären.

Bei vielen Infektionskrankheiten des Respirationstraktes setzt das Virus einen Primärschaden am Flimmerepithel, der dann seinerseits die Vorbedingung für die sekundär-bakterielle Besiedlung schafft. Bei der Influenza fördert die bakterielle Besiedlung wiederum die krankmachende Wirkung des Virus. Möglicherweise ist die häufig beobachtete Wirksamkeit von Antibiotika bei Influenza durch die Behinderung der „Helferbakterien" bedingt.

\section{Klinik}

Während man als „Grippe“ oder „grippalen Infekt" relativ mild verlaufende Erkrankungen durch die "respiratorischen Viren" (Tabelle 2.2) bezeichnet, ist die Influenza („echte Grippe“) eine schwere Erkrankung. Influenza-Infektionen verursachen eine statistisch erfaßbare Übersterblichkeit. I. allg. nimmt die Influenza nur bei älteren oder geschwächten Personen einen tödlichen Verlauf; vorzugsweise bei zusätzlich bestehenden Lungenoder Herzkrankheiten.

Die Influenza ist eine lokale Erkrankung des Bronchialbaums mit systemischem Charakter. Sie tritt nach einer Inkubationsperiode von 1-5 Tagen auf. Die akute Krankheit dauert etwa 8-10 Tage. Es werden hohes Fieber, Kopfschmerzen, Schüttelfrost, Glieder- und Muskelschmerzen sowie allgemeine Hinfälligkeit beobachtet. Oftmals tritt eine Myokarditis mit z.T. lang anhaltender Kreislaufschwäche hinzu. Rauher Hals und Reizhusten tre- ten ebenfalls auf. Eine verstopfte und laufende $\mathrm{Na}$ se ist untypisch. Typisch ist hingegen eine hochfieberhafte Bronchitis. In allen Altersgruppen kann es zur Laryngo-Tracheitis und selten zu einer durch das Influenza-Virus verursachten Pneumonie kommen. Als Komplikation wird bei Kindern Pseudokrupp beobachtet. Weitere Komplikationen sind Otitis media, Meningitis, Enzephalitis und das Reye- sowie das Guillain-Barré-Syndrom. Häufig entstehen durch bakterielle Superinfektionen mit Staphylokokken, Streptokokken oder Hämophilus influenzae hämorrhagische Sekundärpneumonien (Bronchopneumonien). Diese Komplikationen sind zumeist die Todesursache vornehmlich bei alten Menschen.

Influenza-Pandemien oder -Epidemien variieren hinsichtlich ihres Schweregrades beträchtlich. Die "Spanische Grippe“, ursprünglich aus den USA kommend, forderte 1918/19 etwa 20 Mio Todesopfer. Als Folgekrankheit trat die nach v. Economo benannte "postinfektiöse“ Enzephalitis auf. Die „Asien“-Influenza von 1957 hingegen verlief viel leichter; allerdings hat man hier neben vereinzelten Pneumonien auch foudroyante Verläufe mit tödlichem Ausgang beobachtet.

\section{Immunität}

Maßgebend für die Entstehung der Humoral-Immunität gegen das Influenza-Virus ist das außensitzende Hämagglutinin: Es induziert die Bildung von Antikörpern, die zugleich neutralisierend und hämagglutinationshemmend wirken. Die Schleimhaut-Immunität ist der bestimmende Faktor gegen

Tabelle 2.2. Erkrankungen der Atemwege und ihre Erreger

\begin{tabular}{|c|c|c|c|c|c|c|}
\hline Virus & $\begin{array}{l}\text { Banaler } \\
\text { Schnupfen }{ }^{1}\end{array}$ & Pharyngitis ${ }^{2}$ & $\begin{array}{l}\text { Tracheo- } \\
\text { bronchitis }^{3}\end{array}$ & Pneumonie ${ }^{4}$ & Bronchiolitis & Pseudokrupp ${ }^{\text {a }}$ \\
\hline Rhino & ++ & ++ & - & & & \\
\hline Influenza A & - & + & ++ & + & & $(+)$ \\
\hline Influenza B & - & + & ++ & + & & \\
\hline Corona & ++ & ++ & $(+)$ & $(+)$ & & \\
\hline Adeno & + & ++ & $(+)$ & ++ & & \\
\hline Parainfluenza 1-4 & ++ & + & + & + & + & ++ \\
\hline Respiratory-syncytial & ++ & + & ++ & ++ & ++ & $(+)$ \\
\hline Herpes-simplex & & $(+)$ & & & & \\
\hline
\end{tabular}

1, 2, 3, 4 Seltene Fälle bei den genannten Krankheitsformen durch Infektionen mit folgenden Viren: Influenza C-, Epstein-Barr-, Coxsackie A- und B-, ECHO-Virus.

a In den USA: Croup.

++ Großer Anteil, + mittlerer Anteil an allen Infektionen bei Erwachsenen oder Kindern, (+) geringer Anteil. 
Reinfektion. Der lokale und humorale Immunschutz ist subtypenspezifisch und an die Anwesenheit von IgA- und IgG-Antikörpern gebunden. Das Kapsid regt zwar ebenfalls die Bildung von Antikörpern an; da es jedoch im Innern des Partikels liegt, liefert es für die Neutralisation keinen Ansatzpunkt. Das Hämagglutinin induziert somit die Bildung von protektiven Antikörpern, während das Kapsid zur Bildung von nicht-protektiven Antikörpern stimuliert. Die zelluläre Immunität wird durch mehrere Virusproteine stimuliert, sie sorgt für die Eliminierung des Virus.

\section{Labordiagnose}

Die Isolierung der Influenza-Viren erfolgt nach wie vor über das bebrütete Hühnerei (Amnionhöhle). Die Isolierung gelingt nur in den ersten Tagen auf empfänglichen Affennierenzellen; der Nachweis des Befalls erfolgt hier mittels Hämadsorption (s. S. 545), da das Virus keinen ZPE erzeugt.

Routinemäßig wird das Virus nur in Speziallaboratorien isoliert, es ist transportlabil. Die Serodiagnose wird zumeist mit dem S-Antigen (typenspezifisch) oder mit dem V-Antigen (subtypenspezifisch) durch die KBR vorgenommen. Als positiv gelten nur Serumpaare mit mehr als dem vierfachen Titeranstieg. Der Hämagglutinations-Hemmungs-Test (HHT) ist Speziallaboratorien vorbehalten, wie auch die Variantendiagnose. Als Schnelltest dient ein Antigen-IFT in Bronchialepithelzellen und ggf. die PCR. Blutbild: Lymphopenie.

\section{Therapie}

Für Prophylaxe und eine frühzeitige Therapie der pandemischen und der epidemischen Influenza A eignen sich Amantadinpräparate; $2 \times 100 \mathrm{mg} / \mathrm{d}$ sind wirksam und verträglich. Neuerdings werden Neuraminidase-Inhibitoren verwendet (s. S. 515). Relenza ${ }^{\circledR}$ wird als Spray und Tamiflu ${ }^{\circledR}$ oral eingesetzt, u.z. therapeutisch und prophylaktisch. Wichtig ist auch hier ein frühzeitiger Beginn der Therapie ( $<36$ Std. nach Beginn der Symptome). Die Medikamente verkürzen und erleichtern den Verlauf.

\section{Prävention}

Die spezifische Prophylaxe ist mit einem Totimpfstoff („Spaltimpfstoff“) möglich. Seine Anwendung verleiht in $50 \%$ der Fälle einen vollen Schutz gegen die Erkrankung; bei den übrigen Impflingen ist die Schwere der Krankheit abgemildert. Der Impfstoff enthält Hüllmaterial des Influenza-Virus A und B. Die Dauer der Wirkung beträgt etwa ein Jahr. Dann muß mit einem neuen, „aktualisierten“ Impfstoff weitergeimpft werden. Der neue Impfstoff muß das Hüllenmaterial der zuletzt aufgetauchten Subtypvariante (Antigendrift) enthalten. Im Falle von Pandemien bildet das neue, pandemische Virus die Hauptkomponente des Impfstoffs. Indiziert ist die Impfung für alle Personen mit einem Grundleiden (Diabetes, HKL) und bei Senioren. Im Sinne eines „Immunitätsherdes“ innerhalb der Population läßt sich durch Impfung die Ausbreitung des Virus hemmen, sofern möglichst viele Personen geimpft werden und als Überträger ausfallen. Zur Zeit wird ein Lebendimpfstoff (Nasalspray) geprüft. Risikogruppen sind HKL-Kranke u.a., besonders gefährdet sind medizinisches Personal und dasjenige der öffentlichen Verkehrssysteme.

Meldepflicht. Der Tod an Influenza ist meldepflichtig.

\section{Anhang: Das Reye-Syndrom}

Die ersten Fälle wurden um 1930 beschrieben. Um 1970 traten in den USA hunderte von Fällen auf. Die Krankheit befällt vorwiegend Kleinkinder und Schulkinder; sie geht mit hoher Letalität einher. Das Reye-Syndrom ist die direkte oder indirekte Folge von verschiedenartigen Virusinfektionen (Herpes-Viren, Picorna-Viren, Röteln, Masern u. a.) wird aber vorwiegend im Verlauf von Influenza-BInfektionen beobachtet. Die Symptomatik dieser Krankheit erscheint als Kombination einer Enzephalopathie mit einer Hepatitis. Die zerebralen Symptome treten längere Zeit nach dem Abklingen der grippalen Krankheitssymptome auf, das Syndrom wird relativ häufig bei jungen Kindern nach Einnahme von Azetylsalizylsäure beobachtet. Es wird jetzt seltener beobachtet, weil das Medikament seltener eingenommen wird. 
ZUSAMMENFASSUNG: Influenza-Viren

Virus. Orthomyxo-Virus. (-)-Strang-RNS-Virus, acht Segmente mit Replikase im helikalen Nukleokapsid mit umgebendem M-Protein. Zusammengehalten von Hülle mit Spikes (Hämagglutinin, Neuraminidase). Etwa 80$120 \mathrm{~nm}$ Durchmesser. Typen A, B, C sowie Subtypen und Varianten. Ätherempfindlich.

Vorkommen. Mensch, Schwein, Pferd und Vogelspezies.

Epidemiologie. Nach Reassortment im Schwein kann eine Pandemie in Abständen von 10-20 Jahren erfolgen (Antigenshift) Epidemien eines Subtyps in kurzen Abständen infolge Punktmutationen (Antigendrift). Etwa $50 \%$ der Infektionen verlaufen inapparent.

Übertragung. Durch Aerosol-Infektion von Mensch zu Mensch. Wechselseitige Übertragungen zwischen Schwein, Vogelspezies und Mensch, dabei erfolgt Reassortment.

Pathogenese. Ausbreitung von Rachen und Kehlkopf in den Bronchialbaum und die Lunge. Zerstörung der Schleimhaut bis zu Hämorrhagien. Staph. aureus-Protease spaltet zusätzlich HA in HA1 und $\mathrm{HA} 2$, dadurch Steigerung der Infektiosität, oft bakterielle Bronchopneumonien.
Klinik. Die Influenza ist eine schwere Erkrankung (mit Inkubationsperiode von 1-3 Tagen) der mittleren und unteren Luftwege, mit Viruspneumonie, oft sek. bakteriell bedingte Bronchopneumonien $(\mathrm{H}$. influenzae, Staph. aureus, S. pyogenes). Kreislaufkollaps, Myokarditis, lang anhaltendes PostinfektionsSyndrom und Übersterblichkeit. Komplikationen sind Pseudokrupp, Otitis media, Meningitis, Meningoenzephalitis, Reye-Syndrom.

Immunität. IgA-Antikörper der Schleimhaut, humorale Antikörper und zelluläre Immunmechanismen sind für die erworbene Immunität verantwortlich.

Diagnose. Isolierung des Virus im bebrüteten Hühnerei sowie der PCR und Antikörper-Bestimmung in der KBR und im HHT.

Therapie. Symptomatisch, bei Influenza A gibt man Amantadin-Präparate für die Prophylaxe bei Pandemien und zur Therapie. Zanamivir (nasal) und Tamiflu (oral).

Prävention. Influenza-Schutzimpfung mit Spaltimpfstoff bei Personen mit Grundleiden, Senioren und Kindern mit Herzfehlern u.a. Nach Möglichkeit Aufbau einer Herdimmunität.

Meldepflicht. Tod, Erregernachweis. 


\section{EINLEITUNG}

Paramyxo-Viren sind mittelgroße Viren mit einem Durchmesser von 100-200 nm. Die einsträngige RNS, die mit Replikasemolekülen assoziiert ist, liegt in Form eines helikalen Nukleokapsids vor. Dieses bildet seinerseits ein kugeliges Knäuel. Außen ist das Virion von einer lipidhaltigen Hülle („envelope") umgeben. Zwischen dem Envelope und dem Nukleokapsidknäuel befindet sich eine Matrix (M-Protein), das „budding“ erfolgt an der Zellmembran (Tabelle 3.1).

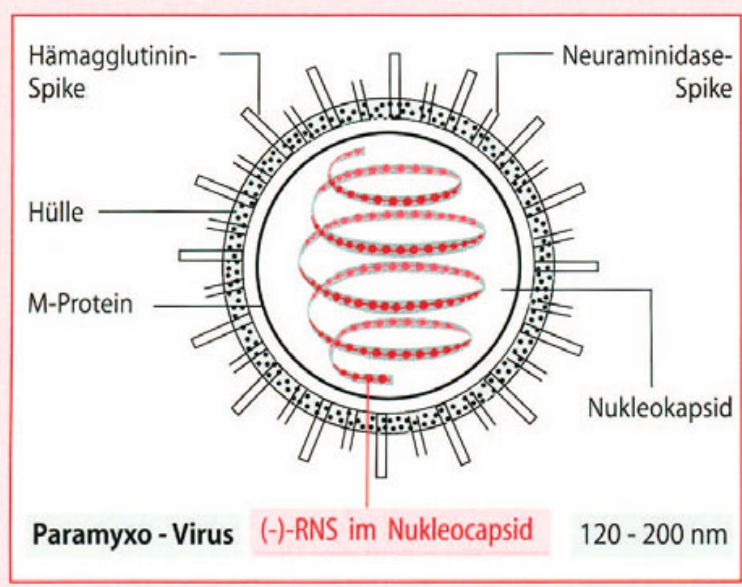

Einige Unterscheidungsmerkmale und Eigenschaften dieser Viren sind in Tabelle 3.1 zusammengefaßt.

\section{Einteilung}

Einige Paramyxo-Viren enthalten im Partikel Neuraminidase. Man unterscheidet in der Systematik daher Neuraminidase-haltige von Neuraminidase-freien Viren. Sie binden sich - ausgenommen das RSVirus - an Erythrozyten und vernetzen diese; auf diese Weise kommt es zur Hämagglutination.

Zur Familie der Paramyxo-Viren zählt man die Genera der

- Parainfluenza-Viren,

- das Mumps-Virus,

- das Masern-Virus.

Das Respiratory-Syncytial-(RS-)Virus bildet die Subfamilie der Pneumoviren.

\subsection{Parainfluenza-Viren}

Parainfluenza-Viren sind Neuraminidase-haltige Paramyxo-Viren, die häufig Erkältungskrankheiten mit Bronchitis, Pseudokrupp und Pneumonie verursachen. Serologisch kennt man 4 Typen. Das Parainfluenza-Virus vom Typ 2 wurde ursprünglich als "croup-associated"-(CA)-Virus bezeichnet.

\subsubsection{Beschreibung}

\section{Genom}

Parainfluenza-Viren enthalten eine (-)-Strang-RNS mit Replikase. Ihre RNS besteht aus einem Molekül im helikalen Nukleokapsid und enthält 16 kb.

\section{Morphologie}

Parainfluenza-Viren sind größer als Influenza-Viren $(\varnothing 150 \mathrm{~nm})$. Das RNS-Molekül ist in einem durchgehenden helikalen Kapsid eingeschlossen; das Kapsid wird wie das des Influenza-Virus von einer Matrix umgeben (M-Protein) und zusätzlich von einer Hülle. Die Parainfluenza-Viren hämagglutinieren mit anschließender Dissoziation. Das 
Tabelle 3.1. Eigenschaften der Ortho- und Paramyxo-Viren

\begin{tabular}{|c|c|c|c|c|c|}
\hline Eigenschaft & Influenza- & Parainfluenza- & Mumps- & Masern- & RS-Virus \\
\hline Genom & Segmente & 1 Strang & 1 Strang & 1 Strang & 1 Strang \\
\hline Reassortment & + & - & - & - & - \\
\hline Replikation & $\mathrm{K}+\mathrm{Z}$ & Z & $z$ & $z$ & $z$ \\
\hline Serotypen & 3 & 4 & 1 & 1 & $1^{*}$ \\
\hline Hämagglutination & + & + & + & + & - \\
\hline Neuraminidase & + & + & + & - & - \\
\hline Hämadsorption & + & + & + & + & - \\
\hline Zellfusion & - & + & + & + & + \\
\hline Wirtsspezies & $\begin{array}{l}\text { Mensch, } \\
\text { Schwein, } \\
\text { Vogelspezies }\end{array}$ & $\begin{array}{l}\text { Mensch, Maus, } \\
\text { Rind }\end{array}$ & Mensch & Mensch & $\begin{array}{l}\text { Mensch, } \\
\text { Affe }\end{array}$ \\
\hline Ätherempfindlichkeit & + & + & + & + & + \\
\hline Umweltstabilität & gering & gering & gering & mittel & hoch \\
\hline
\end{tabular}

K Kern; Z Zytoplasma; * zwei Subtypen.

Hämagglutinin kommt in vier serologisch distinkten Varianten (Typen 1-4) vor. Außer dem Hämagglutinin und der Neuraminidase besitzen diese Viren ein Fusionsprotein (F-Protein). Parainfluenza-Viren besitzen zwei Arten von Spikes.

HN-Spikes. Diese enthalten das Hämagglutinin und die Neuraminidase-Aktivität. Antikörper gegen das Hämagglutinin neutralisieren das Virus und blockieren dessen Adsorption bzw. die Penetration.

F-Spikes. Diese wirken hämolysierend und zellfusionierend; ihr Protein spielt die Rolle eines Ausbreitungsfaktors im Gewebe. Nur Antikörper gegen das Fusionsprotein (F-Protein) hemmen die Ausbreitung der Virus-Infektion im Gewebe: Antikörper gegen die HN-Proteine sind dazu nicht in der Lage. Durch Behandlung mit Formalin wird das FProtein zerstört. Totimpfstoffe auf dieser Basis sind deshalb unwirksam.

\section{Züchtung}

Diese Viren vermehren sich in mehreren Zellinien und in kleinen Nagetieren sowie Kälbern.

\subsubsection{Rolle als Krankheitserreger}

\section{Vorkommen}

Die Parainfluenza-Viren sind bei Mensch und Tier weit verbreitet.

\section{Epidemiologie}

Parainfluenza-Viren verursachen keine größeren Krankheitsausbrüche; sie führen besonders im Winter zu epidemisch auftretenden Erkrankungen. Ein großer Teil der Erkältungskrankheiten geht auf das Konto der Parainfluenza-Viren.

Die Typen der Parainfluenza unterscheiden sich epidemiologisch. Die meisten Kinder machen in den ersten Lebensjahren eine Infektion mit dem Typ 3 durch. Die Durchseuchung mit den anderen Typen erfolgt später; sie erfaßt den Großteil der Kinder bis zum 10. Lebensjahr. Während die Primärinfektionen mit Parainfluenza-Viren meist schwer verlaufen, bleiben die späteren Reinfektionen durch die Restimmunität abgeschwächt.

\section{Übertragung}

Die Übertragung erfolgt vorwiegend durch Tröpfchen und durch Kontakt mit Nasensekret. 


\section{Pathogenese}

Eintrittspforte ist der Nasenrachenraum. Dort kommt es zunächst zur lokalen Virusvermehrung auf dem Flimmerepithel der oberen Atemwege. Beim Erwachsenen entsteht das Bild der katarrhalischen Entzündung. Bei Kleinkindern breitet sich die Infektion jedoch in die Tiefe des Bronchialbaums aus, wobei peribronchioläre Infiltrate und Ödem entstehen. Bei der Pathogenese spielt das $\mathrm{Zu}-$ sammenwirken von primär virusbedingtem Epithelschaden und darauf folgenden Staphylokokkeninfektionen eine wichtige Rolle.

Viele, aber nicht alle Fälle von Laryngo-Tracheitis führen zum Pseudokrupp (Differentialdiagnose: Epiglottitis durch H. influenzae!). Die besonderen Verhältnisse bei dieser Komplikation zeigen sich durch einen erhöhten Gehalt an IgE-Antikörpern und an Histamin im Bronchialsekret. Hieraus kann man für den Pseudokrupp eine immunpathogenetische Komponente ableiten. Man hat aber auch Gründe für die Annahme, daß psychosoziale Faktoren eine Rolle spielen. Bei der Pneumonie entsteht eine Hyperplasie des Alveolarepithels; Erythrozyten und Makrophagen treten im Sekret auf.

\section{Klinik}

Die Inkubationsperiode beträgt 2-4 Tage. Bei Kleinkindern führt die Infektion zu Laryngo-Tracheitis, zum Pseudokrupp und zur interstitiellen Pneumonie. Dagegen bewirkt die Infektion beim Erwachsenen relativ milde Katarrhe der oberen Luftwege.

Der Typ 3 ist für die schweren Fälle von Pneumonie und Bronchiolitis im Kleinkindesalter verantwortlich. Da die protektive Immunität trotz vorhandener Serum-Antikörper nur wenig ausgeprägt ist, sind wiederholte, milde verlaufende Infektionen mit dem gleichen Typ die Regel (Tabelle 2.2).

\section{Immunität}

Die Immunität hat lokalen Charakter: Träger sind die im Bronchialschleim ausgeschiedenen Antikörper der Klasse IgA. Eine Ausschaltung der T-Zellen im Modelltier führt zu Pneumonien. Interferon wird sehr frühzeitig gebildet.

\section{Labordiagnose}

Das Virus läßt sich durch Züchtung auf humanen Zellkulturen isolieren und im HämagglutinationsHemmungstest oder mit dem Neutralisationstest typisieren.

Als Material wird Rachenspülwasser oder Sputum aus der akuten katarrhalischen Phase benötigt.

Die Serodiagnose der akuten Erkrankung kann dann durch die Untersuchung von zwei Serumproben mit Hilfe der Komplementbindungsreaktion erfolgen. Der Hämagglutinations-Hemmungstest ist in der Labordiagnostik nicht gebräuchlich; er wird vornehmlich für Durchseuchungsstudien verwendet. Bei der Komplementbindungsreaktion ist aber zu beachten, daß wegen Antigenverwandtschaften zwischen den 4 Parainfluenza-Viren Mitreaktionen auftreten. Das Virus läßt sich in den Zellen der Rachen- oder Bronchialsekrete durch einen Schnelltest nachweisen. Das Verfahren beruht auf dem IFT bzw. auf dem ELISA-Prinzip.

\section{Prävention}

Ein abgeschwächter Lebendimpfstoff mit Temperatur-Abhängigkeit befindet sich in der Erprobung. Es gibt keine spezifische Therapie. 
ZUSAMMENFASSUNG: Parainfluenza-Virus

Virus. Paramyxo-Virus. (-)-Strang-RNS in einem helikalen Kapsidschlauch. Umgeben von M-Protein und Hülle mit Spikes. Vier Serotypen unterscheiden sich im Hämagglutinin; Hämagglutinin zusammen mit Neuraminidase: HN-Spikes; Fusionsprotein: F-Spikes.

Vorkommen und Übertragung. Beim Menschen (und verwandte Typen beim Kalb); Tröpfcheninfektion.

Epidemiologie. Erkrankungen während des gesamten Jahres, zuerst erfolgt die Durchseuchung mit dem Typ 3.

Pathogenese. Primärer Epithelschaden am Flimmerepithel mit sekundären Staphylokokken-Infektionen. Lokalerkrankung.
Klinik. Katarrhalische Entzündungen der oberen und unteren Luftwege mit Fieber, Laryngitis, Pseudokrupp, Bronchitis und interstitielle Pneumonie.

Immunität. Schleimhautimmunität mit typenkreuzenden sekretonischen IgA-Antikörpern. Zellvermittelte Immunität. Lokal tritt Interferon sehr frühzeitig auf.

Diagnose. Antikörperbestimmung mit der KBR. Virusisolierung in der Zellkultur aus Rachenspülwasser.

Therapie. Symptomatisch.

Prävention. Keine.

Meldepflicht: Keine

\subsection{Mumps-Virus}

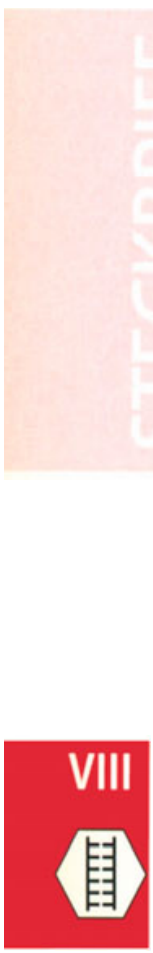

\section{Genom} $\mathrm{kb}$ im helikalen Kapsid.

\section{Morphologie}

Das Mumps-Virus mißt etwa $150 \mathrm{~nm}$ und gehört zu den Neuraminidase-haltigen Paramyxo-Viren.

\section{Züchtung}

Man kann es auf den Affen übertragen und im bebrüteten Hühnerei sowie in Zellkulturen züchten. Das Mumps-Virus erzeugt Zellfusionen und Zellabkugelung. kationen sind die Orchitis und die Meningitis. Ein Kombinationsimpfstoff für Mumps, Masern und Röteln wirkt gut.

\subsubsection{Beschreibung}

Das Mumps-Virus enthält eine (-)-Strang-RNS als durchgehendes Einzelstrangmolekül. Sie enthält 15

\subsubsection{Rolle als Krankheitserreger}

\section{Vorkommen}

Der Mensch ist der einzige natürliche Wirt des Virus.

\section{Übertragung}

Kontagiös ist der Mumpskranke vier Tage vor und sieben Tage nach dem Auftreten der Erstsymptome. Mumps ist jedoch bei weitem nicht so kontagiös wie die Masern oder die Influenza: Der Kontakt zwischen der Infektionsquelle und dem Exponierten muß relativ eng sein. Das Mumps-Vi- 
rus wird durch Speicheltröpfchen oder Nasensekret von Mensch zu Mensch übertragen, man findet es auch im Urin.

\section{Epidemiologie}

Das Virus ist auf der ganzen Welt verbreitet. Man findet bei etwa $80 \%$ der Erwachsenen komplementbindende Antikörper gegen das Mumps-Virus. Durch den höheren Lebens- und Hygienestandard hat sich in den Industriestaaten das Lebensalter, bei dem wir frühestens mit der maximalen Durchseuchung rechnen konnten, zugunsten älterer Jahrgänge verschoben. Deshalb steigt die Zahl der nicht-immunen Erwachsenen an. Dies ist ein wichtiger Grund, die Impfung zu empfehlen. Immunsupprimierte Personen sind nosokomialen Mumps-Infektionen ausgesetzt. Eine saisonale Häufung besteht nicht: Sporadische Fälle findet man das ganze Jahr über. Etwa $30-50 \%$ der Infektionen verlaufen inapparent. Todesfälle durch Mumps gibt es kaum. Es gibt symptomatische Reinfektionen.

\section{Pathogenese}

Das Mumps-Virus dringt in die Mundhöhle und den Nasenrachenraum ein, vermehrt sich dort und gelangt über die Lymphknoten hämatogen in die Parotis. Dort vermehrt es sich u.a. in den Parenchymzellen. Im Rahmen einer Generalisation kann das Virus die Hoden bzw. die Ovarien, das Pankreas, die Schilddrüse, die Mammae und das Gehirn besiedeln. Man nimmt heute an, daß mit der pubertären Reifung im Hoden eine Zellart auftritt, die den Replikationsprozeß des Mumps-Virus und damit den Virusbefall ermöglicht.

\section{Klinik}

Die Inkubationszeit der Mumps-Infektion beträgt im Durchschnitt 18 Tage.

Parotitis. Die Krankheit beginnt stets mit Fieber und in der überwiegenden Mehrzahl der Fälle mit einer einseitigen Parotisschwellung. Diese ist an der Abhebung des Ohrläppchens leicht zu erkennen; die andere Seite wird in $2 / 3$ der Fälle meist etwas später befallen. Es gibt aber auch Mumpsfälle ohne klinisch erkennbaren Parotisbefall, $\mathrm{zu}$ weilen ist nur die Submaxillaris und Sublingualis betroffen.
Pankreatitis und Diabetes mellitus. Die Bauchspeicheldrüse wird nicht selten mit ergriffen. Die Symptome einer Mumps-Pankreatitis sind Erbrechen, Druckschmerz, Enzym-Anomalien, Hyperglykämie.

Nach einer Mumps-Erkrankung entwickelt sich in sehr seltenen Fällen das Bild eines Insulin-abhängigen Diabetes mellitus.

Orchitis. Eine klinisch erkennbare Orchitis tritt als Komplikation bei etwa $20 \%$ der Kranken auf, die älter als 15 Jahre sind. Sie ist meist einseitig. Tritt sie doppelseitig auf, so kommt es wegen der daraus resultierenden Hodenatrophie zur Sterilität. Bei Frauen bleibt der Befall der Ovarien (5\%) dagegen ohne Folgen.

Meningoenzephalitis. In $10 \%$ der Mumps-Fälle tritt, vorwiegend im ersten Lebensjahrzehnt, eine meistens gutartige Meningitis auf. Die Enzephalitis ist sehr selten; Taubheit als Folge ist selten.

Schwangeren-Mumps. Bei Schwangeren kann eine Mumps-Infektion innerhalb der ersten drei Schwangerschaftsmonate zu Aborten führen. Embryopathien sind aber nicht bekannt geworden. Perinatale Infektion durch die seronegative Mutter bewirkt Pneumonie und Meningitis.

\section{Labordiagnose}

Die klinische Diagnose ist nur dort schwierig, wo die Parotisbeteiligung nicht erkennbar ist. Bei nicht-bakteriellen Meningoenzephalitiden sollte man stets auch an Mumps denken. Für die Diagnose ist es wichtig, daß Mumps eine Krankheit der Kinder und der jungen Menschen ist, in höherem Alter kommt sie nur selten vor.

Die Virusisolierung kann aus dem Speichel des Kranken vorgenommen werden. Die Züchtung erfolgt auf Affennierenzellen und in embryonierten Hühnereiern. Für die Praxis ist die Virusisolierung entbehrlich. Für die Labordiagnose sind geeignet: Die Pankreas- bzw. Speicheldrüsen-( $a$-Amylase-!) Funktionstests, die KBR, der IgM- und der IgGELISA sowie die PCR. Die Hämagglutinationsreaktion braucht wegen des einheitlichen Serotyps nicht angewendet zu werden. Die Bestimmung der Antikörper wird in zwei nacheinander entnommenen Serumproben vorgenommen. Als Erreger einer „Parotitis“ gelten auch andere Viren (Coxsackie, ECHO, EBV, Parainfluenza und Influenza A). 


\section{Immunität}

Die Immunität wird durch eine manifeste Erkrankung ebenso erworben wie durch die inapparente Infektion. Der Immunschutz dauert praktisch das ganze Leben an. Es gibt keine manifesten Zweiterkrankungen, wohl aber inapparente Reinfektionen; diese treiben die Immunität jeweils wieder hoch. Die diaplazentar übertragenen Antikörper der Mutter schützen den Säugling während der ersten 6 Monate nach der Geburt vor der Infektion. Bei einer frischen Infektion kann man IgM-Antikörper nachweisen. Die zellvermittelte, zytotoxische Immunität scheint an der Pathogenese der Mumps wesentlichen Anteil zu haben.

\section{Prävention und Therapie}

Schutzimpfung. Die Schutzimpfung wird allgemein empfohlen. Sie wird mit einem Lebendimpfstoff (MMR) ausgeführt. Der Impfstoff ergibt eine Konversionsrate von $95 \%$. Die Impfung kommt für Kinder und für exponierte Erwachsene in Betracht (Krankenhauspersonal, Laborpersonal u.a.), bei denen der Antikörpertest negativ ist. Eine spezifische Therapie gibt es nicht.

Meldepflicht. Bei gehäuften Erkrankungen in Gemeinschaften.

\section{ZUSAMMENFASSUNG: Mumps-Virus}

Virus. (-)-Strang-RNS-Virus. Typisches Paramyxo-Virus mit Neuraminidase; ätherempfindlich.

Vorkommen und Übertragung. Virusreservoir ist der Nasenrachenraum des Menschen. Tröpfcheninfektion.

Epidemiologie. Das Virus ist weltweit verbreitet, etwa $50 \%$ der Infizierten erkranken.

Pathogenese. Das Virus dringt aus dem Nasenrachenraum hämatogen in die Speicheldrüsen (u.a.), bei Männern in die Testes ein.

Klinik. Inkubationszeit 2-3 Wochen. Ein- oder beidseitige Parotitis, Meningoenzephalitis,
Meningitis auch ohne Parotitis, meist einseitige Orchitis, bei beidseitigem Befall Sterilität. Im ersten Trimenon Aborte. Oophoritis ohne Folgen.

Immunität. Lebenslange Immunität durch zytotoxische Lymphozyten; IgA-, IgM- und IgGAntikörper.

Diagnose. KBR oder IgM- und IgG-ELISA, $\mathrm{HHT}$, Virusisolierung.

Therapie. Symptomatisch.

Prävention. Mumps-Schutzimpfung. Meldepflicht: Gruppenerkrankungen. 


\subsection{Respiratory-Syncytial-Virus (RS-Virus)}

Das Respiratory-Syncytial-Virus (RS-Virus) wird aufgrund der Zellveränderungen benannt, die es in Kulturzellen verursacht: Riesenzellen. Bei Säuglingen und Kleinkindern verlaufen die Infektionen häufig sehr schwer. Beim Infizierten entstehen Pseudokrupp, Bronchitis, Bronchiolitis und Pneumonie. Übersterblichkeit bei Senioren. Infekte in der Kindheit disponieren zu Asthmazuständen.

Das RS-Virus gehört zur Familie der Paramyxo-Viren (Genus Pneumo-Virus) ohne Neuraminidase, es besitzt weder hämagglutinierende noch hämolysierende Eigenschaften (s. Tabelle 3.1, S. 552). sungen. Auch bei älteren Erwachsenen und bei Senioren ist es ein wichtiger Erreger von Bronchitis und interstitieller Pneumonie.

Das Virus breitet sich in jedem Winter epidemisch aus. Dieses Verhalten steht im Gegensatz zur Influenza, bei der es nur alle 2-3 Jahre zu einer Epidemie kommt, und auch zur Parainfluenza, bei der die Erkrankungen das ganze Jahr über vorkommen. Die Durchseuchung steigt sehr früh an, so daß am Ende des 2. Lebensjahres alle Kinder Antikörper tragen. Die häufigen Zweitinfektionen verlaufen milder. Asymptomatische Primärinfektionen gibt es kaum.

\section{Übertragung}

Als Überträger dienen Erkrankte und Personen mit abgeklungenem Immunschutz. Das Virus ist hochinfektiös und wird bis zu drei Wochen lang ausgeschieden. Die Übertragung erfolgt durch Tröpfcheninfektion und Kontakt mit Nasenrachensekret, auch von kontaminierter Bettwäsche aus.

\section{Pathogenese}

Das Genom ist ein (-)-Einzelstrang-RNS-Molekül mit $15 \mathrm{~kb}$.

\section{Morphologie}

Die Hülle enthält ein Protein (F-Protein), welches die Fusion der befallenen Zellen zu Synzytien (Riesenzellen) vermittelt, aber kein Hämagglutinin. Die Adsorption wird durch das Glykoprotein (G) vermittelt. Unter der Hülle befindet sich das Matrix-Protein, im Inneren das helikale Nukleokapsid mit der Polymerase.

\section{Züchtung}

Der Nachweis des Virus gelingt in Zellkulturen, ist aber in der Laborpraxis nicht üblich. In der Zellkultur entstehen Riesenzellen.

\subsubsection{Rolle als Krankheitserreger}

\section{Epidemiologie}

Neben den Masern gehört die Infektion mit dem RS-Virus zu den wichtigsten Viruskrankheiten des Kindes und ist ein Hauptanlaß für HospitaleinweiTrachea, der Bronchien, der Bronchiolen und der Alveolen, bei Säuglingen findet es sich im Blut. Dabei entsteht besonders in den Bronchiolen eine Entzündung: Die Zellen runden sich ab oder fusionieren; zusätzlich entstehen interstitielle Infiltrate und Ödeme. Das RS-Virus bewirkt aus den Bronchialepithelzellen und Makrophagen die Freigabe eines IL-1-Inhibitors, von wenig IFN- $\gamma$, aber viel IL-4, -5 und -10. Das Resultat ist eine vorzugsweise Stimulation des TH2-Kompartments der Lymphozyten. Die Vielzahl der Eosinophilen produziert das Chemokin RANTES und das kationische Eosinophilenprotein. Kinder mit Bronchiolitis haben virusspezifische IgE-Antikörper im Bronchialsekret; das Sekret enthält zudem viel Histamin. Die Lymphozyten reagieren auf RS-Virus-Antigen mit verstärkter Proliferation. Kinder mit einer abgelaufenen Bronchiolitis haben eine erhöhte Wahrscheinlichkeit, später im Leben eine „allergische Bronchitis“ oder Asthma zu bekommen.

\section{Klinik}

Nach einer Inkubationsperiode von 4-5 Tagen entsteht bei Kindern eine leichte Rachenentzündung und anschließend eine Bronchiolitis. Die Krankheit ist durch Zyanose, Fieber, keuchenden Husten
Das Virus repliziert sich in den Epithelzellen der 
und zunehmende Dyspnoe gekennzeichnet. Die Bronchiolitis befällt vornehmlich Säuglinge, aber auch Kleinkinder. Besonders gefährlich ist der Verlauf bei Kindern, die sechs Wochen bis neun Monate alt sind; die Bronchiolitis führt dann häufig zu einer Pneumonie. Ein Drittel aller kranken Kinder entwickelt eine Otitis media, die durch bakterielle Superinfektionen kompliziert wird. Bei älteren Kindern und Erwachsenen verläuft die Infektion als Schnupfen bzw. als milde Erkältungskrankheit. Bei Senioren kommt es zu schweren Pneumonien. Achtung: Übersterblichkeit!

\section{Immunität}

Der Gehalt an IgA-Antikörpern im oberen Respirationstrakt geht mit einem Schutzzustand einher, in der Lunge schützen IgG. Andererseits scheiden Kinder, die an einem angeborenen T-Zell-Defekt leiden, das Virus monatelang aus: Die eliminatorische Immunität ist T-Zell-abhängig. Antikörper gegen das F-Protein hemmen die Zellfusion und damit die Ausbreitung der Infektion im Gewebe und wirken schützend.

\section{Labordiagnose}

Das Virus ist serologisch nicht in strengem Sinne einheitlich: Es gibt 2 Subtypen, die untereinander Antigenverwandtschaft zeigen. Die Labordiagnose fußt auf der Komplementbindungsreaktion. Ein kommerzieller IFT erlaubt den Nachweis von RSAntigen in Zellen des Respirationstraktes. Die Schnell-Diagnose im Speichel oder der Lavage ist die wichtigste Voraussetzung für den gezielten Einsatz von humanisierten Antikörpern gegen RSV.

\section{Therapie und Prävention}

Allgemeine Maßnahmen. Gute Betreuung in der Intensiv-Abteilung kann den letalen Ausgang der Bronchiolitis-Pneumonie bei Säuglingen und Kleinkindern verhindern, wichtig ist $\mathrm{O}_{2}$-Beatmung.

Die i.v.-Zufuhr eines "humanisierten“, monoklonalen Antikörpers der Maus gegen das RS-Virus hat sich zur Therapie bei einer begrenzten Zahl von Erkrankungen mit bronchopulmonaler Dysplasie als wirksam erwiesen, die Indikation wird jetzt erweitert.

Ribavirin (s. S. 512): Die Wirksamkeit ist umstritten, vielleicht wirkt eine kombinierte Gabe mit humanisierten AK besser. Ein Impfstoff fehlt.

Meldepflicht. Bei gehäuftem Auftreten.

\section{ZUSAMMENFASSUNG: RS-Virus}

Virus. (-)-Strang-RNS-Virus, typisches Paramyxo-Virus (Genus Pneumovirus) ohne Neuraminidase, ätherempfindlich. Die Hülle enthält F- und G-Protein-Spikes, eine Matrix aus M-Protein, aber kein Hämagglutinin.

Vorkommen und Übertragung. Tröpfcheninfektion vom Nasensekret im oberen und unteren Respirationstrakt des Menschen.

Epidemiologie. Erkrankungen vorwiegend im Winter. Durchseuchung bis zum Ende des 2. Lebensjahres hoch.

\section{VIII}

Pathogenese. Replikation im mittleren und unteren Respirationstrakt. Riesenzellen durch F-Protein-Spikes. Schwere Flimmerepithelschäden am Kehlkopfepithel. Bronchiolitis.
Klinik. Gehört zu den wichtigen Kinderkrankheiten: Bronchitis, Laryngitis, Pseudokrupp, lebensbedrohliche Bronchiolitis-Pneumonie; Otitis media.

Immunität. Langandauernd; ZTL; Antikörper gegen F-Protein verhindern Virusausbreitung infolge Zellfusion; IgA im oberen, $\lg G$ im unteren Respirationstrakt wirksam.

Diagnose. KBR, Virusisolierung in Zellkulturen: Riesenzellen. IFT-Schnelltest auf RS-Virusantigen.

Therapie. Humanisierte Antikörper bei schweren Fällen. Ribavirin-Spray. $\mathrm{O}_{2}$-Inhalation.

Prävention. Bisher keine Impfung möglich. Meldepflicht bei gehäuftem Auftreten. 


\subsection{Masern-Virus}

Das Neuraminidase-freie Paramyxo-Virus erzeugt die Masern mit einer Immunsuppression und vielen Komplikationen. In den Entwicklungsländern sterben jährlich mehr als 1 Mio Kinder an den Masern. Altbekannte nahe Verwandte sind das Hundestaupe- und das Rinderpest-Virus. 1994 hat ein Masern-ähnliches Virus (Hendra-Virus) bei Pferden und Menschen schwere Pneumonien und 1 Jahr später eine schwere Enzephalitis erzeugt. 1998 wurde in Malaysia von Schweinen das Nipahvirus auf den Menschen übertragen (hohes Fieber, Meningoenzephalitis und Pneumonie). Letalität: $37,5 \%$. Die Evolution geht weiter.

\subsubsection{Beschreibung}

\section{Genom}

Das Masern-Virus ist ein (-)-Strang-RNS-Virus, die RNS liegt als durchgehender Einzelstrang mit $15,9 \mathrm{~kb}$ vor.

\section{Morphologie}

Das Virus mißt etwa $150 \mathrm{~nm}$ im Durchmesser; es besitzt eine hämagglutinierende Hülle und ein fusionsaktives Protein. Unter der Hülle befindet sich das M-Protein und im Inneren das helikale Nukleokapsid (Eigenschaften s. Tabelle 3.1, S. 552).

\section{Züchtung}

Die Züchtung in vitro gelingt auf verschiedenen Zellarten, es entstehen Riesenzellen und Chromosomen-Schäden, außerdem wird der G1/S-PhasenÜbergang gehemmt. Zur Züchtung in vivo läßt sich das Masern-Virus auf Affen übertragen.

\subsubsection{Rolle als Krankheitserreger}

\section{Vorkommen}

Einziges Reservoir ist der Masern-kranke Mensch. Die Virusausscheidung ist im katarrhalischen Vorstadium maximal und verschwindet nach dem
Ausbruch des Exanthems, Dauerausscheider gibt es nicht. Demzufolge kann die Ansteckung nur vom katarrhalisch erkrankten Kind her und vom inapparent Reinfizierten erfolgen.

\section{Übertragung}

Die Übertragung geht aerogen von katarrhalisch erkrankten Kindern oder inapparent Reinfizierten aus.

\section{Epidemiologie}

Das Masern-Virus ist leicht übertragbar, und die Empfänglichkeit des Menschen ist sehr hoch. Dementsprechend ist die Krankheit hochkontagiös, sie kann durch allgemein-hygienische Maßnahmen nicht bekämpft werden. Die Exposition von nicht immunen Personen führt so gut wie immer zur Ansteckung; die Krankheit verläuft dabei fast stets manifest und selten inapparent (Manifestationsindex fast 100\%). Dies bedeutet, daß die Bevölkerung bis zum 10 . Lebensjahr fast vollständig durchseucht ist. Häufigkeitsgipfel im Winter.

\section{Pathogenese}

Das Virus dringt aerogen in den Respirationstrakt ein und vermehrt sich zunächst in dessen Epithelzellen. Die weitere Ausbreitung erfolgt per continuitatem in den Bronchialbaum und auf dem Lymphund Blutweg (primäre und sekundäre Virämie) in die Haut (Exanthem); außerdem befällt das Virus Zellen des Immunsystems (Lymphknoten, Milz) sowie Endothelzellen und v.a. Makrophagen und vermehrt sich in ihnen; das ZNS ist aber vielleicht ausgespart. Durch Replikation in und Zerstörung (Apoptose) der dendritischen Zellen resultiert ein Mangel an IL-12, der ein Überwiegen der TH2-Zellen (s. S. 110) bewirkt: Mangel an IL-2 und IFN- $\gamma$ sowie Überwiegen von IL-4. Die 2 Glykoproteine des Masern-Virus stören zudem im T-Lymphozyten die Signalkette des IL-2-Rezeptors. Hieraus resultiert eine Unterfunktion der NK- und T-Zellabwehr. Hier ist die Ursache der allgemeinen Abwehrschwäche von Masernkranken zu suchen. Die T-Zellen reagieren auf mutagene Stimuli (Lektine, Masernantigen) nur wenig, die DTH (s. S. 126) fehlt.

Das Exanthem geht auf eine Entzündung im Bereich der Hautkapillaren zurück, wo sich Endothelzellen zu Warthin-Finkeldey'schen Riesenzellen umbilden, von denen die Entzündung auf die Epi-

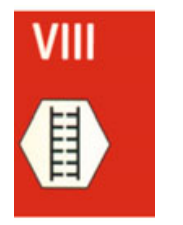


dermis übergreift. Bei Gesunden kann das Masern-Virus-Genom in Blutlymphozyten persistieren. Der Bronchialbaum wird hämatogen (wie die Haut) und per continuitatem vom Rachen aus besiedelt.

Pneumonien sind als Komplikation häufig; sie entstehen überwiegend sekundär-bakteriell. Wegbereiter ist - analog der Influenza - der primär virusbedingte Zellschaden am Bronchialepithel. Bei Immundefizienz tritt die Hecht'sche Riesenzellpneumonie auf.

Gleichzeitig oder im Anschluß kann es zu der para- oder postinfektiösen Enzephalitis kommen, bei denen Entmarkungen die Ursache sind; der Immunapparat zerstört vorwiegend die Markscheiden. Die seltene subakute Einschlußkörperchen-Enzephalitis tritt vorwiegend wenige Monate nach den Masern beim Vorliegen eines Immundefektes auf („measles-inclusion body-encephalitis“, MIBE).

\section{Klinik}

Die Inkubationszeit beträgt 10-14 Tage. Die ersten Erscheinungen sind katarrhalisch: Fieber, Husten, Schnupfen, Konjunktivitis mit Lichtscheue. Typisch und als Frühsymptom wertvoll sind die Koplik'schen Flecken an der Wangenschleimhaut der Mundhöhle; es sind weißliche, 1-2 mm messende flache Bläschen mit nekrotischer Oberfläche.

Dieses präexanthematisch-katarrhalische Krankheitsstadium dauert etwa vier Tage. Dann tritt der Ausschlag auf; er beginnt hinter den Ohren und breitet sich in 1-2 Tagen über den ganzen Körper aus. Im Gegensatz zum Scharlach ist das MasernExanthem grobfleckig-erhaben (makulo-papulös): Zwischen den z.T. konfluierenden, linsengroßen Herden ist unveränderte Haut wahrnehmbar; dies ist für die Unterscheidung von Scharlach wichtig. 1-2 Tage nach dem Auftreten des Exanthems gehen Fieber und Schnupfen zurück. Das Exanthem selbst persistiert bis zu 10 Tagen. Die Symptome sind fast stets charakteristisch ausgeprägt, so daß die Diagnose leicht zu stellen ist (Abb. S. 687).

Die durch das Virus selbst bedingten Komplikationen treten als kindlicher Pseudokrupp, als schwere Bronchitis oder als Bronchopneumonie auf. Oft tritt eine Otitis media hinzu. Beim Vorliegen zellulärer Immundefekte (z.B. bei Leukämien) beobachtet man das Bild der Hecht'schen Riesenzellpneumonie und die „MIBE“.

Die folgenschwerste Komplikation der Masern ist die Enzephalomyelitis. Sie tritt zumeist nach dem Abklingen der akuten Symptome als postinfektiöse Komplikation auf. Es kommt nach der ersten Abfieberung $\mathrm{zu}$ einem zweiten Fieberanstieg mit Benommenheit und u.U. mit Krämpfen. Auf 1000 Masernfälle kommt ein Fall von Enzephalomyelitis. Die Letalität beträgt etwa 15\%. Die Überlebenden zeigen häufig psychotische Persönlichkeitsveränderungen und Lähmungen. Das EEG zeigt im übrigen bei $50 \%$ der komplikationslos verlaufenden Masern reversible Veränderungen; dies deutet darauf hin, daß das ZNS häufiger als bisher angenommen in Mitleidenschaft gezogen wird (Zytokine?).

Die stets tödlich verlaufende subakute sklerosierende Panenzephalitis (SSPE, s. S. 561) wird als seltene Verlaufsform der Masern betrachtet.

\section{Immunität}

Das Masern-Virus ist immunbiologisch einheitlich und zeigt keine Antigenvarianten. Die durch die Krankheit erworbene Immunität ist sehr dauerhaft; sie wird durch inapparente Reinfektionen immer wieder hochgetrieben.

Das Masern-Virus ist das erste Virus, bei dem man immunsuppressive Wirkungen festgestellt hat. IgG-Antikörper verhindern die Generalisation, IgA-Antikörper schützen vor Reinfekten und ZTL bewirken die Elimination des Virus.

\section{Labordiagnose}

Während der Initialphase kann man das Virus aus dem Nasopharynx und dem Blut sowie den Leukozyten isolieren. Verwendet werden Kulturen von menschlichen Zellen. Die Virusisolierung wird nur $\mathrm{zu}$ wissenschaftlichen Zwecken vorgenommen.

Antikörper tauchen beim Kranken früh auf; sie sind durch Neutralisation, durch Hämagglutinationshemmung oder durch Komplementbindung nachzuweisen. Am besten eignen sich die KBR und der IgM- und IgG-ELISA. Differentialdiagnostisch sind alle exanthembildenden Krankheiten in Betracht zu ziehen.

\section{Therapie}

Seit der Einführung der Masern-Schutzimpfung sind die Masern wie auch die schwerwiegenden Komplikationen (Enzephalitis und SSPE) stark zurückgegangen. Eine Chemotherapie für die Masern-Infektion gibt es noch nicht. Möglicherweise 
erweist sich die Chemotherapie mit Ribavirin als brauchbar. Die sekundär-bakteriellen Infektionen (eitrige Otitis und Bronchopneumonie) werden mit Antibiotika behandelt.

\section{Prävention}

Allgemeine Maßnahmen. Die Masern waren in Europa weit verbreitet. Ihre Bekämpfung durch allgemein-hygienische Maßnahmen ist nicht möglich, weil die Infektion aerogen vor sich geht. Für das einzelne Kind ist eine Expositionsprophylaxe wirksam, aber nur zeitweise: Das Kind darf dabei nur von Erwachsenen umgeben sein. Die Expositionsprophylaxe ist indiziert, wenn bei einem ungeimpften Kind eine latente Tuberkulose besteht. Die gleiche Indikation gilt auch für Kinder, die sich in einem schlechten Ernährungszustand befinden, sowie für Diabetiker.

Passive Immunisierung. Ist ein Kind $\mathrm{zu}$ einem festlegbaren Zeitpunkt exponiert gewesen, so kann man den Ausbruch der Masern durch die Gabe von Human-Gammaglobulin verhindern oder den Krankheitsverlauf mildern. Gibt man das Globulin innerhalb von zwei Tagen nach der Exposition, so wird die Krankheit verhindert; gibt man das Globulin zwischen dem 3. und 6. Tag, so wird der Verlauf der Krankheit abgemildert („mitigiert“). Die auf diese Weise erworbene Passiv-Immunität dauert aber höchstens drei Wochen. Indikationen: Noch nicht geimpfte Kinder mit latenter Tuberkulose oder mit Stoffwechselkrankheiten. Die versäumte Aktiv-Impfung ist in diesem Fall unverzüglich nachzuholen!

Aktive Immunisierung. Es wird ein Lebendimpfstoff verwendet. Zur Verfügung steht ein Masernstamm, der durch Passagen abgeschwächt ist. Der Impfstoff wird i.m. injiziert. Der Stamm führt bei einigen Impflingen zwar zu leichtem Fieber und gelegentlich zu einem schwachen Exanthem, ernste Komplikationen sind jedoch nicht bekannt geworden; insbesondere fehlen bei Impflingen EEG-Veränderungen. Die durch Impfung erworbene Immunität dauert offenbar nur etwa 20 Jahre. Die gelegentlich auftretenden Impf-Masern können durch gleichzeitige subkutane Gabe von Gammaglobulin weitgehend vermieden werden. Das Gammaglobulin wird an einer anderen Stelle injiziert als der Impfstoff. Die Lebendimpfung sollte erst dann durchgeführt werden, wenn die mütterlichen $\mathrm{Ma}$ -
sern-Antikörper aus dem kindlichen Organismus verschwunden sind. Die Masern-Impfungen erfolgen (mit Mumps und Röteln) im 12.-15. Lebensmonat, die Boosterimpfungen ab dem 6. Lebensjahr (s. S. 999).

Die Masernimpfung ist aus folgenden Gründen gerechtfertigt und zur breiten Anwendung zu empfehlen:

Fast jede Infektion mit Masern-Virus führt zur Krankheit.

Masern sind wegen der relativ häufigen Komplikationen alles andere als eine „leichte Krankheit“: Pneumonie, Enzephalitis, EEG-Veränderungen, Immunsuppression.

Jeder Mensch wird bis zu seinem 10. Lebensjahr mit dem Wildvirus angesteckt. Dieser Tatbestand ist nicht $\mathrm{zu}$ ändern. Die Isolierung kann ein Einzelkind nur für einen begrenzten Zeitraum vor der Infektion schützen.

Die Zahl der Erkrankungen an Enzephalomyelitis und SSPE nimmt seit Einführung der Schutzimpfung ab.

Durch die Anwendung der Lebendimpfung ist in einigen Staaten Europas das Wildvirus nahezu verschwunden. Im Unterschied zum Polio-Lebendimpfvirus ist das Masern-Impfvirus aber nicht übertragbar; es erscheint nach der Impfung weder im Rachenraum noch im Blut. Die Dauer des Impfschutzes beträgt etwa 20 Jahre, danach können Masern erneut auftreten.

Meldepflicht. Verdacht, Erkrankung, Tod, Erregernachweis.

\subsubsection{Subakute sklerosierende Panenzephalitis (SSPE)}

Allgemeines. Die subakute, sklerosierende Panenzephalitis (SSPE) ist eine Viruskrankheit, die sich nach einer Zwischenperiode von 2-10 Jahren nach einer normal verlaufenen Maserninfektion entwikkelt. Das Virus persistiert dabei im ZNS ohne Zeichen einer Erkrankung. Sie ist sehr selten.

Pathogenese. Pathohistologisch zeigen sich perivaskuläre Infiltrate mit Lymphozyten und Plasmazellen. Die Veränderungen sind über das ganze Gehirn verteilt; in den Basalganglien und in der Rinde treten sie gehäuft auf. Das Masern-Virus persistiert offenbar über Jahre in defekter Form, man 
vermutet eine gestörte Transkription und Translation des M-Proteins infolge von Mutationen, die zu einer Imbalance der Immunabwehr infolge M-Protein-Mangels führt; hierdurch entsteht ein defektes, aber virulentes Virus. 50\% der SSPE-Fälle haben ihre Masern vor dem 2. Lebensjahr durchgemacht. Es könnte sein, daß auf diese Weise die Einnistung des Erregers in einen immunologisch nicht ausgereiften Organismus erleichtert wird. Das SSPE-Masern-Virus hat sich auch als interferon-resistent erwiesen. In der Umgebung der Masern-infizierten Astrozyten findet sich gehäuft das Mx-Effektorprotein des Interferons.

Klinik. Das Krankheitsbild tritt bei Kindern oder Jugendlichen Jahre nach einer abgelaufenen Maserninfektion auf. Der Beginn ist schleichend; man beobachtet motorische Störungen und einen $\mathrm{Ab}$ bau der geistigen Leistungsfähigkeit. Auffallend sind Unaufmerksamkeit und Gefühlslabilität. Im Endstadium treten Konvulsionen und komatöse Zustände auf. Die Prognose ist schlecht. Eine Therapie gibt es nicht.

Labordiagnose. Im Serum und Liquor lassen sich schon frühzeitig exzessiv hohe Titer an komplementbindenden, hämagglutinationshemmenden und neutralisierenden Antikörpern nachweisen; es fehlen jedoch die Antikörper gegen das M-Protein sowie eine IgM-Reaktion. Die Reaktion der Lymphozyten auf Lektine ist normal. Im Gewebe der befallenen Bezirke lassen sich Antigene des Masern-Virus zwar nachweisen, nicht aber infektiöse Viria; die Infektion breitet sich trotzdem im Gewebe aus. Um infektiöse Partikel $\mathrm{zu}$ isolieren, muß man die Verfahren der Zell-Kokultivierung (s. S. 520) anwenden.

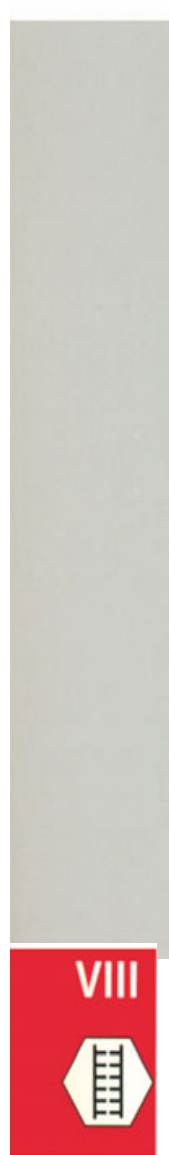

\section{ZUSAMMENFASSUNG: Masern-Virus}

Virus. (-)-Strang-RNS-Molekül, helikales Nukleokapsid. Typisches Paramyxo-Virus, ohne Neuraminidase, ätherempfindlich. M-Protein unter der Spike-tragenden Hülle (Hämagglutinin, F-Protein).

Vorkommen. Nur beim Menschen, Nasenrachenraum, Bronchialbaum, Konjunktiven.

Epidemiologie. Hohe Kontagiosität, kaum inapparente Infektionen, bis zum 10. Lebensjahr vollständige Durchseuchung.

Übertragung. Tröpfcheninfektion, ausgehend vom Nasenrachenraum, von Konjunktiven.

Pathogenese. Systemische Infektion mit hämatogener Ausbreitung: Exanthem ist immunbiologisch bedingt. Durch Flimmerepithelschäden schwere Bronchitis, Masern-Virus-Pneumonien.
Klinik. Inkubationsperiode 10-14 Tage. Schwere Kinderkrankheit. Exanthem, Konjunktivitis, Otitis media, Bronchitis, primäre (Virus-) und sek. bakterielle Pneumonie, EEGVeränderungen, para- und postinfektiöse Enzephalitis, MIBE, SSPE. Bei Immunschaden: Hecht'sche Riesenzellenpneumonie.

Immunität. Dauerhafte Immunität, ZTL, Antikörperbildung, allgemeine Suppression der zellulären Immunität.

Diagnose. KBR, IgM- und IgG-ELISA. Virusisolierung. $P C R$ im Liquor.

Therapie. Symptomatisch.

Prävention. Schutzimpfung.

Meldepflicht. Verdacht, Erkrankung, Tod, Erregernachweis. 


\section{EINLEITUNG}

Corona-Viren erzeugen Schnupfen und wahrscheinlich Gastroenteritis. Corona-Viren sind streng artspezifisch. Ihren Namen tragen diese Viren wegen ihrer Spikes, die weit aus dem envelope herausragen und an den Enden kleine Knöpfchen tragen; diese umgeben das Virion wie eine "Corona". Sie bilden die Familie der Corona-Viren.

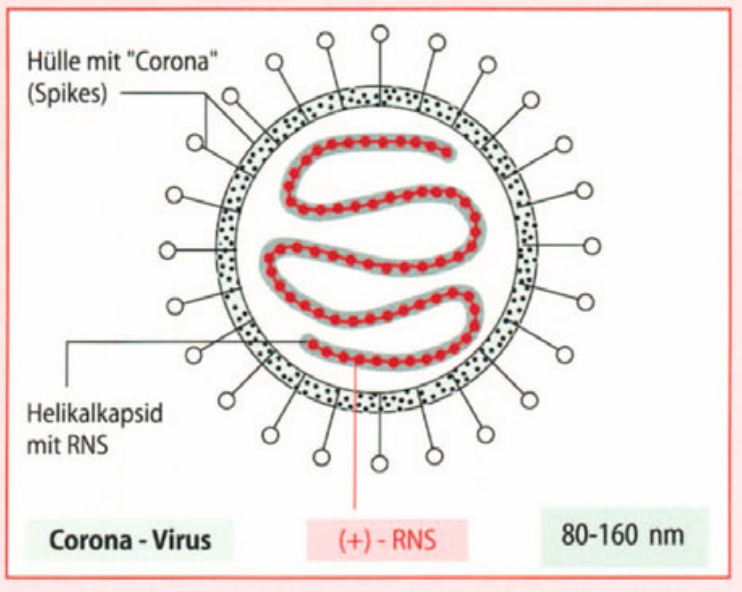

\subsection{Beschreibung}

\section{Genom}

Die Corona-Viren sind (+)-Strang-RNS-Viren mit $30 \mathrm{~kb}$. Das Virus repliziert sich bei $32^{\circ} \mathrm{C}$. Es gibt zwei Serotypen.

\section{Morphologie}

Corona-Viren besitzen eine Hülle; das Virus hat einen Durchmesser von 80-160 nm. Im Inneren der Hülle befindet sich ein helikales Kapsid mit der RNS, auf der Hülle sitzen Spikes. Das Virus ist ätherempfindlich.

\subsection{Rolle als Krankheitserreger Epidemiologie und Übertragung}

Die Durchseuchung ist hoch (90-100\%), sie beginnt im Säuglingsalter. Die Erkrankungen treten im Winter und Frühjahr, v.a. bis zum 12. Lebensmonat infolge von Aerosol- oder Schmutz- und Schmierinfektionen auf. Zwischen den zwei Typen besteht keine Kreuzimmunität. Replikation in den oberen Luftwegen.

\section{Klinik}

Die Inkubationsperiode beträgt 2-5 Tage bei einer Krankheitsdauer bis sieben Tage. Corona-Viren werden für $10-25 \%$ aller Schnupfenfälle verantwortlich gemacht; gelegentlich rufen sie Bronchitis und Pneumonie hervor. Sie erzeugen auch eine Gastroenteritis und als Rarität eine nekrotisierende Enterocolitis bei Frühgeborenen.

Die Immunität ist nicht sehr dauerhaft; es treten deshalb Reinfektionen auf, die bei Erwachsenen oft inapparent verlaufen.

\section{Labordiagnose}

Zur Organkultur wird ein Explantat von kleinen Trachea-Stückchen verwendet. Als „zytopathischer Effekt" wird das Sistieren der Zilienbewegung auf den Epithelzellen registriert. Antikörper gegen Corona-Viren lassen sich im Hämagglutinationshemmungstest und in der KBR nachweisen; ein Routinetest existiert noch nicht. Zur Zeit laufen Versuche, das Virus im Rachen- oder Bronchialsekret 
durch einen Schnelltest nachzuweisen (IFT, ELISA). Der Virusnachweis gelingt im Stuhl mit dem EM.

\section{Prävention}

Bisher gibt es keine wirksamen Maßnahmen zur Prophylaxe abgesehen von Allgemein-Hygiene.

\section{ZUSAMMENFASSUNG: Corona-Viren}

Virus. (+)-Strang-RNS-Virus aus helikalem Kapsid und Hülle mit Spikes: "Corona“. Das Virus ist ätherempfindlich; Replikation bei $32{ }^{\circ} \mathrm{C}$.

Epidemiologie. Hohe Durchseuchung durch Aerosol- sowie Schmutz- und Schmierinfektion. Zwei Serotypen.

Klinik. Erkältungskrankheiten, gelegentlich Bronchitis und Pneumonie sowie Gastroenteritis.
Immunität. Nicht dauerhaft, Reinfektion.

Diagnose. Noch kein Routine-Test, HHT und KBR. Virus im Stuhl mit EM.

Therapie. Symptomatisch.

Prävention. Keine. 


\section{EINLEITUNG}

Die Gruppe der Toga-, Flavi- und Bunya-Viren ist außerordentlich heterogen: Ihre Replikation und die ausgelösten Krankheitserscheinungen variieren außerordentlich. Sie können Hepatitis, Meningitis, Nephritis, Hämorrhagien, Arthritis und Exantheme erzeugen. In den Tropen haben sie eine große Bedeutung. Auch das Virusreservoir ist unterschiedlich: Affen und wildlebende Nagetiere oder nur der Mensch. Die Übertragung erfolgt z.T. durch Aedes-Spezies (Gelbfieber).

\section{1 Übersicht über die Toga-, Flavi- und Bunya-Viren}

\section{Charakteristika und Krankheitsformen}

Die Charakteristika dieser Viren lassen sich in fünf Punkten zusammenfassen:

- Es sind RNS-Viren von sehr unterschiedlicher Größe (50-140 nm) und enthalten 10-22 kb Information.

- Toga- und Flavi-Viren enthalten (+)-Strang-RNS als Einzelmolekül in einem Ikosaeder-Kapsid, während Bunya-Viren drei (-)-Strang-RNS-Moleküle in drei Helikal-Kapsiden mit der Polymerase aufweisen. Die Kapside sind von einer außen liegenden Hülle mit Spikes umgeben.

- Alle Viren replizieren sich im Zytoplasma und werden dort oder an der Zellmembran montiert. Der Replikationsmechanismus der RNSMoleküle ist sehr unterschiedlich.

- Sie befallen verschiedenartige Vertebraten. Ihre Übertragung erfolgt durch Arthropoden. Das Röteln-(Rubi-)Virus wird durch Aerosolinfektion von Mensch zu Mensch, das HCV durch Blut und sexuell übertragen. Bunya-Viren: Hanta-Viren werden durch Staub von Nagetierkot- und Urin, das Pappataci- und das Toskana-Fieber durch Sandfliegen übertragen.

- Sie sind nur z.T. zur Hämagglutination befähigt, aber alle ätherempfindlich.

Krankheitsformen. Bei den Erkrankungen durch Toga-, Flavi- und Bunya-Viren kann man hinsichtlich der klinischen Symptomatik sieben Syndrome herausschälen. Allen gemeinsam ist der hochfieberhafte Charakter:

Schädigung von Leber und Niere mit Gelbsucht und Albuminurie sowie, in wechselndem Ausmaße, Hämorrhagien (Haut, Niere, Magen). Beispiel: Das Gelbfieber (s. S. 566).

- Gelenkschmerzen und/oder Exanthem. Beispiel: Das Dengue-Fieber in Südostasien (s. S. 567); in seiner bösartigen Form tritt es als Folge einer Superinfektion mit einem heterologen Typ des Dengue-Virus als hämorrhagisches Dengue-Fieber z.T. mit Schock auf.

- Benommenheit, Schlafsucht, Krämpfe, Meningoenzephalitis. Beispiel: Die in Ost- und Südosteuropa vorkommende Frühsommer-Meningoenzephalitis (FSME) (s. S. 568).

- Nephropathie, Pneumonie und Hämorrhagien. Beispiele: Das Puumala-, das Hantaan- sowie das Sin-Nombre-Virus der Bunya-Viren (s. S. 571).

- Hämorrhagien (mit Fieber) stehen bei dem sog. "Hämorrhagischen Fieber" im Vordergrund (Hämorrhagisches Fieber der Krim).

- Exanthem, Embryopathien und selten Arthralgien. Beispiel: Das ubiquitäre Röteln-Virus (s. S. 573).

- Hepatitis durch das Hepatitis C-Virus (s. S. 672).

Viele Infektionen verlaufen inapparent oder milde, bei einigen Virusspezies dagegen sehr schwer.

Differentialdiagnostisch ist bei Reisenden aus Zentralafrika und Südamerika mit Fieber und Hämorrhagien an die Marburg-Krankheit oder das Ebola-Fieber (Filo-Viren, s. S. 685) zu denken; ebenso ist das Lassa-Fieber (Arena-Virus, s. S. 584) in Betracht zu ziehen. 


\section{Einteilung}

Die drei Familien von Viren umfassen mehr als 1000 verschiedene Erregerspezies; im Hinblick auf die jeweils entstehenden Krankheitsbilder, auf die Antigenität und auf die Virusstruktur sind sie äußerst heterogen.

Toga-Viren. Sie umfassen folgende Genera:

- Alpha-Virus (Arbo-Virusgruppe): Sindbis-Virus sowie Pferde-, Venezuela-Enzephalitis-Virus, Semliki-Forest-Virus und Ross-River-Virus;

- Rubi-Virus: Röteln-Virus (s. Kap. 5, S. 573).

Flavi-Viren. Diese umfassen folgende Genera:

- Flavi-Virus: Gelbfieber, Dengue-Virus, Japan BEnzephalitis, Zeckenenzephalitis (FSME) u. a.;

- Hepatitis C-Virus (HCV; s. Kap. 14, S. 672).

Bunya-Viren. Sie umfassen fünf Genera: Bunya-, Hanta-, Nairo-, Phlebo- und Tospo-Virus (s. S. 571).

\section{Namensgebung}

Die Bezeichnung „Toga“ leitet sich von der im Vergleich zum Kapsid sehr groß ausgebildeten Hülle ab (die „schlotternde Toga“). „Flavi“ (gelblich) deutet auf den Ikterus hin. Das Präfix „Arbo“ - einige Viren werden auch als Arbo-Viren bezeichnet - bezieht sich auf die Tatsache, daß die Viren durch Arthropoden übertragen werden (arthropod-borne). Die Viren der "Bunya“-Gruppe tragen ihren Namen nach dem Prototyp-Virus, dem Bunyamvera-Virus.

\section{Vorkommen}

Als Reservoir für die Viren dienen Säugetiere (Affen, kleine Nagetiere), die das Virus lange Zeit beherbergen. Die Säugetiere werden von Arthropoden gestochen. Diese nehmen während der virämischen Phase Viren auf; sie können es dann auf andere Wirte (Mensch u.a.) durch Stich übertragen. In Arthropoden kann sich das Virus nicht nur vermehren und „überwintern“, sondern kann auch transovariell übertragen werden; auf diese Weise erhält es sich jahrelang unabhängig vom Vertebraten-Reservoir. Im Falle der Genus Hanta-Viren erfolgt die Übertragung auf den Menschen auch direkt von kleinen Nagetieren aus durch Staub.

Arbo-Viren sind besonders in den Tropen weit verbreitet. Einige von ihnen kommen auch in Europa endemisch vor.
Im Falle der hier dargestellten Arbo-Viren kommen als Vektoren drei Arthropoden in Betracht:

- Übertragung durch Mücken: Virus des DengueFiebers und des Gelbfiebers.

- Übertragung durch Sandmücken: Virus des Pappataci-Fiebers (Bunya-Gruppe).

- Übertragung durch Zecken: Virus der russischen und der zentraleuropäischen Frühsommer-Meningoenzephalitis (FSME).

\section{Toga-Viren}

Die Viren der Alpha-Gruppe mit dem Sindbis-Virus als Prototyp spielen in Mitteleuropa keine Rolle.

\section{Flavi-Viren}

Wichtige humanpathogene Viren dieser Familie sind das Gelbfieber-Virus, das Dengue-Virus und die Viren der Zeckenenzephalitis; in Japan, Indien und Ostasien ist die Japan-B-Enzephalitis bedeutsam.

\subsection{Gelbfieber-Virus}

Das Gelbfieber war ursprünglich nur in Afrika heimisch. Von dort ist es mit Handels- und Sklavenschiffen (mitsamt den Vektoren) nach Amerika transportiert worden und hat dort zu großen Epidemien geführt. Das bekannteste Beispiel sind die Gelbfieber-Ausbrüche beim Bau des Panama-Kanals. Bei diesen Ausbrüchen sind die nicht immunisierten Fremdarbeiter mit Gelbfieber infiziert worden und zu Tausenden gestorben. Walter Reed wies 1900 das Gelbfieber-Virus im Blut Infizierter nach und zeigte die Übertragung durch Aedes aegypti.

\subsubsection{Rolle als Krankheitserreger}

\section{Epidemiologie}

Gelbfieber tritt in Afrika sowie Süd- und Mittelamerika, aber nicht in Asien endemisch und epidemisch auf. In Afrika und Südamerika breitet es 
sich verstärkt aus, weil die Vektoren sich an neue Biotope anpassen.

\section{Übertragung}

Als Überträger für den Menschen dient Aedes aegypti (Gelbfieber-Mücke). Die Krankheit kann von Mensch zu Mensch („urbanes“ Gelbfieber) oder vom Tier (Affen, Vögel u.a.) auf den Menschen übertragen werden. Im ersten Fall spricht man von einer homogenen Infektkette, im zweiten Fall von einer heterogenen Infektkette. In den tropischen Wäldern kennt man eine Seitenlinie der im Urwald ablaufenden Infektkette „Affe-MückeAffe“ („Dschungel-Gelbfieber“).

\section{Klinik}

Das Gelbfieber läuft in zwei Phasen ab. Einige Tage nach der Infektion treten Fieber, Schüttelfrost, Ikterus und Kopfschmerzen auf. Hinzu gesellen sich Muskelschmerzen, Brechreiz und Erbrechen. Nach einigen Tagen verschwinden bei einigen $\mathrm{Pa}$ tienten diese Symptome. Bei anderen folgt nach einer Besserung ein heftiger Relaps mit Fieber, Bradykardie und Hämorrhagien infolge des Leberschadens. Bis zu $50 \%$ der so Erkrankten sterben.

\section{Labordiagnose}

Die Labordiagnose erfolgt durch Isolierung aus dem Blut, den HHT und ELISA. Mittels der PCR läßt sich die RNS nachweisen.

\section{Prävention}

Mückenbekämpfung. Durch gezielte Mückenbekämpfung sind im Hinblick auf die Gelbfieber-Prophylaxe schon sehr früh große Erfolge erzielt worden, z. B. beim Bau des Panama-Kanals.

Impfstoffe. Der D-17-Stamm von Theiler wird in Deutschland verwendet. Die durch Impfung erworbene Immunität hält etwa 10 Jahre an.

Meldepflicht. Verdacht, Erkrankung und Tod. Erregernachweis

\subsection{Dengue-Fieber-Virus}

Das Dengue-Fieber wurde erstmals 1780 beschrieben. Das Dengue-Fieber-Virus in Südostasien bis zur Karibik ist das am weitesten verbreitete Virus der Flavi-Virusfamilie; es kommt in vier Serotypen vor. Es erzeugt Fieber, Kopfschmerzen, „KnochenbruchFieber" und z.T. Hämorrhagien und/oder Schock-Symptome; es breitet sich jetzt weiter aus. 40-80 Mio Menschen erkranken pro Jahr. Der Krankheitskomplex stellt sich mit 3 überlappenden Syndromen dar: "Grippe", Hämorrhagisches Fieber und Schock. Das DHF wird seit 1950 beobachtet.

\subsubsection{Rolle als Krankheitserreger}

\section{Epidemiologie und Übertragung}

In den letzten Jahren wurden große Dengue-Epidemien beobachtet, das gefürchtete „Schock-Syndrom" tritt häufiger als in früheren Jahrzehnten auf.

Dengue-Fieber wird durch Aedes aegypti u.a. Stechmücken übertragen.

Durch den Import von alten Autoreifen ist jüngst ein Vektor (Aedes albopictus) und das Dengue-Virus selbst in die USA importiert worden. Verbreitet in Südostasien, Afrika und Mittel-/ Südamerika.

\section{Pathogenese}

Pathologisch-anatomisch treten im Bereich des Exanthems Schwellungen der Endothelien, perivaskuläre Ödeme und Monozyteninfiltrate auf. Die zentralen Elemente des Dengue-Hämorrhagischen Fiebers (DHF) sind Blutungsneigung, Komplementverbrauch und Zytokinfreigabe aus Makrophagen und Endothelien infolge gesteigerter Aufnahme von Virus-Ak-Komplexen via Fc-Stück: „Antibodydependant enhancement“. Der Dengue-Schock tritt meist bei Personen auf, die nicht neutralisierende Antikörper von vorhergehenden Infektionen mit anderen Dengue-Typen haben; er wird jetzt auch bei Primärinfektionen mit Viren gesteigerter Virulenz beobachtet. Im Schock sind große Mengen an RANTES und IL-8 im Plasma und Exsudat. 


\section{Klinik}

Die Inkubationsperiode beträgt 7-10 Tage. Es werden drei Verlaufsformen (mit Übergängen) unterschieden:

- Das milde 3tägige Dengue-Fieber (Grippe-ähnlich, meist Kinder),

- das Dengue-hämorrhagische Fieber (4-10 Tage; DHF) und

- kombiniert mit Schock-Syndrom (auch ohne DHF).

Das DHF ist Grippe-ähnlich mit zweigipfeligem Fieber bis $\mathrm{zu} 40^{\circ} \mathrm{C}$ sowie heftigen Kopf-, Retroorbital-, Gelenk- und Knochenschmerzen, zweiphasigem Erythem-Exanthem und generalisierten Lymphknotenschwellungen sowie Hepatomegalie; Tod ist selten. Dauer 4-10 Tage. Nach 2-4tägiger Besserung oder vom 6. Tag ab kann eine Verschlechterung des Zustandes erfolgen: Schwitzen, Hypotension mit spontanen Hämorrhagien, Abfall der Granulo- und Thrombozyten sowie Temperaturabfall, dabei steigt der Hämatokrit an. Bildet sich der Schock aus, gesellen sich Exsudate in Perikard, Thorax und Abdomen hinzu; unbehandelt sterben 50\% der Patienten. Der Schock kann ohne hämorrhagische Diathese plötzlich auftreten. Er manifestiert sich durch plötzlichen Austritt von Plasma in die Körperhöhlen. Dies deutet auf einen besonderen „Tropismus“ des ursächlichen Effektorenmechanismus für die Gefäße der serösen Häute hin (IL-8). Wird der Schock überstanden, erfolgt alsbaldige Erholung. Die Therapie ist symptomatisch mit Infusionen und Kreislaufstützung.

\section{Labordiagnose}

Die Labordiagnose erfolgt durch Isolierung des Virus in Moskito-Zellinien oder durch die PCR. Die Serodiagnose der vier Typen erfolgt durch den HHT oder einen IgM- und IgG-ELISA vom 8.-10. Tag an. DD: Hanta-Viren, Leptospiren, Malaria.

\section{Prävention}

Bekämpfung des Vektoren-Reservoirs. Ein Impfstoff wird erprobt.

\section{Meldepflicht}

Verdacht, Erkrankung, Tod, Erregernachweis.

\subsection{Virus der Frühsommer- Meningoenzephalitis (FSME)}

Das FSME-Virus ruft die Frühsommer-Meningoenzephalitis hervor. Das Virus kommt in Deutschland endemisch vor, wird durch Zekken übertragen und ist somit ein wichtiger Krankheitserreger. Das FSME-Virus ist ein (+)-Strang-RNS-Virus der Flavi-Viren.

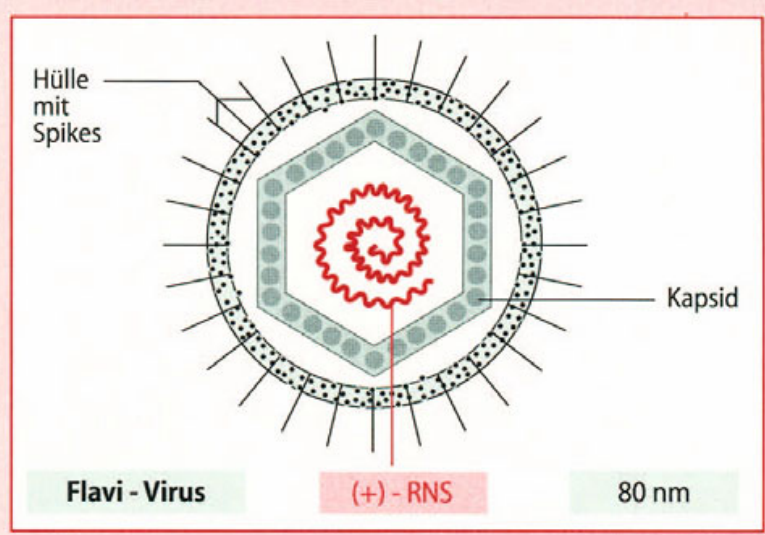

\subsubsection{Rolle als Krankheitserreger}

\section{Vorkommen}

Erreger-Reservoir sind wildlebende, kleine Nagetiere, Rehe, Igel, Schafe u.ä., wobei die Zecke (Ixodes ricinus, Holzbock) den Hauptüberträger darstellt. Das Virus kann auf die Zecke nur beim Saugen auf einem virämischen Wirt übergehen. Es kann in den Zecken längere Zeit persistieren und sogar überwintern, da die Möglichkeit eines transovariellen Überganges auf die Zeckeneier besteht.

\section{Epidemiologie}

In Zentraleuropa kommt das FSME-Virus v.a. in der Slowakei und im südlichen Teil von Österreich vor. In Deutschland gibt es v. a. am Oberrhein und in Bayern im Bereich der Donau und Altmühl endemische Virusherde, insgesamt werden etwa 150300 Fälle pro Jahr beobachtet. Die meisten Erkrankungen treten nach Freizeitaktivitäten auf.

Von den Personen, welche von virushaltigen Zecken gestochen worden sind, erkranken $30 \%$. Die virusverseuchten Naturherde sind z.T. sehr klein. Im Wiener Wald ist 1 unter 50, im Schwarzwald 1 unter 2000 Zecken virushaltig. In Naturherden ist die Durchseuchung bei Waldarbeitern hö- 
her als bei Stadtbewohnern; sie liegt bei $1-5 \%$. Es gibt Jahre mit verstärktem Zeckenbefall.

\section{Übertragung}

Die infizierten Zecken sitzen auf Gräsern und Büschen; sie lassen sich auf den Wirt fallen, setzen sich durch Stich auf der Haut fest und saugen Blut. Dabei wird das Virus übertragen. In Hochendemieregionen kann sogar durch die Milch von Rindern u. a. das Virus auf den Menschen übertreten.

\section{Pathogenese}

Nach dem Zeckenstich vermehrt sich das FSMEVirus zunächst lokal und gelangt dann ins Blut. Es wird lokal zuerst durch Makrophagen, Langerhans-Zellen und Granulozyten sowie Endothelzellen aufgenommen und vermehrt sich dort. Durch virämische Ausbreitung entsteht nach 7-10 Tagen ein erster Krankheitsgipfel. Im Anschluß daran erfolgt eine zweite Virämie, die zu den Organmanifestationen in den Meningen und im Gehirn führt. Diese Zweigipfligkeit des Verlaufs kann mit dem Verlauf der Polio verglichen werden. Im Rückenmark werden vorwiegend die motorischen Vorderhornzellen befallen.

\section{Klinik}

Die Inkubationszeit beträgt 7-14 Tage. Nur 30\% der Infektionen verlaufen apparent (Abb. 5.1).

Bei den apparent verlaufenden Formen unterscheidet man zwei Phasen.

Primärstadium. Im Primärstadium entwickelt sich in $90 \%$ der Erkrankten ein uncharakteristisches
Krankheitsbild in Form eines grippalen Infektes mit Kopf-, Kreuz- und Gliederschmerzen. Gelegentlich werden gastrointestinale Symptome beobachtet. Die Körpertemperatur übersteigt selten $38^{\circ} \mathrm{C}$. Dieses erste Stadium dauert $2-4$ Tage, gefolgt von einem fast beschwerdefreien Intervall.

Sekundärstadium. Die zweite Phase beobachtet man bei $10 \%$ aller Erkrankten. Sie ist durch den Befall des ZNS gekennzeichnet und kann sich als Meningitis, Meningoenzephalitis, Meningoenzephalomyelitis oder als Meningitis mit Radikuloneuritis manifestieren. Meningitis wird bei ihnen in $60 \%$, die Formen der Enzephalitis in etwa 40\% der Fälle beobachtet. Beim Vorliegen einer Meningitis treten heftige Kopfschmerzen auf, die häufig mit Fieber bis $40^{\circ} \mathrm{C}$ einhergehen. Bei Mitbeteiligung des Gehirns treten Hyperkinesien, Bewußtseinstrübungen, Bewußtlosigkeit und Sprachstörungen auf. In einem geringen Prozentsatz der Fälle werden Paresen im Bereich des Okulomotorius und des Fazialis sowie Blasenlähmungen festgestellt; außerdem treten Sensibilitätsstörungen auf. Die schlaffen Spätlähmungen können im Bereich von Hals, Schultergürtel und oberen Extremitäten auftreten; sehr selten gehen sie in eine Landry'sche Paralyse über. Bei Kindern überwiegt die meningitische, bei Erwachsenen die enzephalitische Form. Die Letalität beträgt etwa $1 \%$. Die Meningitis heilt ohne Folgen aus, nach dem enzephalitischen Verlauf bleiben bei etwa 5-7\% der Fälle Restzustände mit geringen Lähmungen zurück, gut $90 \%$ heilen komplett aus.

\section{Immunität}

Das Glykoprotein der Hülle regt die Bildung von neutralisierenden und hämagglutinationshemmen-
Abb. 5.1. Ablauf einer FSME-Infektion: Zweiphasige Fieberkurve und Spätlähmung, Virusnachweis und Antikörperbildung

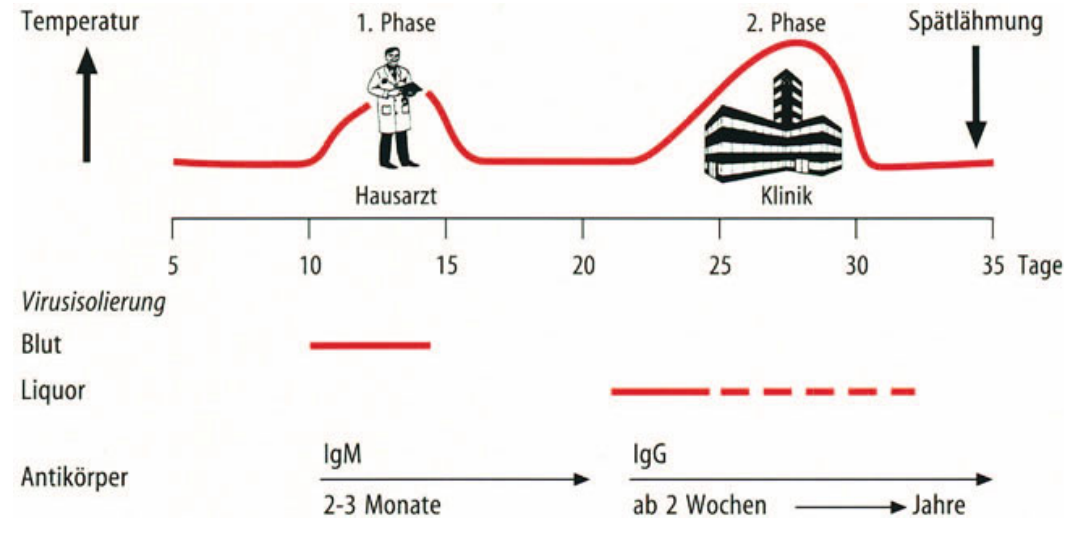


den Antikörpern an. Es entstehen im Verlauf der Infektion zuerst IgM- und dann IgG-Antikörper. Die Frühdiagnose gelingt auch durch den Nachweis von gering aviden IgG-Antikörpern. Die Entstehung einer zellulären Immunität ist wahrscheinlich.

\section{Labordiagnose}

Die Diagnose erfolgt durch Nachweis des Antikörper-Anstiegs mit Hilfe eines $\mu$-Ketten-spezifischen IgM-ELISAs, die RT-PCR erlaubt den Nachweis des Virus in der Zecke. Differentialdiagnostisch ist die ebenfalls durch Zecken übertragene Lyme-Krankheit zu nennen, die $20 \times$ häufiger vorkommt als die FSME. Die Frühdiagnose gelingt auch durch den Nachweis gering avider IgG-Antikörper.

\section{Therapie}

Keine spezifische Therapie.

\section{Prävention}

Allgemeine Maßnahmen. Für Wanderer in Endemiegebieten sind Mittel zur Abwehr blutsaugender Ektoparasiten zu empfehlen („Repellents“).
Schutzimpfung. Als Impfstoff gegen die FSME dient ein Totimpfstoff, der gut wirksam und verträglich ist; die Wirksamkeit der Impfung hält 2-3 Jahre an. Eine Empfehlung zur Schutzimpfung besteht insbesondere für Waldarbeiter in bekannten Endemiegebieten. Die ständige Impfkommission (StiKo) klassifiziert die aktive Schutzimpfung gegen FSME als eine "Risikoimpfung“ bzw. eine „Reiseimpfung“. Die Grundimmunisierung erfolgt durch drei Impfungen, zwei Impfungen werden in 1-3monatigem Abstand appliziert; nach Ablauf eines Jahres verabfolgt man eine Booster-Impfung. Zur Auffrischung wird alle drei Jahre eine weitere Impfung empfohlen. Bei Zeckenstichen in Endemiegebieten ist bei Ungeimpften unter 14 Jahren eine passive Immunprophylaxe nicht ratsam. Der Verlauf soll dann schwerer als normal sein. Passive Immunisierung innerhalb von 1-2 Tagen nach Stich. Infolge der aktiven Schutzimpfung ist die Zahl der Fälle in Österreich von etwa 600 auf 100 pro Jahr zurückgegangen.

Meldepflicht. Verdacht, Erkrankung und Tod; Erregernachweis.

\section{ZUSAMMENFASSUNG: Zeckenenzephalitis-(FSME-)Virus}

Virus. (+)-Strang-RNS-Virus, Ikosaeder-Kapsid mit spikestragender Hülle.

Vorkommen. Einzelne Regionen in Deutschland, Südösterreich, Slowakei.

Epidemiologie. Weniger als $1 \%$ der Zecken in Endemiegegenden sind infiziert. Weniger als $30 \%$ der gestochenen Personen erkranken. Höhere Durchseuchung bei Waldarbeitern u.a.

Übertragung. Durch Zecken von kleinen $\mathrm{Na}-$ getieren auf den Menschen übertragen.

Pathogenese. Zuerst Virämie nach dem Stich der virushaltigen Zecke mit grippalem Infekt, dann Virämie mit Organmanifestation im ZNS.
Klinik. Inkubationsperiode 7-14 Tage. Primärstadium mit grippalem Infekt (90\%) von 2-4 Tagen, nach Intervall (10\%) Meningitis oder Meningoenzephalitisformen.

Immunität. Lebenslange humorale und zelluläre (?) Immunität.

Diagnose. Anamnese: Zeckenstich in bestimmten Regionen (Oberrhein, Donau), IgGund IgM-Bestimmung, ggf. Virusisolierung. DD: Lyme-Krankheit, die etwa $20 \times$ häufiger auftritt.

Therapie. Symptomatisch.

Prävention. Aktive Schutzimpfung, Gabe von IgG (bei Kindern unter 14 Jahren nicht mehr empfohlen), Verwendung von Repellents.

Meldepflicht. Verdacht, Erkrankung und Tod. Erregernachweis 


\subsection{Bunya-Viren}

In Mitteleuropa haben zwei Virustypen Bedeutung: Das PuumalaVirus und das Dobrava-Virus. Sie werden durch Nagetiere verbreitet und rufen die Nephropathia epidemica (NE) und das Hämorrhagische Fieber mit dem Renalen Syndrom (HFRS) hervor. In den USA hat jüngst ein neuer Typ, das Sin-Nombre-Virus und seine Verwandten, das "Hantavirus-Pulmonary-Syndrom" (HPS) bewirkt; dieses schwere Syndrom ist auch in Deutschland aufgetreten. Weltweit erkranken pro Jahr etwa 200000 Personen, 4000-12000 von ihnen sterben.

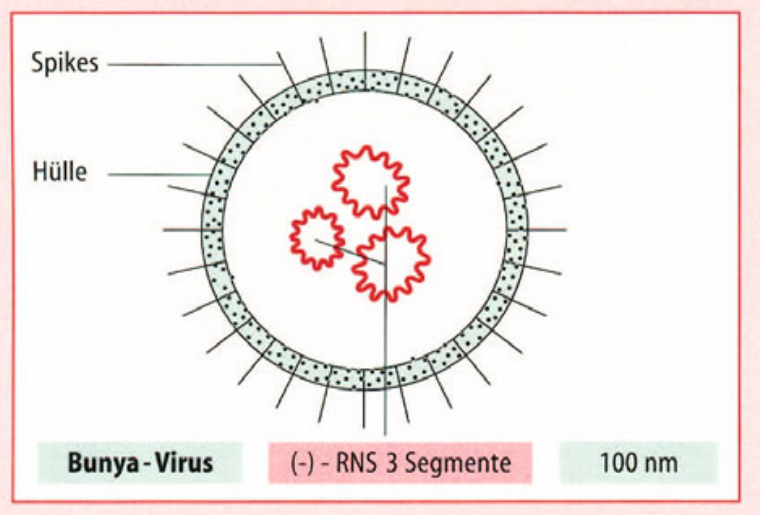

\section{Geschichte}

Während des Korea-Krieges wurde bei den USamerikanischen Truppen ein hochfieberhaftes Krankheitsbild mit starken Schmerzen im Rumpf beobachtet. Typisch für die epidemisch-endemisch auftretenden Erkrankungen sind Hämorrhagien und eine Nephropathie. Später kamen einschlägige Berichte aus vielen Regionen der Welt. Im Norden Skandinaviens war während des 2 . Weltkrieges unter finnischen und deutschen Soldaten eine „Nephropathia epidemica" beobachtet worden; auch in Bosnien-Herzegovina sind solche Erkrankungen durch Hanta-Viren bekannt.

\subsubsection{Beschreibung des Virus}

\section{Genom und Morphologie}

Bunya-Viren enthalten (-)-Strang-RNS, die in drei verschieden großen Segmenten vorkommt; sie enthalten etwa $20 \mathrm{~kb}$. Die Hülle des Virus trägt Spikes, im Innern befinden sich drei helixartige, ringartige Nukleokapside und die Polymerase. Der Durchmesser beträgt etwa $100 \mathrm{~nm}$.

\section{Einteilung}

Die Familie der Bunya-Viren enthält fünf Genera (s. S. 566) mit mehr als 300 verschiedenen Virusspezies. Hierzu zählen die Viren der CaliforniaGruppe, das La-Crosse- und Tahyña-Virus (Enzephalitis). Die infektiologisch wichtigen Typen in Deutschland sind das Puumala- und das DobravaVirus. Sie sind an bestimmte Nagetierspezies gut angepaßt und rufen in ihren Biotopen Infektionen des Menschen hervor. - In Afrika ist das Rift-Valley-Fieber wichtig (Fieber, Gelenkschmerzen, Hepatitis, hämorrhagische Pneumonie, Meningoenzephalitis). Es wird durch Aedes sp. übertragen; das Reservoir bilden Wiederkäuer.

\subsubsection{Rolle als Krankheitserreger}

\section{Vorkommen, Epidemiologie, Übertragung}

Die Epidemiologie der weltweit verbreiteten HantaViren des Menschen beruht auf der geographischen Verteilung der persistent infizierten Nagetierspezies, an die sich das jeweilige Virus angepaßt hat. Infolge dieser Anpassung haben sich verschiedene Virulenzmerkmale herausgebildet. Der Mensch wird mit den Hanta-Viren durch Speichel und Ausscheidungen von Ratten und Mäusespezies direkt durch Staubpartikel oder durch kontaminierte Lebensmittel infiziert. In Deutschland kommen die Serotypen Hantaan- und Puumala-Virus vor; betroffen sind v.a. Wald- und Landarbeiter, die Durchseuchung liegt bei 1,7\%. Infektionen von Mensch zu Mensch gibt es wahrscheinlich. In Serbien kommt das Belgrad- und das Dobrova-Virus vor.

\section{Pathogenese}

Diese systemische Viruserkrankung wird wahrscheinlich vorwiegend durch Zytokinfreigabe aus infizierten Endothelien der Niere oder der Lunge verursacht.

\section{Klinik}

Die Inkubationsperiode beträgt 12-24 Tage. Das Krankheitsbild läßt sich durch plötzlichen Beginn und einen biphasischen Verlauf (1. Phase: Fieber und Stirn-Retrobulbärkopf- sowie Muskelschmerzen; 2. Phase: Nephropathie, auch kombiniert mit 
Hämorrhagien (HFRS)) sowie Pneumonie mit "Schock“ diagnostizieren.

- Nephropathie: Die Nephropathie geht mit Oligurie und $\mathrm{N}_{2}$-Retention, aber ohne Blutdruckerhöhung, einher. Für den Beginn der Krankheit ist eine Oligurie typisch (Puumala-Virus), die später in eine Polyurie übergeht. Dies ist eine leichte Erkrankungsform (NE, Nephropathia epidemica). Die Letalität beträgt $\ll 1 \%$.

- Hämorrhagien: Sie kommen durch erweiterte Blutgefäße, Thrombozytopenie und Extravasate zustande. Die Nierenschäden und Rumpfschmerzen sind Folge der Gefäßschädigungen mit Endothelbefall (Hantaan-, Seoul- und Dobrava-Virus): Hämorrhagisches Fieber mit renalem Syndrom (HFRS). Mittelschwerer Verlauf, Letalität: 5-25\%.

- Interstitielle Pneumonie (Sin-Nombre-Virus u. a.) mit Lungenödem, Pleuratranssudat, Herzversagen, Endothelbefall mit Thrombozytopenie: „Hantavirus-Pulmonary-Syndrom“ (HPS) mit schwerem Verlauf; die Letalität beträgt bis $60 \%$, es finden sich kaum Hämorrhagien (Tropismus!).

\section{Toskana- und Pappataci-Fieber}

Das Toskana-Fieber wurde verschiedentlich nach Mitteleuropa eingeschleppt. Es kommt in der Toskana, in Sizilien, Neapel und Mittelmeerländern vor. Von Springmäusen wird es durch Phlebotomen (Sandfliegen) auf den Menschen übertragen. Die Inkubationsperiode beträgt 2-6 Tage, es folgt (selten) eine „Grippe“, dann eine Remission von 7 Tagen mit anschließender Meningitis (gutartig) von 7 Tagen Dauer. Das Pappataci-Fieber tritt auf dem Balkan auf. Die Inkubation beträgt 2-6 Tage nach der Übertragung von Schafen, Rindern und Nagetieren durch Phlebotomen. Das klinische Bild manifestiert sich mit 3-7tägiger Dauer durch hohes Fieber, Kopfund Gliederschmerzen, Photophobie, Konjunktivitis bds., Erbrechen, Diarrhoe und Exanthem. Der Verlauf ist gutartig. Der Nachweis beider Viren erfolgt durch den IFT oder den ELISA sowie die PCR. Es gibt 3 Serotypen. DD: Influenza, DengueFieber, West-Nile-Fieber und Rift-Valley-Fieber. Anamnese: Reise in welche Region?

\section{Labordiagnose}

Zum Nachweis der Antikörper dient ein Immunfluoreszenz-Test; zur Bestätigung lassen sich ein Immunoblot und die PCR heranziehen. Die Erkrankung soll eine lebenslange Immunität hinterlassen.

\section{Prävention und Therapie}

Die Bekämpfung von Infektionsmöglichkeiten (Nagetierplage) ist das beste Mittel zur Verhütung der Erkrankungen. Ribavirin wurde offenbar mit Erfolg gegeben, es wirkt jedoch gegen die Infektion, nicht aber gegen den Schock. Dobutamin bekämpft den Schock. Im Korea-Krieg hat Kortison bei hämorrhagischem Schock die Symptome gebessert. In Mäuseversuchen hat jetzt ein Antikörper gegen den TNF$\beta$-Rezeptor den Schock aufgehoben.

Meldepflicht. Verdacht, Erkrankung und Tod. Erregernachweis

\section{ZUSAMMENFASSUNG: Bunya-Viren}

Virus. (-)-Strang-RNS, drei Segmente, Hantaan-Virus, wenig- und hochvirulente Stämme.

Vorkommen, Übertragung, Epidemiologie. Weltweit, Ausscheidung mit Kot und Urin von Ratten und Mäusen, Staubinfektion, Durchseuchung etwa $1 \%$.

Klinik. Inkubationsperiode 12-24 Tage. 1. Phase: Fieber, Kopf- und Muskelschmerzen; 2. Phase: Nephropathie, Hämorrhagien, Pneumonie. "Hanta-Virus-Pulmonary-Syndrom" (HPS), Nephropathia epidemica (NE), Hämor- rhagisches Fieber mit Renalem Syndrom (HFRS).

Diagnose. Immunfluoreszenz-Test, Westernblot, PCR. Hochsicherheitstrakt.

Prävention. Bekämpfung von Ratten und Mäusen.

Therapie. Ribavarin.

Meldepflicht. Verdacht, Erkrankung und Tod. Erregernachweis. 


\section{EINLEITUNG}

Das Röteln-Virus erzeugt die Röteln und kann Embryopathien hervorrufen. Es wurde 1938 durch Ultrafiltrate aus Rachenspülwasser von Erkrankten auf Affen und Menschen übertragen. 1941 wurde von dem australischen Augenarzt Sir Norman Gregg beobachtet, daß nach einer Röteln-Epidemie gehäuft Embryopathien aufgetreten waren, die er auf während der Frühschwangerschaft durchgemachte Rötelnerkrankungen zurückführen konnte. 1962 gelang Weller die Züchtung in vitro.

Seit der Einführung der Schutzimpfung im Jahre 1969 ist die Zahl der Röteln-Erkrankungen ständig zurückgegangen. Obwohl man seit über 20 Jahren einen Impfstoff zur Verfügung hat, gibt es pro Jahr in Deutschland immer noch etwa 100 Embryopathien.

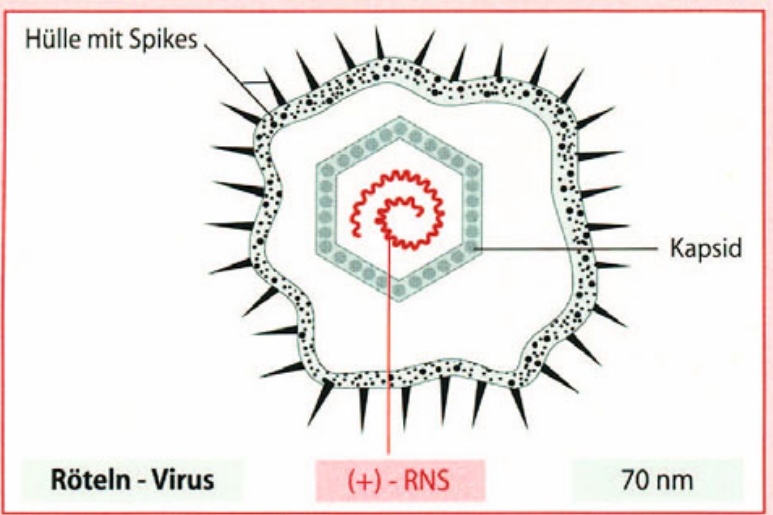

\subsection{Beschreibung des Virus}

\section{Genom}

Das Röteln-Virus ist ein (+)-Strang-RNS-Virus mit einem 9,75 kb Genom. Auf Grund seiner Genomstruktur wird es als Genus Rubi-Virus zur Familie der Toga-Viren gezählt.

\section{Morphologie}

Das Röteln-Virus mißt etwa $70 \mathrm{~nm}$. Das Virion besteht aus einem kugeligen RNS-Knäuel, welches von einem Ikosaeder-Kapsid und einer weiten, faltigen Hülle („schlotternde Toga“) umschlossen ist. Die Hülle trägt hämagglutinierende Spikes aus 2
Glykoproteinen, das Kapsid wird durch 1 Protein gebildet. Es gibt nur einen einzigen Serotyp.

\section{Züchtung}

Die Züchtung ist in Zellkulturen möglich. Das Virus erzeugt einen ZPE und repliziert sich im Plasma der Zelle, die Montage erfolgt an der Zellmembran.

\section{Resistenz}

Das Virus ist außerhalb des Körpers wenig beständig und ist ätherempfindlich.

\subsection{Rolle als Krankheitserreger}

\section{Epidemiologie}

Die Röteln treten vornehmlich im Frühjahr auf. Epidemische Häufungen von Röteln beobachtet man alle 3-5 Jahre. In Mitteleuropa sind z.Z. etwa $10 \%$ der Frauen im gebärfähigen Alter seronegativ. Dieser Durchseuchungsgrad reicht keineswegs aus, um sporadische und epidemische Rötelnfälle bei Frauen zu verhindern.

Etwa $40 \%$ der Röteln-Infektionen verlaufen inapparent. Inapparente Verläufe können bei Schwangeren genauso zur Embryopathie führen wie klinisch manifeste Verläufe. 


\section{Übertragung und Vorkommen}

Die Infektion erfolgt nur bei engem Kontakt von Mensch zu Mensch, in der Hauptsache durch Tröpfchen- und Schmierinfektion. Das Virus findet sich auch im Zervix-Sekret von Schwangeren, hat aber im Hinblick auf den Befall des Embryos durch eine Infektion keine Bedeutung. Infektiös sind das Sputum, das Blut, aber auch der Urin, der Stuhl und das Konjunktivalsekret der Kranken und Infizierten. Das Röteln-Virus kommt nur beim Menschen vor.

Als Infektionsquelle kommen in Betracht:

- Kranke, die sich als Kleinkinder oder später infiziert haben und akute Röteln durchmachen. Die Infektiosität beginnt sieben Tage vor Ausbruch des Exanthems. Klinisch bedeutsam ist die Tatsache, daß seronegative Krankenschwestern die Röteln bekommen und dann auch übertragen können. Das gesamte Krankenhauspersonal sollte vor Dienstantritt auf Röteln-Antikörper getestet und ggf. geimpft werden (s. S. 508).

- Kinder gelten als dauernde Quelle, wenn sie pränatal infiziert waren und deshalb eine chronische Rötelnerkrankung entwickeln. Die Kinder sind über mehr als zwei Jahre nach der Geburt kontagiös; sie können seronegative Personen aus ihrer Umgebung, z.B. Säuglingsschwestern, anstecken.

- Erwachsene im Verlauf von flüchtigen (inapparenten) Reinfektionen.

\section{Pathogenese}

Als Eintrittspforte des Virus dient der Nasen-Rachenraum. Das Virus vermehrt sich zunächst im Epithel der oberen Luftwege. Es kommt zu einer Generalisation auf dem Lymph- und Blutweg mit Virämie und $\mathrm{zu}$ multipler Organlokalisation. Das Virus ist u.a. in den Lymphknoten und in der Haut nachweisbar. Die Röteln-Infektion verläuft, wenn sie post partum erworben wird, stets $z y$ klisch; der Infizierte wird nach Ablauf der Krankheit virusfrei. Ob das Exanthem durch eine Immunkomplex-Vaskulitis zustandekommt, ist nicht klar; der Ausschlag tritt auf, wenn die Virämie endet. Virusantigen läßt sich bei Arthralgien auch in der Synovialflüssigkeit nachweisen. Bei der pränatalen Infektion verläuft die Infektion hingegen chronisch; es kommt zur Embryopathie und nach der Geburt $\mathrm{zu}$ ausgeprägt protrahiertem Verlauf mit massiver Virus-Produktion und -Ausscheidung. In diesen Fällen liegt ein Immunschaden vor, der sich in einer persistierenden IgM-Produktion äußert (gestörter IgM $\rightarrow$ IgG-switch). Das gestörte Längenwachstum der großen ExtremitätenKnochen führt man auf das in den Epiphysen vorhandene Röteln-Virus zurück; die ablaufenden Zellteilungsvorgänge werden durch die Produktion von Interferon und die Induktion von Apoptose unter Mitwirkung von p53 behindert (Abb. 6.1).

Besent

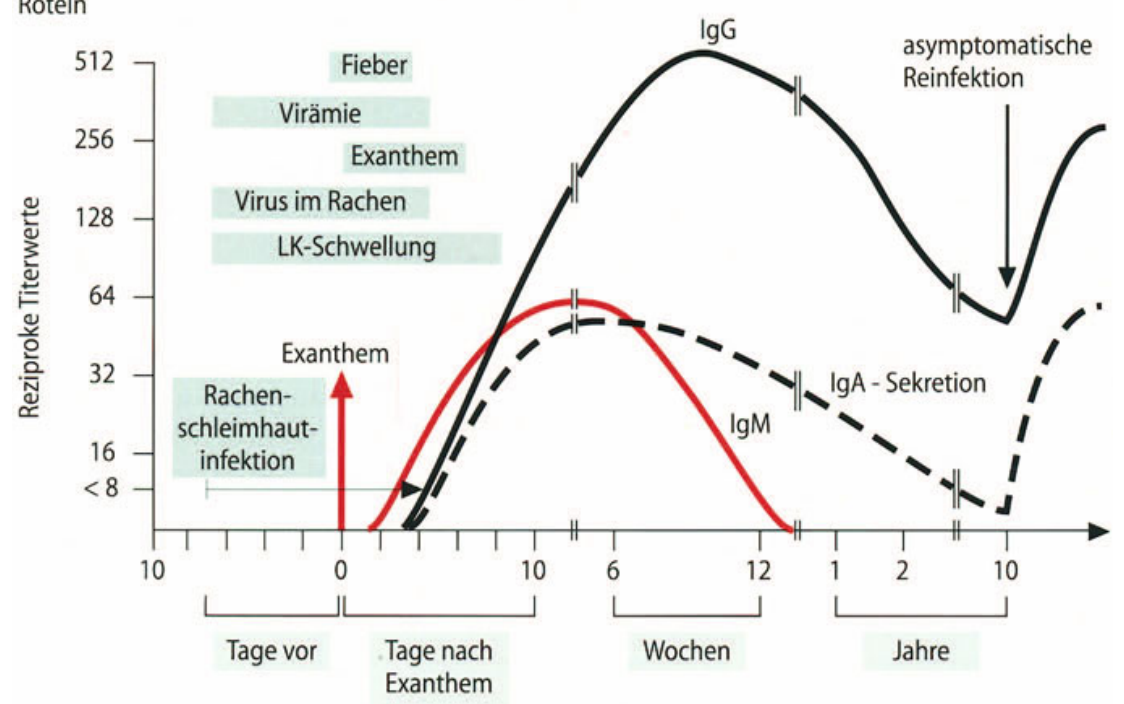

Abb. 6.1. Ablauf einer Röteln-Infektion mit Antikörperverlauf, Reinfektion, sowie Exanthem und klinischen Daten 


\section{Klinik}

Röteln. Die manifeste Krankheit der Röteln beginnt nach einer Inkubationsperiode von etwa 2-3 Wochen mit einer katarrhalischen Initialphase von etwa zwei Tagen bei nur geringfügiger Temperaturerhöhung. Charakteristisch sind dabei die Schwellung der zervikalen und okzipitalen Lymphknoten. In 50\% der Fälle ist die Milz geschwollen. Nicht selten werden rheumatoide Gelenkschmerzen beobachtet, besonders wenn Erwachsene an Röteln erkranken. Der Ausschlag beginnt hinter den Ohren und dehnt sich auf Brust und Bauch aus. Die Flecken sind kleiner als bei Masern, aber größer als bei Scharlach und konfluieren nicht; das Exanthem ist kurzdauernd. Es ist etwa 2-3 Tage sichtbar, oft aber auch nur Stunden (Abb., s. S. 687).

Die Abgrenzung von Erythema infectiosum (Ringelröteln durch Parvo-Virus B19), von Exanthema subitum (HHV-6), von Scharlach und von Masern ist nicht leicht. Differentialdiagnostisch sind Picorna-Viren, das EBV sowie flüchtige Arzneimittelexantheme $\mathrm{zu}$ berücksichtigen. Für die Diagnose wichtig ist die Leukopenie mit Lymphozytose bei auffallend vielen monozytoiden jugendlichen Zellen.

Komplikationen sind bei den akuten postnatalen Röteln sehr selten. Es wurde über postinfektiöse Enzephalitis, hämolytische Anämien, Myound Perikarditis, Thrombopenie sowie Arthralgien bei Frauen berichtet.

Embryopathie: Auge, Ohr, Gehirn, Herz. Wenn eine Schwangere an Röteln erkrankt oder eine inapparente Infektion durchmacht, so kann das Virus im Zuge der Generalisation auf den Embryo übertragen werden; es verursacht dort eine chronische Infektion. Die Infektion des Embryo wirkt zytolytisch (ZPE) und behindert vermutlich die Zellteilungsvorgänge; sie verursacht besonders in den ersten drei bis vier Schwangerschaftsmonaten Schädigungen. Die Schädigung des Embryo führt entweder zum Abort oder zum konnatalen RötelnSyndrom des Neugeborenen. Die postnatalen Erscheinungen der Embryopathie sind vielfältig: Katarakt, Glaukom, Retinopathie, Taubheit, Mikrozephalie, geringe Körperlänge bei der Geburt, angeborene Herzfehler (persistierender Ductus Botalli), Verlangsamung des Wachstums, Zahndefekte, Hepatosplenomegalie mit Stauungsikterus, thrombozytopenische Purpura, hämolytische Anämie. Man hat auch einen insulinabhängigen Diabetes melli- tus (IDDM) und eine subakute sklerosierende Panenzephalitis (SSPE) beobachtet.

Das Risiko der Embryopathie ist während des ersten Schwangerschaftsmonats am höchsten (60\%); es fällt bis zum 3./4. Monat progressiv auf $10-15 \%$ ab. In den späteren Schwangerschaftsmonaten ist das Risiko zwar geringer, es kann aber doch zu Sprach- und Hörstörungen kommen, die erst nach einigen Jahren auffallen. Als Folge der Röteln-Embryopathie sterben einige der betroffenen Kinder vor Abschluß des ersten Lebensjahres. Eine Röteln-Infektion kurz vor der Konzeption birgt kein Risiko. Die Reinfektion einer Graviden, die über natürlich erworbene Antikörper verfügt, ist ohne Gefahr für den Embryo, wenn der hämagglutinationshemmende Titer bei 1:16 oder höher liegt.

\section{Immunität}

Das Röteln-Virus ist immunologisch einheitlich. Das Überstehen der Krankheit hinterläßt eine lange, wahrscheinlich sogar lebenslange humorale und zelluläre Immunität. Diese verhindert zwar erneute Erkrankungen, schützt aber nicht vor lokalen Reinfektionen des Nasenrachenraumes. Die Immunität des Erwachsenen beruht auf Antikörpern der Klasse IgG und IgA. IgG-Antikörper sind das ganze Leben hindurch nachweisbar; sie werden von der Mutter auf das Kind übertragen und verleihen diesem über einen Zeitraum von 3-6 Monaten Schutz. Die in der Frühschwangerschaft mit Röteln-Virus infizierten Neugeborenen weisen keine voll ausgebildete Immuntoleranz gegen das Virus auf; sie bilden vielmehr über lange Zeit eigene Antikörper der Klasse IgM. Die Wahrscheinlichkeit, IgM-Antikörper beim Kind nach der Geburt aufzufinden, ist umso größer, je früher die Infektion in der Schwangerschaft erfolgt ist.

\section{Labordiagnose}

Isolierung des Virus. Am besten eignet sich Rachenspülwasser. Die Isolierung erfolgt in Zellkulturen.

Antikörpernachweis beim akuten Fall (auch bei rötelnexponierten Graviden). Er erfolgt in zwei separat im Abstand von 10 Tagen entnommenen Serumproben. Man untersucht die beiden Proben im Hämagglutinations-Hemmungstest (HirstTest) und im IgM- und im IgG-ELISA gleichzeitig.

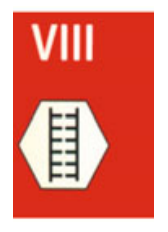


IgM-Antikörper hat man bis zu sechs bis neun Monaten nach der Infektion nachgewiesen.

Anamnestischer Antikörpernachweis. Er erfolgt im Hirst-Test mit einer einzigen Serumprobe. Man findet Titer zwischen 1:16 und 256. Bei akuten Infektionen beträgt der Titer bis $\mathrm{zu}$ 1:1024 und mehr. Nach Schutzimpfungen liegen die Titerwerte generell niedriger als bei der natürlichen Durchseuchung. Sie sinken auch schneller ab. Niedrige Titerwerte im HHT von 1:8 und 1:16 bedeuten keinen sicheren Schutz vor der Embryopathie. Dementsprechend gilt, daß alle Frauen mit Kinderwunsch beim Vorhandensein von niedrigen Werten $(1: 8,1: 16)$ erneut getestet und ggf. geimpft werden und weiter überprüft werden. Die IgM- und IgGAntikörper steigen nach Schutzimpfungen langsamer an als bei der natürlichen Röteln-Infektion. IgM-Antikörper hat man bis zu 6 Monaten nach der Impfung nachgewiesen.

Antikörpernachweis im Blut des Neugeborenen bei Verdacht auf Embryopathie erfolgt in der IgMFraktion (Auftrennung über eine Austauscher-Säule oder im Saccharose-Gradienten). Man setzt einen IgM- und einen IgG-ELISA an, nur der IgMWert ist beweisend für eine frische Infektion.

Antikörpernachweis im Nabelschnurblut in utero bei Verdacht auf Röteln-Infektion: Besteht bei einer seronegativen Graviden solch ein Verdacht, wird ihr Serum untersucht (s.o.). Im Nabelschnurblut erfolgt der Test auf das nicht plazentagängige IgM wie üblich. Ist er positiv, ist ein Abbruch zu erwägen, die Entscheidung liegt bei den Eltern. Mütterliche Blutbeimengungen lassen sich durch Erythrozytenkontrolle ausschließen. Kindliches IgM wird von der 22. Woche ab gebildet; ist es nicht vorhanden, liegt keine Infektion des Föten bzw. keine Embryopathie vor. Zur Sicherung des Befundes soll die PCR angesetzt werden. Sie erlaubt eine Diagnose in den Chorionzotten oder im Fruchtwasser ab der 12. Schwangerschaftswoche.

\section{Prävention}

Schutzimpfung. Der Lebendimpfstoff ist sehr wirksam, er wird weltweit mit gutem Erfolg angewendet. Wegen des relativ baldigen Absinkens der Antikörper ist vor jeder Schwangerschaft eine Ti- terbestimmung erforderlich. Die Impfung sollte auch Jungen erfassen; die Herdimmunität wird dadurch verstärkt und eine geringere Gefahr für seronegative Gravide resultieren. Heute erfolgt die erste Impfung mit 12-15 Monaten, die zweite im 5.-6. Lebensjahr als 3-fach-Impfstoff: MMR (Masern-Mumps-Röteln und ggf. Varizellen) und vor der Menarche (nur Röteln) sowie später bei Bedarf (Anhang, s. S. 999 ff.).

Als Nebenwirkung der Impfung ergeben sich nur gelegentlich Arthralgien. Die Impfprophylaxe zielt auf die Verhinderung der Embryopathie.

Während der Gravidität ist die Impfung kontraindiziert. Nach einer Schutzimpfung ist eine Karenzzeit von drei Monaten bis zur nächsten Konzeption einzuhalten. Allerdings sind bisher keine durch das Impf-Virus hervorgerufenen Embryopathien bekannt geworden.

Gammaglobulin-Prophylaxe. Hat eine seronegative und schwangere Frau mit Rötelnkranken Kontakt gehabt, wird Human-Röteln-Gammaglobulin verabreicht. Die Wirkung ist nur dann sicher, wenn das Gammaglobulin innerhalb von 1-2 Tagen nach der Exposition gegeben wird. Die passiv zugeführten Antikörper machen sich serologisch bemerkbar. Zur Überprüfung der Wirksamkeit der passiven Schutzimpfung muß bis zum Ende der gefährdeten Phase kontrolliert werden, ob eine Serokonversion erfolgt oder nicht. Erfolgt ein Titeranstieg, muß mit einer Embryopathie gerechnet werden.

\section{Schwangerschaftsabbruch}

Ist bei Schwangeren vor dem 4. Monat ein Ausbruch von Röteln klinisch, serologisch und durch die PCR auch beim Kind festgestellt worden, so ist ein Abbruch der Schwangerschaft indiziert. Dies erfolgt nur in Absprache mit den Eltern. Stellt man während einer Schwangerschaft fest, daß eine Frau für Röteln seronegativ ist, so muß sie fortlaufend auf Antikörper kontrolliert werden; die aktive Schutzimpfung sollte nachgeholt werden (Impfung im Wochenbett).

Meldepflicht. Röteln-Embryopathien sind meldepflichtig. 


\section{ZUSAMMENFASSUNG: Röteln-Virus}

Virus. (+)-Strang-RNS-Virus, bestehend aus Ikosaeder-Kapsid und Hülle, gehört als RubiVirus zur Toga-Familie; nur 1 Serotyp.

Vorkommen und Übertragung. Weltweit, alleiniger Wirt ist der Mensch. Tröpfcheninfektion durch Erkrankte, Kinder mit Embryopathie, inapparent Infizierte und reinfizierte Personen.

Epidemiologie. Kinderkrankheit, bei Primärinfektion einer seronegativen Schwangeren besteht das Risiko der Entstehung einer Embryopathie. Frauen sollten zu mehr als $95 \%$ Antikörperträger sein!

Pathogenese. Zyklische Viruskrankheit mit Elimination des Virus. $40 \%$ der Infektionen verlaufen inapparent.

Klinik. Inkubationsperiode 14-21 Tage. Kinderkrankheit mit Exanthem und kaum Nebensymptomen. Gefahr der Embryopathie (Auge, Ohr, Gehirn, Herz!) im 1.-4. Schwangerschaftsmonat, abnehmend von $60 \%$ auf $10 \%$ (Mittel: 30-40\%).
Immunität. Lebenslange Immunität gegen die Röteln, bei Antikörpertitern im HHT unter 1:32 bei der Schwangeren Gefahr der Rötelnembryopathie. Bei Titern von 1:8/16 Test wiederholen, ggf. Impfung und Test.

Diagnose. Klinisch nicht möglich, deswegen HHT sowie IgM- und IgG-ELISA, ggf. PCR. Störfaktoren: Cave! DD: Masern, Scharlach, Arzneimittelexantheme, Picorna-Infektionen, Exanthema subitum, infektiöse Mononukleose, Erythema infectiosum.

Therapie. Symptomatisch.

Prävention. Schutzimpfung, Impfung im Wochenbett. Bei Mädchen: dreimalige Schutzimpfung, auch Jungen impfen: Aufbau einer Herdimmunität! Impfung von medizinischem Personal mit ungenügendem Antikörpertiter (unter 1:32).

Meldepflicht. Bei Embryopathie. 


\title{
Tollwut-Virus
}

\author{
D. FALKE
}

\section{EINLEITUNG}

Die zur Familie der Rhabdoviren gehörige Spezies Rabies-Virus erzeugt die Tollwut (Genus Lyssa). Die Tollwut ist seit dem Altertum bekannt. In Indien wurden 1992500000 Personen geimpft. 1985 erkrankten dort 25000 Personen. In Deutschland wird das Reservoir (Füchse) erfolgreich mit einem Köder-Lebendimpfstoff bekämpft.

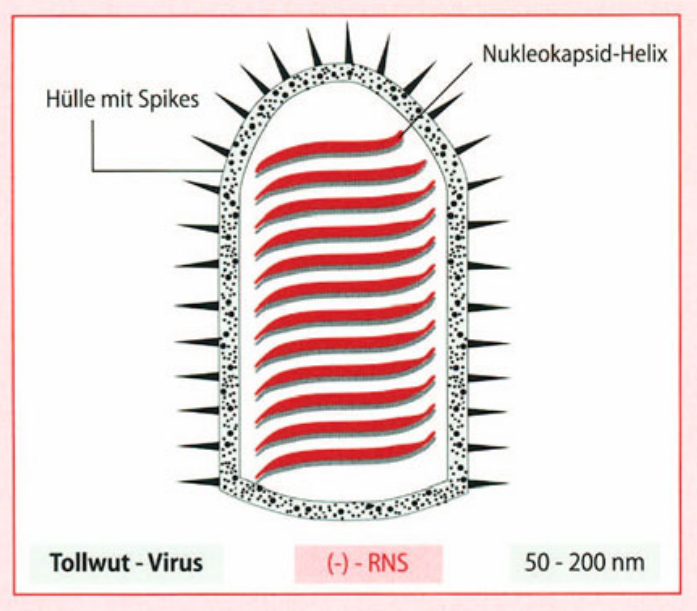

\subsection{Beschreibung}

\section{Genom}

Das Tollwut-Virus zählt zu den (-)-EinzelstrangRNS-Viren. Das Genom enthält 12,0 kb.

\section{Morphologie}

Das Virus besitzt eine patronenförmige Gestalt: Länge $200 \mathrm{~nm}$ und Durchmesser $50 \mathrm{~nm}$. Die RNS ist in einem schraubenförmig angeordneten Helikal-Kapsid enthalten; das Nukleokapsid ist von einem M-Protein umgeben und in eine Hülle mit Spikes eingebettet. Die Montage des Virus erfolgt im endoplasmatischen Retikulum.

\section{Züchtung}

Das Tollwut-Virus läßt sich züchten und passagieren:

- im Gehirn des Kaninchens und der Maus,

- im bebrüteten Ei (Enteneier),

- in der Zellkultur aus humanen Diploid-Zellen u. a.

Man unterscheidet beim Tollwut-Virus die in Passagen gehaltenen Laborstämme von dem in der Natur vorkommenden Wildvirus; dieses wird auch als "Straßenvirus" bezeichnet. Als Prototyp der Laborstämme gilt das sog. „Virus fixe“. Damit wird ein Stamm bezeichnet, der durch intrazerebrale Inokulation in Kaninchen-Passagen fortgeführt wird; hierdurch hat er seine ursprüngliche Virulenz verloren. Der von Pasteur seinerzeit adaptierte und als Virus fixe bezeichnete Stamm ist heute nur noch als "Hempt"-Impfstamm in den Entwicklungsländern in Gebrauch; Gefahr: Impfenzephalitis!

\section{Resistenz}

Das Virus verliert durch Ätherbehandlung, Seifenlösungen und Detergentien sehr bald seine Infektiosität.

\subsection{Rolle als Krankheitserreger}

\section{Vorkommen}

Die Tollwut ist eine weitverbreitete Tierkrankheit (Zoonose), die den Menschen nur ausnahmsweise 
befällt. Es ergeben sich permanente Infektketten innerhalb des Tierbestandes; diese verleihen der Krankheit endemischen Charakter. Die Infektion des Menschen erfolgt fast immer durch den Biß eines Tieres.

In Deutschland sind Füchse, Rehwild, Marder und Dachse das Virusreservoir, in den USA sind es die Waschbären und Skunks (sylvatische Tollwut). Von hier aus werden Rinder, Katzen, Schafe und Hunde in abnehmender Häufigkeit infiziert, die dann neue Infektketten unter sich oder in Kombination mit anderen Tierspezies bilden können. Eine „epidemiologische Sackgasse“ stellt die relativ häufige Infektion des Rindes dar: Das auf der Weide durch Bißverletzungen infizierte Rind überträgt die Infektion so gut wie niemals weiter. Der Mensch wird in Deutschland in der Regel durch Hunde oder Katzen infiziert (urbane Tollwut). Anstelle des Hundes können Wölfe (Osteuropa) oder Schakale (Südafrika) die Krankheit auf den Menschen übertragen. In Südamerika wird das Virusreservoir durch blutsaugende Fledermäuse (Vampire) unterhalten; von hier aus wird das Virus auf das Rind und auf andere Tiere übertragen.

Die Infektion verläuft bei Tier und Mensch stets manifest und endet immer tödlich. Eine Ausnahme bilden in dieser Hinsicht lediglich die Fledermäuse: Sie erkranken inapparent oder sie überleben die manifeste Krankheit und sind dann in gesundem Zustand als „Dauerausscheider" infektiös.

An der Nord- und Ostseeküste zwischen Holland und Finnland gibt es eine Variante mit abweichendem Antigenverhalten (ähnlich dem Duvenhage-Virus); sie verursacht die Tollwut der Fledermäuse (Eptesicus serotinus und Myotis dasycneme).

\section{Epidemiologie}

Seit dem Ende des 2. Weltkriegs breitete sich die sylvatische Tollwut westwärts von Rußland bis nach Frankreich mit einer Geschwindigkeit von etwa $30 \mathrm{~km}$ pro Jahr aus. Hunderte von Tieren haben sich jedes Jahr als tollwutinfiziert erwiesen. In den schutzgeimpften Gebieten ist die Fallzahl praktisch auf Null abgesunken, Menschen sind nur ausnahmsweise erkrankt. Der letzte Fall in Deutschland ist 1996 aufgetreten; der Patient war in Indien von einem Hund gebissen worden. Von 1981-1997 gab es in Deutschland 4 Fälle. In England und Spanien gibt es nur die Fledermaustoll- wut. In Dänemark ist jüngst ein Schaf von einer Fledermaus infiziert worden.

\section{Übertragung}

Keimreservoir ist das erkrankte Tier; die Infektion erfolgt durch $\mathrm{Bi} ß$ mit virushaltigem Speichel von Tier zu Tier. Das infizierte Tier wird erst kurz vor Beginn der klinischen Erscheinungen kontagiös: Vom Auftreten des Virus im Speichel bis zum Auftreten der typischen Symptome vergeht höchstens eine Woche und bis zum Tode des Tieres höchstens eine weitere Woche. Dies bedeutet, daß ein Hund, der 10 Tage lang in Isolierung gehalten wird und keine klinischen Erscheinungen zeigt, als Infektionsquelle nicht in Betracht kommen kann.

Die Tollwut wird nur durch den Biß übertragen. Hantieren mit virusbehaftetem Material führt nur beim Vorhandensein von Hautverletzungen zur Infektion (Gummihandschuhe!).

Als Eintrittspforte beim Menschen dienen Hautwunden; in Betracht kommen vornehmlich Bißwunden, aber auch oberflächliche Abschürfungen. Das Virus kann auch durch die unverletzte Schleimhaut der Lippen, der Nase und (extrem selten) der Augen eindringen. Als extreme Seltenheit werden Infektionen durch Aerosole beschrieben (Fledermaushöhlen). - In Endemieregionen sind Übertragungen beim Nächtigen im Freien beschrieben.

\section{Pathogenese}

Wirtsspektrum und Organotropismus. Das Tollwut-Virus hat ein extrem breites Wirtsspektrum. Dieses erstreckt sich auf alle Warmblüter und reicht vom Rind bis zur Fledermaus. Das Virus ist hinsichtlich seiner pathogenen Wirkung neurotrop: Die Tollwut verläuft als bösartige Enzephalitis. Bezüglich seiner Vermehrungsfähigkeit ist das Tollwut-Virus jedoch neuro-viszerotrop: Es befällt neben dem ZNS v.a. die Speicheldrüsen und z.B. auch die Drüsen der Haarfollikel.

Während das Straßenvirus im Hinblick auf seine Vermehrungsfähigkeit neuro-viszerotrop ist, verhält sich das Virus fixe dagegen exklusiv neurotrop: Es hat durch die Passagen die viszerotrope Eigenschaft des Straßenvirus eingebüßt. Das Strassenvirus wird im Speichel massenhaft ausgeschieden, während das Virus fixe im Speichel nicht erscheint. Diese Eigenschaften des Virus fixe in Kaninchenpassagen beruhen auf einer Anreicherung derjenigen Varianten, welche „hohe Neurovirulenz 
bei geringer Invasivität für das ZNS und fehlender Viszerotropie" besitzen. Die Neurovirulenz wird durch Eigenschaften des Glykoproteins bestimmt.

Ausbreitung. An der Infektionsstelle vermehrt sich das Virus zunächst in den Muskelzellen (sowie Makrophagen und Lymphozyten), ehe es $\mathrm{Zu}$ gang $\mathrm{zu}$ den Nervenendigungen findet; vermutlich wandert das Virus als Nukleokapsid mit Überspringen der Synapsen axonal zum ZNS, vermehrt sich dort und gelangt dann zentrifugal in die Speicheldrüsen, das Pankreas, die Haarbalgdrüsen u.a., in denen eine starke Vermehrung erfolgt. Da sich das Virus fast exklusiv im Nervensystem aufhält, wird das Immunsystem erst dann stimuliert, wenn sich das Virus in großen Mengen vermehrt hat, d.h. am Ende der klinisch manifesten Erkrankung.

Die pathologisch-anatomische Schädigung. Die pathologisch-anatomische Schädigung betrifft nur das ZNS, und zwar vornehmlich die Gegenden des Hippokampus (Ammonshorn), der Medulla und des Kleinhirns. Später werden aber auch die übrigen Regionen der Großhirnrinde und der Pons betroffen. Die Virusvermehrung erfolgt nur in den Neuronen. Sie führt zum Auftreten von Einschlußkörperchen (Negri-Körperchen), auch in den Epithelzellen der Speicheldrüsen und den Konjunktivalzellen. Später kommt es zum Untergang des Neurons, zur Neuronophagie und zur herdförmigen Zellinfiltration mit Gliawucherung. Die histologischen Veränderungen erscheinen im Vergleich zur Schwere des Krankheitsbildes geringfügig. Man vermutet Zytokine als Ursache der Funktionsstörungen. Im Endzustand findet man ausgedehnte Zerstörungen der grauen und der weißen Substanz. Die späten Lähmungen sind immunologisch bedingt. In der z. T. sehr langen Inkubationszeit verbleibt das Virus zunächst lokal und wandert dann schnell $(400 \mathrm{~mm} /$ Tag) zum ZNS (Abb., s. S. 690).

\section{Klinik}

Beim Menschen verläuft die Tollwut in drei Stadien. Zwischen den ersten Symptomen und dem tödlichen Ausgang liegen höchstens sieben Tage. Die Einweisungen erfolgen oft in eine HNO-Klinik.

Inkubationszeit. Die Inkubationszeit beträgt durchschnittlich 1-3 Monate, in Extremfällen kann sie aber 10 Tage oder auch 10 Monate dauern. Neben der Virusmenge beeinflußt die räumliche Ent- fernung der Bißstelle vom ZNS die Dauer der Inkubationszeit: Bei Kopfverletzungen ist mit einer kürzeren Inkubationszeit $\mathrm{zu}$ rechnen als bei Extremitätenverletzungen.

Prodromalstadium. Beim Menschen besteht eine Hyperästhesie in der Gegend der Bißwunde: Der Patient klagt über lokales Brennen und Jucken. Es tritt Fieber mit uncharakteristischen Krankheitsbeschwerden (Kopfschmerzen, Appetitlosigkeit) auf.

Exzitationsstadium (,rasende Wut"). Der Patient bekommt Angstgefühle und wird motorisch unruhig. Es beginnen Krämpfe der Schluckmuskulatur, die jeweils durch den Schluckakt ausgelöst werden. Der Patient vermeidet dementsprechend das Schlukken: Er hat Angst, zu trinken und läßt aus Furcht vor den schmerzhaften Krämpfen den Speichel lieber aus dem Mund tropfen, als ihn zu verschlukken. $\mathrm{Zu}$ der motorischen Unruhe kommen abwechselnd aggressive und depressive Zustände der Psyche. Charakteristisch ist die Wasserscheue: Die optische oder akustische Wahrnehmung von Wasser führt $\mathrm{zu}$ Unruhe und $\mathrm{zu}$ Krämpfen, die sich auf die gesamte Muskulatur erstrecken können. Zum Unterschied von Tetanus besteht aber kein Trismus.

Paralyse ("stille Wut ${ }^{\prime \prime}$ ). Einige Stunden vor dem Tod lassen die Krämpfe und die Unruhezustände nach. Es kommt zu Paresen, zu fortschreitenden Lähmungen und schließlich zum Exitus.

Erkrankung beim Tier. Beim Hund beobachtet man verändertes Benehmen, blinde Aggressivität, Herumstreunen, Verschlingen ungenießbarer Gegenstände, heiseres Bellen und Heulen. Es besteht beim Hund jedoch keine Wasserscheu. Beim Wild fällt das Fehlen der natürlichen Scheu in Kombination mit Aggressivität auf.

\section{Immunität}

Es gibt sieben serologische Typen, davon sechs in Fledermäusen. In Europa kann man weiterhin mit der serologischen Einheitlichkeit des klassischen Tollwut-Virus rechnen, die Fledermausviren differieren antigenetisch.

Der Mensch entwickelt während der Rabies weder neutralisierende noch komplementbindende Antikörper, da der Tod vorher eintritt. Neutralisierende IgM- und IgG-Antikörper können nur durch die Schutzimpfung entstehen. 


\section{Labordiagnose}

Die Labordiagnose „Tollwut“ wird durch Nachweis der Antigene bzw. der Negri-Körperchen im IFT gestellt. In Zweifelsfällen muß ein Tierversuch angesetzt oder die Zellkultur infiziert werden (s.u.), in Zweifelsfällen wird die PCR im Liquor eingesetzt.

Morphologischer Virusnachweis durch Fluoreszenzserologie. Hierbei wird in den Zellen des verdächtigen Tieres oder des menschlichen Falles nach Virus-Antigen gesucht. Die Darstellung geschieht mit einem Anti-Tollwutserum im IFT. Folgende Tests sind im Gebrauch:

Nachweis der Negri-Körperchen im ZNS. Post mortem werden mehrere Schnitte aus der Gegend des Hippokampus, speziell des Ammonshorns, angefertigt und im Sandwichverfahren gefärbt. Zusätzlich färbt man Schnitte nach Giemsa. Die Negri-Körperchen erscheinen im Zytoplasma als 2-10 $\mu \mathrm{m}$ messende eosinophile Einschlüsse.

Kornealtest. Vom lebenden Tier oder vom Patienten werden Kornealzellen durch Abklatschen auf ein Deckglas gebracht, fixiert und fluoreszenzserologisch gefärbt. Im positiven Falle sieht man mikroskopisch Antigenanhäufungen in den Pflasterepithelzellen.

Haut-Biopsien. Neuerdings stellt man die Diagnose der Tollwut beim Lebenden auch durch Untersuchung von Haut-Biopsien (Hautstanzen) aus dem Nackengebiet. Auch hier geht es um den Nachweis von Tollwut-Antigen durch den IFT. Das Virusantigen ist in den Zellen der Haarfollikeldrüsen enthalten.

Isolierung des Virus. Früher erfolgte die Isolierung des Virus durch intrazerebrale Verimpfung des verdächtigen Materials auf Mäuse; sie zeigten ggf. typische Symptome, und im ZNS fanden sich Negri-Körperchen. Heute wird das Tollwut-Virus nach 1-2 Tagen in Neuroblastom-Zellen mit dem IFT nachgewiesen. RT-PCR.

\section{Prävention}

Prophylaktische Impfungen von Waldarbeitern und Reisenden in den Orient und nach Indien sind ratsam.

Vorgehen nach dem $\mathrm{Bi}$ durch ein tollwutverdächtiges Tier. Nach jeder Bißverletzung durch einen Hund ist das Tier nach Möglichkeit einzufangen und $\mathrm{zu}$ isolieren. Das Tier muß mindestens sieben Tage lang durch einen Veterinär beobachtet werden. Treten nach sieben Tagen keine Symptome der Tollwut auf, so ist der Hund als gesund anzusehen; eine Exposition des gebissenen Patienten ist in diesem Fall nicht anzunehmen. Unabhängig davon muß mit den aktiv-prophylaktischen Maßnahmen sofort nach der Bißverletzung dann begonnen werden, wenn das Tier als tollwutverdächtig anzusehen ist. Zeigt der Hund deutliche Symptome der Tollwut, so wird er getötet und virologisch untersucht. Ist der Hund nach dem Biß unauffindbar, so besteht für den Patienten in jedem Fall Expositionsverdacht. Schwierig wird die Beurteilung, wenn der Hund sofort nach dem Biß getötet worden ist. Hier wird man das Hirn und die Speicheldrüsen zum Isolierungsversuch verwenden müssen.

Bei Verdacht auf Tollwut-Exposition unter Berücksichtigung der epidemiologischen Situation muß die nächste amtlich zugelassene Wutschutzstelle konsultiert werden. Ist eine Exposition anzunehmen, so sind folgende Maßnahmen indiziert:

Es wird eine lokale und allgemeine Wundbehandlung durchgeführt. Man exzidiert die Wunde und spült mit starken Seifenlösungen oder mit Detergentien. Zusätzlich umspritzt man die Wunde mit Anti-Tollwut-Hyperimmunglobulin. Nach wie vor bleibt die aktive Tetanusprophylaxe notwendig.

Der Exponierte erhält möglichst noch am Tage der Exposition eine intramuskuläre Gabe von Anti-Tollwut-Hyperimmunglobulin.

Man verabreicht dem Exponierten einen Tag nach der Gabe des Immunserums (und später mehrmals) die vorgeschriebene Dosis des amtlich empfohlenen Totimpfstoffes. Dieses Vorgehen erstreckt sich auch auf Verletzungen nach Kontakt mit Fledermäusen (in Europa hat es in drei Jahrzehnten drei solcher menschlichen Fälle gegeben), obwohl nur eine geringe Kreuzreaktion besteht.

Schutzimpfung. Die lange Inkubationszeit der Tollwut eröffnet die Chance, infizierte Personen durch Verabfolgen von Virus-Antigen aktiv zu immunisieren und das in der Wunde befindliche Virus passiv vor dessen Ankunft im peripheren Nervensystem durch spezifische Neutralisation $\mathrm{zu}$ inaktivieren. Dies gelingt, sofern die Immunisierung früh genug erfolgt, d.h. spätestens innerhalb von drei Tagen nach der Exposition. Die virusspezifischen Antikörper reagieren dann mit Virionen in der Wunde und deren Umgebung. Damit sind die 
betroffenen Partikel unfähig, die peripheren Nerven und damit die zentralen Neuronen zu befallen, die Infektion wird kupiert.

Für den Diploidzell-Impfstoff für den Menschen wird das Tollwut-Virus in der Zellkultur (humane diploide Stämme) gezüchtet und inaktiviert. Diese Vakzine hat sich sehr bewährt.

Der Embryofibroblasten-Impfstoff wird in Deutschland seit sechs Jahren mit gutem Erfolg eingesetzt. Die Indikation zur Impfung kann großzügig gestellt werden.

Verschiedene attenuierte Stämme für die $L \boldsymbol{e}$ bendimpfung werden als Abkömmlinge des FluryStammes verwendet. Die Impfung eignet sich aber nur für die Anwendung bei Tieren. Sie wird z.B. für den Schutz der Rinder in Südamerika und für die Impfung von freilebenden Füchsen angewendet. In der Schweiz, in Deutschland u.a.o. haben sich die Impfungen der Füchse mit infizierten Ködern sehr bewährt. Die Zahl der Tollwutverdachtsfälle geht stark zurück. In den USA setzt man einen Vaccinia-Hybridimpfstoff ein.

Verkleinerung des Virusreservoirs. Die Bekämpfung der Tollwut erfolgt durch Verringerung des Bestandes an Überträgertieren durch Köderimpfungen. In Deutschland beseitigt man außerdem streunende Hunde und Katzen. In den USA bekämpft man Fledermäuse und impft alle Hunde. Zeitweise ist Hundesperre notwendig, u.U. Maul- korbzwang. Eine Impfpflicht für Katzen und Hunde besteht in Deutschland nicht.

Prophylaktische Immunisierung von Tieren. In Betracht kommen v.a. Hunde, Füchse und Katzen.

Meldepflicht. Der Verdacht besteht im Sinne der Meldepflicht dann, wenn Kontakte mit tollwutkranken oder tollwutverdächtigen Tieren nachgewiesen werden. Neben dem Hund kommt als Infektionsquelle für Jäger, Waldarbeiter und Metzger auch Wild in Betracht (Rehe, Hasen, Füchse). Die Infektion kann in diesen Fällen durch Hantieren mit infektiösen Organen (Ausweiden) zustandekommen. Beim erkrankten Tier müssen alle Organe als kontagiös angesehen werden, da sich das Virus auch außerhalb des ZNS in vielen Organen, z.B. den Speicheldrüsen, vermehrt. Eine indirekte Infektion kann durch Hundespeichel zustandekommen, wenn der Maulkorb oder die Hundeleine als Vehikel dienen.

Nach dem Infektionsschutzgesetz (2000) sind der Krankheitsverdacht, die Erkrankung und der Tod an Tollwut zu melden. Darüber hinaus ist jede Verletzung eines Menschen durch ein tollwutkrankes oder ansteckungsverdächtiges Tier sowie die Berührung eines solchen Tieres oder Tierkörpers meldepflichtig; ebenso der Erregernachweis.

Amtstierarzt benachrichtigen! S.a.:www.yellowfever.rki.de/INFEKT/RATGEBER/RAT8.HTM 
Zusammenfassung: Tollwut-Virus

Virus. (-)-Strang-RNS-Virus mit helikalem Kapsid in einer Hülle mit Spikes. Geschoßähnliche Gestalt.

Vorkommen. Zoonose, bei vielen Tierspezies, u.a. Füchse, Katzen, Skunks, Wölfe, Fledermäuse: "Strassen-Virus"; attenuiertes Virus heißt "Virus fixe".

Übertragung. Durch den Biß eines tollwütigen Tieres, Infektiosität des Tieres bereits einige Tage vor Ausbruch der Symptome. Isolierung des Tieres 8-10 Tage zur Beobachtung zwecks Nachweis von Negri-Körperchen.

Epidemiologie. Tollwut ist eine Zoonose mit gelegentlichem Übergang auf den Menschen. Fortschreiten in Ost-West-Richtung, jetzt Eindämmung durch Fuchslebendimpfung mit Ködern. "Sylvatische" und "urbane" Tollwut.

Pathogenese. Inkubationsperiode 1-3 (-10) Monate. Primäre Replikation des Virus in Muskelzellen an der Bißstelle, erst dann Eindringen in Nervenfasern, Rückenmark und Gehirn; von dort Wanderung in Speichelund Hautdrüsen.
Klinik. Jucken und Schmerzen an der Bißstelle, Fieber. Ausbruch mit "rasender" und Übergang in "stille" Wut. Hydrophobie, motorische Unruhe; vor dem Tod Nachlassen der Krämpfe und beginnende Lähmungen.

Immunität. Antikörper entstehen erst zum Zeitpunkt der Erkrankung, keine Bedeutung für Sero-Diagnose. Die Lähmungen entstehen immunpathogenetisch.

Diagnose. Ohne Biß-Anamnese gibt es keine Tollwut. Nachweis von Negri-Körperchen im ZNS; beim Menschen Hautbiopsien und Konjunktivaltupfpräparate zum IFT, ggf. PCR im Liquor.

Therapie. Symptomatisch, Impfung möglichst frühzeitig in der Inkubationszeit.

Prävention. Schutzimpfung mit Totimpfstoff als Prophylaxe (Waldarbeiter und Orient-Reisende) und als aktive und passive Exponierten-Impfung. Säuberung der Wunde(!) und Tetanusimpfung. Schutzimpfung der Füchse und der Haustiere mit Lebendimpfstoff.

Meldepflicht. Verdacht, Erkrankung und Tod. Erregernachweis. Amtstierarzt! 
D. FALKE

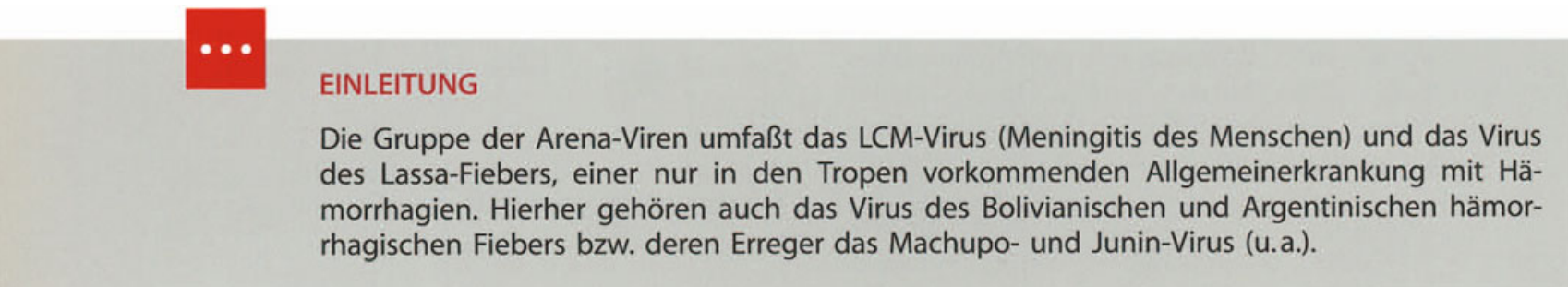

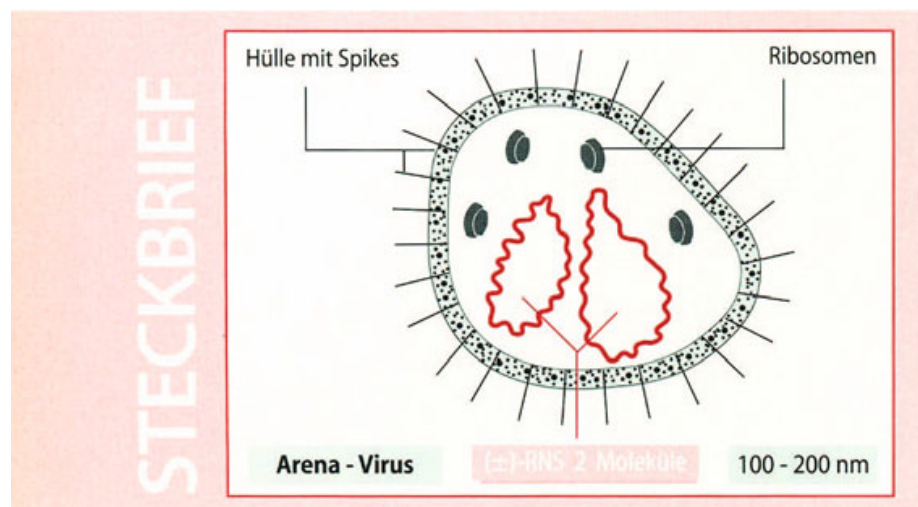

\subsection{LCM-Virus}

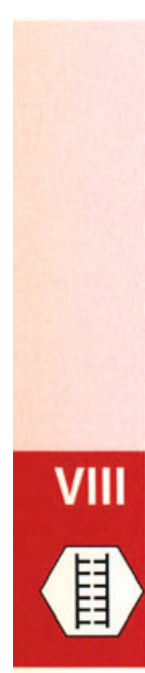

\subsubsection{Beschreibung}

\section{Genom}

Das LCM-Virus zählt zu den ambisense (+/-)RNS-Viren, d.h. das Genom enthält (+)- und (-)Strangabschnitte. Das Genom besteht aus einem hantelförmigen großen und einem kleinen Molekül. Das Genom enthält 11,0 kb.

\section{Morphologie}

Das annähernd kugelförmige Viruspartikel mit einem Durchmesser von etwa $100-150 \mathrm{~nm}$ besitzt eine lipoproteinhaltige Hülle mit Spikes; es zeigt im Inneren in charakteristischer Weise elektronendichte Körner („Pantherfellzeichnung“). Die Hülle des Virus trägt zwei Glykoproteine. Im Innern des Virus kann man einen Nukleoprotein-Komplex nachweisen, der ein Protein, die RNS und eine Replikase enthält.

\section{Züchtung}

Das LCM-Virus läßt sich in BHK- und Affennierenzellen züchten und auf Mäuse übertragen. Die Replikation erfolgt im Plasma der Zelle. Merkwürdigerweise enthält das Virion Ribosomen, die durch Mitnahme aus der Zelle in das Virion gelangen. Bei der Ausschleusung aus der Wirtszelle bilden sich charakteristische Knospen in Form einer Membranausstülpung, die das Virusmaterial umgibt. Alle Arena-Viren sind in der Zellkultur nicht zytopathogen. Bei der Replikation des Virus entstehen in großer Zahl defekte Virionen. 


\section{Resistenz}

Arena-Viren sind außerhalb des Wirtes relativ stabil, sie sind aber ätherempfindlich.

\subsubsection{Rolle als Krankheitserreger}

\section{Vorkommen}

Reservoir für das LCM-Virus sind Ulus musculus, die Labormaus und der Goldhamster („Hamsterkrankheit"). Innerhalb eines betroffenen Mäusebestandes hat der Befall mit LCM-Virus endemischen Charakter. Die Mäuse infizieren sich untereinander entweder horizontal, d.h. von Tier zu Tier, oder vertikal, d.h. von der Mutter auf die immunologisch unreife Nachkommenschaft in frühen Stadien der Embryogenese. Die vertikal infizierten Mäuse entwickeln nach der Infektion eine „Immuntoleranz" (s.u.) und werden zu Trägermäusen. Die horizontale Übertragung von Tier zu Tier erfolgt wahrscheinlich durch Aerosole, wobei eingetrockneter Kot und Urin die Hauptrolle spielen dürften.

\section{Epidemiologie}

Im Verhältnis zur Häufigkeit der LCM-Infektion bei Mäusen ergreift die Krankheit den Menschen selten; USA: $8 \%$ aller Meningitiden sind durch das LCM-Virus verursacht.

\section{Übertragung}

Wahrscheinlich wird das Virus auf den Menschen durch kontaminierte Nahrungsmittel oder kothaltigen Staub von virusausscheidenden Trägermäusen übertragen.

\section{Pathogenese und Immunität}

Die LCM-Infektion der Maus ist ein Paradigma für alle Infektionskrankheiten, deren Verlauf überwiegend von den Abwehrreaktionen des Wirtes und weniger von der direkten Wirkung des Erregers bestimmt wird. Für die Pathogenese der LCM-Infektion ist so gut wie ausschließlich die Immunreaktion gegen ein nicht direkt zytopathogenes Virus maßgebend. Pathohistologisch finden sich perivaskuläre Infiltrate der Hirnhäute mit vielen
Lympho- und Monozyten (daher „LCM“) in den Meningen.

Die Virulenz der verschiedenen LCM-Stämme variiert beträchtlich, verantwortlich hierfür sind Mutationen im Hüllglykoprotein.

Wird eine erwachsene Maus mit dem LCM-Virus erstmals infiziert, so erkrankt sie unter dem Bilde einer schweren Meningitis. Die Krankheit geht mit hohen Virustitern in allen Organen einher und führt bei einem Teil der Tiere zum Tode; die überlebenden Tiere erweisen sich nach der Rekonvaleszenz als virusfrei und zeigen keine Krankheitsfolgen. Zuerst wird Interferon- $\alpha / \beta$ gebildet, und NK-Zellen werden aktiv, dann treten neutralisierende Antikörper und spezifisch-reagible TLymphozyten auf; diese sind für die Immunität verantwortlich. Werden Mäuse dagegen in utero oder kurz nach der Geburt infiziert, so entwickelt sich in der Mehrzahl der Fälle trotz massiver Virusvermehrung kein erkennbares Krankheitsbild. Erst nach 10-12 Monaten kommt es $\mathrm{zu}$ einer "Spätkrankheit"; bei dieser dominiert eine chronisch-entzündliche Nierenschädigung (s.u.). Die im Stadium der immunologischen Unreife infizierte Maus scheidet lebenslang Virus aus; sie wird als Carrier-Maus bezeichnet. Die für diesen Zustand verantwortliche virusspezifische Immuntoleranz, eine sog. periphere Toleranz, erstreckt sich v.a. auf die zellvermittelte Immunität; Antikörper werden zwar gebildet, aber verzögert und in verringerter Menge.

Die Erklärung für diese Verhältnisse liegt in der Erkenntnis, daß die LCM-Infektion als solche die befallenen Wirtszellen nicht schädigt: Das Virus kann von der Zelle gewissermaßen „nebenbei“, d.h. ohne Nachteil, vermehrt werden, lediglich "luxury-functions" werden abgeschaltet (Wachstumsfaktoren etc.). Ein schädigendes Moment entsteht aber dann, wenn der vom Virus befallene Organismus eine Immunreaktion gegen die im Virion enthaltenen Antigene produziert. Hierbei sind folgende Situationen zu unterscheiden: Bei der akuten Krankheit, wie sie nach Infektionen des erwachsenen, immunologisch reifen Tieres auftritt, wird Virus-Antigen von der Membran befallener Zellen präsentiert. Dementsprechend dient sie als Ziel für virusspezifische ZTL, wie sie als Antwort auf den viralen Antigenreiz vom thymusabhängigen Immunorgan der Maus gebildet werden. Durch diese Situation entstehen schwere Zellschädigungen. Dies gilt aber nicht für die virushaltigen Neuronen, weil diese kein MHC bilden und kein 
Antigen präsentieren. Daneben bildet die akut erkrankte Maus virusspezifische Antikörper, die zur Neutralisation befähigt sind. - Die zweigleisig erfolgende Immunantwort schädigt somit nicht nur die Viren, sondern auch den Wirtsorganismus. Angelpunkt der Schädigung ist das in die Wirtszellmembran eingebaute oder präsentierte VirusAntigen.

Wird das Tier hingegen vor Erlangung seiner immunologischen Reife infiziert, so entwickelt sich eine periphere Toleranz (infolge "Anergie" und anderer Phänomene) gegen Virus-Antigene. Die Toleranz hält im Hinblick auf die zellvermittelte Immunität das ganze Leben an. Im Hinblick auf das B-Zell-System ist die Toleranz unvollständig. Es entstehen Antikörper gegen Virusmaterial; diese sind unfähig, das Virus zu eliminieren und die Infektion zu überwinden. Sie bilden aber mit Antigenkomponenten des Virions und Komplement Immunkomplexe, die im Glomerulum abgelagert werden, Komplement binden und eine Entzündung auslösen und so $\mathrm{zu}$ einer Nierenschädigung (= Spätkrankheit) führen (Immunkomplex-Nephritis). Überdies wirkt das LCM-Virus suppressiv auf die humorale und T-Zell-Immunantwort gegenüber dem Virus selbst, so daß z.B. auch dendritische Zellen zerstört werden; dadurch wird zusätzlich die Antigenpräsentation blockiert. Die Toleranz geht nicht mit einer kompletten Eliminierung der T-Zellen im Thymus einher; sie können vielmehr ihre Aktivität unter experimentellen Bedingungen wieder entfalten, indem aus dem Knochenmark neue T-Lymphozyten hervorgehen.

Folgende Befunde sind dabei besonders bedeutsam:

- Immunsuppressive Maßnahmen verhindern nach Infektion der erwachsenen Maus den Ausbruch der akuten Krankheit. Wirksam sind Röntgenstrahlen, Immunsuppressiva und Antilymphozytenseren.

- Bei neonatal thymektomierten Tieren bleibt die akute Krankheit nach der Infektion aus.

- Die T-Zellen von infizierten und akut erkrankten Erwachsenen-Tieren zeigen Killeraktivität gegenüber syngenetischen Zellen von pränatal infizierten Tieren.

\section{Klinik}

Von den Infektionen des Menschen verlaufen viele inapparent. Die manifeste Erkrankung (Inkubationsperiode 5-15 Tage) erweist sich zunächst als grippeähnlicher, mild, aber fieberhaft verlaufender Infekt (erste Krankheitsphase). In einer zweiten Phase tritt als häufigste Komplikation eine aseptische Meningitis mit erhöhten Lymphozytenzahlen im Liquor auf. Sie ist durch einen neuen Fieberschub und durch heftige Kopfschmerzen gekennzeichnet. Die Prognose der Meningitis ist gut. Sehr selten kommt es im Verlauf der menschlichen LCM-Infektion $\mathrm{zu}$ anderen Organerkrankungen (Enzephalitis, Orchitis, Myokarditis u.a.) oder gar zu einer tödlichen Allgemeininfektion. Während der Schwangerschaft kann die Infektion sehr selten Aborte oder aber Gehirnschäden (Hydrozephalus, Chorioretinitis) beim Neugeborenen herbeiführen.

\section{Labordiagnose}

Virusisolierung. Die virologische Diagnose stützt sich auf die Virusisolierung aus dem Liquor und dem Blut mittels Zellkultur (Nachweis des Antigens durch den IFT) oder besser in der lebenden Maus. PCR.

Antikörpernachweis. Daneben untersucht man auf neutralisierende und komplementbindende Antikörper. Ein ELISA zum Nachweis von IgM- und IgG-Antikörpern ist verfügbar.

\section{Prävention}

Die hygienischen Maßnahmen zur Prophylaxe konzentrieren sich auf die Bekämpfung der Hausmaus. Eine Schutzimpfung und eine spezifische Therapie existieren nicht.

Meldepflicht. Bei Meningitis und Tod.

\subsection{Lassa-Fieber-Virus}

$\mathrm{Zu}$ den Arena-Viren gehört auch das Lassa-FieberVirus. Das Lassa-Fieber rückte durch drei nach Deutschland eingeschleppte Fälle in den Blickwinkel der Öffentlichkeit. In Westafrika treten jedes Jahr etwa 200000 Fälle auf, von denen mehrere tausend tödlich ausgehen. Natürlicher Wirt für das Virus ist die persistent infizierte Ratte Mastomys natalensis, die das Virus mit dem Urin ausscheidet. Durch engen Kontakt infiziert sich der Mensch. Sekundärfälle verlaufen leichter als der Indexfall. Nach 
3-14tägiger Inkubation beginnt die Krankheit schleichend mit den Zeichen einer "Grippe" (Pharyngitis, $70 \%)$. Hauptsymptome sind dann Erbrechen, Diarrhoe, Brust- und Leibschmerzen, Blutungen (Konjunktiven) und Transaminasenerhöhung. Schwere Fälle gehen mit Hypotension, ausgedehnten Hämorrhagien und Enzephalitis einher. Weiterhin wurde Hörverlust, Orchitis, Perikarditis und Uveitis beobachtet. Die Letalität beträgt 520\% der hospitalisierten Fälle. 90-95\% der Infektionen verlaufen sonst mild oder inapparent.

Bei der Anamneseerhebung sind Reisen, Tierkontakte, Aufenthaltsweise und Impfungen(!) zu erfragen.
Labordiagnose. Arbeiten im Sicherheitslabor Klasse 4! Züchtung, RT-PCR, IgM- und IgG-Antikörper im IFT oder ELISA.

Differentialdiagnose (s. S. 527). Influenza, Gelbfieber, Dengue-Fieber, Hanta-Viren, Marburg-Ebola-Viren, Leptospiren, Japan B-Enzephalitis. Ribavirin hat sich als wirksames Chemotherapeutikum bewährt.

Meldepflicht. Bei Verdacht, Erkrankung und Tod; Erregernachweis.

\section{ZUSAMMENFASSUNG: Arena-Viren (Lymphozytäre Chorismeningitis)}

Virus. Ambisense RNS-Virus, pleomorphe Hülle mit Spikes, kein Kapsid, zwei Moleküle RNS, Ribosomen im Partikel: „arenosus” (lat. körnig).

Vorkommen. Das LCM-Virus ist endemisch bei wildlebenden Mäusen, Ausscheidung mit Urin und Kot. Goldhamster, Labormäuse.

Übertragung. Von Mäusen und Hamstern erfolgt durch Aerosole und Staub die Infektion des Menschen. Carrier-Mäuse übertragen das Virus vertikal auf Nachkommen.

Epidemiologie. Carrier-Mäuse scheiden das Virus lebenslang aus, hochgradige Anpassung des Virus an den Wirt ohne Beeinträchtigung der Lebensdauer.

Pathogenese und Immunologie. Inkubationsperiode 15 Tage. Mensch: Akute Virus- krankheit, sehr selten, häufig inapparent, ist immunologisch bedingt, kein primärer Viruszellschaden. Maus: Trägermaus in utero infiziert, lebenslang Virus in vielen Organen, TZell-Immun-Toleranz, nur wenig Antikörper, diese bewirken Immunkomplex-Nephritis. Virus wirkt immunsuppressiv. Erwachsene Maus: Akute Immunkrankheit durch ZTL.

Klinik. Meist grippaler Infekt, selten Meningitis mit Enzephalitis.

Diagnose. Anamnese! IgM- und -IgG-ELISA. Virusisolierung. RT-PCR.

Therapie. Symptomatisch.

Prävention. Sanierung von Tierzuchten.

Meldepflicht. Lassa: Verdacht, Erkrankung und Tod, Erregernachweis. 
D. FALKE

\section{EINLEITUNG}

Die Gastroenteritis wird beim Menschen durch Viren und durch Bakterien verursacht. Die viral bedingte Gastroenteritis ist die Hauptursache der hohen Säuglings- und Kleinkindersterblichkeit in den Tropen. Man schätzt, daß dort pro Jahr etwa 1-2 Mio Kinder an einer VirusGastroenteritis sterben. Zu den Viren, die eine Gastroenteritis verursachen, zählt man die Rota- und Adeno-Viren. Epidemiologische Studien haben aber gezeigt, daß dafür noch weitere Virusspezies in Frage kommen, die man als "kleine, runde Viruspartikel" zusammenfaßt; es sind Calici-Viren (Norwalk-Agens u.a.), Astro- und wahrscheinlich Corona-Viren (s. S. 563).

\subsection{Rota-Viren}

Rota-Viren rufen bei Säuglingen und Kleinkindern Gastroenteritis hervor. 1943 wurde gezeigt, daß sich die menschliche Gastroenteritis durch Ultrafiltrate übertragen läßt. 1973/74 wurden dann bei der elektronenmikroskopischen Direktuntersuchung des Stuhlmaterials von erkrankten Säuglingen und Kleinkindern Viruspartikel, bestehend aus zwei konzentrisch angeordneten Kapsiden, beobachtet.

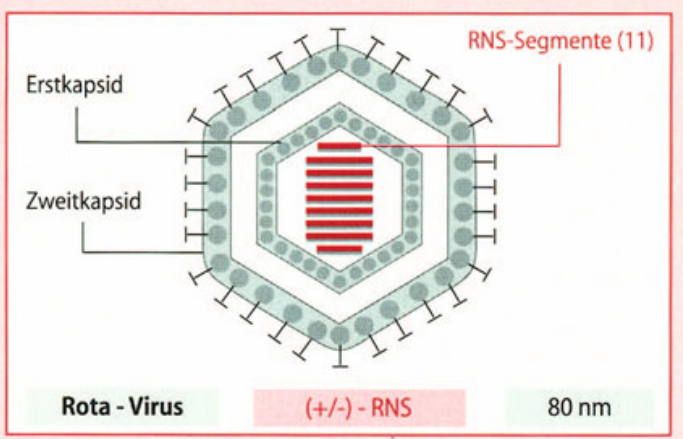

\subsubsection{Beschreibung}

\section{Genom}

Rota-Viren enthalten Doppelstrang-RNS. Sie liegt in 11 Segmenten in einem "core" vor und enthält $24 \mathrm{kbp}$. Jedes Segment kodiert für ein Protein, zwei Proteine sind glykosiliert. Das Virion enthält eine RNS-abhängige Replikase.

\section{Morphologie}

Das Virus besteht aus zwei ineinander verpackten Kapsiden. In der Negativkontrastierung ergibt sich das Bild eines Rades mit Speichen, daher der Name. Es trägt kurze, dicke „Spikes“. Der Durchmesser des Virus beträgt etwa $80 \mathrm{~nm}$. Das äußere Kapsid besitzt hämagglutinierende Eigenschaften.

\section{Züchtung}

Rota-Viren replizieren sich im Zytoplasma. Die menschlichen Rota-Viren lassen sich nur bei niedrigem Serumgehalt in vitro züchten.

\section{Einteilung}

Das Genus der Rota-Viren wird in Gruppen (A, B, C-G) und Subgruppen (AI, II, III) sowie Typen A $(1,2,3,4$ und 5) eingeteilt. Die Gruppen- und Untergruppenspezifität wird durch die inneren, die Typenspezifität durch die äußeren Kapsidantigene bestimmt. Alle Typen sind Umwelt-stabil. Ferner kennt man G- und P-Serotypen.

\subsubsection{Rolle als Krankheitserreger}

\section{Vorkommen}

Rota-Viren sind im Tierreich weit verbreitet, u.a. bei Kälbern und Rhesusaffen. 
Die meisten der bisher bei Mensch und Tier isolierten Rota-Viren gehören zu der Gruppe A.

Die Gruppe B stammt vom Schwein und ist jetzt beim Menschen heimisch geworden.

\section{Epidemiologie}

Die Kontagiosität des Virus ist sehr hoch, so daß im Alter von drei Jahren fast alle Kinder Antikörper tragen. Die Infektionen erfolgen meist in der kalten Jahreszeit (enger Kontakt). In den Tropen sind Infektionen mit Rota-Viren weit verbreitet und die Hauptursache für die hohe Kindersterblichkeit. Infektionen bis zum Alter von drei Monaten verlaufen meist asymptomatisch. Jugendliche und Erwachsene werden erneut infiziert; sie erkranken aber nur selten; zumeist fungieren sie als gesunde Ausscheider und Überträger. Die Ausscheidung des Virus dauert bei primären Infektionen 8-14 Tage, bei inapparenten Reinfekten nur einige Tage und bei Immundefizienz Monate.

Infektionen bei alten Menschen verlaufen oftmals schwer. Es werden Kindergarten-, Krankenhaus- und Altenheim-Epidemien beobachtet.

Die Viren der Gruppe B (Schweinerota-Viren) wurden zunächst bei durchfallkranken Erwachsenen (Bergarbeiter in China) isoliert, ehe man sie später auch bei Säuglingen feststellte.

Die serologische und genetische Variabilität der Rota-Viren ist groß. Innerhalb einer Epidemie ändern sich die Subgruppen- und Typenspezifitäten sehr schnell. Diese Erscheinung geht wahrscheinlich auf Punktmutationen (Antigendrift) sowie auf einen Austausch von RNS-Segmenten (Reassortment) oder Teilen davon zurück: Rearrangements.

\section{Übertragung}

Infektionsquelle sind der Stuhl (bis $10^{11} \mathrm{PFU} / \mathrm{ml}$ ) und verunreinigtes Trinkwasser. $10^{2}$ Partikel wirken krankheitserzeugend. Es gibt aber auch Hinweise auf eine Übertragung durch Tröpfcheninfektion. Außerhalb des Menschen ist das Virus sehr stabil.

\section{Pathogenese}

Unsere Kenntnisse über die geweblichen Veränderungen bei Rota-Virusinfektionen stammen aus Freiwilligenversuchen und aus der experimentell erzeugten Infektion von Kälbern. In den Epithelzellen der Dünndarmzotten läßt sich Rota-Antigen nachweisen. Das Epithel der Zotten wird durch die
Infektion zerstört; es regeneriert sich jedoch schnell. Man findet Verkürzungen der Zotten und monozytäre Infiltrate bis zur Lamina propria. Dieser Prozeß setzt sich von kranial nach kaudal fort. Ein Nichtstrukturprotein (NSP4) wirkt als Enterotoxin. Der Schaden entsteht an den Mitochondrien und dem endoplasmatischen Retikulum; es tritt eine $\mathrm{Ca}^{++}$-Anreicherung und ein $\mathrm{Cl}^{-}$-Verlust auf.

Die Infektion bleibt meist auf den Dünndarm beschränkt. Diese Tatsache ist wahrscheinlich durch Proteasen bedingt, die nur in diesem Darmabschnitt vorkommen. Die Proteasen spalten ein virales Glykoprotein in zwei Untereinheiten und erhöhen damit die Infektiosität des Virus: Analogie zum Influenza-Virus (s. S. 547).

Pathophysiologisch beobachtet man eine Malabsorption: D-Xylose und Fette werden nicht absorbiert. Der starke Wasserverlust bewirkt eine Dehydratation; in Tierversuchen ließ er sich durch Inhibitoren von Neurotransmittern verhindern. - Invaginationen entstehen nicht.

\section{Klinik}

Die Inkubationsperiode beträgt 1-3, die Erkrankung dauert etwa 4-7 Tage. Ein Häufigkeitsgipfel besteht im Winter. In den Tropen erfolgen die Infektionen ganzjährig. Befallen werden vorwiegend Säuglinge und Kleinkinder im Alter von 3-36 Monaten. Andere Altersgruppen sind seltener betroffen (Tabelle 9.1).

Das Krankheitsbild ist durch eine Trias aus Diarrhoe, Erbrechen und Fieber gekennzeichnet. Bauchschmerzen sind selten, eine Dehydratation wird in der Hälfte der Fälle beobachtet. Gelegentlich lassen sich Infekte des oberen Respirationstraktes feststellen, die zeitlich mit der Gastroenteritis korreliert sind. Ganz selten sind Fieberkrämpfe, Enzephalitis sowie hämorrhagischer Schock.

Auch asymptomatische Infektionen werden im ersten Lebenshalbjahr beobachtet. Sie entstehen vermutlich unter dem Einfluß von passiv übertragenen Antikörpern der Mutter und erzeugen nur eine geringgradige Aktiv-Immunität.

Bei immungeschädigten Personen verläuft die Infektion chronisch und gelegentlich mit Hepatitis; die Virusausscheidung hält über Monate an.

\section{Immunität}

IgA-Antikörper. Verantwortlich für die Immunität sind sekretorische IgA-Antikörper; sie vermitteln 
eine Schleimhautimmunität. Bei Säuglingen werden sie durch die Muttermilch aufgenommen. Sie reduzieren den Schweregrad der Erkrankung und die Dauer der Ausscheidung, aber auch noch unbekannte Faktoren werden vermutet. ZTL sind von geringer Bedeutung.

IgG-Antikörper. Im Gegensatz zu IgA-Antikörpern verleihen intrauterin übertragene IgG-Antikörper keinen Schutz. Bei abgestillten Kindern findet man IgA-Antikörper bereits eine Woche nach Beginn der Erkrankung im Darm. IgM-, IgA- und IgG-Antikörper treten später im Serum auf und mit niedrigen Titern. Es ist bisher nur wenig über die Dauer, den Mechanismus und die Typenspezifität der postinfektiösen Immunität bekannt.

\section{Labordiagnose}

ELISA. Bei Rota-Viren ist mittels ELISA eine Schnelldiagnose im Stuhl möglich. Bei diesem Test werden die Viren durch gruppenspezifische Antikörper, die an die feste Phase gebunden sind, aus den Stuhlextrakten „herausgefischt“: „Antigen-ELISA“.

Immun-Elektronenmikroskopie. Im Gebrauch ist auch die Immun-Elektronenmikroskopie für die Identifizierung der Rota-Viren (u.a.).
HHT. Für die serologische Typendiagnose eignet sich ein Hämagglutinations-Hemmungstest. Die KBR ergibt keine brauchbaren Ergebnisse.

\section{Therapie und Prävention}

Die Prognose der Erkrankungen ist in den Industriestaaten meist gut. Entscheidend ist die Substitution von Wasser mit Elektrolyten. In den Entwicklungsländern sind die Rota-Infektionen in Verbindung mit der mangelhaften Ernährung und der ungenügenden Pflege die Hauptursache für die hohe Säuglingssterblichkeit. Die fäkal-orale Übertragung deutet auf den besten Weg zur Verhütung: Optimale Allgemeinhygiene. In den Entwicklungsländern gilt das Motto: $\mathrm{Zu}$ allererst sauberes Trinkwasser. Die Chlorierung des Trinkwassers gegenüber dem Virus ist wirkungslos. Ein Impfstoff vom Rhesus-Rota-Virus mit einer Human-Komponente wurde aus dem Verkehr gezogen, weil Darminvaginationen auftreten (s. Adeno-Viren). Ein rein humaner Impfstoff von einem Kind mit einer leichten Diarrhoe befindet sich jetzt in der Erprobung. Die beste Vorbeugung besteht in allgemeiner Hygiene, sauberem Trinkwasser und Stillen der Säuglinge.

Meldepflicht. Verdacht und Erkrankungen, Erregernachweis.

\section{ZUSAMMENFASSUNG: Rota-Viren}

Virus. Doppelstrang-RNS-Virus (11 Segmente) im core mit Doppelkapsid und Enzymen: "Rad mit Speichen“. Replikation im Plasma der Zelle.

Vorkommen und Übertragung. Rota-Viren im Tierreich weit verbreitet, beim Menschen meist Gruppe A mit mehreren Typen. Schmutz- und Schmierinfektion, verunreinigtes Trinkwasser; Ausscheidung 8-14 Tage. Vor allem im Winter.

Epidemiologie. Vorwiegend bei Kleinkindern, sonst sporadisch, erwachsene Viruszwischenträger. Reassortment, Rearrangement und Antigendrift als Ursache von Epidemien und Endemien.
Pathogenese. Enteritis aboral fortschreitend, gestauchte und verbreiterte Dünndarmzotten mit Epithelverlust, schnelle Regeneration.

Klinik. Inkubationsperiode 2-3 Tage. Diarrhoe, Fieber, Erbrechen, Wasserverlust, Malabsorption.

Immunität. Sekretorische IgA-Antikörper.

Diagnose. Virus im Stuhl durch Antigen-ELISA, sowie ggf. durch EM.

Therapie. Symptomatisch, Flüssigkeits-, Glukose- und Salz-Infusionen.

Prävention. Allgemeine Hygiene, sauberes Trinkwasser, Stillen der Säuglinge. HumanRota-Impfstoff.

Meldepflicht. Verdacht, Erkrankungen. Erregernachweis. 


\subsection{Enteritische Adeno-Viren (Typ 40 und 41)}

Erstmals wurden 1975 Adeno-Viren als Ursache einer Gastroenteritis beschrieben. Adeno-Viren vom Typ 40 und 41, aber auch die Typen 12, 18 und 31 können eine Gastroenteritis auslösen.
Schmierinfektion. Die Durchseuchung erfolgt frühzeitig bei Säuglingen und Kleinkindern.

Über die Pathogenese ist kaum etwas bekannt.

\section{Klinik}

Adeno-Viren werden in 4-12\% aller Stuhlproben von Säuglingen, Kleinkindern und Kindern mit akuter Gastroenteritis nachgewiesen. Die Infektionen kommen ganzjährig vor. Sie betreffen vorwiegend Säuglinge und Kleinkinder; bei Jugendlichen und Erwachsenen sind Erkrankungen seltener.

Leitsymptome sind Diarrhoe und seltener Erbrechen und Fieber. Die Diarrhoe kann bis zu 10 Tage andauern. Zusätzlich werden respiratorische Symptome beobachtet. Eine Dehydratation ist selten.

Genom, Morphologie, Resistenz. Die enterischen Adeno-Viren gleichen den übrigen AdenoViren in vieler Hinsicht (s. S. 625). Die Viren sind Umwelt-stabil.

Züchtung. Sie lassen sich nur in bestimmten Zellstämmen bei niedrigem Serumgehalt züchten.

\subsubsection{Rolle als Krankheitserreger}

\section{Epidemiologie und Pathogenese}

Die enteritischen Adeno-Viren kommen nur beim Menschen vor. Sie werden mit dem Stuhl ausgeschieden. Die Übertragung erfolgt fäkal-oral durch

\section{Labordiagnose}

Die Züchtung ist bisher nur in einigen Labors möglich. Ein Antigen-ELISA zum Nachweis der Viruspartikel im Stuhl hat sich in die Routinediagnostik eingebürgert. Für wissenschaftliche Zwekke werden Antikörper mit dem IFT auf infizierten Zellkulturen nachgewiesen. Nachweis durch EM.

\section{Therapie, Prävention}

Es gibt keine spezifische Therapie; ein Impfstoff ist in der Entwicklung. Flüssigkeits- und Salzinfusionen bei Dehydratation. Zur Prävention dienen allgemein-hygienische Maßnahmen.
\end{abstract}

Meldepflicht. Verdacht, Erkrankung und Erregernachweis.

\section{ZUSAMMENFASSUNG: Adenotypen 40 u. 41}

Virus. Wie Adeno-Viren. Schlecht züchtbare, stabile Viren.

Vorkommen und Übertragung. Beim Menschen im Stuhl, ganzjährig. Die Übertragung erfolgt fäkal-oral als Schmutz- und Schmierinfektion.

Epidemiologie. Frühzeitige Durchseuchung bei Säuglingen und Kleinkindern.
Diagnose. Antigen-ELISA. Züchtung nur in Speziallabors.

Therapie. Symptomatisch, Flüssigkeits- und Salzinfusionen.

Prävention. Allgemeine Hygiene.

Meldepflicht. Verdacht, Erkrankung und Erregernachweis.

Klinik. Diarrhoe, Erbrechen und Fieber. 


\subsection{Calici-Viren}

Das Norwalk-Agens und seine Verwandten gelten als Erreger der Gastroenteritis beim Menschen. Sie werden mit weiteren Viren (Snow-Mountain-Virus, Hawaii-Virus und Sapporo-Virus) zur Familie der Calici-Viren (Calix, lat. Kelch) gezählt.

Die Identifizierung des Virus als "kleine, runde Viruspartikel" erfolgte 1972 durch Immun-Elektronenmikroskopie. Die Benennung des Virus erfolgte nach dem Ort Norwalk, Ohio (USA) unter Bezugnahme auf einen dort beobachteten Ausbruch von Gastroenteritis.

\subsubsection{Beschreibung}

\section{Genom}

Die Nukleinsäure der Calici-Viren und ihrer Verwandten ist eine Einzel-(+)-Strang-RNS, sie enthält 7,7 kb. Man kennt 2 Genus (Norwalk- und Sapporo-like viruses).

\section{Morphologie}

Diese Viren haben einen Durchmesser von 27-30 $\mathrm{nm}$; ihre Kapsomeren sind derart angeordnet, daß in der Negativkontrastierung ein Muster entsteht, welches an eine kreisförmige Anordnung von nach außen gerichteten Tassen erinnert. Die U-förmigen „Tassen“ des Norwalk-Agens sind allerdings kleiner als die der typischen Calici-Viren. Im Innern erkennt man die Ikosaedersymmetrie. Der Durchmesser beträgt $30 \mathrm{~nm}$.

\section{Züchtung}

Die Züchtung ist bisher noch nicht gelungen, Calici-Viren sind Umwelt-stabil.

\section{Vorkommen}

Die Viren kommen im Stuhl des Menschen in sehr großer Menge vor; man bedient sich für viele Studien dieser Quelle. Sie sind weltweit verbreitet.

\subsubsection{Rolle als Krankheitserreger}

\section{Epidemiologie}

Ein wichtiges Merkmal der Calici-Gastroenteritis ist die Tatsache, daß Infektionen und Erkrankungen kaum in den ersten Lebensjahren vorkommen; diese treten vielmehr erst bei Jugendlichen und Erwachsenen auf. Die Kontagiosität ist also geringer als die der Rota-Viren.

Außerdem sind die Calici-Viren sehr häufig die Ursache von kleinen Lokal-Epidemien in Familien, Heimen, Lagern, Schulen u.ä.; es gibt dabei typische Explosiv-Epidemien. Auch dies steht im Gegensatz zur Epidemiologie der Rota-Viren.

Das Virus ist auch als Ursache von Gastroenteritis-Fällen anzusehen, die durch kontaminierte Lebensmittel ausgelöst werden. So sind Salat, $\mathrm{Mu}$ scheln, Krabben und Austern die Ausgangspunkte von Epidemien gewesen. Auch verunreinigte Wasserversorgungssysteme waren die Ursache von Calici-Virusepidemien. Eine jahreszeitliche Häufung von Infektionen gibt es nicht - ein weiterer Unterschied im Vergleich zu den Rota-Viren. In den USA sind im Erwachsenenalter 2/3 oder mehr aller Personen Antikörperträger.

\section{Übertragung}

Die Übertragung des Virus erfolgt fäkal-oral, häufig durch kontaminiertes Trinkwasser oder Lebensmittel.

\section{Pathogenese}

Magen und Kolon der Erkrankten sind normal. Die Zotten des Jejunums erscheinen jedoch "gestaucht", die Mucosa ist nur teilweise zerstört. Monozytäre Zellen und segmentierte Leukozyten werden in der Lamina propria festgestellt. Die interzellulären Spalten sind erheblich verbreitert; dies wird bereits $24 \mathrm{~h}$ nach der experimentellen Infektion beobachtet. Nach zwei Wochen sind alle Veränderungen verschwunden.

\section{Klinik}

Calici-Viren erzeugen nach einer Inkubationsperiode von 1-3 Tagen eine typische Diarrhoe, die häufig mit Erbrechen, Magen-Darm-Krämpfen und Fieber verbunden ist, das Auftreten der Neben- 
symptome variiert jedoch. Calici-Viren gelten neben dem Rota-Virus als eine der häufigsten Ursachen für die Reise-Diarrhoe. Die Stühle sind wäßrig, aber nicht schleimig oder blutig. Malabsorption von Fett und D-Xylose ist häufig.

\section{Immunität}

Im Verlaufe von Infektionen entstehen Antikörper, die sich durch Immun-Elektronenmikroskopie oder im ELISA mit definiertem Virusmaterial nachweisen lassen. Es handelt sich dabei jedoch nicht um protektive Antikörper. Ob im Jejunum schützende Schleimhaut-Antikörper auftreten, ist nach den bisherigen Erkenntnissen ungewiß. Die Immunität gegen eine Reinfektion scheint nur etwa zwei Monate anzudauern. Offenbar gibt es aber auch unspezifische Mechanismen, die eine Reinfektion verhindern.

\section{Labordiagnose}

Eine Labordiagnose ist routinemäßig noch nicht möglich, eine spezifische Therapie gibt es nicht, es werden jedoch Routinetests entwickelt. EM und RT-PCR.

\section{Prävention}

Prophylaktisch ist die Allgemein-Hygiene wichtig: Gemeinschaftseinrichtungen, Krankenhäuser.

Meldepflicht. Verdacht, Erkrankung, Erregernachweis. Gruppenerkrankungen.

\section{ZUSAMMENFASSUNG: Calici-Viren}

Virus. RNS-haltiges, kleines Virus. Bisher nicht züchtbar.

Vorkommen. Nur beim Menschen im Stuhl in großen Mengen, während des ganzen Jahres.

Epidemiologie. Erkrankungen treten erst bei Jugendlichen und Erwachsenen auf. Lokale Kleinepidemien.

Übertragung. Schmutz- u. Schmierinfektionen, Lebensmittel-Epidemien, verunreinigtes Leitungswasser.

Pathogenese. Epithelnekrose, die Zotten des Jejunums erscheinen gestaucht, Malabsorption. Nach zwei Wochen spätestens Regeneration der Schleimhaut.
Klinik. 1-3tägige Inkubationsperiode: Vorwiegend Diarrhoe, seltener Fieber und Erbrechen.

Immunität. Nachweis der Antikörper durch Immun-Elektronenmikroskopie oder ELISA.

Labordiagnose. Nicht routinemäßig, RT-PCR.

Therapie. Symptomatisch.

Prävention. Allgemeine Hygiene.

Meldepflicht. Verdacht, Erkrankung, Erregernachweis. Gruppenerkrankungen. 


\subsection{Weitere Enteritis-erzeugende Viren}

\subsubsection{Astro-Viren}

Astro-Viren sind seit 1975 bekannt. Die Viruspartikel tragen ihren Namen von ihrer „Stern“-ähnlichen Struktur mit vier oder sechs Strahlen. Sie haben einen Durchmesser von $28 \mathrm{~nm}$ und bestehen nur aus dem Kapsid.

Das (+)-Strang-RNS-Genom enthält 7,2 kb. Das Virus vermehrt sich im Zytoplasma, es gibt sieben Serotypen, von denen Typ 1 am wichtigsten ist. Man kennt bisher nur 1 Genus; Astro-Viren sind nur wenig untersucht.

Die Epidemiologie gleicht z.T. der des NorwalkAgens, v.a. sind aber junge Kinder befallen. Im Alter von einem Jahr sind 50\% der Kinder seropositiv (London); das Virus ist verantwortlich für 5$10 \%$ aller Gastroenteritis-Fälle. Die Infektion wird fäkal-oral übertragen, auch innerhalb von Familien. 4-5\% der Gastroenteritisfälle werden durch Astro-Viren hervorgerufen. Die Ausscheidung dauert 1-4 Tage.

\section{Klinik}

Nach einer Inkubationsperiode von 1-4 Tagen macht sich eine leichte Erkrankung mit wäßriger
Diarrhoe, Erbrechen und wenig Fieber von 1-4 Tagen Dauer bemerkbar. Sie tritt vorwiegend bei Säuglingen und Kleinkindern auf.

\section{Labordiagnose}

Der Nachweis gelingt mit einem Antigen-ELISA im Stuhl, die reverse PCR ist jedoch empfindlicher. Ein kommerzieller Antikörper-Test existiert noch nicht, jedoch ist ein Antigen-ELISA verfügbar.

\subsubsection{Corona-Viren (s. S. 563)}

Die zwei Genus der Corona-Viren rufen Respirations- oder/und Gastrointestinalinfektionen hervor. Dies gilt auch für das 2. Genus der Coronaviridae, die Toro-Viren. Es gibt leichte und schwere Verlaufsformen. Der Stuhl kann wäßrig oder blutig sein. Betroffen sind vorwiegend Kinder. Bei gestorbenen Kindern wurde pathohistologisch eine nekrotisierende Enterokolitis festgestellt. In den Zellen waren Viruspartikel zu erkennen; man hat Anhaltspunkte dafür, daß - wie bei der Cholera - das cAMP in seiner Aktivität beeinflußt wird und der Elektrolyttransport gestört wird.

Einzelheiten über die Corona-Viren finden sich im Kap. 4 (s. S. 563) auch hier gibt es weitere Viren, die noch kaum untersucht sind. Differentialdiagnostisch wichtig: Akutes Abdomen. 


\subsubsection{Weitere Gastroenteritis-Viren}

Die oben beschriebenen Viren (Rota-, Adeno-, Calici- und Astro-Viren) sind im „Hauptberuf“ Gastroenteritis-Erreger. Hinzu treten weitere Viren. Außer den oben beschriebenen Adeno-Viren der Typen 40 und 41 rufen auch andere Adeno-Virustypen eine Gastroenteritis hervor. Es sind dies die Typen $12,18,31 \mathrm{u}$. a. Bei ihnen ist allerdings die Gastroenteritis nur Nebensymptom. Dies gilt z.B. auch für Picorna- und Parvo-Viren.
Auch weitere, „kleine, rundliche Viruspartikel“, die man zu den Calici- und Astro-Viren zählt, sowie Corona-Viren rufen eine Gastroenteritis hervor. Man vermutet, daß man bisher nur einen Teil der Viren kennt, die eine Gastroenteritis erzeugen. Relativ häufig werden auch mit dem Antigen-ELISA oder dem Elektronenmikroskop Viruspartikel festgestellt, ohne daß eine Erkrankung vorliegt; sehr wahrscheinlich handelt es sich um asymptomatische Infektionen (Tabelle 9.1).

Tabelle 9.1. Klinisch wichtige Daten von Rota-, Adeno-, Calici-, Astro- und Corona-Virus-Erkrankungen

\begin{tabular}{|c|c|c|c|c|c|}
\hline & Rota-Virus & Adeno-Virus & Calici-Virus & Astro-Virus & Corona-Vurs \\
\hline Inkubationsperiode & 1-3 Tage & 8-10 Tage & 1-3 Tage & 1-4 Tage & $?$ \\
\hline Virusausscheidung & 14 Tage & 10-14 Tage & 3-5 Tage & 3-5 Tage & $?$ \\
\hline Dauer der Krankheit & 4-7 Tage & $\begin{array}{l}\text { 7-10 Tage } \\
\text { z.T. länger } \\
\text { oder chronisch }\end{array}$ & 2-3 Tage & 2-4 Tage & $?$ \\
\hline Häufigkeit & Winter, & $\begin{array}{l}\text { Ganzjährig } \\
\text { Tropen: ganzjährig }\end{array}$ & Ganzjährig & Winter & Ganzjährig \\
\hline $\begin{array}{l}\text { Säuglinge und } \\
\text { Kleinkinder }\end{array}$ & Häufig & Häufig & Selten & Häufig & Häufig \\
\hline $\begin{array}{l}\text { Kinder, Jugendliche, } \\
\text { Erwachsene }\end{array}$ & Selten & Selten & Häufig & Selten & \\
\hline Symptome & $\begin{array}{l}\begin{array}{l}\text { Diarrhoe } \\
\text { Erbrechen }(88 \%) \\
\text { Fieber }(77 \%)\end{array} \\
\begin{array}{l}\text { Bauchschmerzen } \\
\text { (selten) }\end{array}\end{array}$ & $\begin{array}{l}\text { Diarrhoe } \\
\text { Erbrechen } \\
\text { Fieber } \\
\text { Dehydratation } \\
\text { respiratorische } \\
\text { Symptome }\end{array}$ & $\begin{array}{l}\text { Diarrhoe } \\
\text { Erbrechen } \\
\text { Fieber } \\
\text { Dehydratation } \\
\text { Krämpfe }\end{array}$ & $\begin{array}{l}\text { Diarrhoe } \\
\text { Erbrechen } \\
\text { aber leicht } \\
\text { Magen-Darm- }\end{array}$ & Diarrhoe \\
\hline Züchtbarkeit & Begrenzt & Begrenzt & Sehr begrenzt & + & $(+)$ \\
\hline Virus-Diagnose & Antigen-ELISA & Antigen-ELISA & EM & $\begin{array}{l}\text { Antigen-ELISA } \\
\text { RT-PCR, EM }\end{array}$ & $\begin{array}{l}\text { ELISA, EM, } \\
\text { RT-PCR }\end{array}$ \\
\hline Diarrhoe & wäßrig & wäßrig & wäßrig & wäßrig & wäßrig \\
\hline Anteil & $70 \%$ & $12 \%$ & $8 \%$ & $8 \%$ (bei Kindern) & $?$ \\
\hline
\end{tabular}

Nicht entzündlich (s.a. ETEC, Cholera) Kein Blut im Stuhl. Entzündlich: Shigellen, Salm. typhi, Amöben, EHEC u.a. 
D. FAlKe, G. Gerken

\section{EINLEITUNG}

Retro-Viren sind eine Gruppe von RNS-Viren, bei denen die Integration des Retrotranskripts als DNS in das Wirtszellgenom (Provirus) Voraussetzung für die Replikation ist. Sie transformieren z.T. in vitro Zellen und sind die Ursache für viele Tumorarten beim Tier. Die Transformationsgene der Viren sind aus der Zelle "gestohlene" Regulatorgene des Zellzyklus. Sie haben die Spur zu den "Krebsgenen" des Menschen freigelegt. Beim Menschen sind Retro-Viren (HIV) die Erreger von AIDS („Acquired Immundeficiency Syndrom") und einer Leukämie des Erwachsenen (HTLV).

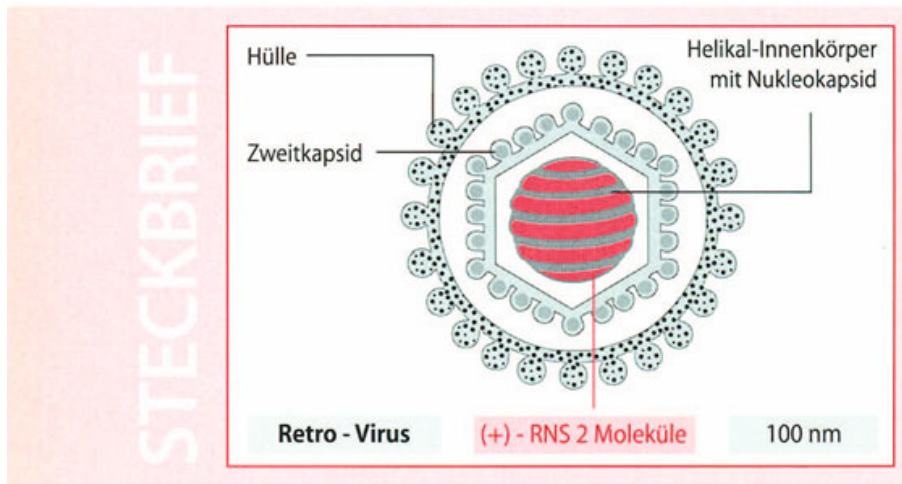

\subsection{Gruppe der Retro-Viren}

\subsubsection{Genom}

Die Retro-Viren zählen zu den (+)-EinzelstrangRNS-Viren. Die Gene der Retro-Viren kodieren für Strukturproteine und Funktionsproteine (Reverse Transkriptase und Regulatorproteine). Einige transformierende Viren enthalten außerdem ein Transformationsgen. Das Genom der Retro-Viren neigt zu Mutationen, Rearrangements und Defektbildungen, auch sind Rekombinationen zwischen verschiedenen Vertretern dieser Gruppe beschrieben worden. Es gibt auch endogene, aber defekte Retro-Viren des Menschen ohne (?) pathogenetische Bedeutung. Veränderungen der Genomstruktur und Mutationen beeinflussen die Virulenz.
Im einzelnen unterscheidet man folgende Gene (s. Abb. 10.1):

- Das gag-Gen (group specific antigen),

- das Polymerase-Gen (pol),

- das Envelope-Gen (env),

- Das v-onc-Gen (virus-oncogen);

- LTR-Sequenzen: Am 5'- und 3'-Ende des Genoms befinden sich „long terminal repeats“.

\subsubsection{Einteilung}

Retro-Viren werden nach ihrer Gestalt (A-, B-, C-, D-Partikel sowie Lenti-Viren) und der Genomstruktur eingeteilt (HIV s.S. 597).

Sie kommen bei Kaltblütern ebenso vor wie bei Vögeln und Säugetieren einschließlich des Menschen. Retro-Viren werden horizontal sowie vertikal als Provirus übertragen.

\section{Spuma- oder Foamy-Viren}

Spuma- (oder Foamy-)Viren tragen ihren Namen von der Vielzahl an zytoplasmatischen Vakuolen in Polykaryozyten. Es handelt sich um Auftreibungen des Golgi-Apparates und des endoplasmatischen Retikulums, in denen die Replikation erfolgt. Die Virionen sind morphologisch charakterisiert durch lange Spikes sowie durch ein kugelartig angeordnetes, helikales Erstkapsid. Das Genom ist als Provirus dauernd integriert. Vertreter der Spuma-Viren hat man in vielen Säugetieren festgestellt, speziell bei Primaten, von denen sie gele- 
gentlich auf den Menschen übertreten (asymptomatisch). Beim Menschen kennt man jedoch endogene Retro-Viren in Teratomen und der Plazenta. Defekte Retro-Viren und „Transposons" sind offenbar ohne pathogenetische Bedeutung.

\section{Lenti-Viren}

Lenti-Viren erzeugen v.a. das AIDS des Menschen (HIV). In die Familie der Lenti-Viren gehören u.a. das Virus der Pferdeanämie, die Viren der Immundefizienz bei Affen (SIV), bei Katzen (FIV) und bei Rindern (BIV) sowie das Maedi- und das Visna-Virus. Bisher kennt man im Bereich der $\mathrm{Hu}-$ manmedizin zwei pathogene AIDS-Viren, HIV1 und HIV2. Das HIV1 kommt in 3 Subtypen vor: $\mathrm{M}$ (ajor), $\mathrm{N}(\mathrm{ew})$ und $\mathrm{O}$ (utlier). Sie sind jeweils vom Schimpansen auf den Menschen übergetreten. Der Subtyp M umfaßt die Varianten A-I. Von allen Aufspaltungen entstehen „Quasispezies“.

\subsection{Human-Immundefizienz-Virus (HIV)}

HIV1 und 2 sind die Erreger des erworbenen Immundefektsyndroms (acquired-immune-deficiency-syndrome, AIDS). Es überzieht die Erde in einer Pandemie. Infolge der Immunschwäche treten opportunistische Infektionen auf. Die Erkrankung verläuft fast immer tödlich. 2 Mio Kinder sind bereits mit dem HIV infiziert. Insgesamt schätzt man 1999 etwa 40 Mio Infizierte und AIDSKranke. 1998 waren 2,5 Mio Personen gestorben.

\subsubsection{Beschreibung}

\section{Genom}

Die Nukleinsäure hat einen Informationsgehalt von etwa $9 \mathrm{~Kb}$. In jedem Partikel gibt es zwei identische (+)-Strang-RNS-Fäden. Durch die hohe Mutationsrate können „Quasispezies“ entstehen. Das DNS-Retroskript des Virusgenoms wird in das Genom der Wirtszelle als Provirus an beliebiger Stelle inte- griert. Die RNS für neue Viria entsteht ebenso wie die mRNS durch Transkription des Provirus.

\section{Genfunktionen}

Außer den zwei Strukturgenen und dem Polymerase-Gen existieren regulationsaktive Gene. Die gag-, pol- und env-Vorläuferproteine werden nach ihrer Entstehung durch eine Protease in verschiedene Untereinheiten gespalten.

Das Genom des HIV besteht im Detail aus den folgenden Regulationssequenzen und Genen (Abb. 10.1).

LTR-Abschnitt (5'-Ende). Er enthält Promotoren der Genexpression und Enhancer-Elemente; es sind dies Bindungsstellen für zelluläre und virale Regulatorproteine (z. B. für $\mathrm{NF} \kappa \mathrm{B}$ und Tat).

Gag-Gen. Das primäre Genprodukt (p 55) wird in Untereinheiten gespalten (cleavage) (p 25, 17, 9 und 6). Die Spaltprodukte werden zum Aufbau der beiden Kapside verwendet. Sie sind für die Gruppenspezifität verantwortlich.

Pol(ymerase)-Gen. Es kodiert für die reverse

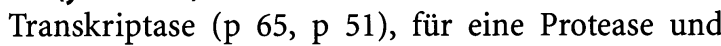
für die Endonuklease (Integrase, p 32). Die Protease bewirkt die Spaltung der Vorläuferproteine.

Env-Gen. Die Genprodukte Glykoprotein (gp) 120 und gp 41 werden in die Hülle eingebaut. Das gp 41 ist für die Zellfusion verantwortlich, das gp 120 für Bindung an die Rezeptoren. Es soll toxisch für Neuronen wirken und besitzt Typen bzw. Subtypenspezifität. Der Präkurser ist das gp 160.
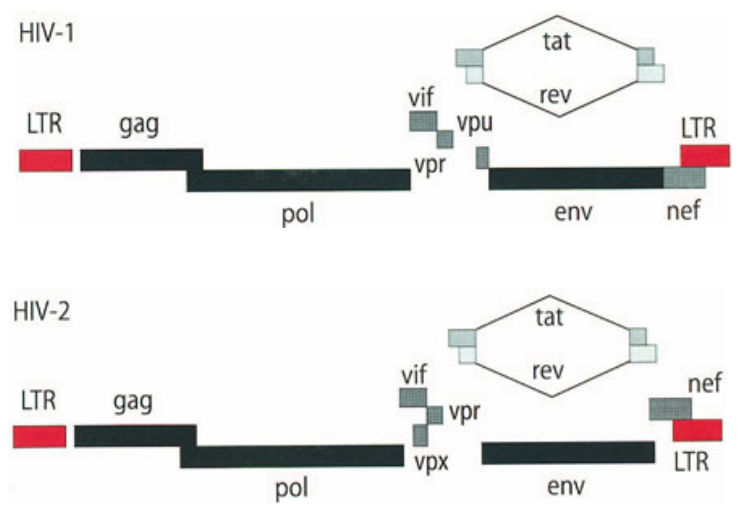

Abb. 10.1. Die Gene des HIV1- und 2-Genoms. Das Genom wird von einem 5'- und 3'-LTR eingefaßt. In 5'-3'-Richtung sind das gag-, das pol- und das env-Gen angeordnet. Die Regulatorgene entstehen durch Spleißen in der env-Region 
Tat-Gen. Das Gen entsteht durch Zusammenfügen zweier Regionen des Virus-Genoms (transactivation transcription) durch Spleißen. Das Genprodukt verstärkt im Sinne einer positiven Rückkopplung die Transkription durch "Transaktivierung“ (Abb. 10.2) aller Gene des HIV am 5'-LTR; es wird auch aus der Zelle abgegeben.

Rev-Gen. Regulator der Expression der Virusproteine, das die Expression der Virus-mRNS und den Transport nicht gespleißter mRNS reguliert.

Vif (Virus-Infektions-Faktor). Er steigert die Infektiosität bei Adsorption und Penetration.

Nef (am 3'-Ende, „negativer" Faktor). Er steigert die virale mRNS-Synthese. Man vermutet, daß dieses Protein toxisch für Glia-Zellen und Astrozyten wirkt. Es reduziert die Expression von MHC- und CD4-Faktoren auf der Zellmembran.

Vpu und vpr. Sie verstärken die Replikation sowie die Virusfreigabe und schalten die MHC-Synthese ab. Vpr ist ein Zytokinregulator und erzeugt Apoptose. Es existiert noch ein tev-Gen (s. Abb. 10.1).

LTR-Abschnitt. (3'-Ende) (s. o.).

\section{Morphologie}

Das Virus besteht aus einem helikalen Kapsid, das in Form eines stumpfen Kegels vorliegt und von einem isometrischen Zweitkapsid eingeschlossen ist. Dieses ist zusätzlich von einer Hülle mit „spikes“ umgeben (Abb. 10.3). Innen befindet sich die RNS mit einigen Molekülen an $\mathrm{p} 9$ und $\mathrm{p} 6$ und reverser Transkriptase sowie Integrase und Protease. Die Montage des HIV erfolgt an der Zellmembran („budding“), seine Reifung erst nach der Freigabe durch die Proteasespaltung der gag-Proteine.

\section{Die Replikation des HIV}

Die Adsorption erfolgt durch Anlagerung des gp 120 an den CD4- und an CCR5- bzw. CXC-Chemokin-Rezeptoren der Zelle (s. S. 603), das HIV wird dann durch Fusion von der Zelle aufgenommen (Penetration). Nach dem Uncoating erfolgt im Zytoplasma die reverse Transkription (Angriffspunkt für Inhibitoren der reversen Transkriptase) und der Transport der DNS in den Kern mit der Integration (Provirus). Zelluläre Transkripta-

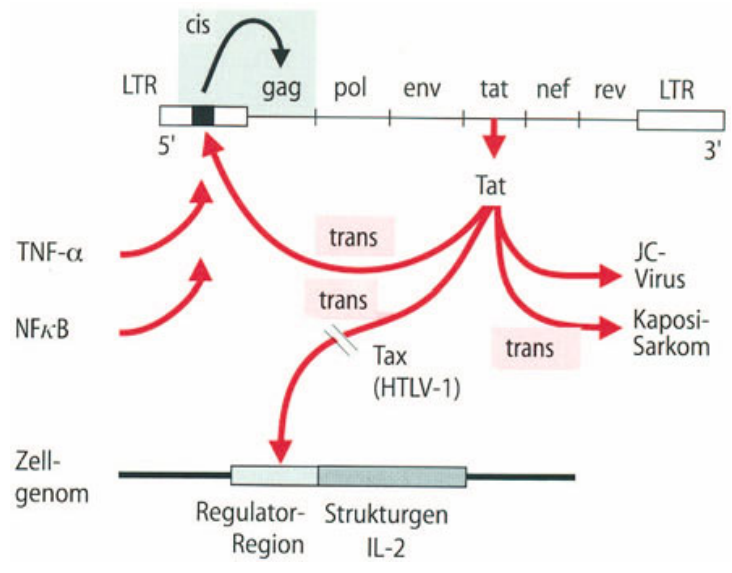

Abb. 10.2. Gen-Regulation durch HIV. Das Tat-Protein wirkt in "trans", d.h. entfernt auf der Regulator-Region (LTR) des HIV auf einer bestimmten Basensequenz transkriptionssteigernd; es steigert auch die Replikation des JC-Virus und die Teilung von Kaposi-Zellen. Das Tax-Protein des HTLV bindet an die Regulatorregion des IL-2Gens. "Cis"-Aktivierung erfolgt von einer Promotor-Region aus (",down-stream" in 3'-Richtung) und wirkt transkriptionssteigernd. Der $\mathrm{NF} \kappa \mathrm{B}$-Faktor ist ein zentraler Transkriptionsfaktor. Schreibweise: tat $=$ Gen; Tat $=$ Protein

sen produzieren mRNS und Genom-RNS. Nach der Translation an den Polysomen erfolgt die Spaltung der Vorläuferproteine in kleinere Moleküle. Die Wirkung der Protease hat sich als wichtiger Angriffspunkt für die Chemotherapie (s. S. 515) herausgestellt. Dann erfolgt die Montage neuer Viruspartikel an der Zellmembran, die durch Knospung („budding“) frei werden. Das Tat-Protein bewirkt verstärkte Ablesung des Genoms (Abb. 10.4).

\section{Züchtung}

Das Virus läßt sich in CD4-Zellen (T-Helferzellen) und in Makrophagen züchten. Die Züchtung des Virus in peripheren Blutlymphozyten gelingt nur, wenn Wachstumsfaktoren (IL-2) und Mitogene zur Stimulierung der T-Helferzellen zugegeben werden.

\section{Tierpathogenität}

Das HIV1 läßt sich auf Schimpansen übertragen; es verursacht hier zunächst eine persistierende, aber inapparente Infektion. Die Zahl der CD4-Zellen ändert sich dabei anfangs nicht. Erst Jahre später treten erste Zeichen einer Erkrankung auf. 
Abb. 10.3. Das HIV, bestehend aus zwei Molekülen (+)-Strang-RNS, reverser Transkriptase, Erst- und Zweit-Kapsid und Hülle mit Proteinen

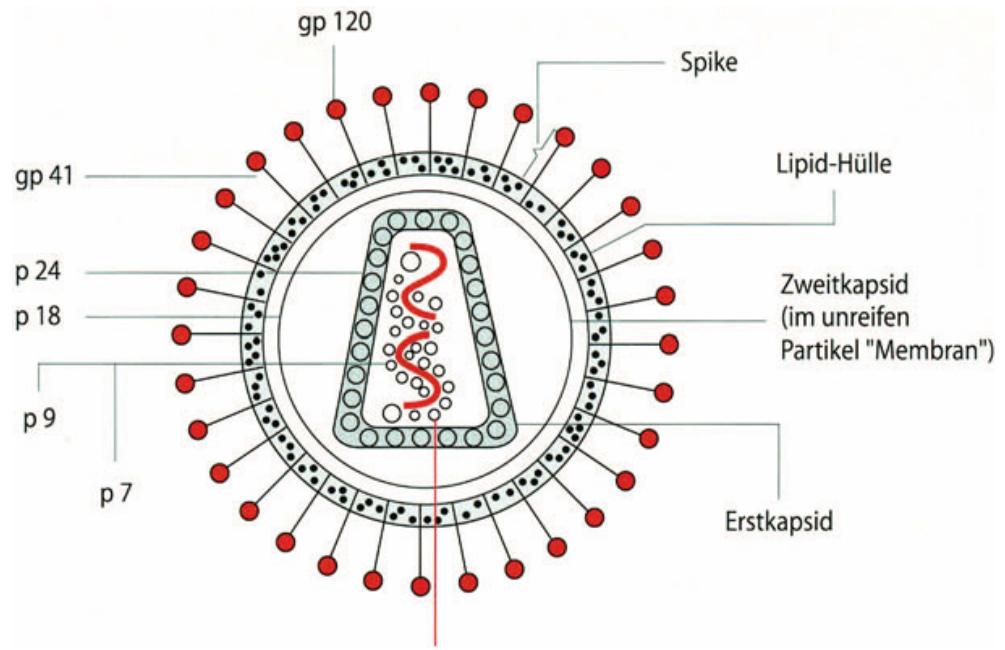

2 Moleküle (+) - RNS

mit reverser $(p 66)$

Transkriptase (0)

\section{Replikation des HIV}

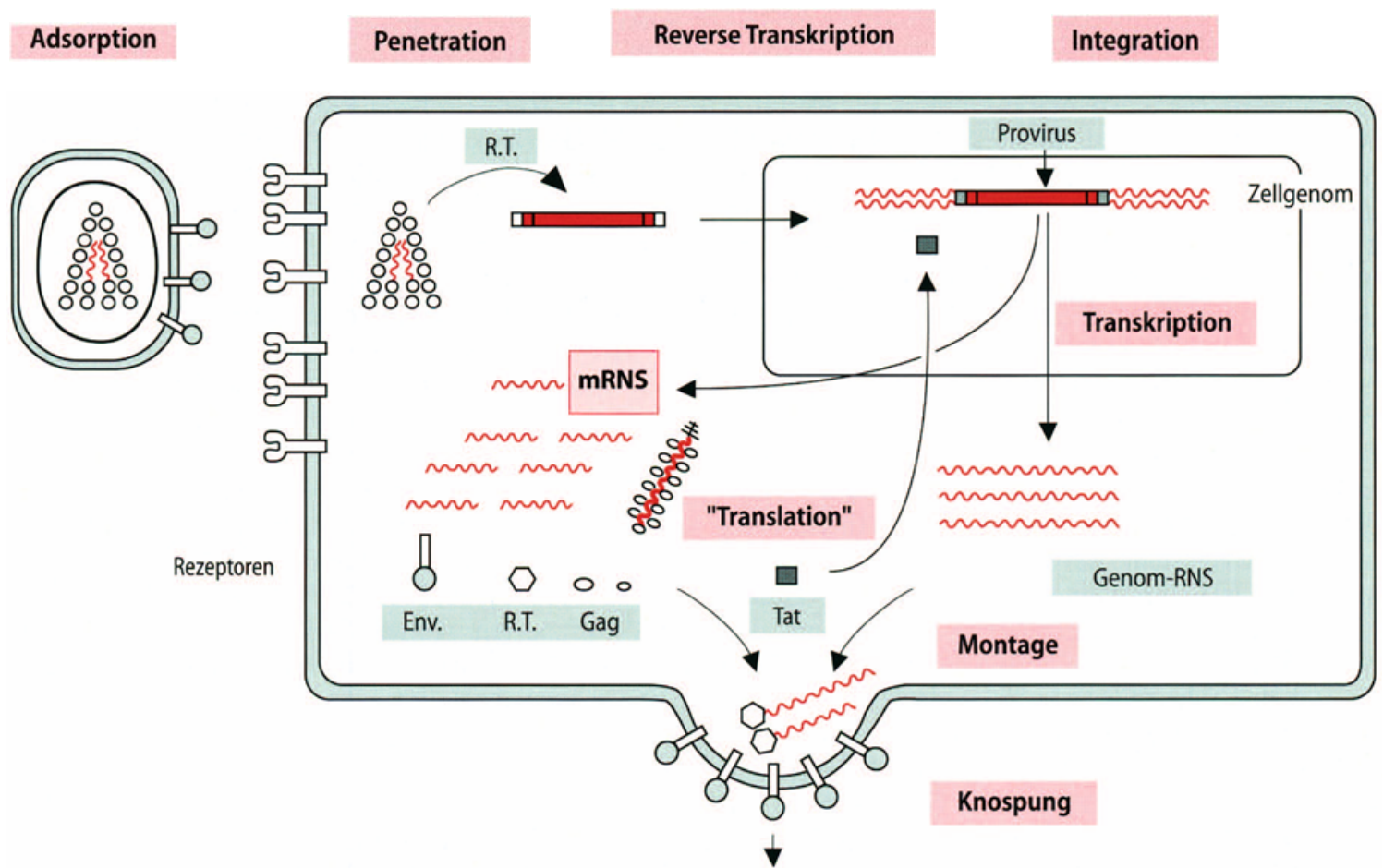

Abb. 10.4. Replikation des HIV. Die Adsorption erfolgt an den CD4- und Chemokin-Rezeptoren, Penetration durch Fusion der Virushülle mit der Zellmembran, reverser Transkription in DNS und Integration in das Zellgenom (Provirus). Transkription und Translation der env-, gag- und pol- sowie Regulatorgene, Cleavage der VorläuferProteine, Montage und Knospung des neuen Virus. RT = Reverse Transkriptase 


\section{Inaktivierung des HIV}

Das HIV ist wegen seiner lipidhaltigen Hülle sehr empfindlich für Lipidlösungsmittel. Außerhalb des Organismus verliert es durch Austrocknen nach mehreren Stunden 90-99\% seiner Infektiosität; bei hoher Konzentration kann dies einige Tage dauern. In zellfreien Kulturflüssigkeiten hält sich das Virus bei Raumtemperatur bis zu 15 Tagen. Die Inaktivierbarkeit bei $56^{\circ} \mathrm{C}$ und $60^{\circ} \mathrm{C}$ hängt vom Eiweißgehalt der Flüssigkeit ab. In Anwesenheit von $10 \%$ fetalem Kälberserum oder $50-90 \%$ menschlichen Serums erfolgt Infektiositätsverlust bei $56^{\circ} \mathrm{C}$ nach $8-30 \mathrm{~min}$. Bei $60^{\circ} \mathrm{C}$ und Anwesenheit von $10 \%$ fetalem Kälberserum erfolgt die Inaktivierung innerhalb von 2 min. Desinfektion: Desinfektionsmittelliste der DGHM. Stand 1. 3. $2000 \mathrm{mhp}$-Verlag, Wiesbaden.

\subsubsection{Rolle als Krankheitserreger}

\section{Geschichte und Herkunft}

1981 wurde in San Francisco und Los Angeles bei fünf jungen Männern ein bis dahin unbekanntes Krankheitsbild festgestellt: AIDS. Die Patienten litten an Pneumocystis-carinii-Infektionen, bei jungen Personen damals ein ganz ungewöhnliches Ereignis. In New York hatte man außerdem vier junge Männer mit einem Kaposi-Sarkom beobachtet, das bis dahin nur bei Senioren bekannt war. Bereits vorher war in der Gruppe der Homosexuellen eine Zunahme von Geschlechtskrankheiten in Verbindung mit einer atypischen Lokalisation von Infekten („Gay bowel syndrome“, Entzündungszustände des Enddarms), festgestellt worden. Serologisch konnten retrospektiv in Afrika Infektionen ab 1960 festgestellt werden. Erst ab 1979 haben sich dann HIV-Infektionen verstärkt ausgebreitet.

Das HIV1 ist in Zentralafrika dreimal auf den Menschen übergetreten. Sein natürlicher Wirt scheint der Schimpanse zu sein, da HIV1 und die Schimpansen-Viren genetisch eng verwandt sind.

HIV2 ist in Westafrika von Mangaben-Affen (Cercocebus atys) wahrscheinlich mehrfach auf den Menschen übergetreten. Die genetische Verwandtschaft $\mathrm{zu}$ den Affenviren ist jedenfalls sehr eng. Während in den natürlichen Wirten keine Erkrankungen zustande kommen, diese aber lebenslang persistent infiziert bleiben, erkrankt der
Mensch, wenn er infiziert wird. Interessanterweise verläuft die HIV2-Infektion langsamer als die mit HIV1; auch der Verlauf ist leichter.

In Afrika wurden aus gesunden, aber persistent infizierten Grünen Meerkatzen (Cercopithecus aethiops) und Mangaben-Affen Retro-Viren isoliert, die man als SIV (Simian immune-deficiency virus) bezeichnete. In Gefangenschaft gehaltene RhesusAffen (Macaca mulatta) hingegen, die kein entsprechendes Virus beherbergen, erkrankten jedoch nach der Infektion an SAIDS (Simian-AIDS). Sie lassen sich also als Versuchstiere verwenden. Auch gilt die SCID-Maus (severe-combined-immune-deficiency) nach Rekonstitution mit Knochenmark des Menschen als erfolgversprechendes Versuchstier. Auf jeden Fall deuten die Befunde bei Affen darauf hin, daß es angeborene Eigenschaften eines Wirtes gibt, die die Entstehung von (S)AIDS verhindern (Simian).

\section{Allgemeines über AIDS und HIV}

AIDS ist ein Krankheitskomplex, der mit einer Letalität von fast $100 \%$ einhergeht, die Inkubationsperiode beträgt 1-15 Jahre. Man beobachtet Gewichtsabnahme, Schwächezustände, Fieber sowie zahlreiche opportunistische Infektionen (z.B. Pneumonie, orale Haarleukoplakie, HSV-bedingte Ulzera der Haut sowie Chorioretinitis und Magendarm-Ulzera durch ZMV). Auch tritt das Kaposi-Sarkom auf. In Afrika verläuft die Erkrankung wegen der extremen Magersucht unter der Bezeichnung "slim-disease“ (Tabelle 10.2, „Marker-Krankheiten“).

Als konstanter Befund ergab sich eine starke Reduktion der T-Helfer-Zellpopulation; dies deutete auf eine Beteiligung des Immunapparates beim Krankheitsgeschehen hin. Anfangs wurden v.a. männliche Homosexuelle betroffen; dazu gesellten sich später Prostituierte, männliche und weibliche Drogenabhängige, Hämophile, Empfänger von Blutkonserven und schließlich auch Kinder von HIV-infizierten Müttern: Die Übertragung des Virus erfolgt sexuell sowie durch kontagiöses Blut und dessen Produkte.

\section{HIV1}

Bereits 1983 gelang Montagnier und seiner Arbeitsgruppe am Institut Pasteur in Paris die Isolierung eines Retro-Virus aus den Lymphozyten eines jungen Homosexuellen mit den Krankheitszeichen des Lymphadenopathie-Syndroms (III. AIDS- 
Stadium). 1984 haben Gallo und seine Arbeitsgruppe in den USA ähnliche Retro-Viren von $\mathrm{Pa}$ tienten isoliert, die das voll ausgebildete Krankheitsbild AIDS aufwiesen. Die isolierten Viren werden jetzt als HIV1 (Human-Immundefizienz-Virus) bezeichnet.

\section{HIV-2}

Nachdem 1983 und 1984 das HIV1 isoliert worden war, wurde 1986 in Westafrika das HIV2 von AIDS-Patienten isoliert. Hier läßt sich die Spur des Virus bis Anfang der 70er Jahre zurückverfolgen. Das HIV2 ist verwandt, aber nicht identisch mit dem HIV1. Im Gegensatz zu HIV2 war HIV1 überwiegend in Zentralafrika festgestellt worden. Bei den Kreuztesten zeigte sich, daß die Glykoproteine der Virushülle bei HIV1 und 2 völlig verschieden waren, die Polymerase und die Kapsid-Antigene lieBen jedoch eine Verwandtschaft zwischen HIV1 und HIV2 erkennen. HIV1 und HIV2 gehören also zu derselben Gruppe von Viren; sie unterscheiden sich aber bezüglich ihrer Typenspezifität.

\section{Epidemiologie}

Im globalen Maßstab läßt sich die Pandemie als Zerfallen in viele Einzelepidemien beschreiben, die ihre eigenen Genom-Eigenschaften besitzen (Subtypen). $\mathrm{Zu}$ Beginn der Epidemie erfolgte in den Industrieländern die Weitergabe meist durch Homosexuelle; jetzt überwiegen intravenös Drogenabhängige, wobei zunehmend mehr Frauen und Kinder infiziert werden.

Sogar innerhalb einer Person liegt das HIV als "Quasispezies" vor oder als Schwarm von nahe verwandten Viren; sie sind dem Selektionsdruck des Immunsystems ausgesetzt und ggf. dem einer Chemotherapie, es treten also „Escape“-Mutanten in großer Häufigkeit auf. Pro Replikationszyklus erfolgt pro Genom 1 Basenaustausch!

Während es 1981 in den USA 219 Todesfälle an AIDS gab, waren es 1985 bereits 2469 Todesfälle und 7531 Erkrankte. Die Hauptrisikogruppe in den USA, die Homosexuellen, sind in den großen Metropolen zu fast 100\% durchseucht. Die Durchseuchung in der Bundesrepublik Deutschland mit HIV1 ist bei Homosexuellen und Prostituierten mit i.v. Drogenabhängigkeit besonders hoch. Deshalb besteht die Gefahr, daß auf diese Weise - etwa durch bisexuelle Männer und drogenabhängige Prostituierte - die Infektion in die heterosexuell lebende Bevölkerung hineingetragen wird. Besonders tragisch ist die Durchseuchung der Hämophilen, die durch kontaminierte Faktor-VIII-Präparate infiziert wurden. Weltweit rechnet man für das Jahr 2000 mit 40 Mio oder mehr Infizierten. Das Zahlenverhältnis zwischen Männern und Frauen betrug in den Industrieländern zu Anfang der Pandemie 14:1, jetzt werden relativ mehr Frauen infiziert. Die Zahl der klinisch Kranken steigt dramatisch: Sie verdoppelt sich etwa alle 3-5 Jahre. In Deutschland waren bis Ende 199615682 AIDSFälle gemeldet und über 10000 Gestorbene bekannt. Die Gesamtzahl der Infizierten in Deutschland wird auf 50000-60000 geschätzt (weltweit etwa 40 Mio). Die Zahl der Neuinfektionen pro Jahr beträgt 2000-2500, davon sind 55\% Homosexuelle, $15 \%$ Drogenabhängige, $13 \%$ Heterosexuelle, 17\% Personen aus Hochrisikoländern (südliches Afrika, Südostasien), <1\% Säuglinge. HIV2-Antikörper wurden bei 194 Personen festgestellt, HIVO bei einer Person aus Kamerun.

Das HIV1 Variante $M$ ist in die verschiedenen Regionen des Erdballs zu unterschiedlichen Zeitpunkten verschleppt worden, HIVO dagegen findet sich bevorzugt in Kamerun; die fünf Subtypen AE des HIV2 sind vorwiegend in Westafrika verbreitet. Je nach Besiedlungsdauer haben sich in den Regionen unterschiedlich viele Quasispezies angereichert. Hauptvermehrungsgegenden sind heute Afrika, Indien und Südostasien, während in den Industrieländern die Gesamtzahl der Seropositiven kaum noch steigt.

\section{Übertragung}

Das HIV wird durch homo- oder heterosexuellen Geschlechtsverkehr, sowie durch Blut oder Blutprodukte übertragen. Sperma und Vaginalsekret sind ebenfalls Infektionsquelle. Die Viruslast ist der Hauptfaktor für das Risiko der sexuellen Übertragung unterhalb von 1500 Kopien RNS/ $\mu$ l ist es gering. Nach Schätzungen ist beim Vaginalverkehr die Übertragungsgefahr geringer als beim Analverkehr. Andererseits wird das Virus offenbar leichter vom Mann auf die Frau übertragen als umgekehrt, obwohl der Virusgehalt im Vaginalsekret oft hoch ist. Der Grund für diesen Unterschied dürfte darin bestehen, daß beim Analverkehr häufig Mikrotraumen entstehen, durch die das Virus leicht in den Körper gelangt. Je geringer die CD4-Zahl ist, desto mehr HIV läßt sich im Vaginalsekret nachweisen. Speichel ist viel weniger virushaltig als Blut. Durch 
den Biß seropositiver Personen wurde das HIV in einem von 600 Fällen übertragen. Für die Übertragung durch Kuß gibt es keine epidemiologischen Hinweise, es sei denn, daß entzündliche Veränderungen in der Mundhöhle vorliegen. Orale Übertragung durch Speichel erfolgt, wenn dessen Hypotonie durch Milch oder Sperma aufgehoben wird, auch gibt es unspezifische Inhibitoren des HIV. Auch Muttermilch, Tränen, Schweiß und Urin enthalten Virus.

Die Infektion der Neugeborenen (etwa 8\%) durch seropositive Mütter erfolgt vorwiegend perinatal, aber auch durch Stillen. Die Faktoren, die die Übertragung auf Embryo oder Säugling bestimmen, sind unbekannt. Die Übertragung erfolgt umso häufiger, je höher die Viruslast der Mutter ist.

Insgesamt gesehen ist die Kontagiosität des HIV geringer als die des Hepatitis B-Virus. Bisher sind nur wenige Infektionen durch kontaminierte Kanülen bei ärztlichem Personal bekannt geworden. Durch Verletzungen beim „recapping“ von kontaminierten Kanülen erfolgen Übertragungen mit einer Rate von 1:300. Die gemeinsame Benutzung von Spritzen bei Drogenabhängigen bildet jedoch einen Hauptausbreitungsweg. Endoskope etc. sind peinlich genau zu reinigen. 3-5\%ige Na-Hypochloritlösung, 20\% Alkohol oder Formalin wirken viruzid. Infektionsgefahr besteht auch beim Tätowieren, bei der Akupunktur und bei der Beschneidung. Unbedingt sollte verhindert werden, daß Blut von Seropositiven auf die unbedeckte Haut gerät (kleine Wunden lassen sich nie ausschließen). Bisher sind vier Fälle von Serokonversion bekannt geworden, bei denen eine größere Virusmenge auf die ungeschützte Haut gelangte. Bei Ekzematikern besteht eine erhöhte Infektionsgefahr, weil die bei ihnen im Epithel vorhandenen Langerhans-Zellen vermehrt CD4-Rezeptoren u. a. ausbilden.

Eine Ansteckung innerhalb von Wohngemeinschaften, durch pflegerischen Umgang mit Seropositiven oder AIDS-Kranken durch Händeschütteln ist nicht beschrieben. Die Desinfektion von Räumlichkeiten, in denen ein AIDS-Kranker gestorben ist, ist nicht erforderlich; allgemeine hygienische Regeln sollten jedoch beachtet werden.

In Afrika, der Karibik und in Südostasien wird die HIV-Infektion vorwiegend durch heterosexuellen Verkehr in Verbindung mit Promiskuität übertragen. Das Verhältnis von infizierten Männern zu Frauen beträgt dort etwa 1:1. In den großen Städten Zentralafrikas sind bis zu 20\% oder mehr der Einwohner durchseucht.
Während der gesamten Latenz- und Krankheitsphase ist der Mensch potentiell als kontagiös anzusehen. Die Infektionsgefahr ist umso größer, je geringer die Zahl der CD4-Zellen und je größer die Primärlast durch HIV-RNS-Moleküle ist.

\section{Pathogenese}

Die Infektion erfolgt durch Makrophagen-tropes HIV. Die ersten infizierten Zellen im Organismus sind dendritische Zellen der Darmschleimhaut (mit oder ohne besonderen Rezeptor), die das HIV in die Lymphknoten transportieren, wo es sich vermehrt. Makrophagen/Monozyten des Blutes verschleppen das Virus in das ZNS.

Der Infektions- und Krankheitsverlauf (Abb. 10.5) von AIDS wird dann durch einen progredienten virusbedingten Eingriff in das Wirkungsnetz des Immunapparates bezüglich seiner zellulären und humoralen Komponenten einschließlich der Zytokine bestimmt. Hinzu tritt der Befall von Zellen des ZNS. Die Interaktion des Virus mit den verschiedenen Zelltypen hat sich als variabel erwiesen, z. T. bedingt durch die hohe Mutationsrate (Quasispezies) des Virus. HIV1 und 2 infizieren vorzugsweise THelferzellen, die das CD4-Molekül tragen. HIV-1 ist aber auch in CD8-Zellen, in Makrophagen, dendritischen und Langerhans'schen Zellen, in Enddarmschleimhautzellen sowie in der Mikroglia nachgewiesen worden. Der Grad der Immundefizienz wird nach dem Wert des CD4/CD8-Quotienten beurteilt; die Situation wird kritisch, wenn die CD4-Zellzahl unter 200/ $\mu$ l absinkt. Die Zahl der HIV-RNSMoleküle im Plasma, die „Plasmaviruslast“, ist als Faustregel - umgekehrt proportional zur Zahl der CD4-Zellen; die Zahl der RNS-Moleküle etwa 1/2 Jahr nach der Infektion läßt Voraussagen über die Progressivität der Infektion zu. Liegt sie unter $10^{3}$, so ist mit einer sehr langen Latenz zu rechnen, liegt sie zwischen $10^{3}$ und $3 \times 10^{4}$, ist mit einer Latenz von 4-6 Jahren, liegt sie über $10^{5}$, ist mit einer kurzen Latenz von 1-2 Jahren zu rechnen. Als Folge der Immundefizienz treten dann opportunistische Infektionen und schließlich AIDS auf.

Ein Teil der Langzeitüberlebenden von HIV-Infizierten besitzt außer einer hohen Zahl von TH1Zellen einen Defekt in einem Chemokinrezeptor: Das HIV kann nicht penetrieren und die CD4-Zellen überleben. Dies ist ein interessantes Beispiel einer "angeborenen Resistenz" gegenüber einem Virus; aber auch bestimmte HLA-Konstellationen verleihen Schutz gegen die Infektion. 
Abb. 10.5. Pathogenese des AIDS. In 1 ist Virusreplikation und Antikörperbildung, in 2 ist das Verhalten der Lymphozyten und Lymphokine, in 3 die Viruslast und die Dauer der "Latenzphase" dargestellt

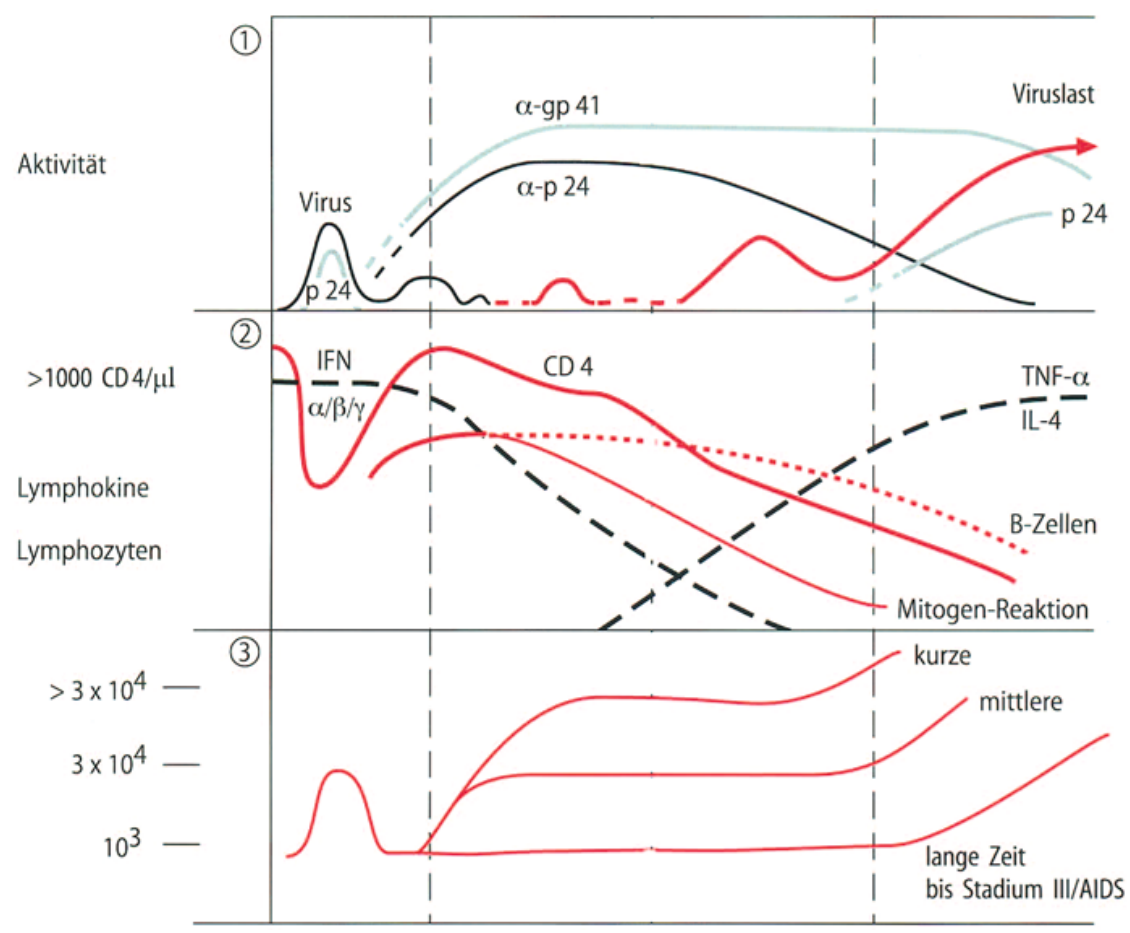

Stadium
॥
III
Die Infektiosität für CD4-Zellen wird durch Eigenschaften des env-Gens, des HIV und der CXCChemokine (s. S. 119) bestimmt. Infizierte Lymphozyten können das Virusgenom als Provirus längere Zeit latent beherbergen; $z$. T. liegt aber auch eine abortive Replikation mit defekter DNS vor. Erst durch Antigenerkennung erfolgt die Aktivierung und der Beginn des produktiv-lytischen Synthesezyklus.

Durch die Virusreplikation wird offenbar nur ein Teil der CD4-Lymphozyten direkt zerstört (direkter Zellschaden). Die Berührung von CD4-Zellen durch bereits infizierte Zellen (mit Tat, Env) kann außerdem direkt Apoptose auslösen. Neuerdings weiß man, daß auch CD8-Zellen (nach CD4Expression) infiziert und zerstört werden.

Die Zytopathogenität für Makrophagen ist geringer als für CD4-Lymphozyten. Makrophagen tragen CCR5-Rezeptoren und fungieren als produktiv-nicht lytische Zielzellen und dauerhaftes Virusreservoir und zugleich als immunregulatorische Elemente, die die Virusreplikation und das Ausmaß des CD4-Zellschadens bestimmen. So steigt die Lymphokinproduktion von Monozyten und Makropha- gen (Interferon, IL-1 und 6, Tumornekrosefaktor u. a.). Der Makrophage kann, ohne Schaden zu nehmen, lange Zeit als Virusreservoir dienen und das Virus bei seiner Wanderung im Organismus verbreiten. Die Montage des Virus erfolgt im Zytoplasma, in dem sich große Mengen an Virus ansammeln und nicht an der Zellmembran. Aus Makrophagen stammendes Virus kann CD4-Lymphozyten infizieren und damit zerstören, aber nicht umgekehrt. Aus den Makrophagen stammt das HIV in den Endstadien, wenn die CD4-Zellen zerstört sind und kein Virus mehr bilden können.

Bei den B-Zellen kann man bereits im Stadium I („Mononukleose“) eine polyklonale Stimulation beobachten: Die Serum-Immunglobulinspiegel sind erhöht. Man beobachtet auch Autoantikörper und Immunkomplexe. HIV-Antigen-präsentierende BZellen und dendritische Zellen werden von CD8positiven ZTL erkannt und zerstört.

Antikörper gegen neue Antigene werden kaum noch gebildet. Im fortgeschrittenen Stadium der Erkrankung werden die B-Zellen inaktiv, so daß die Antikörper-Pegel gegen das HIV zurückgehen. 
Die zytopathogene Eigenschaft des HIV variiert im Verlauf der Infektion:

- Im Stadium I („Mononukleose“) wird kurzfristig synzytiumbildendes Virus (= Primärphase),

- in der sog. klinischen „Latenzphase“ lediglich langsam replizierendes Makrophagen-tropes Virus ohne Befähigung zur Riesenzellbildung festgestellt.

- Erst beim Übergang von Stadium II zu III steigt die Menge des schnell replizierenden Virus mit Synzytiumbildung erneut an (=AIDS-Phase).

Die zentrale Frage der AIDS-Forschung ist es, warum nach einer symptomfreien, aber variablen klinischen „Latenzperiode“ von einigen Jahren der Krankheitsprozeß zu einem beliebigen Zeitpunkt einsetzt. Jede infektions- und impfbedingte Stimulation des Immunsystems aktiviert infizierte CD4Zellen und induziert dadurch Virusproduktion.

In der Latenzphase finden sich viele dendritische Zellen mit Virus-AK-Komplexen beladen in den Lymphknoten und der Milz; im AIDS-Stadium ist dann die Architektur des Gewebes zerstört, das Netzwerk der dendritischen Zellen und die Keimzentren fehlen. Die dadurch verursachte mangelhafte Antigenpräsentation mit dem IL-12-Mangel steuert ihren Teil zur Immundefizienz bei. Im Laufe der Jahre hat sich ergeben, daß dabei eine Vielzahl von Einzelprozessen verändert wird. So verschiebt sich die Relation der TH1- und TH2-Zellen zu Ungunsten des TH1-Anteils. Die verstärkte Sekretion von IL-4 und IL-10 durch TH2-Zellen beeinträchtigt auch die Zahl und die Funktion der TH1-Zellen, wodurch ein Mangel an IL-2 und IFN$\gamma$ resultiert. Andererseits steigt der Pegel von TNF$a$ im Blut an, der durch Apoptoseinduktion zytolytisch für infizierte Zellen wirken kann.

Bei Personen mit lang anhaltender Latenzphase überwiegen hingegen die TH1-Zellen und die von ihnen produzierten Zytokine (IL-2, IFN- $\gamma$ ).

ZTL (CD8-positiv) tragen nach den heutigen Vorstellungen die Hauptlast der Elimination der infizierten CD4-Zellen. Die Zerstörung von infizierten CD4-Zellen bewirkt einen Mangel an IL-2 und IFN- $\gamma$. Über lange, aber wechselnde Zeitspannen hinweg kann das Knochenmark trotzdem den Verlust von $5 \times 10^{9}$ HIV-produzierenden CD4-Zellen pro Tag aus dem Pool von $10^{11}$ latent infizierten Zellen ausgleichen, obwohl $10^{9}$ infektiöse RNSMoleküle pro Tag entstehen. Aus welchem Grund der Nachschub von CD4-Zellen letztendlich erlischt, ist unklar. Man vermutet u.a. einen zytoto- xischen Effekt des HIV für gewisse Zellpräkursoren.

CD8-Zellen wirken nicht nur als ZTL, vielmehr können Subpopulationen auch Stoffe abgeben, die die Virusreplikation verhindern. Auch Chemokine (RANTES, MIP 1- $\alpha$ und $-\beta$ u. a.) blockieren die Adsorption. Versagen aber diese virushemmenden Mechanismen, fallen zu viele CD4-Zellen aus und können kein IL-2 und IFN- $\gamma$ mehr abgeben, so versagt die ZTL-Abwehr schließlich ganz. Ein multikausaler Prozeß führt im Lauf der Zeit zum Versagen der Immunabwehr. So machen sich dann opportunistische Infektionen bemerkbar: Zuerst die Haarleukoplakie der Zunge und orale Candidiasis, dann Zoster, Tuberkulose und Zytomegalie. Auch tritt verstärkt Molluscum contagiosum auf und schließlich ulzerativer Herpes, das Kaposi-Sarkom sowie Zervix-Karzinome u.a.

Das Kaposi-Sarkom (s. S. 610) wird vorwiegend bei seropositiven Homosexuellen, selten bei HIVTransfundierten, aber nicht bei Hämophilen mit HIV-Infektion beobachtet. Offenbar wird die Zahl der Kaposi-Sarkome bei den Erstmanifestationen jetzt geringer ( $12,5 \%$ gegen $20 \%$ früher). Im Gegensatz hierzu steigt die Zahl der malignen Lymphome an (s. S. 610).

Ist die Krankheit genügend weit fortgeschritten, so setzt u.a. nahezu regelmäßig die immunsuppressorische Wirkung des exazerbierten Zytomegalie-Virus auf Vorläufer-Zellen des Knochenmarkes ein und verstärkt die allgemeine Immunschwäche.

\section{Klinik}

Der Verlauf der HIV-Infektion wird anhand der klinischen Stadieneinteilung der CDC/WHO von 1993 (Tabelle 10.1) bestimmt. Auch wurde die pulmonale Tuberkulose, das invasive Zervix-Karzinom und rezidivierende bakterielle Infektionen sowie das Vorliegen von weniger als 200 CD4-Lymphozyten/ $\mu$ l Blut als AIDS-definierende Krankheiten in die revidierte Stadieneinteilung der CDC aufgenommen (Tabelle 10.1).

Diese Stadieneinteilung berücksichtigt die klinischen Symptome mit den AIDS-definierenden Krankheiten sowie die immunologischen Veränderungen, die im Verlauf der HIV-Infektion auftreten.

Akute HIV-Infektion. (I, Abb. 10.5). Nach 3-12 Wochen kommt es zu einer Virämie und bei 20$30 \%$ der Betroffenen tritt ein Krankheitsbild auf, das klinisch der "Infektiösen Mononukleose“ des 
Tabelle 10.1. HIV: Klassifikation der HIV-Infektion und AIDS-Falldefinition für Erwachsene (1993) (MMWR (1997) 46:1-19)

\begin{tabular}{llll}
\hline & \multicolumn{2}{l}{ Klinik } \\
\cline { 2 - 4 } CD4+T-Zellen/ $\mu$ l & A & B & C \\
\hline (1) $>500$ & A1 & B1 & C1 \\
(2) $200-499$ & A2 & B2 & C2 \\
(3) $<200$ & A3 & B3 & C3 \\
\hline
\end{tabular}

A: asymptomatische HIV-Infektion; persistierende generalisierende Lymphadenopathie; akute, primäre HIV-Infektion

B: symptomatische HIV-Infektion ohne AIDS-definierende Krankheiten, jedoch solchen, die auf einen Defekt in der zellulären Abwehr inkl. HIV-Infektion schließen lassen oder durch eine HIV-Infektion erschwert werden

C: AIDS-definierende Krankheiten

AIDS-Fall: A3, B3, C1, C2 und C3

EBV ähnelt. Zusätzlich treten Diarrhoen, Exantheme, Muskelschmerzen und eine leichte Meningo-Enzephalitis auf. Statt der Lymphomonozytose sind bei der akuten HIV-Infektion die Gesamtleukozyten normal oder erniedrigt. Es kommt zu einem raschen Anstieg und einem raschen Abfall der HIV-RNS mit einer disseminierten Verteilung des HIV in das lymphatische Gewebe. HIV-spezifische Antikörper sind etwa ab der dritten Woche nach Infektion nachweisbar. Der Verlauf der akuten HIV-Infektion ist partiell selbstlimitierend.

Klinisch asymptomatische HIV-Infektion. (II, Abb. 10.5). Nach Infektion bzw. nach Abklingen der akuten HIV-Infektion folgt eine asymptomatische Phase, „Latenz“. Klinisch kann eine persistierende Lymphadenopathie auftreten. Es kommt dann zu einem langsamen Abfall der Zahl der CD4-Lymphozyten. Der zeitliche Verlauf des Fortschreitens bis zum Endstadium AIDS ist eng mit der Menge der HIV-RNS 6-12 Monate nach der Infektion korreliert (s. S. 602/603).

Der weitere Verlauf ist gekennzeichnet durch das Auftreten unspezifischer Symptome wie Abgeschlagenheit, ungeklärtes anhaltendes Fieber oder eine chronische Diarrhoe ohne Erregernachweis. Daneben kommt es zu Episoden von oralem Soor (C. albicans), der oralen Haarleukoplakie (EpsteinBarr-Virus) oder gehäuftem Auftreten bakterieller Infektionen durch z.B. Streptococcus pneumoniae oder Salmonella sp. Es kann zu Rezidiven der latenten Infektion wie dem Auftreten eines Herpes Zoster oder einer Lungentuberkulose kommen. Die Zahl der RNS-Moleküle steigt dabei langsam an (s.
Abb. 10.5). Insgesamt ist der „AIDS“-Fall (A3, B3, C1-3) unterschiedlich definiert.

AIDS. (III, Abb. 10.5). AIDS ist das Endstadium der HIV-Infektion. Es tritt nach einer Inkubationszeit von 1-14 Jahren auf und ist charakterisiert durch viele und generalisierte opportunistische Infektionen oder typische Tumoren wie das KaposiSarkom oder Morbus Hodgkin und Non-HodgkinLymphome u. a. (Tabelle 10.2).

Die absolute Zahl der CD4-Lymphozyten ist ein wichtiger Parameter zur Bestimmung des Ausmaßes der HIV-induzierten Immundefizienz. Sinkt die Zahl der CD4-Lymphozyten unter 200/ $\mu$ l Blut (Normalwert: $>1000 / \mu$ l Blut) muß mit dem Auftreten AIDS-definierender opportunistischer Infektionen gerechnet werden. Das Kaposi-Sarkom, die

Tabelle 10.2. HIV: AIDS-definierende Krankheiten (MMWR (1997) 46:1-19); „Marker"-Krankheiten

Viren (vor allem Herpesviren: Reaktivierung)
ZMV: Retinitis, Enzephalitis, Pneumonie, Kolitis
HSV: chronisches Herpes-Simplex-Ulkus (>1 Monat), Pneumonie,
$\quad$ Bronchitis, Ösophagitis
HHV8: Kaposi-Sarkom, Castleman-Syndrom
JC Virus: progressive multifokale Leukoenzephalopathie
HIV-bedingtes Wasting-Syndrom
HIV-Enzephalopathie
VZV-Zoster (generalisatus)
Protozoen
Cryptosporidium parvum: chronische Diarrhoe (>1 Monat)
Isospora belli: chronische Diarrhoe (>1 Monat)
Toxoplasma gondii: Enzephalitis
Pneumocystis carinii: Pneumonie
Bakterien
PPEM z. B. MAl: Mykobakteriose (disseminiert, extrapulmonal)
Mycobacterium tuberculosis: Tuberkulose
Sepsis durch Salmonellen, auch rekurrierend
Rekurrierende Pneumonie
Pilze
Candida: Ösophagitis, Pneumonie, Bronchitis
Histoplasma capsulatum: Histoplasmose (disseminiert, extrapulmo-
nal)
Crytococcus neoformans: Kryptokokkose (disseminiert, extrapulmo-
nal)
Coccidioidis immitis: Kokzidiomykose (disseminiert, extrapulmonal)
Tumoren
Non-Hodgkin-Lymphome (EBV-assoziiert), M. Hodgkin
Kaposi-Sarkom (HHV8 assoziiert s. 0.)
Invasives Zervix-Karzinom (HPV-assoziiert), Cond. acuminata

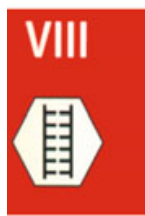


HIV-Enzephalopathie und auch das maligne NonHodgkin-Lymphom können sich auch bei höheren Zahlen der CD4-Lymphozyten manifestieren. Die Zahl der HIV-RNS-Moleküle ist der wichtigste Parameter für den Verlauf.

\section{Prognose}

Die Prognose der Kranken mit AIDS ist jetzt besser geworden, neue Substanzen (ABT378/Ritonavir) bewirken trotzt Resistenz des HIV eine Lebensverlängerung. Die Infektion muß z.T. als Geschlechtskrankheit angesehen werden; Verhütungsmaßnahmen müssen dies berücksichtigen. Zur Verhinderung einer weiteren Ausbreitung ist eine intensive Aufklärungsarbeit vonnöten (Drogenabhängige!). Eine soziale Ausgrenzung der Infizierten oder Erkrankten muß vermieden werden.

\section{Labordiagnose}

Die Ansteckungsfähigkeit beginnt schon kurze Zeit nach der Infektion. Die Virusisolierung aus Blut oder Lymphozyten sowie aus dem Liquor ist routinemäßig nicht möglich. Die ersten Antikörper lassen sich beim Menschen etwa 3 Wochen nach der Infektion nachweisen. Bereits vorher kann man die Virus-RNS und -DNS in den Lymphozyten feststellen. Im menschlichen Körper werden vorwiegend Antikörper gegen Hüllantigene (gp 120, gp 41), gegen Kapsid-Antigene und gegen die Polymerase gebildet. Es gibt Personen, die erst längere Zeit (mehrere Monate) nach der Infektion Antikörper bilden, ihre ZTL lassen sich aber bereits frühzeitig spezifisch stimulieren.

Die serologisch-virologische Diagnose erfolgt zunächst durch einen Antikörper-Screening-ELISA mit dem core- und env-Antigen. Dies gilt auch für die Untersuchung von Blutspendern. Jeder Verdachtsfall wird dann durch einen „Bestätigungstest" mit mindestens zwei Banden abgeklärt (Westernblotting), ggf. auch IFT. Die Screening-Tests der 3. Generation sind sehr spezifisch und empfindlich, sie erfassen alle Subtypen, eine Wiederholung ist an einem 2. Serum erforderlich, um Versehen auszuschließen.

Die serologische Diagnostik wird später nicht wiederholt, vielmehr wird alle 3-5 Monate die Zahl der HIV-RNS-Moleküle im Plasma bestimmt und daraus die Wirksamkeit der Therapie geprüft.

Zur Diagnose der Infektion beim Säugling wird die RT-PCR eingesetzt, da selten Antikörper auftreten.

\section{Diagnose der HIV-Infektion}

- Screening auf HIV (ELISA)

- Bestätigungstest (IFT, Westernblot)

- Bestimmung der Viruslast (RT-PCR)

- Therapie (Resistenzbestimmung)

- Alle 3-5 Monate Kontrolle der Viruslast.

\section{Therapie (z.B.)}

Die alleinige Therapie mit AZT (Nukleosid-Reverse-Transkriptase-Inhibitor, NRTI) hat keine Verlängerung der Überlebenszeit erbracht. Erst die Kombination von z.B. AZT mit Nevirapin (Nonnukleosid-Hemmstoff, NNRTI) und einem Protease-Inhibitor (PI) hat deutliche Fortschritte gebracht: HAART („highly active antiretroviral therapy").

\section{Therapie}

- Dreifach: $\mathrm{NRTI}_{1}+\mathrm{NRTI}_{2}+\mathrm{PI}$

- Vierfach: $\mathrm{NRTI}_{1}+\mathrm{NRTI}_{2}+\mathrm{NNRTI}$ $\mathrm{NRTI}_{1}+\mathrm{NRTI}_{2}+\mathrm{NNRTI}+\mathrm{PI}$

Man unterscheidet eine Initialtherapie von Umstellungsoptionen, die sich je nach Resistenz, Verträglichkeit, Überschneiden von Nebenwirkungen und Liquorgängigkeit unterscheiden. Zur Auswahl stehen zur Verfügung: 5 PI's, 3 NNRTI's und 6 NRTI's.

Die Therapie wird jetzt möglichst frühzeitig nach der Infektion mit einer 3- oder 4fach-Kombination begonnen und die Zahl der RNS-Moleküle mit der PCR alle 3-5 Monate bestimmt. Da auch bei dieser Vorgehensweise inhibitorresistente $\mathrm{Mu}$ tanten auftreten, ist es angezeigt, in den gleichen Zeitabständen Resistenzteste durchzuführen. Sollte das HIV gegen eine Substanz resistent sein, kann die Substanz durch eine geeignete andere ersetzt werden, um volle Empfindlichkeit zu gewährleisten. Ist die Viruslast unter die Nachweisgrenze gesunken, steigt die Zahl der CD4-Zellen.

Die Behandlung von schwangeren Frauen mit AZT hat eine Reduktion der Zahl der infizierten Babys von HIV-positiven Müttern um $60 \%$ erbracht. Die Kombination von AZT und 3TC sowie frühzeitiger Kaiserschnitt haben die Übertragungshäufigkeit auf unter $2 \%$ (von etwa 30\%) gesenkt. Indinavir wirkt toxisch. S. a. www.rki.de/GESUND/GESUND.HTM

\section{Prävention}

Unbedingt muß darauf geachtet werden, daß im klinischen Alltag bei Blutentnahmen Einmalgeräte etc. benutzt werden. Auf den Gebrauch von Gummi- 
handschuhen ist strengstens $\mathrm{zu}$ achten. Beim Stechen mit Kanülen durch nicht erlaubtes „recapping" erfolgt in 1 von 300 Fällen Übertragung. Dann innerhalb von $30 \mathrm{~min}$ antiretrovirale Therapie (auch bei Schnittverletzungen). WEB-Seite: www.RKI.de.

Impfstoffe. Es sind noch keine Impfstoffe in Sicht. Die Schwierigkeiten liegen darin, daß mehrere HIV-Typen, Subtypen und Varianten vorkommen; außerdem gibt es Quasispezies. Bei ein und demsel- ben Patienten lassen sich gleichzeitig Viren isolieren, die serologisch verschiedenartig sind.

Schutzimpfungen bei Seropositiven. Lebendimpfstoffe und Totimpfstoffe aktivieren Lymphozyten! Trotzdem sollte auf notwendige Impfungen nicht verzichtet werden.

Meldepflicht. Anonyme Meldepflicht für bestätigten Verdacht, Erkrankung und Tod an das RobertKoch-Institut (RKI). Erregernachweis.

\section{ZUSAMMENFASSUNG: HIV1 und 2}

Virus. Lenti-Viren, zwei Typen mit Subtypen, zwei Moleküle (+)-Strang-RNS mit Reverser Transkriptase in konischem Kapsid, umgeben von Zweitkapsid und Hülle mit Spikes. p 17, 25,40 und gp 41,120 . Strukturgene, Funktionsgene und Regulatorgene. Integration der Nukleinsäure ist Voraussetzung für Replikation. Auftreten von Quasispezies.

Vorkommen. HIV1 in Zentralafrika, USA, Karibik und weltweit. HIV2 vorwiegend in Westafrika. Nur beim Menschen. Bei Affen nahe verwandte Viren als Reservoir und Ursprung des menschlichen Virus.

Übertragung. Durch homo- und heterosexuellen Verkehr, i.v. Drogenmißbrauch, Prostitution, infolge Infektion mit virushaltigen Faktor-VIII-Präparaten, intrauterine und konnatale Infektion, Verletzungen etc. bei ärztlichem Personal. Cave: Intensivstationen, Blutproben, ärztliche Geräte, Blut und Blutprodukte, Samen, Speichel und Körpersekrete. Eintrittspforten sind kleine Hautverletzungen, Wunden; die Übertragung erfolgt auch durch Injektionen, Bluttransfusionen.

Epidemiologie. Das Virus ist weltweit verbreitet, man schätzt 30-40 Mio Infizierte. Risikogruppen: Homosexuelle, i.v. Drogenabhängige, Prostituierte und Hämophile.

Pathogenese. Adsorption des Virus an CD4und Chemokin-Rezeptor-positive Zellen, Integration, durch Aktivierung der Lymphozyten erfolgt Virusreplikation. Defekte Replikation,
Virus-Mutanten, langsame Replikation. Zellfusion bei der produktiven Replikation. Zerstörung von T-Helferzellen. Makrophagen mit langsamer Replikation verbreiten das Virus, Ansiedlung in Glia-Zellen im ZNS. Durch Ausschaltung des Immunsystems opportunistische Infektionen (Viren und Bakterien), Pilze, Protozoen.

Klinik. Drei Stadien: I. „Infektiöse Mononukleose", II. Latenz mit Lymphadenopathie sowie Absinken von CD4-Zellen und III. AIDS mit opportunistischen Infektionen. KaposiSarkome. "Marker-Infektionen" (s. S. 608 ff.).

Immunität. Bildung von Antikörpern erst $a b$ 6-12 Wochen, später starke Immunsuppression durch CD4-Zellbefall.

Diagnose. Screening-ELISA, IFT, Westernblot, quantitativer Nachweis von HIV-RNS durch die PCR. CD4/CD8 $\leqslant 1$; kritischer Wert $<200$ CD4 ${ }^{+}$-Zellen/ $/$l.

Therapie. Symptomatisch, Therapie opportunistischer Infektionen. NRTI, Nonnukleosid- sowie Protease-Inhibitoren versprechen Lebensverlängerung: HAART. Kontrolle der Zahl der RNS-Moleküle durch RT-PCR. Resistenzteste.

Prävention. Verhütung der Übertragung des HIV beim Geschlechtsverkehr, Verringerung der Drogenabhängigkeit, Screening von Blutkonserven, Reinigung ärztlicher Geräte, Verwendung von Einmalspritzen etc.

Meldepflicht. Bestätigter Verdacht, Erkrankung, Tod an das Robert Koch-Institut. 


\subsection{AIDS-definierende Infektionen durch opportunistische und obligat pathogene Erreger}

Das klinische Vollbild AIDS ist durch die auftretenden Infektionen und ihre Folgen bestimmt. Die frühzeitige Diagnostik, Therapie und Prävention dieser Infektionen hat entscheidend zur Lebensverlängerung bei Patienten mit AIDS beigetragen. Weitere Angaben über Epidemiologie, Übertragung, Pathogenese sowie Diagnose, Therapie und Prophylaxe finden sich in den jeweiligen Kapiteln.

Bei der Mehrzahl der opportunistischen Infektionen im Rahmen von AIDS handelt es sich um die Exazerbation persistierender oder latenter Infektionen, die normalerweise durch das zelluläre Immunsystem kontrolliert werden, bis dieses zusammenbricht. Die wichtigsten AIDS-assoziierten Krankheitsbilder sind in Tabelle 10.3 zusammengefaßt.

Außer den opportunistischen Erregern können auch bestimmte obligat pathogene Erreger, v.a. Mycobacterium tuberculosis und Salmonellen, bei HIV-seropositiven Patienten schwere Erkrankungen verursachen. Typisch sind rasch progrediente und häufiger disseminierte Infektionsverläufe. Es kommt zu ungewöhnlichen Verläufen, etwa der
Landouzy-Sepsis durch M. tuberculosis oder durch Salmonella typhimurium.

Beim HIV-seropositiven Patienten kann es in jedem Organsystem zu unspezifischen Symptomen kommen. Ursache dafür sind meist opportunistische Infektionen. Das HIV ist auch Ursache für eigenständige Krankheitsbilder wie die HIV-Enzephalopathie oder das Wasting-Syndrom.

In der Tabelle 10.4 sind häufige Erreger HIV-assoziierter Infektionen zusammengestellt. Die bakteriologischen und parasitären Erkrankungen finden sich in den entsprechenden Kapiteln. Im folgenden werden die Besonderheiten von Viruserkrankungen und Tumorbildungen abgehandelt.

\section{Zytomegalie}

Klinik. Die häufigste Erkrankung ist die nekrotisierende ZMV-Chorioretinitis (Abb. S. 689). Die ZMV-Pneumonie stellt sich als interstitielle Pneumonie dar und führt unbehandelt schnell zum Tod. Die gastrointestinale Manifestation einer ZMV-Erkrankung äußert sich im Ösophagus und Magen mit starken retrosternalen Schmerzen und im Kolon mit persistierenden Durchfällen.

Im Spätstadium von AIDS ( $<50 \mathrm{CD} 4 / \mu \mathrm{l})$ kommt es bei vielen Patienten $\mathrm{zu}$ einem Befall vieler Organe mit ZMV generalisata.

Tabelle 10.3. HIV-assoziierte Krankheitsbilder und ihre Symptome nach Organsystemen

\begin{tabular}{|c|c|c|}
\hline Organsystem & Symptome & Krankheitsbild/Erreger \\
\hline \multirow[t]{3}{*}{ ZNS } & Krampfanfall & ZNS-Toxoplasmose, primäres ZNS-BZL, progressive multifokale Leukenzephalopathie \\
\hline & Wesensveränderung & ZNS-Toxoplasmose, Kryptokokkenmeningitis, PML \\
\hline & Demenz & HIV-Enzephalopathie, periphere Neuropathie, PML \\
\hline Lunge & Pneumonie & $\begin{array}{l}\text { Pneumocystis-carinii-Pneumonie, Lungentuberkulose, bakterielle Pneumonie, Pilz- } \\
\text { Pneumonie, Kaposi-Sarkom }\end{array}$ \\
\hline \multirow[t]{4}{*}{ Gastrointestinal-Trakt } & Mundschleimhaut-Läsionen & Soor, ZMV, HSV, orale Haarleukoplakie, BZL, Kaposi-Sarkom \\
\hline & Diarrhoe & $\begin{array}{l}\text { Salmonellen, Shigellen, Kryptosporidien, Mykobakterien, Amöben, Clostridien, Cam- } \\
\text { pylobacter, ZMV, HIV, BZL, Kaposi-Sarkom }\end{array}$ \\
\hline & Oberbauchschmerz & Kryptosporidiose der Gallenwege, Pankreatitis (ZMV, Medikamente) \\
\hline & Schluckbeschwerden & Soor-Ösophagitis, ZMV-Ösophagitis \\
\hline Haut & Exantheme, Bläschen, Ulzera & Kaposi-Sarkom, HSV, VZV, Medikamenten-Allergie \\
\hline Knochenmark & Leuko-Thrombopenie & $\begin{array}{l}\text { Mykobakterien, BZL-Infiltration des Knochenmarkes, Medikamente (Zidovudin, } \\
\text { Cotrimoxazol, Pyrimethamin, Interferon, Ganciclovir) }\end{array}$ \\
\hline Immunologie & & Hypersensitivität auf Medikamente \\
\hline Gelenke & Arthralgien & HIV-Arthropathie \\
\hline Augen & Sehverschlechterung & ZMV-Retinitis, ZNS- oder Retina-Toxoplasmose, ZNS-BZL. \\
\hline \multirow[t]{2}{*}{ systemisch } & Fieber & Pneumocystis-carinii-Pneumonie, Tuberkulose, MAC \\
\hline & Gewichtsabnahme & infektiöse Enteritis, HIV-Wasting \\
\hline
\end{tabular}


Tabelle 10.4. Häufige Erreger AIDS-assoziierter Infektionen

\begin{tabular}{ll}
\hline Bakterien & \\
PPUM (Umwelt-Mykobakterien) & s.S. 377 \\
Mycobacterium tuberculosis & s.S. 377 \\
Salmonellen & s.S. 265 \\
Viren (vor allem Herpesviren: Reaktivierung) & \\
ZMV & \\
HSV & s.S. 641 \\
VZV & s.S. 630 \\
EBV & s.S. 637 \\
JC-Virus & s.S. 646 \\
Pilze & s.S. 622 \\
Candida & \\
Histoplasma capsulatum & \\
Cryptococcus neoformans & s.S. 701 \\
Coccidioides immitis & s.S. 726 \\
Protozoen & s.S. 706 \\
Cryptosporidium parvum & s.S. 731 \\
Isospora belli & \\
Toxoplasma gondii & \\
Pneumocystis carinii & s.S. 778 \\
\hline & s.S. 780 \\
\hline & s.S. 784 \\
& s.S. 733 \\
\hline
\end{tabular}

\section{Herpes-simplex-Virus-Infektionen}

Klinik. Die häufigste Manifestation einer Erkrankung durch das HSV sind ausgedehnte Schleimhautläsionen, die sehr schmerzhaft sein können. Bei Patienten mit ausgeprägtem Immundefekt können sich aus den kleinen Läsionen ständig vergrößernde, mukokutane Ulzera entwickeln, die bis in die Subkutis reichen, der sog. nekrotisierende Herpes. Befallen sind außerdem die Genital-/Analregionen. Auch kennt man schwere HSV-Pneumonien (Abb., s. S. 688).

\section{Varizellen-Zoster-Virus-Infektionen}

Klinik. Bei Patienten mit schwerem Immundefekt können mehrere Hautsegmente befallen sein (Zoster multiplex). Auch ein Zoster generalisatus wird gelegentlich beobachtet. Eine schwere Erkrankung durch das VZV sind Pneumonie und Enzephalitis (s. S. 639).

Ein Zoster bei Patienten unter 30 Jahren sollte Anlaß zur HIV-Testung sein.

\section{Orale Haarleukoplakie}

Klinik. Am Rand der Zunge lassen sich dichte, weiBe, nicht abwischbare Beläge feststellen. Differentialdiagnostisch ist der Soor zu beachten (S. 648).

\section{HIV-Enzephalopathie}

Epidemiologie. Bei 5\% der Patienten manifestiert sich das Stadium AIDS mit einer HIV-Enzephalopathie. $30 \%$ der Patienten, die länger als 18 Monate das Stadium AIDS überleben, haben Zeichen einer HIV-Enzephalopathie.

Pathogenese. Die Infektion des ZNS durch HIV erfolgt bereits während der initialen „Mononukleose" durch an eine bestimmte MakrophagenFraktion gebundenes HIV. Infiziert wird zuerst die Mikroglia, in der inkomplette Zyklen ohne integrierte DNS beobachtet wurden. Freigesetzte Lymphokine (TNF- $a$, IFN- $\gamma$ ) induzieren auf der Mikroglia (und Neuronen?) MHC-I- und -II-Antigene und machen diese für das HIV suszeptibel; zytopathische und zelltoxische Effekte (gp 120, TNF- $a$, IL-1 $\beta$ ) schädigen die Makroglia bzw. die Neuronen. Die ausgeprägte Demenz ist pathohistologisch durch Riesenzellen der Mikroglia gekennzeichnet. Astrozyten und Mikroglia sind vermehrt, im Hirnstamm finden sich Gliazellknötchen. Die AIDS-bedingte PML (s. S. 623) infolge einer Reaktivierung des JC-Virus läßt sich durch die PCR im Liquor nachweisen (s. S. 623).

Klinik. Die HIV-Enzephalopathie beginnt häufig bereits bei HIV-seropositiven Patienten ohne nennenswerten Immundefekt. Die ersten Symptome sind Leistungsminderung, Beeinträchtigung des Gedächtnisses sowie Konzentrationsstörungen. Da$\mathrm{zu}$ kommen Störungen der Motorik, bevorzugt mit Schwierigkeiten bei schnellen Bewegungen. Es entwickelt sich im weiteren eine langsam progrediente Demenz mit Abfall der intellektuellen und sozialen Fähigkeiten. Neuropathie mit Kribbeln, Zuckungen u. a.

Diagnose. Im EEG sieht man eine Verlangsamung der elektrischen Hirnaktivität. CT und Kernspintomographie zeigen eine äußere und innere Hirnatrophie, die im Verlauf zunimmt. Der typische Liquorbefund ist eine Vermehrung der Gesamtproteine bei normaler oder nur leicht erhöhter Zellzahl. Es lassen sich autochthone Antikörper gegen HIV nachweisen. Differentialdiagnose: PML (s. S. 526).

Therapie. Nach einer Therapie mit NRTI und NNRTI sowie Proteaseinhibitoren bessert sich die Symptomatik. Die Therapie ist sonst symptomatisch orientiert. Eine wirksame HIV-Therapie mit Anstieg der CD4-Zellen hat eine Besserung der ZNS-Symptomatik und der Neuropathie zur Folge. 
Wasting-Syndrom

(AIDS-Kachexie-Syndrom, Slim-disease)

Epidemiologie. Das Wasting-Syndrom kommt als AIDS-Manifestation etwa gleich häufig wie die HIV-Enzephalopathie in Afrika vor. In Europa ist es jetzt infolge HAART selten geworden (hochaktive anti-Retrovirus-Therapie).

Pathogenese. Als Ursache für den progredienten Gewichtsverlust wird eine ungenügende enterale Resorption von Nährstoffen diskutiert.

Klinik. Die meisten Patienten mit Wasting-Syndrom leiden unter immer wiederkehrenden Durchfallepisoden. Es lassen sich keine Erreger nachweisen. Die Patienten haben einen progredienten Gewichtsverlust, der bis zu einer ausgeprägten Kachexie führen kann. Der Gang der Patienten ist langsam und schleppend, die Haltung gebückt, die Patienten wirken vorgealtert, die Haut ist trocken, das Haar schütter.

Diagnose. Die Diagnose ergibt sich aufgrund des klinischen Bildes und der Gesamtkonstellation. Patienten mit Wasting-Syndrom haben eine weit fortgeschrittene HIV-Infektion mit sehr niedrigen CD4-Lymphozytenwerten $(<100 / \mu l)$.

Therapie. Die Therapie besteht in hochkalorischer Ernährung sowie Substitution von Vitaminen und Spurenelementen. Da die Resorption gestört ist, empfiehlt sich parenterale Ernährung. Bei einigen Patienten bessert sich das Krankheitsbild unter Steroid-Behandlung oder Behandlung mit Anabolika.

\section{Kaposi-Sarkom (KS)}

Klinik. Das KS beginnt meist an der Haut, seltener an der Mundschleimhaut oder in Lymphknoten. Die Flecken können zu Beginn mit anderen Effloreszenzen verwechselt werden. Sie sind klein, rötlich-livide, länglich nach den Spaltlinien der Haut angeordnet. Sie können einzeln oder von Anfang an disseminiert auftreten. Nicht selten ulzeriert das KS.

Bei Befall des Lymphsystems kann es zu ausgeprägten peripheren Ödemen kommen. Alle Organe mit Ausnahme des ZNS können befallen sein. Die klinischen Symptome sind Atemnot bei Lungen$\mathrm{KS}$, gastrointestinale Blutungen und gelegentlich Ileussymptomatik beim intestinalen KS (HHV8; S. 654).

\section{B-Zell-Lymphome (BZL)}

Epidemiologie. In Europa manifestierten sich bei AIDS etwa $5(-20) \%$ BZL. Sie sind mono- oder polyklonal und man unterscheidet 4 Formen, etwa $50 \%$ sind EBV-positiv.

Klinik. Die BZL können sich im Abdomen, in den Lymphknoten, im ZNS und als „Burkitt-Lymphom" manifestieren. Schmerzen, Inappetenz und Zeichen eines Ileus können bei gastrointestinalen BZL im Vordergrund stehen. Auf ein primäres BZL des Zentralnervensystems weisen je nach Lokalisation sehr unterschiedliche Symptome wie Antriebsstörungen, Krampfanfälle, Gangstörungen und Lähmungserscheinungen hin. Auch verdächtige Hautläsionen sollten bioptisch abgeklärt werden. Nicht selten zeigen sich zunächst nur Allgemeinsymptome wie Fieber, Nachtschweiß, progredienter Gewichtsverlust und Anämie. Grundsätzlich sollte bei jeder Lymphknotenvergrößerung auch an ein BZL gedacht werden.

Diagnostik. Beweisend ist der histopathologische Nachweis aus verdächtigem Gewebe. Bei Verdacht auf ein gastrointestinales oder zerebrales BZL sollte eine Endoskopie mit Biopsie verdächtiger Herde bzw. ein CT des Schädels die Diagnose sichern. Lymphknotenvergrößerung im CT von Thorax und Abdomen sowie BZL-Infiltration in der Beckenkammbiopsie ergeben das Stadium des BZL.

Die Zahl der CD4-Lymphozyten kann normal oder erniedrigt sein; in der Mehrzahl der Fälle ist sie $<250 / \mu$ l.

Therapie. Unter der Behandlung mit Chemotherapeutika (z.B. CHOP-Schema), ggf. mit reduzierter Dosis oder Einsatz von hämatologischen Wachstumsfaktoren (G-CSF) ist auch bei vielen AIDS-Patienten mit einer Remission zu rechnen.

Bei primärem ZNS-Lymphom kommt eine Bestrahlungsbehandlung in Frage.

\section{Zervix-Karzinom}

Epidemiologie. 60\% der HIV-infizierten Frauen haben einen dysplastischen Zervix-Abstrich. Die Inzidenz des invasiven Zervix-Karzinoms beträgt $5-10 \%$, ist aber steigend.

Diagnostik. Die Diagnose einer zervikalen Dysplasie oder eines Zervix-Karzinoms wird durch den Abstrich nach Papanicolaou sowie den HPVDNS-Nachweis gestellt. Dieser sollte bei allen HIV- 
infizierten Frauen alle 6 Monate durchgeführt werden. Verdächtige Befunde sollten durch eine Kolposkopie kontrolliert werden.

Therapie. Die Therapie besteht wie bei den nicht HIV-infizierten Frauen primär in der chirurgischen Exzision, evtl. gefolgt von Radio- oder Chemotherapie.

\subsection{Human-T-Zell-Leukämie- Virus1 (HTLV1)}

In Japan wurde 1980 bei Erwachsenen mit aggressiven, fatalen TZell-Leukämien erstmals ein menschenpathogenes Retro-Virus isoliert. In den USA wurde dann ein nahe verwandtes Virus festgestellt.

Man bezeichnete das Virus als HTLV1 (Humanes T-Zell-Leukämie-Virus). Kurze Zeit danach isolierte man ein Virus aus Haarzelleukämien, welches HTLV2 benannt wurde.

HTLV1 und 2 waren damit die ersten beim Menschen nachgewiesenen Retro-Viren. Sie heften sich an das CD4-Molekül der THelferzellen. Das Virus erzeugt beim Menschen Lymphome und Leukämien; es wirkt immunsuppressiv.

\subsubsection{Beschreibung}

\section{Genom}

Das (+)-Einzelstrang-RNS-Genom $(8,0-8,8 \mathrm{~kb})$ des Virus besitzt außer den typischen Retro-Virus-Genen ein Zell-immortalisierendes Gen, das sog. taxGen, das bezüglich seiner Wirkung neuartig ist. Die Besonderheit des Virusgenoms besteht darin, daß es an beliebiger Stelle in das Wirtszellgenom integriert werden kann; von dort aus wirkt das tax-Gen über sein Genprodukt „trans"-aktivierend (s. Abb. 10.2, S. 598) auf das am 5'-Ende des Genoms gelegene LTR-Element ein und verstärkt damit die Replikation des Virus. Ein weiteres, als „rex" bezeichnetes Regulatorgen, wirkt ähnlich wie das rev-Gen beim HIV.

\section{Morphologie}

Das Virus besteht aus einem helikalen Erst- und einem Ikosaeder-Zweitkapsid (s. S. 599) innerhalb der Hülle.

\section{Züchtung und Replikation}

Die Isolierung erfolgte durch Kokultivierung der Lymphozyten mit virusfreien Nabelschnur-Lymphozyten in Gegenwart von IL-2 und Mitogenen. Hauptziel sind CD4-Zellen, die immortalisiert werden. Die Montage des HTLV1 erfolgt ausschließlich an der Zellmembran durch Knospung („budding“).

\subsubsection{Rolle als Krankheitserreger}

\section{Epidemiologie}

Die T-Zell-Leukämie der Erwachsenen kommt hauptsächlich in Japan, Afrika, in der Karibik und den USA sowie in Melanesien vor; aber auch in Europa wird diese Krankheit jetzt häufiger beobachtet, v. a. bei Drogenabhängigen. In Deutschland sind etwa $0,02 \%$ der Blutspender seropositiv (s. Tabelle 7.14, S. 528). Alle erwachsenen Leukämiepatienten in Japan sind seropositiv für HTLV1. In Japan gibt es regionale Häufungen; dort sind die Familienangehörigen der Kranken bis zu 40\% seropositiv. In Endemie-Gebieten sind etwa 1-5\% der Bevölkerung als Antikörperträger anzusehen, während in anderen Gegenden seropcsitive Individuen selten sind. Von 2000 Seropositiven erkrankt einer an Leukämie, die übrigen sind also inapparent infiziert. Es wird geschätzt, daß von den 15-25 Mio weltweit Infizierten $1-5 \%$ eine Leukämie entwickeln.

\section{Übertragung}

Das Virus wird wahrscheinlich durch Intimkontakt von Männern auf Frauen und seltener umgekehrt ausschließlich zellgebunden übertragen. Mütter geben es mit den T-Zellen der Muttermilch an Kinder weiter, vielleicht wird es auch transplazentar übertragen. 1/2 Jahr nach der Geburt steigt die Durchseuchung. Bei der Häufigkeit der heute vorgenommenen Bluttransfusionen sind diese sehr wahrscheinlich eine weitere Infektionsquelle. Insgesamt ist der Infektionsweg stets horizontal.

Man vermutet, daß das HTLV aus Afrika, wo es vermutlich von Affen auf den Menschen übertragen wurde, durch den Sklavenhandel in die Karibik, nach Südamerika und die USA verschleppt wurde. Es gibt ferner Hinweise, daß HTLV1 mehrfach von Affenspezies auf den Menschen übertragen wurde: Die sechs Hauptverbreitungsgebiete

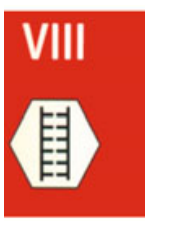


decken sich mit den sechs Subtypen des HTLV1. Bei afrikanischen und asiatischen Makaken sowie Schimpansen hat man Verwandte des HTLV1 entdeckt, sog. S(imian)TLV1-Viren.

\section{Pathogenese}

Das tax-Gen-Produkt (s. S. 598) wirkt immortalisierend auf die T-Zellen ein, u.z. wirkt es als Initiator, es kontrolliert den Zellzyklus und soll mutativ wirken. In tax-transgenen Mäusen entstehen Leukämien. Angesichts der langen Inkubationsperiode ist es wahrscheinlich, daß zur Leukämieentstehung weitere Faktoren hinzutreten müssen. Die Entstehung der Leukämie verläuft klinisch in mehreren Stadien:

- Präleukämisches Stadium (nur Provirus);

- „Smoldering“, beginnende Leukämie (Lymphome, aber normale Leukozytenzahl);

- Chronische, manifeste Leukämie (Haut-Lymphome und Leukozytenanstieg);

- Akute Leukämie (Lymphome generalisiert, Leukozyten sehr hoch).

Die ersten beiden Stadien, die in $50 \%$ zurückgehen, sollen polyklonal, die späten Stadien monoklonal sein; die Zellen werden wegen des Aussehens der Kerne als „Flower-cells“ bezeichnet.

Alle Tumorzellinien enthalten das gesamte Virusgenom. Die DNS läßt sich auch in Lymphozyten von Seropositiven nachweisen, freies Virus im Blut gibt es jedoch nicht. Keine Quasispeziesbildung! Das HTLV1-Provirus ist auch in seronegativen Blutspendern gefunden worden.

Die Immortalisierung der T-Zellen wird von einer gesteigerten Expression z. B. der Gene des IL-2 und seines Rezeptors begleitet, die durch das TaxProtein ausgelöst wird. Die Malignisierung erfolgt dann infolge stufenweise auftretender Genomveränderungen mit Selektion von hochmalignen Zellvarianten. Alle Tumorzellen eines Individuums enthalten das Virusgenom an der gleichen Integrationsstelle. Diese Stelle variiert aber bei jedem der befallenen Individuen. Die Tumorzellen eines Kranken sind somit monoklonal. Die Zellinien tragen meist den CD4-Marker, nur wenige sind CD8positiv, sehr selten sind es B-Zellen. Außer den Lymphozyten werden auch Endothelzellen und Fibroblasten befallen. Die immunbiologische Funktion der befallenen Zellen (Helfer-Zellen) ist gestört; insgesamt gesehen ist die schädigende Wirkung dieses Virus im Vergleich mit dem HIV gegenüber dem Immunsystem gering. Die Hauptproteine, ge- gen die der Mensch Antikörper bildet, sind das p 24 (Kapsid) und das gp 42 (Hüllprotein).

\section{Klinik}

Man schätzt die Inkubationsperiode nach einer Infektion mit HTLV1 auf 10-20 Jahre. Die T-ZellLeukämie kommt in vier Krankheitsformen vor:

- T-Zell-Leukämie i.e.S. des Erwachsenen (ATL);

- Lymphosarkom mit begleitender T-Zell-Leukämie;

- Kutane Form der T-Zell-Lymphome;

- Auch die Mycosis fungoides sowie das SézarySyndrom werden vermutlich durch das HTLV hervorgerufen, ebenso Arthropathien.

- Es gibt auch Entzündungsprozesse (Alveolitis, Polymyositis, infektiöse Dermatitis u.a.) als Folge der immunsuppressiven Wirkung der HTLVInfektionen.

Man vermutet, daß die in Afrika, in der Karibik und in Indien vorkommende tropische spastische Paraparese mit Entmarkungen ebenfalls auf die Infektion mit dem HTLV1 zurückzuführen ist. Bei ihr entstehen viele $Z T L$, die jedoch bei der ATL fehlen; man vermutet deswegen eine Immunpathogenese. In Japan kennt man eine HTLV-assoziierte Myelopathie (HAM) mit Uveitis. Im Verlaufe der Tumorentstehung erfolgt eine polyklonale B-Zellstimulation; außerdem machen sich opportunistische Infektionen bemerkbar. Die Diagnose und das Blutprobenscreening erfolgt durch ELISA, Westernblot und RT-PCR. Durch Verhinderung der sexuellen Übertragung läßt sich die Zahl der Infizierten reduzieren.

Therapie. Wirksam sind nicht Inhibitoren der reversen Transkriptase, aber monoklonale Antikörper gegen den IL-2-Rezeptor.

\subsection{HTLV2}

In den USA beobachtet man eine andere Form der Leukämien: Die sog. Haarzell-Leukämie; sie trägt ihren Namen nach der Form der Lymphozyten mit langen, haarartigen Ausläufern. 2000 Fälle werden dort pro Jahr festgestellt. IFN- $a$ ist als Therapeutikum von der FDA zugelassen. Als Erreger der Leukämie gilt das HTLV2. Es tritt vorwiegend bei Indianern und Pygmäen auf (Prävalenz 3-20\%). Die Übertragung erfolgt wie bei HTLV1. Mit 1$18 \%$ wird es bei Drogenabhängigen beobachtet. 


\section{ZUSAMMENFASSUNG: HTLV1/2}

Virus. Retro-Virus (s. HIV), zwei Typen, transaktivierendes tax-Gen.

Vorkommen. HTLV1 in Japan, Neuguinea, Afrika und Westindien, sporadisch weltweit. Bei i.v. Drogenabhängigen: HTLV2: USA.

Übertragung. Intimkontakte, Muttermilch, Bluttransfusionen. Vektoren?

Epidemiologie. Erwachsene mit T-Zell-Leukämie haben Antikörper, Familienangehörige dann bis $40 \%$, sonst $\ll 1 \%$.

Pathogenese. Immortalisierung der Lymphozyten durch tax-Genprodukte, monoklonaler Tumor durch stufenweise auftretende Chro- mosomenabnormalitäten. Kein freies HTLV1 im Blut, nur zellgebunden.

Klinik. 10-20jährige Inkubation; HTLV1: TZell-Leukämie des Erwachsenen, die in vier Stadien entsteht. HTLV2: „Haarzell-Leukämie“.

Immunität. HTLV wirkt immunsuppressiv.

Diagnose. Klinisch, pathohistologisch, ELISA, Westernblot, ggf. PCR in Blutzellen.

Therapie. Bei HTLV2: Interferon.

Prävention. Ausschaltung von positiven Blutspendeproben und Vermeidung der sexuellen Übertragung. 


\title{
11 Parvo-Viren: Parvo-Virus B19
}

\author{
D. FALKE
}

\section{EINLEITUNG}

Infektionen mit dem Parvo-Virus B19 (Genus Erythro-Virus) verursachen beim Menschen die Ringelröteln; bei Infektionen in utero können sie Hydrops fetalis und Abort auslösen. Persistierende Infektionen sind die Ursache von Arthritis, Arthropathie und aplastischer Anämie. Die pathogene Wirkung wurde 1983 durch intranasale Infektion von seronegativen gesunden Normalpersonen bewiesen.

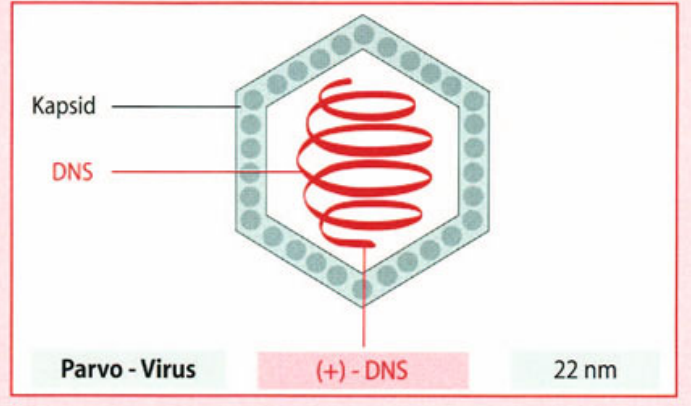

\subsubsection{Beschreibung}

Genom. Das Parvo-Virus B19 ist ein kleines DNShaltiges Virus. Die lineare Einzelstrang-DNS enthält 5,6 kb. Der Informationsgehalt der Virus-DNS ist so gering, daß das Virus für seine Replikation im Kern der Zelle gewisse Funktionen der Wirtszelle während der S-Phase der Zelle in Anspruch nehmen muß. Man kennt sechs Genotypen.

Morphologie. Das Virus besitzt einen Durchmesser von $22 \mathrm{~nm}$, die Ikosaeder-Kapside bestehen aus zwei Proteinen (VP1 und 2).

Resistenz gegen äußere Einflüsse. Das ParvoVirus B19 ist ätherresistent und in der Außenwelt sehr stabil; es überlebt $60 \mathrm{~min}$ bei $56^{\circ} \mathrm{C}$, läßt sich jedoch durch Formalin und $\beta$-Propiolacton inaktivieren. Es ist $\mathrm{pH}$-stabil von 3-9.

\subsubsection{Rolle als Krankheitserreger}

\section{Vorkommen}

Das Parvo-Virus B19 kommt nur beim Menschen vor; ein ähnliches Virus erzeugt bei Rhesusaffen identische Symptome.

\section{Epidemiologie}

Eine saisonale Häufung ist alle 3-5 Jahre im Frühjahr zu verzeichnen, dann nämlich, wenn eine genügend große Anzahl empfänglicher Kinder (4-10 Jahre alt) herangewachsen ist. Parvo-Viren erreichen in der Weltbevölkerung eine Durchseuchung von $50-90 \%$. In Familien, Kindergärten, Kinderheimen und Schulen erfolgt die Ausbreitung schnell. Inapparente Infektionen liegen in etwa $30 \%$ vor, auch abortive Verläufe sind häufig. Etwa in $33 \%$ der Infektionen von seronegativen Frauen mit einer Schwangerschaft wird das Virus auf den Embryo/Fötus übertragen. Ein Hydrops fetalis tritt in $5-9 \%$, intrauteriner Frühtod in $9-13 \%$ aller Infektionen der Mutter auf. Das Parvo-Virus B19 ist die Ursache von $10-15 \%$ aller Fälle von Hydrops fetalis. Es gibt Mehrfachinfektionen.

\section{Übertragung}

Sie erfolgt wahrscheinlich durch Tröpfcheninfektion. Kinder mit Exanthem sind nicht mehr infektiös für ihre Umgebung. Das Virus wird über die Sekrete des Nasenrachenraums ausgeschieden und ist im Urin nachweisbar. Auch Blutkonserven und Plasma- 
produkte können das Virus übertragen, man schätzt eine Übertragung auf 20000 Transfusionen.

\section{Pathogenese}

Die Replikation der Parvo-Viren erfolgt nur im Kern von Zellen, die sich in der S-Phase des Zellzyklus befinden. Als Rezeptor wurde die Blutgruppen-PSubstanz (s. S. 87) identifiziert. Man findet das Virus deshalb vorwiegend in den Erythroblasten, d.h. in den unreifen Vorstufen der roten Blutzellen. Ob die DNS des Virus in das Zellgenom integriert wird, ist noch nicht bekannt, es persistiert jedoch bei vielen Personen im Knochenmark.

Die Replikation der Viren verursacht eine Hemmung der Erythropoese. Pro ml Blut wurden bis $\mathrm{zu}$ $10^{11}$ Viruspartikel gezählt, Virus-DNS ist aber bereits vor Ausbruch des Exanthems nachweisbar. Die Erythropoese ist für die Dauer von 7-11 Tagen gehemmt. Die Entstehung des Exanthems ist wahrscheinlich durch Virus-Antikörper-Komplexe bedingt, da es am Ende der Virämie auftritt. Die Arthralgien (8\% aller Kinder, $80 \%$ der Erwachsenen) sollen ebenso durch Immunkomplexe zustande kommen, bei ihnen findet man B19-DNS lange Zeit nach der akuten Infektion in den Synovialmembranen und Persistenz im Blut. Durch die Infektion entsteht keine Embryopathie, sondern ein Hydrops fetalis. Durch elektronenmikroskopische Untersuchungen und durch die PCR wurde beim Vorliegen des virologisch bedingten Hydrops fetalis in zahlreichen Organen des Fötus mit Erythropoese (Leber, Milz, Lunge) Virus-DNS nachgewiesen. Im Fruchtwasser findet man auch dann noch Virus-DNS, wenn die Mutter hohe IgG-Antikörperspiegel aufweist. Auch in Abortmaterial läßt sich Virus-DNS nachweisen. Neben der Hemmung der Erythropoese tritt beim Föten auch eine starke Hämolyse auf. Infolge Erythrozytenzerfalls und Anämie ist $\mathrm{O}_{2}$-Mangel das zentrale pathogenetische Element. Nach pränatalen Infektionen vermutet man eine Persistenz des Virus.

\section{Klinik}

Die Inkubationsperiode bis zum Auftreten der ersten Symptome beträgt 5-10 Tage. Etwa 20-30\% der Infektionen verlaufen inapparent. In einer 1 . Phase der Krankheit bilden sich plötzlich hohes Fieber, Kältegefühl, Kopf- und Muskelschmerzen sowie Anämie aus - es entsteht das Bild eines grippalen Infektes. Einige Tage danach, in der 2.
Phase, tritt erneut Fieber auf. Es bildet sich ein (manchmal fehlendes) Exanthem; es ist an den Wangen in Schmetterlingsform und, später auftretend, am übrigen Körper in Girlandenform ausgebildet: Das namengebende Erythema infectiosum (Ringelröteln, 5. Krankheit) (Abb., s. S. 687 u. 688). Zum Exanthem gesellen sich Erbrechen, Arthralgien, Kopfschmerzen, Enzephalopathie (Genotyp 5), starker Pruritus sowie eine Lymphadenopathie hinzu. Sehr selten ist eine fulminante Hepatitis. Leuko- und Lymphopenie, Thrombozytopenie, Retikulozytopenie sowie Eosinophilie wurden ebenfalls beobachtet. Bei Kindern tritt die Arthralgie seltener auf als bei Erwachsenen (Frauen!). Die Arthropathie kann Monate, z. T. Jahre andauern. Sehr selten manifestiert sich die Infektion mit Vaskulitis, Uveitis, Pneumonie, Hepatitis, Myokarditis oder Enzephalitis. Bei der Infektion von gesunden Personen wird nur eine passagere Störung der Erythropoese beobachtet, die endet, sobald die Antikörperantwort einsetzt (Abb. 11.1).

Parvo-Virus B19 kann bei der Primärinfektion von Personen mit einer Sichelzellen-Anämie eine transitorische aplastische Krise auslösen. Wahrscheinlich führt das Virus auch bei chronisch hämolytischen Anämien zu aplastischen Krisen (Agranulozytose?). Bei Immungeschädigten (AIDS) kann die Infektion chronisch werden: Man beobachtet eine persistierende Anämie und eine chronische Arthritis. Sie soll sich durch Antikörperzufuhr bessern lassen.

Fetale Komplikationen sind v.a. im 2. und 3. Trimenon zu befürchten. Dies steht im Gegensatz zu den Fruchtschäden nach Infektionen mit dem Röteln- und dem Varizellen-Zoster-Virus: Bei diesen Infektionen besteht für die Frucht nur während der ersten 3-4 Schwangerschaftsmonate Gefahr. Der Abbruch einer Schwangerschaft wegen einer Gefährdung durch eine Infektion mit ParvoViren gilt als nicht indiziert. Bei allen Fällen von Erythema infectiosum während der Schwangerschaft erlaubt die Ultraschalluntersuchung eine sichere Erkennung des Hydrops fetalis und damit die Durchführung einer intrauterinen Austauschtransfusion. Bei der Mutter ist die Konzentration an $a$-Fetoprotein erhöht. Je höher der Gehalt ist, desto größer soll die Gefahr für das Kind sein.

\section{Immunität}

IgM-Antikörper lassen sich für die Dauer von drei Monaten nachweisen. IgG-Antikörper vermitteln 


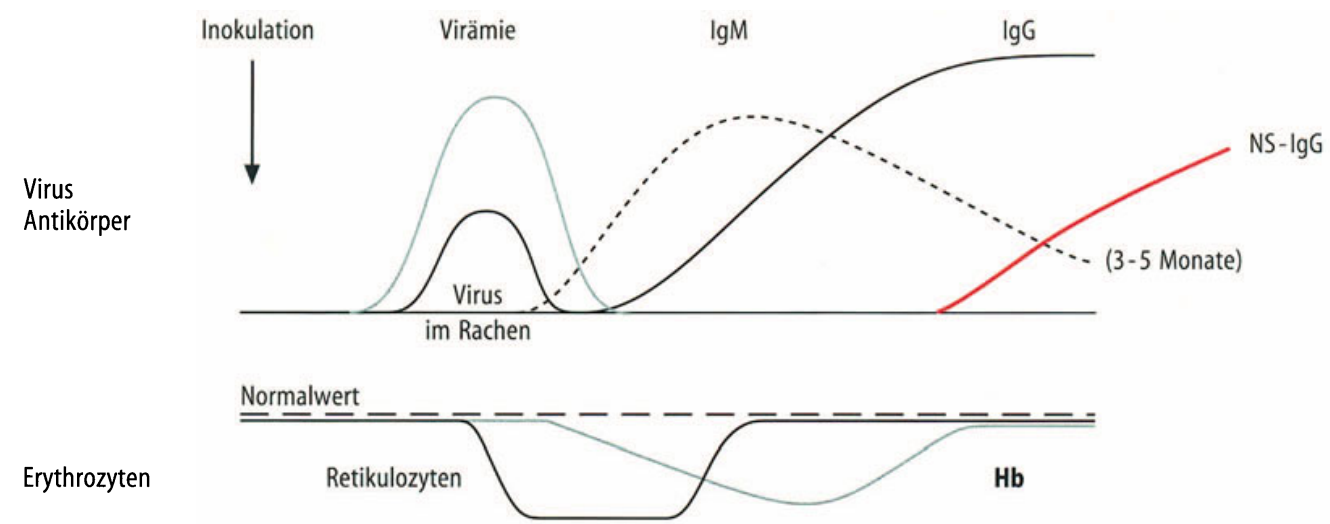

Klinik

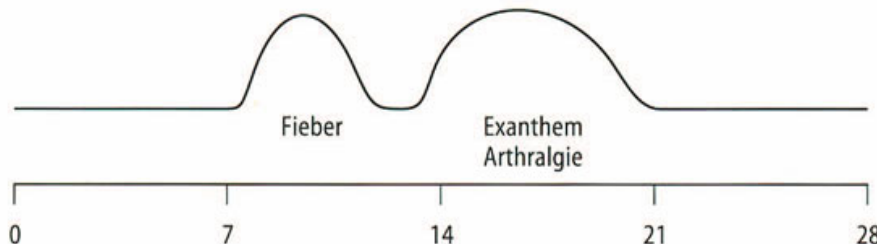

Abb. 11.1. Ablauf einer Parvo-Virus B19-Infektion: Virämie, Antikörperbildung, Erythrozytenzahl, TempeTage

\begin{tabular}{|c|c|c|}
\hline $\mid$ & $T$ & $T$ \\
\hline 0 & 7 & 14 \\
\hline
\end{tabular}
ratur und Exanthem sowie Arthralgie

eine lebenslange Immunität. Boosterungen des Antikörperpegels - wie bei den Röteln - haben sich bislang nicht nachweisen lassen. Bei chronischschweren Infektionsverläufen haben sich Antikörper gegen Nichtstrukturproteine (NS-IgG) in $80 \%$ ab der 5. Woche nachweisen lassen, auch entstehen ZTL. Gesunde oder Rekonvaleszenten zeigen diese in $22 \%$.

\section{Labordiagnose}

Die Züchtung von Parvo-Viren in vitro ist in Knochenmarkzellen mit Zugabe von Erythropoetin gelungen. Der ELISA und der Westernblot dienen zum Nachweis von IgM- und IgG-Antikörpern, die PCR zum Virusnachweis im Speichel, Blut oder Gewebe. Das Parvo-Virus B19 läßt sich elektronenmikroskopisch im Biopsiematerial von exanthematischen Regionen darstellen. Differentialdiagnostisch sind alle anderen exanthembildenden Erkrankungen bzw. Viren (Masern, Röteln, Coxsackie-, ECHO-Viren, HHV 6, infektiöse Mononukleose, Arzneimittelexantheme) zu beachten, da das Exanthem oft nicht typisch ist.

Gegebenenfalls kann Nabelschnurblut des Föten zur Antikörper-Diagnose herangezogen werden. Parvo-B19-DNS kann mit der PCR z.B. auch im Fruchtwasser nachgewiesen werden. U.S.-Kontrolle bei Graviden!

\section{Prävention und Therapie}

Über eine Immunprophylaxe durch passive Zufuhr von Antikörpern liegen bisher keine Daten vor. Durch intrauterine Bluttransfusionen des infizierten Fötus wurde die Letalität von $50 \%$ auf $25 \%$ (U.K.) reduziert. Ringelröteln treten oft epidemisch in Kindergärten etc. auf. Deshalb sollten sich Schwangere dort nicht aufhalten.

\subsection{Adeno-assoziierte Viren (AAV)}

Adeno-assoziierte Viren sind defekte Viruspartikel; sie benötigen Adeno- oder Herpes-Viren u.a. für ihre Replikation. Man rechnet sie zum Genus der Dependo-Viren der Parvoviridae. Serologische Studien haben gezeigt, daß die Viren weit verbreitet sind; man kennt aber noch keine Krankheit, die sie verursachen. Das Virus ist in embryonalem Gewebe und in Uterusgewebe nachgewiesen worden, AAV-DNS wurde wie HPV-DNS in Zervix-Biopsien nachgewiesen, das Virus wirkt Transformationshemmend. Das Genom persistiert als integrierte Doppelstrang-DNS in den infizierten, aber unveränderten Zellen. Die Integration erfolgt an einer bestimmten Stelle im Chromosom 19. Im 
Labor kann man das Virus u.U. entdecken, wenn man eine als virusfrei angesehene Zellkultur mit Adeno-Viren überinfiziert. Das defekte Virus wird dann frei (das Adeno-Virus wirkt als „Helfer"). Die Durchseuchung beginnt bereits in der Kindheit und erreicht bei 10jährigen $70 \%$, Schwangere sind in $80 \%$ positiv. Auch Neugeborene können bereits IgM positiv sein. Beim Menschen kennt man die Typen 2, 3 und 6. Bei Müttern mit AAV-DNS-positiven Amnionflüssigkeiten, vorzeitigem Blasensprung und vorzeitigen Wehen war AAV-DNS signifikant häufiger nachweisbar.
AAV-Infektionen können in frühen und späten Stadien der Schwangerschaft erfolgen. Die Rolle der AAV in der Schwangerschaft bedarf weiterer Untersuchungen.

Anhang. Vor kurzem wurde ein neues, aber differentes Parvo-Virus bei einem Kind entdeckt. Es ruft eine Anämie und eine Lympho-Neutropenie hervor. Die Durchseuchung beginnt in der Kindheit und erreicht bei 10 -Jährigen $70 \%$, Schwangere sind in $80 \%$ seropositiv. Neugeborene können IgM-positiv sein.

\section{ZUSAMMENFASSUNG: Parvo-Viren}

Virus. Parvo-Virus B19: Kleines, DNS-haltiges Virus (Einzelstrang); 5,6 kb. Ikosaeder.

Vorkommen und Übertragung. B19 nur beim Menschen, bei vielen Spezies andere Parvo-Viren. Durch Tröpfcheninfektion, Blutkonserven und Plasmaprodukte übertragbar. Intrauterine Transmission auf den Embryo oder den Fötus möglich (5-9\%).

Epidemiologie. Durchseuchung hoch, epidemisch in Familien, Kindergärten, Heimen etc.

Pathogenese. Replikation nur in schnell proliferierenden Zellen der kernhaltigen Erythrozyten-Vorstufen. Hemmung der Erythropoese in zahlreichen Organen des Embryo bzw. des Föten. Transitorische aplastische Krise.

Klinik. Inkubationsperiode 5-10 Tage.

- Grippaler Infekt, mit Fieber.

- Schmetterlingserythem im Gesicht und Erythema infectiosum (Ringelröteln),
- aplastische Krise, z.T. Foudroyanz,

- Hydrops fetalis, Abort oder Totgeburt,

- selten Pneumonie. Immunität. Wahrscheinlich durch Antikörper und ZTL bedingt.

Diagnose. PCR zum DNS-Nachweis. Antikörpernachweis durch IgM- und IgG-ELISA sowie Westernblot. Ultraschalluntersuchung des Embryos bei nachgewiesenen Primär-Infektionen. Differentialdiagnose: Röteln und andere exanthematische Krankheiten sowie Arzneimittelexantheme.

Therapie. Symptomatisch, ggf. intrauterine Austauschtransfusion, wenn das $\mathrm{Hb}<10 \mathrm{~g} / \mathrm{dl}$ beträgt.

Prävention. Vermeidung der Exposition von Schwangeren in Kindergärten etc. bei Erythema infectiosum.

Keine Meldepflicht. 


\section{EINLEITUNG}

Papova-Viren (Papillom, Polyoma, Vacuolating Agent) sind im Tierreich weit verbreitete DNSViren. Sie besitzen wegen ihrer Tumorerzeugenden Wirkung eine große Bedeutung: Beim Menschen rufen sie gut- oder bösartige Tumoren hervor. Bei Immundefizienz lösen sie eine Enzephalopathie (PML) aus. In neugeborenen Mäusen und Hamstern bilden sich nach der Inokulation Tumoren.

Die Papova-Viren werden eingeteilt in:

- Gruppe A: Menschliche Papillom-Viren (HPV) sowie Rinder- und Kaninchenpapillom-Virus.

- Gruppe B: Polyoma-Virus der Maus, das vakuolisierende Virus (Simian Virus (SV) 40) des Affen sowie das BK- und JC-Virus des Menschen.

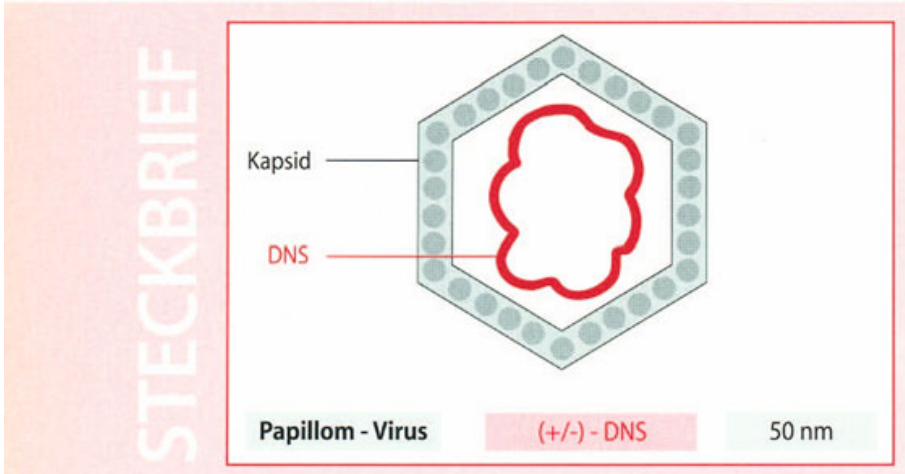

\subsection{Papillom-Viren des Menschen}

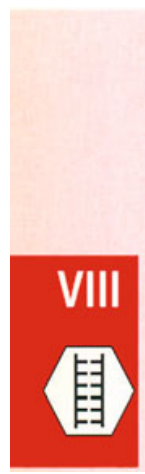

Die Papillom-Viren erzeugen beim Menschen zahlreiche, z. T. gutartige, z. T. selten oder auch häufig malignisierende Tumoren. Die Pathobiologie und Virologie der menschlichen Papillom-Viren (Human Papilloma Virus, HPV) ist heute ein intensiv bearbeitetes Gebiet, von dem man sich wichtige Einsichten in die Entstehung von gutartigen Zellproliferationen (Papillome, „Warzen") und den Übergang zur bösartigen Zelle (Transformation, Transplantierbarkeit und autonomes Wachstum) verspricht. Die Transformationsproteine der HPVs haben die Entdeckung der "Antionkogene" oder "Suppressorgene" ermöglicht. Insbesondere ist die Beteiligung der HPV bei der Entstehung des menschlichen Zervixkarzinoms, u.a. Tumoren, wichtig. Sie lösen im Epithel keine Entzündungen aus.

\section{Geschichte}

Die Warzen des Menschen sind seit altersher bekannt. Ihre Übertragbarkeit von Mensch zu Mensch wurde durch Variot bereits 1893 und durch Jadassohn 1896 gezeigt. Die Ultrafiltrierbarkeit wurde 1907 bewiesen. Heute wird die Epidemiologie dieser Tumorviren, die Tumorentstehung und die prospektive Erkennung von Frauen mit einem Krebsrisiko studiert.

\subsubsection{Beschreibung}

\section{Genom}

Die DNS liegt als zirkuläres Doppelstrangmolekül $(+/-)$ vor. Es enthält $8 \mathrm{kbp}$ (Papillom-Viren) bzw. $5 \mathrm{kbp}$ (Polyoma-Viren). Man kennt Früh- bzw. Spät-Gene, die für Regulator- bzw. Strukturproteine kodieren; die Frühproteine werden als E1, 2, 4, 5, 6 und 7, die Spätproteine als L1 und 2 bezeichnet. Die Information der menschlichen Papillom-Viren enthält außer den Strukturproteinen solche für die episomale Persistenz, für vier Transformationsproteine (v.a. E6 und 7), außerdem sind beim HPV-16 u. a. Regulatorsequenzen für die Bindung von Hormonen auf der DNS vorhanden. Es werden gutartige Viren (HPV1, 3, 10 u.a.), Niedrigrisiko- (HPV6, 11 u. a.) sowie Hochrisikoviren (HPV16, 18, 31 u.a.) bzgl. der Tumorbildung unterschieden. 


\section{Morphologie}

Die Viruspartikel haben einen Durchmesser von $50 \mathrm{~nm}$ und bestehen aus einem Ikosaeder-Kapsid, das eine histonverpackte DNS enthält.

\section{Resistenz}

Die HPV's sind umweltstabil und Äther-resistent.

\section{Einteilung}

Man kennt mehr als 80 verschiedene Typen des menschlichen Papillom-Virus. Bislang läßt sich das Virus nur begrenzt in Gewebe- („raft“-) Kulturen züchten. Die Gruppen- bzw. Typeneinteilung der HPVs beruht daher auf dem Grad der Kreuz-Hybridisierbarkeit ihrer DNS; gentechnologisch hergestellte Kapside reagieren serotypspezifisch. Das Vorkommen von bestimmten HPV-Typen in bestimmten Tumoren (Tabelle 12.2) läßt hoffen, daß man einen Impfstoff herstellen kann.

\subsubsection{Rolle als Krankheitserreger}

\section{Epidemiologie}

Die Entstehung der Zervix-Karzinome beginnt mit der Sexualaktivität.

Die Durchseuchung der Haut mit den HPVs ist nicht genau bestimmbar, da die Antikörper bald wieder verschwinden. Hautwarzen sind jedenfalls bei Kindern und Jugendlichen häufig, viele Infektionen verlaufen inapparent.

Die Durchseuchung mit den Hochrisiko-HPVs beträgt bei $18-24$ jährigen Frauen $8-12 \%$, bei über 35jährigen $2-5 \%$. Dies bedeutet transiente Infektionen bei jungen Frauen, bei älteren ist die Durchseuchung stabiler und offenbar eng mit der Entstehung des Zervixkarzinoms verknüpft. Pro Jahr gibt es in Deutschland ca. 6000 neue Fälle von Zervixkarzinom, weltweit 500000; 2500 bzw. 300000 Frauen sterben. Bei Immunsupprimierten (bei AIDS oder nach Transplantationen) werden gehäuft HPV-Ausscheidung (Haut, Sekrete), Warzen und Zervixkarzinome festgestellt.

Bei jungen Frauen läßt sich im Zervixmaterial in Abhängigkeit von der Sexualaktivität HPV-DNS nachweisen. Die Antikörperbildung erfolgt verzögert und geht zurück, wenn das Virus eliminiert wird. Man vermutet bei einer Persistenz der Antikörper auch eine Persistenz des Virus. Wahrschein- lich sind häufige inapparente Infektionen für die Verbreitung der Infektion mitverantwortlich.

Die Genitalwarzen weisen eine Altersverteilung wie auch andere venerische Infektionen auf. Prostituierte lassen eine Häufung von Genitalwarzen und Zervixkarzinom erkennen. Auch bei Promiskuität ist dies Risiko erhöht. Die Bowen'sche Papillomatose und das Peniskarzinom des Mannes (HPV-16) bilden z.B. das Reservoir für die Übertragung des HPV-16 auf die Frau. Frauen mit dem HLA Typ DQw3 sowie B 7 u.a. haben ein höheres Risiko für die Entstehung des Zervixkarzinoms.

\section{Übertragung}

Die Übertragung erfolgt durch direkten Hautkontakt, indirekt durch Kleider oder z. B. durch Fußböden in Waschräumen. Die juvenile Papillomatose des Kehlkopfes (HPV-6 und -11) wird sehr wahrscheinlich beim Durchtritt durch den Geburtskanal (perinatal) übertragen; dies gilt auch für die Typen 16 und 18. Hierfür spricht, daß man in den flachen Kondylomen der Frau die DNS eben dieser Typen nachweisen kann. HPVs können sich auch in Wunden ansiedeln. Die Übertragung der Typen 6, 11, 16, 18, 31 u.a. erfolgt besonders durch Intimverkehr. Kinder übertagen HPVs mit den Handwarzen zum Genitale.

\section{Pathogenese}

Warzen haben Inkubationsperioden von bis $\mathrm{zu}$ zwei Jahren. HPVs gelangen durch Mikrotraumen etc. in das Epithel: oral, genital oder durch die Haut, in der das HPV latent wird. In den Basalzellen erfolgt eine Expression der Frühproteine und die Replikation des episomalen Genoms; auf diese Weise erfolgt eine Proliferation: Akanthose (Verdickung). Nur in den differenzierten Epithelzellen erfolgt eine komplette Replikation und verstärkte Keratinbildung (Hyperkeratose). Im Stratum granulosum bilden sich Koilozyten, d.h. große vakuolisierte Zellen (= „ZPE“). Dies führt nach Monaten zur Warzenbildung.

In diesen Papillomen findet sich infektiöses Virus nur in den differenzierten Keratinozyten, in den Basalzellen dagegen findet man nur episomale Virus-DNS. Die Karzinome sind hingegen frei von Virus, enthalten aber HPV-DNS. Ihre Entstehung stellt man sich folgendermaßen vor: Papova-Viren vermehren sich vorzugsweise in differenzierten Epithelzellen der Haut oder Schleimhäute. Infolge 
der geringen Stoffwechselaktivität dieser Zellen, die den Viren nur eine geringe Replikationsrate ermöglichen würde, haben die genannten Viren einen Mechanismus entwickelt, die Zellen $\mathrm{zu}$ vermehrten Teilungen anzuregen. Dies erfolgt durch funktionelle Inaktivierung von Suppressorgen-Proteinen (s. S. 502) sowie durch weitere Störungen der Regulation der Zellteilung durch die Produkte der Transformationsgene (E4-7). Die Folge ist eine verstärkte Proliferation der Keratinozyten zugleich mit einer Behinderung der Differenzierung des Epithels. Das Resultat ist die Entstehung von Papillomen, aus denen HPV frei wird.

Papillom-Viren und Zervixkarzinom. Das Hauptproblem der HPV-Forschung betrifft die Beteiligung der HPVs bei der Entstehung des Zervixkarzinoms: In Zellatypien und in der zervikalen intraepithelialen Neoplasie (CIN) I und II stellt man vorwiegend HPV-6 und -11 fest. Hingegen lassen sich im Stadium CIN III und im metastasierenden Karzinom bis zu 90\% die Typen 16 und 18 u. a. nachweisen. Man schätzt die „Inkubationsperiode" zumindest auf 10 bis 20 Jahre. In den USA unterscheidet man nur gering- und hochgradige squamöse, intraepitheliale Läsionen (SIL). I. allg. liegt die DNS der HPVs in den Frühstadien (Zellatypien, CIN I, II und M. Bowen) in episomaler Form vor, während sie in den Spätstadien der Neoplasie und in den Karzinomen in das Zellgenom integriert ist und exprimiert wird.

Die Analyse der Tumorentstehung hat ergeben, daß HPV 16 und 18 u.a. immortalisierend wirken. Für den kompletten Transformationseffekt ist zusätzlich ein aktiviertes c-ras- oder c-fos-Gen erforderlich; das c-myc-Gen ist diesbezüglich unwirksam (s. S. 499). Durch die Integration der Hochrisiko-Virus-DNS steigt die Synthese der Frühproteine E6 und E7 beträchtlich, die Suppressorgen-

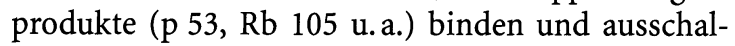
ten. Außerdem wirkt die Integration der HPV-DNS genotoxisch, d.h. mutagenisierend (s. S. 502) auf viele, nur z.T. identifizierte zellteilungsregulierende Gene ein. Auch wird z.B. die Zahl der Rezeptoren für Wachstumsfaktoren gesteigert (durch E5), aber die Expression der MHC-Proteine verringert, so daß die Immunerkennung erschwert wird. E7 aktiviert auch die für Metastasenbildung wichtigen Proteasen. Die Niedrigrisikotypen 6, 11 u. a. hingegen integrieren nicht, die E6/7-Proteine binden auch nur schwach an das p 53, das also aktiv bleibt. Das p 53 (Suppressorgen) ist beim Men- schen polymorph; es kodiert in Position 72 für Prolin oder Arginin. Liegt ein homozygoter Argininpolymorphismus vor (Arg-Arg), so kann das $\mathrm{p}$ 53 weitaus leichter durch das E6-Protein (Transformationsprotein) abgebaut werden. Dies wirkt sich offenbar nur dann auf das Karzinomrisiko aus, wenn im E6 in Position 350 ebenso ein Polymorphismus vorliegt.

HPVs kommen in einem hohen Prozentsatz von Zervixkarzinomen vor. Integrierte HPV-DNS wird regelmäßig in fast allen Tumorzellen eines Zervixkarzinoms festgestellt.

Zervixkarzinome entstehen wahrscheinlich durch das Zusammenwirken von zwei oder mehr Faktoren: Außer den hochonkogenen HPVs sind HSV oder ZMV im Zervix-Sekret nachgewiesen. Außerdem verstärken chemische Karzinogene aus Verbrennungsprodukten des Tabaks und Hormone in einer vorläufig noch nicht bekannten Weise die Genotoxizität der HPVs bei der Entstehung des Zervixkarzinoms. Andererseits vermutet man ,interferierende“ Faktoren der Normalzellumgebung eines Proliferationsherdes (Zytokine, s. S. 500), die dem DysplasieProzeß entgegenwirken und Apoptose hervorrufen; auf diese Weise erklärt man sich heute das häufige Verschwinden von kleinen intraepithelialen Tumoren. HLA-Faktoren wirken prädisponierend.

Zusammenfassend unterscheidet man also intrazelluläre, extrazelluläre sowie immunologische Kontrollmechanismen bei der Entstehung der Zervixkarzinome. - HPVs sind auch bei der Entstehung von Kopf- und Nackenkarzinomen beteiligt.

\section{Klinik}

Es werden drei Lokalisationen der Ausprägungsformen unterschieden (Tabelle 12.1 und 12.2):

- Haut: Vulgäre Warzen, EV, Plantarwarzen und filiforme Warzen;

- Schleimhaut: Mundhöhle, Kehlkopf mit Leukoplakien, Papillomen und Karzinomen;

- Anogenitalbereich: Kondylome, M. Bowen, Karzinome der Vulva, des Penis, der Zervix und im Bereich des Anus.

Gemeine Warzen und Konjunktival-Papillom. Unterschiedliche HPV-Typen bewirken die Entstehung verschiedener Tumortypen, die sich morphologisch, histologisch und bezüglich ihrer Lokalisation am Körper unterscheiden. Virusarten, deren DNS Homologien aufweisen, besitzen ähnliche pathobiologische Eigenschaften. Die gemeinen War- 
Tabelle 12.1. Gruppen, Typen und Läsionen durch HPV

\begin{tabular}{|c|c|c|}
\hline Gruppe & Typ & Läsionen \\
\hline A & HPV 1 & Verruca plantaris und vulgaris \\
\hline \multirow[t]{2}{*}{ B } & HPV 2, 27 & $\begin{array}{l}\text { Verruca vulgaris, Karzinom in } \\
\text { Mundhöhle }\end{array}$ \\
\hline & HPV $3,10,28,41,49$ & Verruca plana \\
\hline C & HPV 4 & Verruca vulgaris, plantaris \\
\hline \multirow[t]{3}{*}{ D } & HPV 5 bei $85 \%$ & EV mit Hautkarzinom \\
\hline & HPV $9,12,14,15,47,50$ & EV \\
\hline & $\begin{array}{l}\text { HPV } 8,17,19-25,36-38, \\
46-50\end{array}$ & EV mit Hautkarzinom \\
\hline \multirow[t]{3}{*}{$\mathbf{E}$} & HPV 6 u. 11 & $\begin{array}{l}\text { In } 80 \% \text { aller Kehlkopfpapil- } \\
\text { lome, Kond. acuminata und } \\
\text { plana, }\end{array}$ \\
\hline & HPV $2,6,11,16$ & $\begin{array}{l}\text { Orale Papillome und Leukopla- } \\
\text { kien }\end{array}$ \\
\hline & HPV 6, 11 & $\begin{array}{l}\text { Konjunktival-Papillom, CIN I } \\
\text { und II }\end{array}$ \\
\hline $\mathbf{F}$ & HPV7 & $\begin{array}{l}\text { Verruca vulgaris, butchers } \\
\text { warts }\end{array}$ \\
\hline G & $\begin{array}{l}\text { HPV } 16,18,31,33,35 \text {, } \\
\text { u.a. }\end{array}$ & $\begin{array}{l}\text { M. Bowen, Kond. acuminata, } \\
\text { CIN III, Zervix-, Penis-, Anus- } \\
\text { Karzinom, Kehlkopf-Karzinom, } \\
\text { Karzinom in der Mundhöhle; } \\
\text { Plattenepithel der Haut }\end{array}$ \\
\hline
\end{tabular}

CIN (cervikale intraepitheliale Neoplasie, Stadium I, II, III) EV (Epidermodysplasia verruciformis)

Tabelle 12.2. Die Beziehung zwischen den Papillom-Virus-Typen des Menschen und Lokalisation des Tumors

\begin{tabular}{ll}
\hline Typ & Lokalisation \\
\hline HPV 1, 2, 3, 4, 7, 10, 28, 29, 32, 41 & Warzen der Haut \\
HPV5, 8, 9, 12, 14, 15, 17, 19-25, 36-38, EV \\
$46-50$ & \\
HPV 13, 6, 11, 32, 7, 16 & Mundschleimhaut \\
HPV6, 11, 30 & Kehlkopf, Genitale \\
HPV 16, 18, 31, 33, 34, 35, 39, 40, 42-44, & Genitale \\
$45,51,51,53-55,6,11$ u. a. & \\
HPV6, 11 & Konjunktiven \\
\hline
\end{tabular}

zen sind gutartig, ebenso das Konjunktival-Papillom. Die gemeinen Warzen treten häufig mit der Pubertät auf und verschwinden später oft ohne $\mathrm{Zu}$ tun. Die Inkubationsperiode beträgt 2-3 Monate. Diese gutartigen Tumoren sind epithelial oder fibroepithelial und können ebenso wie Zervix-Neo- plasien nach unterschiedlich langer Zeit spontan zurückgehen.

Epidermodysplasia verruciformis. Infolge eines angeborenen Defektes der zellulären Immunität entstehen familiär gehäuft bei den betroffenen Kindern flache Warzen, die aber persistieren und allmählich die ganze Hautoberfläche überziehen (ausgenommen sind Kopfhaut, Fußsohlen und Handinnenflächen). Die HPV-Typen 5 und 8 erzeugen flache Warzen, rötliche Plaques und Pityriasis-versicolor-ähnliche Veränderungen. Die Histologie ist typisch, daher der Name Epidermodysplasia verruciformis (EV). Nach einer Inkubationsperiode von 10-20 Jahren entwickeln sich in 25$50 \%$ der Fälle Karzinome. Für die Malignisierung macht man die zusätzliche Einwirkung von UVLicht verantwortlich. Bei der EV kommt die DNS episomal vor; in den Karzinomen läßt sich keine integrierte Virus-DNS nachweisen.

Bösartige Tumoren. Nur aus bestimmten Papillomformen - infiziert mit bestimmten HPV-Typen - können nach langen Inkubationsperioden (10-20 Jahre) Karzinome hervorgehen, nämlich aus den Kondylomata acuminata und den flachen Kondylomen, der Epidermodysplasia verruciformis sowie aus den Kehlkopfpapillomen der Erwachsenen. Die juvenilen Kehlkopfpapillome sind nicht im eigentlichen Sinne bösartig, jedoch bilden sie sich nach der Exstirpation bald wieder neu. Ein Drittel der Erkrankungen beginnt jenseits des 20. Lebensjahres; von ihnen malignisieren $20 \%$.

\section{Immunität}

Der Mensch reagiert auch auf HPV-Infektionen immunologisch. Typspezifische Antikörper gegen die Kapside (L1) treten während der akuten Durchseuchung auf, bei Karzinomträgerinnen stellt man vermehrt Antikörper gegen L1, sowie gegen die Frühantigene E4 und E7 fest, die möglicherweise einen prognostischen Wert für die Entstehung des Zervixkarzinoms haben. E7-Antikörper korrelieren mit der Tumorlast.

$\mathrm{Da}$ Warzen und Zervixkarzinome bei immunsupprimierten Personen gehäuft vorkommen, denkt man an die Mitwirkung der zellulären Immunität bei der Elimination des Virus. Man beobachtet dabei aktivierte Langerhans-Zellen sowie Infiltrate aus Makrophagen und CD4-Lymphozyten in den Tumoren gegen Peptide des E7. Bei humo- 
ralen Immundefekten wurde keine Häufung von Warzen festgestellt.

\section{Labordiagnose}

Die meisten Warzenarten lassen sich klinisch diagnostizieren. Schwierigkeiten bereitet die Diagnose der EV und der flachen Kondylome. Der Nachweis der Antikörper zur Diagnose hat sich bislang nicht durchgesetzt.

Der Nachweis viraler DNS durch Hybridisierung und PCR ist nur in Speziallabors durchführbar. Die Hybridisierung mit Biotin-markierter DNS findet jetzt aber allgemeine Anwendung. Dies gilt ganz besonders für die Vorsorgeuntersuchungen von Frauen beim Vorliegen von Epithelatypien im Rahmen der üblichen Untersuchung der Zellabstriche oder besser von Biopsien.

Der Nachweis der HPVs $(16,18$. u. a.) im Zervixmaterial ist wegen der hohen Rate an falsch-negativen Resultaten (bis zu 50\%) bei der Untersuchung mit der herkömmlichen Papanicolaou-Methode als Ergänzung wichtig. Optimal scheint die Kombination beider Verfahren zu sein.

Bei der Beurteilung des Nachweises von HPVDNS im Zervixmaterial muß jedoch auch die Menge der DNS berücksichtigt werden: Während der Durchseuchungsphase ist nur wenig DNS vorhanden, nach Beginn der Malignisierung enthalten jedoch viele Tumorzellen viele integrierte Kopien des Genoms.

\section{Therapie}

Warzen verschwinden oft spontan oder nach Suggestivmaßnahmen. Der Arzt kann Silbernitratstifte, Salizylsäurepräparate oder die Kryotherapie anwenden oder chirurgisch vorgehen. Die juvenilen Kehlkopfpapillome lassen sich durch Behandlung mit Interferon $a$ oftmals zum Verschwinden bringen. Rezidive sind jedoch häufig. Auch bei Patienten mit malignisierter $\mathrm{EV}$ hat sich Interferon als wirksam erwiesen. Kleine Tumoren der Art des M. Bowen sprechen gut an, während große invasive Karzinome refraktär gegen $a$-Interferon sind.

Auch HPMPC (Cidofovir, s. S. 515) hat sich bei lokaler Anwendung von anogenitalen Kondylomen und direkt in juvenile Kehlkopfpapillome injiziert als dauerhaft wirksam erwiesen. Imiquimod- (Aldara-)Creme (s. S. 515) hat infolge lokaler Zytokininduktion bei $56 \%$ der Kondylome völlige Abheilung erbracht, es wirkt auch im CIN III-Stadium.

\section{Prävention}

Die Wirksamkeit eines geeigneten Impfstoffes würde das wichtigste Beweisstück für die Mitwirkung der HPVs bei der Entstehung der Zervix-Karzinome sein. In Tierversuchen haben sich rekombinante Impfstoffe aus Kapsiden (,virus-like particles") oder E6/E 7-Protein als wirksam erwiesen.

\subsection{JC-Virus. Virus der progressiven multifokalen Leukoenzephalopathie (PML)}

Das JC-Virus ist der Erreger der progressiven multifokalen Leukoenzephalopathie des Menschen (PML), es wurde 1971 aus dem Gehirn von PML-Kranken isoliert. Die PML tritt bei immungeschädigten Patienten auf (Transplantationsempfänger, Tumorpatienten, Personen mit angeborenem Immunmangelsyndrom und v.a. bei AIDS-Patienten). In geeigneten Tierspezies induziert das Virus die Bildung von Tumoren. Beim Menschen wurde es in Medulloblastomen festgestellt. Man unterscheidet einen "Archetyp" in der Niere sowie einen "rearrangierten Typ" im ZNS, auch beim BKVirus.

\subsubsection{Beschreibung}

Der Erreger ist ein DNS-haltiges Virus von $45 \mathrm{~nm}$ Durchmesser. Das Virion besteht aus einem Ikosaeder-Kapsid, das eine Doppelstrang-DNS umschließt. Das Virus gehört zur Gruppe B der Papova-Viren und wird als JC-Virus bezeichnet. Die Namensgebung erfolgte nach den Initialen des $\mathrm{Pa}-$ tienten. Bisher kennt man fünf Genotypen.

Man kennt die Replikationsweise, die DNS und die Proteine des Virus gut. In den mit dem JC-Virus infizierten Zellkulturen werden nukleäre Einschlußkörperchen beobachtet. Die Kulturflüssigkeit enthält hämagglutinierende Viruspartikel. Ein zytopathischer Effekt wird erst nach mehr als $10 \mathrm{Ta}$ gen beobachtet; er tritt in Primärkulturen menschlicher Fötal-Gliazellen sowie in Astrozyten auf. Die Virus-DNS liegt episomal vor oder ist in die DNS der befallenen Zelle integriert. 


\subsubsection{Rolle als Krankheitserreger}

\section{Epidemiologie}

Die Durchseuchung mit diesem Virus ist sehr hoch; bereits im 4 . Lebensjahr beträgt sie $50 \%$, im 10. $70-100 \%$. Trotzdem ist die PML sehr selten; sie kann im Rahmen einer Primärinfektion oder als Reaktivierung einer zurückliegenden Infektion bei Immundefekten auftreten.

\section{Vorkommen und Übertragung}

Die Viren sind artspezifisch. Der Übertragungsmodus ist aerogen oder eine Schmierinfektion. Das JC-Virus wird mit dem Urin ausgeschieden, übertragen wird der Archetyp.

\section{Pathogenese}

Die Primärherdreplikation erfolgt in den Lymphozyten und Stromazellen der Tonsillen. Nach der Primärinfektion mit Virämie (Archetyp-Virus) wird das JC-Virus mit dem Urin ausgeschieden und persistiert dann symptomlos lebenslang in der Niere, den Lymphknoten und den B-Zellen sowie wahrscheinlich im ZNS. Reaktivierungen gibt es bei Graviden, bei AIDS-Patienten und in 10-40\% der Empfänger von Organtransplantaten; das Virus wird dann erneut im Urin ausgeschieden. Der Genotyp 2 wird häufig bei PML-Patienten gefunden. Bei diesen Patienten wird der Rearrangement-Typ festgestellt; bei ihm sind in der nichtkodierenden Region Deletionen oder Duplikationen erfolgt, wodurch die Regulation der Replikation in Wechselwirkung mit zellulären Transkriptionsfaktoren verändert wird.

Vorwiegend sind Oligodendrogliazellen, seltener Astrozyten befallen, Neuronen bleiben ausgespart. Die Zeichen der Infektion sind Vergrößerung der Kerne, nukleäre Einschlußkörperchen und Pyknose. Das Hauptelement der Pathogenese ist die zytozide Infektion der myelinproduzierenden Oligodendroglia, der sich multifokale Entmarkungen anschließen. Diese Verteilung wird durch eine hämatogene Besiedlung erklärt. - Das exprimierte TAntigen des JC-Virus wurde in Kolon-Karzinom(und Normal)-Zellen nachgewiesen. Man vermutet eine Genom-destabilisierende Wirkung bei der Entstehung dieses Tumors.

\section{Klinik}

Die PML ist eine seltene Entmarkungskrankheit des Menschen, sie tritt gehäuft bei Personen bei Immun-Mangelzuständen auf, bei AIDS in 5-10\% der Patienten; sie ist also die Folge einer Reaktivierung.

Die ersten klinischen Anzeichen sind Sprachstörungen und Demenz. Lähmungen, Sensibilitätsstörungen und Rindenblindheit bestimmen das sonst variable, zum Tode führende klinische Bild. Im Gefolge der HIV-Therapie bessert sich auch die PML. Eine spezifische Therapie gibt es nicht.

\section{Labordiagnose}

Das Virus läßt sich züchten und IgM- und IgG-Antikörper nachweisen. Die PCR im Liquor und im Biopsiematerial ist die Diagnostik der Wahl. Ohne Biopsie kann eine Diagnostik nur neurologisch und radiologisch betrieben werden.

\subsection{BK-Virus}

Das zur Gruppe der Polyoma-Viren gehörende BKVirus wurde 1971 erstmals nach einer Nierentransplantation im Urin nachgewiesen. Die Bezeichnung BK leitet sich von den Anfangsbuchstaben des Patientennamens $a b$, bei dem das Virus isoliert wurde.

75\%-100\% der Weltbevölkerung besitzen Antikörper. Die Infektion des Menschen erfolgt früher als die mit dem JC-Virus. Sie verläuft subklinisch, das BK-Virus persistiert dann lebenslang.

Man hat Anhaltspunkte dafür, daß das BK-Virus leichte Infekte der Atemwege, Zystitis bei Kindern sowie bei Knochenmarktransplantat-Empfängern eine hämorrhagische Zystitis hervorrufen kann. Bei Allograft-Patienten kennt man eine Nephropathie.

Das Virus wird v.a. von Immunsupprimierten mit dem Urin ausgeschieden. Eine vermehrte Ausscheidung läßt sich auch während der Gravidität beobachten; dabei werden häufig IgM-Antikörper gebildet.

Die unterschiedlichen Tropismen werden wahrscheinlich durch zellspezifische unterschiedliche Transkriptionsfaktoren für Promoter und Enhancer bewirkt. Exprimiert wird das T(umor)-Antigen, aber nicht die Spätantigene. Diese Antigene 
binden an das $p R B$ und das p53. Die T-Antigene beider Viren (JCV und $\mathrm{BKV}$ ) erzeugen in vitro chromosomale Aberrationen. Das T-Antigen des SV40 war in Mesotheliomen, Osteosarkomen und Gehirntumoren exprimiert. Vielleicht ist das SV40 sogar ein Parasit des Menschen.
Das BK-Virus läßt sich in embryonalen Nierenzellen des Menschen züchten. In vitro transformiert es menschliche Zellen, die im Versuchstier Tumoren bilden.

Der Nachweis der DNS erfolgt durch die PCR, Antikörper lassen sich durch einen ELISA und den HHT feststellen.

ZUSAMMENFASSUNG: Papova-Viren des Menschen

Virus. DNS-Viren mit zirkulärem Doppelstrang. Ikosaeder, mehr als 80 Typen, Typisierung durch Hybridisierung. Virus ist stabil.

Vorkommen und Übertragung. Artspezifische Viren bei Mensch und Tier. Weltweit. Durch Hautkontakt (direkt, indirekt), im Geburtskanal, Intimverkehr.

Epidemiologie. Durchseuchung mit WarzenViren hoch. Typ 16 und 18 bis $50 \%$.

Pathogenese. Gutartige Tumoren (gemeine und flache Warzen); andere zunächst gutartige können entarten ( $E$. verruciformis, Kondylomata plana und acuminata). Zervixdysplasien (Typ 6 u. 11) können entarten. Die hochtumorigenen Typen 16 und $18 \mathrm{u}$.a. findet man in $90 \%$ der Zervixtumoren, die DNS der niedrigtumorigenen Typen 6 und 11 in den Kondylomen.

Klinik. Gemeine und flache Warzen, Papillome im Mund, im Kehlkopf und den Konjunktiven; Kondylome, E. verruciformis, M. Bowen, Zervixdysplasien, Penis- und Zer- vixkarzinom. Stadien CIN I-III, metastasierendes Karzinom.

Immunität. Antikörperbildung gegen Kapside und Frühproteine; zytotoxische Immunität durch T-Lymphozyten. Im Verlauf der Infektion entstehen typspezifische Antikörper gegen Kapside. ZTL sind für die Immunität verantwortlich.

Labordiagnose. Bisher keine Züchtung möglich. Hybridisierung; PCR zum Nachweis.

Therapie. Chirurgie, Silbernitrat, Salizylsäure zur Keratolyse, IFN $\alpha$ bei juvenilen Kehlkopfpapillomen, Imiquimod.

JC- und BK-Virus. Weite Verbreitung, das JCVirus ist der Erreger der PML bei immungeschädigten Personen. Mit großer Wahrscheinlichkeit sind sie bei der Entstehung von Tumoren beteiligt. Nachweis durch ELISA, HHT oder PCR. Ausscheidung mit dem Urin. Unterscheidung von Archetyp des JCV und Rearrangement-Typ. 


\section{EINLEITUNG}

Adeno-Viren erzeugen Erkältungskrankheiten, Konjunktivitis, Keratitis, Meningitis und Gastroenteritis. Sie persistieren lange Jahre in den Tonsillen und können bei Immundefekten reaktiviert werden. Ob sie beim Menschen Tumoren erzeugen können, ist noch nicht ausgeschlossen.

Das Virus wurde erstmals 1954 in Explantaten von Tonsillengewebe anhand seines zytopathischen Effekts nachgewiesen. 1956 erhielten die Isolate die Bezeichnung "Adeno-Viren" (Tonsillen=adenoides Gewebe). Der Typ 12 war das erste Human-Virus, bei dem man Tumorigenität im Tier beobachtete.

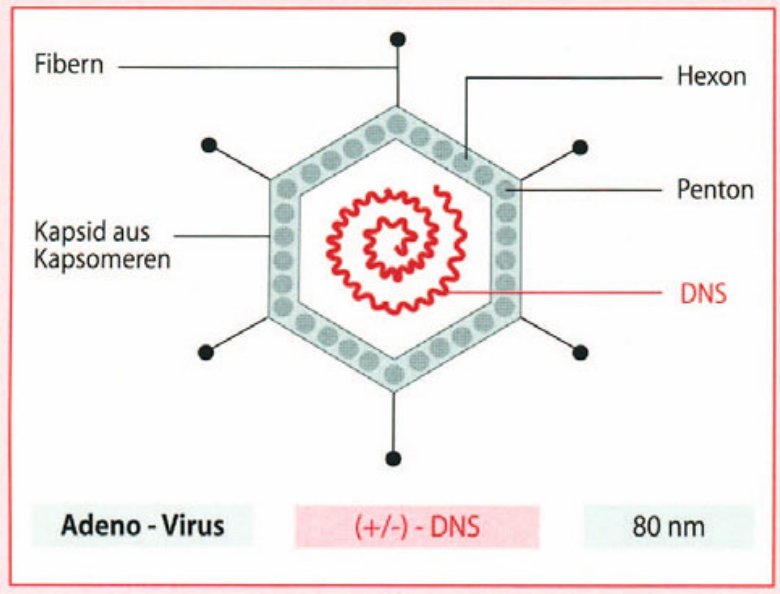

\subsection{Beschreibung}

\section{Genom}

Die DNS des Adeno-Virus ist ein lineares Doppelstrangmolekül (+/-) mit 36-38 kbp. Am 5'-Ende der beiden Stränge sitzt jeweils ein kovalent gebundenes Proteinmolekül, das Virus besitzt Transformationsgene.

\section{Morphologie}

Der Durchmesser des Virions beträgt $80 \mathrm{~nm}$. Das Ikosaeder-Kapsid besteht aus 252 Untereinheiten (Kapsomeren). Hiervon zeigen 240 eine sechseckige Form; diese „Hexone“ tragen das bei allen Adeno-Viren vorkommende gruppenspezifische Anti- gen. 12 Kapsomere sind fünfeckig; sie enthalten in Gestalt der „Pentone“ und der daran inserierenden „Fibern“ das typenspezifische Antigen. Die DNS befindet sich im Innern des Kapsids.

\section{Züchtung}

Adeno-Viren lassen sich in Human-Zellkulturen gut züchten. Die Vermehrung erfolgt im Zellkern. In Mäuse- oder Hamsterzellen wirken einige Typen der Adeno-Viren transformierend, man unterscheidet im Tierversuch niedrig- und hochtumorigene Viren.

\section{Einteilung}

Die Mehrzahl der Adeno-Viren agglutiniert Erythrozyten bestimmter Tierspezies, obwohl AdenoViren keine Hülle besitzen. Man kennt jetzt 47 Typen, sie zeigen untereinander Antigenverwandtschaft. Die Hämagglutination kann zur serologischen Typisierung verwendet werden, steht aber an Bedeutung dem Neutralisationstest nach; sie wird durch Antikörper gegen die Fibern und die Pentone bewirkt.

Eine Feindifferenzierung der Adeno-Viren gelingt durch vergleichende Analyse der DNS mit Hilfe von Restriktionsenzymen (RE-Analyse) oder durch die Sequenzierung.

\section{Resistenz}

Das Virus ist außerhalb des Menschen relativ stabil; seine Infektiosität wird durch Äther nicht zerstört. 


\subsection{Rolle als Krankheitserreger}

\section{Vorkommen}

Adeno-Viren kommen bei Mensch und Tier vor, sie sind jedoch streng artspezifisch: Nur menschliche Adeno-Viren sind humanpathogen.

\section{Epidemiologie}

Im Alter von zwei Jahren haben viele Kinder eine Adeno-Infektion durchgemacht. Etwa 50\% der Infektionen im Kindesalter verlaufen inapparent.

\section{Übertragung}

Adeno-Viren werden ausschließlich von Mensch zu Mensch übertragen, und zwar vorwiegend durch Tröpfcheninfektion in der kalten Jahreszeit. Es kann die Übertragung aber auch durch Stuhl und Urin erfolgen (Schmutz- und Schmierinfektion). Die Ansteckung erfolgt leicht und schnell.

Als Infektionsquelle kommt der akut Erkrankte, und möglicherweise der latent Infizierte, in $\mathrm{Be}$ tracht. Beim akut Erkrankten wird das Virus im Speichel bzw. im Stuhl ausgeschieden. Beim latent Infizierten gelangt das Virus nur fluktuierend in den Speichel.

Einige Typen der Adeno-Viren treten auch im Stuhl auf, z.B. Adeno-Virus 31. Als typische Gastroenteritis-Erreger erscheinen die Typen 40 und $41 \mathrm{im} \mathrm{Stuhl} \mathrm{(s.} \mathrm{S.} \mathrm{591).}$

Gefürchtet sind bei Augenärzten, in Augenkliniken und bei Betriebsärzten nosokomiale Infektionen mit den Typen 3, 7, 8, 11, 19 und 37. Die Infektionen breiten sich schnell aus, wenn Tropfpipetten mehrfach benützt werden. In den Augenkliniken sind ungenügend sterilisierte Geräte, z.B. Tensiometer, eine weitere Ansteckungsquelle, v.a. aber der untersuchende Finger.

\section{Pathogenese}

Eintrittspforten für die Adeno-Viren sind der Nasenrachenraum und die Konjunktiven. Sie replizieren sich vorwiegend auf den Schleimhäuten der Luftwege (Nase, Rachen, Larynx, Konjunktiven, Bronchien) bzw. im Gastrointestinal-Trakt und in den dazugehörigen Lymphknoten sowie selten in den Meningen.
Im Sinne einer latenten Infektion beherbergt ein Teil der Menschen in den Tonsillen („adenoides Gewebe") und im Urogenitaltrakt Adeno-Viren über lange Zeit, ohne klinische Erscheinungen zu zeigen und meist ohne infektiöses Virus auszuscheiden. In den letzten Jahren hat sich ergeben, $\mathrm{da} ß$ latente Adeno-Virusinfektionen reaktiviert werden können, z. B. im Verlauf von Masern-Infektionen oder bei Knochenmarktransplantationen. Dementsprechend fluktuiert die Virusausscheidung. Krankheitssymptome werden aber nicht immer beobachtet. - Die latente Infektion bleibt trotz der Anwesenheit von humoralen Antikörpern und ZTL bestehen, vermutlich werden keine MHC-Antigene auf der Zellmembran exprimiert. AdenoDNS hat man in Blutlymphozyten festgestellt. Für das Ausmaß der Lungenveränderungen bei der Pneumonie scheinen frühe Proteine (E1B, Bcl-2ähnlich) verantwortlich zu sein, die die Wirkung des TNF- $a$ aufheben und damit den Zelltod (Apoptose) verhindern, das Virus vermehrt sich dann stärker.

\section{Klinik}

Die Inkubationsperiode beträgt 2-6 Tage. AdenoViren verursachen eine Vielfalt von Krankheitsbildern. Die Symptomatik ist nicht streng typgebunden. Folgende Krankheitsbilder werden beobachtet (Tabelle 13.1):

Akute fieberhafte Pharyngitis. Sie wird vorzugsweise bei Kindern beobachtet. Die Symptome sind Husten, verstopfte Nase, entzündeter Rachen und geschwollene Zervikal-Lymphknoten. Die AdenoViren der Typen 1, 2, 3, 5, 6 und 7 sind für diese meist sporadischen Infektionen verantwortlich.

Pharyngokonjunktival-Fieber. Dieses Krankheitsbild tritt epidemisch in Schulen und Kindergärten auf. Die Symptome sind Pharyngitis, Fieber und allgemeines Krankheitsgefühl. Bei den Typen 3 und 7 (und weiteren) steht als charakteristisches Symptom eine follikuläre Konjunktivitis im Vordergrund. Die Infektion erfolgt in diesen Fällen häufig in Schwimmbädern durch nicht-gechlortes Wasser („Schwimmbadkonjunktivitis“ - diese Konjunktivitis ist jedoch nicht $\mathrm{zu}$ verwechseln mit der durch Chlamydien erzeugten Krankheit, die ebenfalls als „Schwimmbadkonjunktivitis“ bezeichnet wird). 
Tabelle 13.1. Krankheiten durch Adeno-Viren

\begin{tabular}{|c|c|c|c|c|}
\hline Krankheit & Alter & $\begin{array}{l}\text { Häufige } \\
\text { Typen }\end{array}$ & $\begin{array}{l}\text { Seltene } \\
\text { Typen }\end{array}$ & $\begin{array}{l}\text { Isolie- } \\
\text { rung }\end{array}$ \\
\hline \multicolumn{5}{|c|}{ Respirationstraktinfekte } \\
\hline Pharyngitis & Junge Kinder & $1,2,5$ & $3,6,7$ & Rachen \\
\hline $\begin{array}{l}\text { Akutes resp. } \\
\text { Syndrom }\end{array}$ & Jugendliche & 4,7 & $3,14,21$ & Rachen \\
\hline \multirow[t]{2}{*}{ Pneumonie } & Jugendliche, & 4,7 & & Rachen \\
\hline & Junge Kinder & 3,7 & $1,2,4,5$ & Rachen \\
\hline \multicolumn{5}{|l|}{ Augeninfekte } \\
\hline $\begin{array}{l}\text { Pharyngo-kon- } \\
\text { junktival-Fieber }\end{array}$ & Kinder & 3,4 & $1,2,6,7$ & $\begin{array}{l}\text { Rachen } \\
\text { Auge }\end{array}$ \\
\hline $\begin{array}{l}\text { Epidemische Ke- } \\
\text { rato-Konjunk- } \\
\text { tivitis }\end{array}$ & Alle Altersstufen & 8,37 & 19,11 & Auge \\
\hline \multicolumn{5}{|c|}{ Genital/Urogenital-Infekte } \\
\hline Zervizitis & Erwachsene & 37 & 19 & $\begin{array}{l}\text { Genital- } \\
\text { sekrete }\end{array}$ \\
\hline Urethritis & Erwachsene & 37 & & \\
\hline $\begin{array}{l}\text { Hämorrh. } \\
\text { Zystitis }\end{array}$ & Junge Kinder & 11 & 21 & Urin \\
\hline \multicolumn{5}{|c|}{ Enteritische Infekte } \\
\hline Gastroenteritis & Junge Kinder & 40,41 & 31 & Stuhl \\
\hline \multicolumn{5}{|c|}{ Infekte bei Immundefekten } \\
\hline $\begin{array}{l}\text { Enzephalitis- } \\
\text { Meningitis }\end{array}$ & $\begin{array}{l}\text { alle Altersgrup- } \\
\text { pen }\end{array}$ & $11,34,35$ & 7,12 & Liquor \\
\hline Pneumonie & $\begin{array}{l}\text { vor allem bei } \\
\text { AIDS }\end{array}$ & & & Lunge \\
\hline Gastroenteritis & & & $43-47$ & Stuhl \\
\hline Generalisation & & & 2,5 & Blut \\
\hline
\end{tabular}

Die Typen 19 und 37 werden auch genital übertragen. Die Typen 4247 wurden bei Patienten mit AIDS isoliert. 90\% aller Isolate werden von den Serotypen 1-8 gestellt (abgesehen von den Typen 40 und 41). Die Typen 3, 7, 11, 14 u. a. werden mit dem Urin ausgeschieden. Eine Meningoenzephalitis ist selten.

Keratokonjunktivitis. Die Typen 8, 11, 19 und 37 nehmen eine Sonderstellung ein. Nach einer Inkubationsperiode von 8-10 Tagen verursachen sie eine schmerzhafte Keratokonjunktivitis. Die Schmerzhaftigkeit der Adeno-Erkrankung ist ein differentialdiagnostisches Merkmal: Die HerpesKeratitis verläuft demgegenüber schmerzlos. Es treten im Verlauf der Entzündung Hornhauttrübungen auf, die trotz ihrer längeren Dauer gutartig sind. Typisch für dieses Krankheitsbild ist die Schwellung der präaurikulären Lymphknoten. Diese Keratokonjunktivitis tritt bei Metallarbeitern („shipyard eye") und als nosokomiale Infektion in Augenkliniken auf (Abb., s. S. 688).
Akutes respiratorisches Syndrom. Dieses Syndrom ist durch Fieber, Pharyngitis, Bronchitis, Husten, Krankheitsgefühl und Lymphadenitis colli charakterisiert. Es tritt in epidemischer Form bei Adoleszenten, und bei Soldaten (USA, Typ 4 und 7) auf. Man findet vorwiegend die Typen 3, 4, 7, 14, 21 und 24. Die Erkrankungen sind i. allg. gutartig und bleiben auf die oberen Luftwege beschränkt. Die Infektion kann sich aber bis zur interstitiellen VirusPneumonie steigern. Bei Kindern verläuft die Pneumonie in seltenen Fällen tödlich.

Otitis media. Als Folge einer Adeno-Virusinfektion kann es schließlich auch zu einer Otitis media kommen. Auch hier gilt, daß Viren zumeist die Wegbereiter einer bakteriellen Superinfektion sind.

Meningitis. Eine Meningitis durch Adeno-Viren (Typen 3, 4, 7, 12) ist selten.

Hämorrhagische Zystitis. Eine hämorrhagische Zystitis ist bekannt (Typen 11, 21). Adeno-Viren kommen auch als Erreger einer Urethritis und einer Zervizitis vor, meist bei Immundefekten.

Mesenterial-Adenitis. Eine durch Adeno-Virus bedingte Mesenterial-Adenitis täuscht eine Appendizitis vor. Die Adeno-Viren der Typen 1, 2, 3 und 5 können Invaginationen des Darmes hervorrufen.

Gastroenteritis. siehe S. 591.

Pneumonie. Besonders gefährlich ist eine Pneumonie bei immundefizienten oder immunsupprimierten Personen. Auch im Gefolge einer durch eine Masern-Erkrankung hervorgerufenen Immunsuppression kann eine Adeno-Virus-Pneumonie auftreten.

Generalisierte Infektionen. Generalisierte Infektionen v.a. bei Immundefekten werden als obliterierende Bronchiolitis, als Meningoenzephalitis, als Hepatitis, als Myokarditis, z.T. mit Exanthemen, beobachtet (Typen 4, 7, 34, 35); sie sind aber selten. 15\% der Myokardbiopsien bei dilatativer Myokarditis sind positiv für Adeno-Viren.

\section{Immunität}

Adeno-Virusinfektionen verursachen eine relativ dauerhafte Immunität. Kinder zeigen wegen der geringen Anzahl der vorausgehenden Infekte eher typenspezifische Seroreaktionen als Erwachsene. Es bilden sich neutralisierende und nicht-neutralisierende Antikörper, Monozyten und NK-Zellen werden aktiviert und ZTL entstehen. 


\section{Labordiagnose}

Die Labordiagnose von Adeno-Virusinfektionen läuft über eine Isolierung des Virus selbst, die nur in einigen Speziallabors durchgeführt wird. Die Isolierung der Adeno-Viren bei der akuten Infektion gelingt aus Rachenspülwasser, Konjunktivalsekret, aus dem Liquor und dem Stuhl. Bei Gastroenteritis-Verdacht wird ein Antigen-ELISA in Stuhlextrakten eingesetzt (s. S. 591). In der Latenzphase ist die Isolierung des Virus aus den Tonsillen nur durch Langzeitkultivierung des Gewebes möglich; im Direkt-Extrakt erweist sich das Gewebe meist als virus-negativ. Durch die PCR kann man den direkten Virusnachweis aber auch in diesen Fällen führen. - Antikörper lassen sich mit der gruppenspezifischen KBR und dem eher typenspezifischen HHT oder IgM/IgG-ELISA nachweisen, die Typisierung erfolgt durch den Neutralisationstest.

Durchseuchungsstudien lassen sich mit der KBR nur bedingt durchführen, weil die Antikörper nach einigen Jahren verschwinden. Bei der Pneumonie durch Adeno-Viren fehlen die Kälteagglutinine; dies steht im Gegensatz zu den Infektionen mit M. pneumoniae.

\section{Prävention}

Allgemeine Maßnahmen. Schmutz- und Schmierinfektionen lassen sich durch Allgemeinhygiene reduzieren. In Schwimmbädern verhindert Chlorierung des Wassers lokale Epidemien. In Augenkliniken ist strengste Hygiene einzuhalten. Das gehäufte Auftreten von Infektionen in Kindergärten etc. läßt sich durch gezielte Hygienekontrollen verhindern oder zumindest reduzieren. Ein Chemotherapeutikum gibt es nicht.

Vakzination. Zur Verhütung der akuten Atemwegserkrankungen wurde in den USA ein Lebendimpfstoff entwickelt. Man verwendet Adeno-Virus vom Typ 3, 4, 7 und 21. Das Impf-Virus wird in menschlichen Zellen gezüchtet; man appliziert es in Gelatine-Kapseln. Auf diese Weise kann ein Angehen der Infektion im Nasenrachenraum verhindert werden; erst im Magen wird das Virus frei und stimuliert den Immunapparat.

Meldepflicht. Erregernachweis bei epidemischer Kerato-Konjunktivitis.

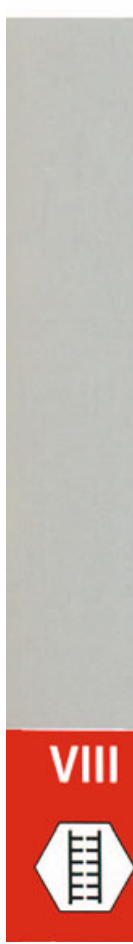

\section{ZUSAMMENFASSUNG: Adeno-Viren}

Virus. Doppelstrang-DNS-Viren in IkosaederKapsid mit Fibern an 12 typspezifischen Pentonen; 240 gruppenspezifische Hexone; 47 Typen. ZPE in menschlichen Zellen, Transformation tierischer Zellen und Tumorbildung.

Vorkommen. Bei vielen Tierspezies und beim Menschen vorkommend, streng artspezifisch.

Epidemiologie. Weit verbreitet, frühzeitige Durchseuchung.

Übertragung. Tröpfcheninfektion, Konjunktival-, Nosokomialinfektion, Virus ist relativ stabil.

Pathogenese. Akute Erkrankung durch primären Zellschaden. Adeno-Viren persistieren latent für Jahre in den Tonsillen ohne Erkrankung.
Klinik. 2-6tägige Inkubationsperiode: Fieberhafte Pharyngitis, Pharyngokonjunktivalfieber, akutes respiratorisches Syndrom, schmerzhafte Keratokonjunktivitis, Meningitis, Pneumonie u.a.

Immunität. Relativ dauerhaft.

Labordiagnose. Virusisolierung in einigen Labors, HHT zur Typendifferenzierung, KBR wegen Kreuzreaktionen unbefriedigend. REAnalysen, PCR.

Therapie. Keine spezifische Therapie.

Prävention. Verhütung von nosokomialen Infektionen, Impfstoff nicht gebräuchlich.

Meldepflicht. Erregernachweis bei epidemischer Kerato-Konjunktivitis. 


\section{EINLEITUNG}

Die Herpes-Viren sind klinisch außerordentlich bedeutsam. Sie erzeugen eine Vielzahl ganz unterschiedlicher Symptome bzw. Krankheiten: Enzephalitis, Pneumonie, Exantheme, Hepatitis u. v.a. Gemeinsam ist ihnen die Eigenschaft der Reaktivierbarkeit aus der Latenz. Alle Viren der Herpes-Gruppe persistieren trotz der Anwesenheit von neutralisierenden Antikörpern und von zytolytischen Gedächtniszellen lebenslang im Organismus. Die Infektionsfolgen bei Immundefizienz sind gefürchtet und oft lebensbedrohlich. Das EBV und das HHV 8 sind an der Entstehung von vielen Tumorarten beteiligt. Einen Lebendimpfstoff gibt es gegen die Windpocken. Akute Infektionen lassen sich jetzt durch Chemotherapeutika behandeln.

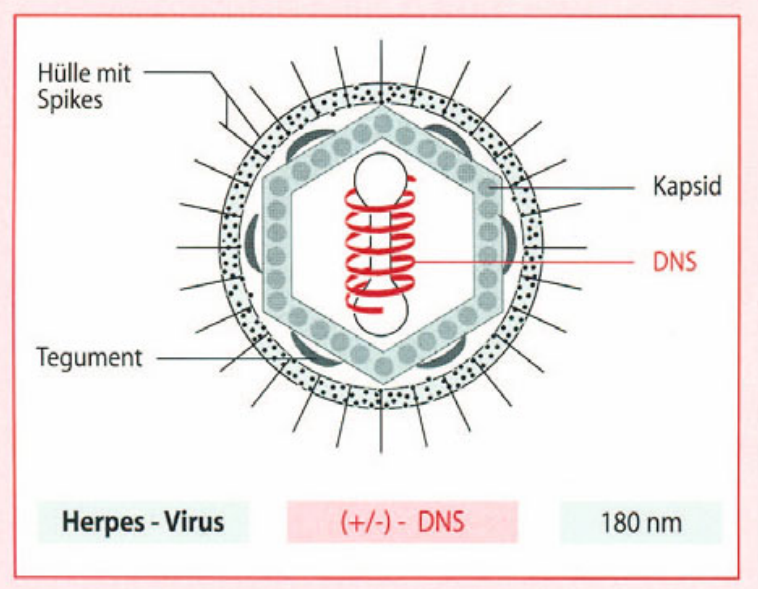

\section{Genom}

Die Doppelstrang-DNS (+/-) besitzt ein Molekulargewicht von $125-220 \mathrm{kbp}$. Die isolierte DNS ist selbst infektiös. Ein Vergleich der DNS-Eigenschaften von verschiedenen Herpes-Viren erlaubt Aussagen über die phylogenetische Verwandtschaft innerhalb der Herpes-Virus-Gruppe.

\section{Morphologie}

Die Erreger der Herpes-Gruppe besitzen einen zentralen DNS-Innenkörper. Dieser ist in ein ikosaederförmiges Kapsid mit 162 Kapsomeren eingebaut. Das Virion mißt etwa $180 \mathrm{~nm}$ im Durchmesser. Außen ist das Kapsid von einer lipidhaltigen Hülle umgeben. In diese Hülle sind verschiedene
Glykoproteine eingebaut, die unterschiedlich lange Spikes bilden. Zwischen Hülle und Kapsid befindet sich das Tegument.

\section{Einteilung}

Die Herpes-Gruppe umfaßt folgende Erreger:

- Herpes-simplex-Virus: $a$-Herpes-Virus (HSV, Typ 1 und 2);

- Varizellen-Zoster-Virus: $a$-Herpes-Virus (VZV);

- Zytomegalie-Virus: $\beta$-Herpes-Virus (ZMV);

- Epstein-Barr-Virus: $\gamma$-Herpes-Virus (EBV);

- Humanes Herpes-Virus 6: $\beta$-Herpes-Virus (HHV 6);

- Humanes Herpes-Virus 7: $\beta$-Herpes-Virus (HHV 7);

- Humanes Herpes-Virus 8: $\gamma$-Herpes-Virus (HHV 8).

\section{Resistenz}

Die Viren der Herpes-Gruppe sind in der Außenwelt relativ stabil, wegen ihrer Lipidhülle jedoch ätherempfindlich.

\section{Vorkommen}

Der Mensch beherbergt zwei Typen des Herpessimplex-Virus sowie die anderen menschenpathogenen Herpes-Viren.

Bei verschiedenen Affenarten treten Tumoren der weißen Blutkörperchen auf, die man auf Infek- 
tionen mit Viren der Herpes-Gruppe (H. saimiri, H. ateles u. a.) zurückführt. Tumoren treten in den natürlichen Wirten nicht auf, nur bei der experimentellen Infektion anderer Affenspezies.

Das Virus der als Marek'sche Geflügellähme bezeichneten Tumorkrankheit ist ebenso ein HerpesVirus. Durch Immunisierung mit dem nicht tumorigenen, aber kreuzimmunisierenden Puten-Herpes-Virus kann man das Entstehen der Geflügellähme verhindern. Das Herpes-Virus des Frosches erzeugt das Luckésche Adeno-Karzinom der Niere. Cynomolgus- und Rhesusaffen beherbergen das für den Menschen hochpathogene Herpes-B-simiae-Virus.

\subsection{Herpes-simplex-Virus}

Der Typ 1 des Herpes-Virus wird als „Oraltyp“ bezeichnet, weil die Primärinfektion vorwiegend über die Mundhöhle erfolgt. Bis zum 6.-10. Lebensjahr werden viele Kinder mit dem Typ 1 infiziert. Der Typ 2 wird als "Genitaltyp" bezeichnet. Er ist seltener und verursacht vornehmlich bei Jugendlichen und Erwachsenen herpetische Erkrankungen am Genitale.

Die Infektion mit dem HSV 1 verläuft in etwa $90 \%$ bis $95 \%$ der Fälle inapparent und bleibt das ganze Leben über als latente Infektion bestehen. Aus dieser Situation entwickeln sich wiederholt kurzdauernde Exazerbationen, meistens als bläschenförmige, harmlose Hauteruptionen: Herpes recidivans. In Einzelfällen aber verursacht das Herpes-simplex-Virus lebensbedrohliche Krankheiten (Enzephalitis, Herpes neonatorum), sei es als direkte Folge der Primärinfektion (Primärerkrankung) oder als Rezidiv, besonders bei Immundefekten (AIDS).

\subsubsection{Beschreibung}

\section{Genom}

Das Virusgenom kodiert für etwa 90 Proteine; diese werden in „Sofort"-Proteine, „Früh“-Proteine und „Spät"-Proteine bzw. $a$-, $\beta$ - und $\gamma$-Proteine eingeteilt. Ihre Synthese wird vom Genom in einer 3-Stufen-Kaskade abgerufen. Die Sofortproteine üben Regulationsfunktionen aus, während die Frühproteine zumeist Enzyme der DNS-Synthese sind (DNS-Polymerase, Thymidin-Kinase, Ribonukleotid-Reduktase u.a.). Als Spätproteine werden diejenigen Genprodukte bezeichnet, die relativ spät nach der Infektion auftreten und vorzugsweise als
Strukturproteine des Virus dienen; zu ihnen gehört ein transaktivierendes Protein (s. S. 467).

\section{Replikation}

Das Virus wird im Kern der Zelle montiert, wobei ein Teil der Kernmembran die Matrix für die Virushülle abgibt (s. Schema S. 473). Diese Matrix enthält 12 Glykoproteine, die beim Befall humorale und zelluläre Immunreaktionen auslösen. Sofortproteine, Kapsid und Enzyme regen gleichermaßen die Bildung von Antikörpern an. Unter der Hülle läßt sich ein „Tegument" nachweisen; es enthält ein Protein (pp 65), das zwar als Spätprotein gebildet wird, aber nach dem Eindringen des Virus in die Zelle die Wirkung der Sofortproteine verstärkt („Transaktivator"-Wirkung). „Latency associated transcripts" (LATs) treten im Kern von latent infizierten Zellen (Neuronen) auf. Einige Gene induzieren die Fusion der befallenen Zellen, ein anderes blockiert die Präsentation der Oligopeptide. HSV 1 besitzt ein Gen mit zelltransformierenden Eigenschaften, bei HSV 2 sind es zwei. Die DNS des HSV wirkt auBerdem mutagenisierend, DNS-Synthese-steigernd und DNS-amplifizierend auf die Zelle. HSV 2-DNS kooperiert in vitro nach Transfektion mit HPV 16DNS bei der Transformation von Epithelzellen.

\section{Züchtung}

- Auf der Chorioallantois-Membran des bebrüteten Hühnereies.

- Auf der Kornea des lebenden Kaninchens.

- In der Zellkultur. Hierzu sind zahlreiche Zellspezies geeignet.

Der zytopathische Effekt besteht in Abkugelung mit nachfolgender Lyse und in Chromosomenschäden sowie in einer synzytialen Verschmelzung (Fusion) der vom Virus befallenen Zellen (Polykaryozyten). Man beobachtet Riesenzellen sowohl in vitro als auch im Organismus. In den Kernen der infizierten Zellen befinden sich typische Einschlußkörperchen.

\section{Einteilung}

Das HSV kommt in zwei Typen, Typ 1 und Typ 2, vor, die sich durch ihre biologischen und pathogenetischen Eigenschaften beträchtlich unterscheiden. Die Typen 1 und 2 enthalten die typspezifischen Glykoproteine G1 bzw. G2 sowie typspezifische Epitope der Glykoproteine C1 und C2. 


\section{Resistenz}

Das HSV ist bei höherer Temperatur sehr empfindlich; dagegen hält es sich längere Zeit im Kühlschrank und ist bei $-70^{\circ} \mathrm{C}$ stabil. Seine Infektiosität wird durch Lipidlösungsmittel und durch $\mathrm{Na}$ Hypochlorit schnell zerstört.

\subsubsection{Rolle als Krankheitserreger}

\section{Vorkommen}

Das Wirtsspektrum des HSV ist breit; es umfaßt neben dem Menschen als natürlichem Wirt zahlreiche Nagetiere, darunter das Kaninchen.

\section{Epidemiologie}

Die Durchseuchung mit HSV 1 steigt in den Entwicklungsländern durchweg viel früher an als in den Ländern mit hohem Lebensstandard, diejenige mit HSV 2 ist v.a. in einigen Risikogruppen (Prostituierte, Homosexuelle) hoch. Die RE-Analyse von HSV-Stämmen aus Japan und aus den USA hat ergeben, daß es Kontinent-spezifische DNS-Sequenzen gibt. Die Herpes-Enzephalitis ist mit 50\% Hauptrepräsentant aller Enzephalitiserkrankungen in unseren Breiten. In Deutschland kommen bei einer Durchseuchung von mehr als $95 \%$ etwa 200 Fälle von Herpes-Enzephalitis pro Jahr vor; die ebenfalls gefürchtete Herpes-Sepsis der Neugeborenen erbringt 100-500 Fälle, die Zahl steigt an. In den USA sind z.Z. 25\% aller Frauen HSV 2 positiv.

\section{Übertragung}

Die Infektion durch das HSV erfolgt von Mensch zu Mensch; sie zeigt endemischen Charakter: 10$15 \%$ aller Menschen, die älter sind als 6 Jahre, scheiden während ihres Lebens das HSV in der Tränenflüssigkeit, im Speichel oder im Genitalsekret für kürzere oder längere Zeit aus. Prostituierte beherbergen im Genitale oft den Typ 2. Die Durchseuchung mit dem HSV2 steigt seit zwei Jahrzehnten deutlich an; sehr wichtig sind asymptomatische Ausscheider für die Übertragung. Bei der Primärinfektion wird das Virus etwa drei Wochen lang durch den Speichel, durch den Stuhl oder durch Genitalsekrete ausgeschieden, bei Rezidiven nur einige Tage.
Die Kontagiosität ist nicht sehr hoch: Ein intimer Kontakt im Sinne der Schmierinfektion ist notwendig. In Betracht kommt die Infektion von Mund zu Mund, durch Direktkontakt oder als Schmierinfektion über ein Vehikel (Finger), ferner die Infektion durch Geschlechtsverkehr (für Typ 2 und 1) sowie die Infektion während der Geburt. Die Herpes-Sepsis tritt auch bei den Neugeborenen von symptomfreien Graviden auf. Es gibt selten auch nosokomiale Infektionen, z. B. durch Säuglingsschwestern, durch kontaminierte Hände. Der Ursprung der nosokomialen Infektionen läßt sich durch RE-Analysen der HSV-DNS aufklären (s. S. 522).

\section{Pathogenese}

Allgemeines. Die Besonderheit der Wirts-VirusBeziehungen beim HSV besteht darin, daß nach der Primärinfektion das Virus - dies gilt für alle Herpes-Viren - dauernd im Organismus verbleibt. Seit 1930 ist bekannt, daß Herpes-Rezidive nur bei denjenigen Personen auftreten, welche bereits neutralisierende Antikörper aufweisen. Man sprach vom „immunologischen Herpes-Paradoxon“. Diese Erscheinung läßt sich durch die Tatsache erklären, daß das latente Virus in den Neuronen der Spinalganglien keine Proteine bildet und dadurch dem $\mathrm{Zu}$ griff der humoralen und der zellulären Immunabwehrfaktoren entzogen ist. Die Situation wird noch komplizierter, wenn man bedenkt, daß bei schon vorhandener Typ 1-Infektion eine genitale Superinfektion mit dem Typ 2 erfolgen kann (Abb. 14.1).

Die latente Infektion. Nach der Übertragung auf die Haut oder die Schleimhäute sowie der Replikation gewinnt das Virus alsbald Zugang zu den sensorischen Nervenendigungen des zuständigen Dermatoms; es erreicht nach einer axonalen Wanderung von 1-2 Tagen das sensorische Ganglion; im Falle einer oralen oder genitalen Infektion werden meist das Trigeminus-Ganglion bzw. die Lumbosakralganglien besiedelt. Dort vermehrt sich das Virus etwa 6-8 Tage lang. Das Virus wird aber nicht eliminiert. Vielmehr persistiert die Virus-DNS lebenslang. Sie bildet einen Ring und verbleibt in nicht-integriertem Zustand im Neuron, wobei nur das Gen für die LAT's (latency-associated transcripts) transkribiert wird. Damit hat sich das Stadium der Latenz herausgebildet. Infektiöses Virus läßt sich jetzt nicht mehr nachweisen. Die Anwesenheit des Virusgenoms läßt sich aber durch Ko- 


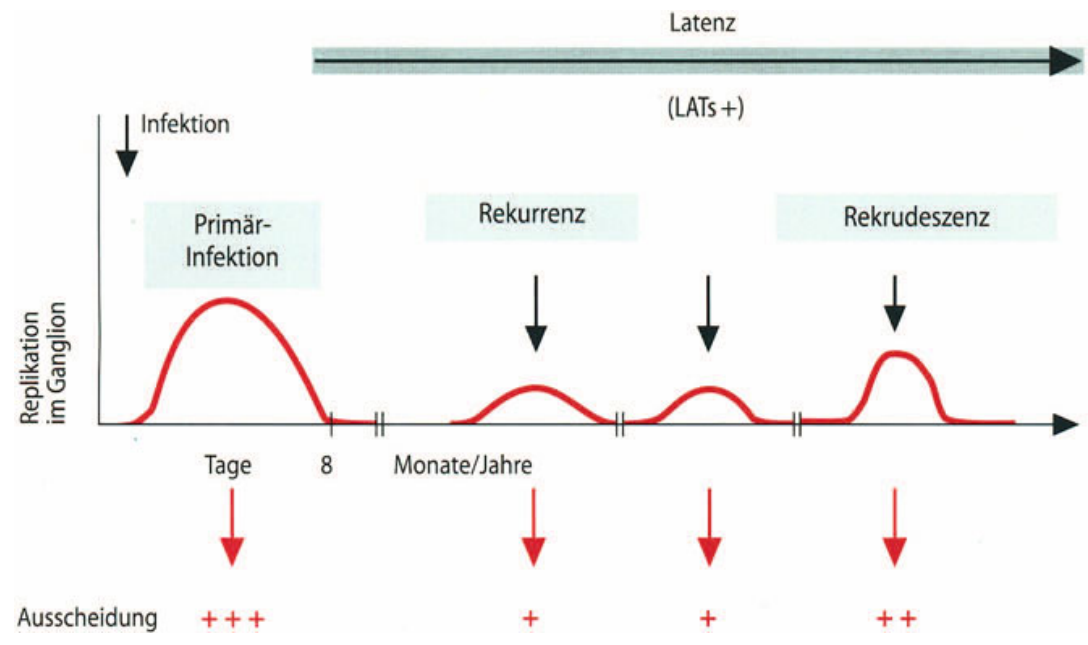

Abb. 14.1. Latenz des Herpessimplex-Virus: Primärinfektion, Rekurrenz und Rekrudeszenz, Virusreplikation im Ganglion, Ausscheidung sowie Anwesenheit der LATs in den Neuronen kultivierung und Hybridisierung beweisen. Es gibt Anhaltspunkte dafür, daß HSV-DNS auch im ZNS und in den Neuronen des Frankenhäuser'schen Plexus der Vagina persistiert bzw. latent bleibt.

Reaktivierung. In welcher Weise exogene Noxen (Fieber, Menstruation u.a.) die Reaktivierung des HSV-Genoms bewirken, ist noch nicht klar. Man vermutet ein Nachlassen der zellgebundenen Immunität und zieht hormonale Einflüsse in $\mathrm{Be}-$ tracht. Im Tierexperiment hat sich zeigen lassen, daß bei Mäusen eine $U V$-Bestrahlung der Haut die Entstehung von Suppressorzellen hervorruft. Nach einer Reaktivierung wird HSV im Spinalganglion in relativ großen Mengen gebildet. Das Virus wandert dann über das Axon zurück zur Peripherie. Es verläßt die Nervenendigungen und gewinnt $\mathrm{Zu}-$ gang $\mathrm{zu}$ den Epithelzellen der Haut und vermehrt sich dort (s.u.). Damit ist das Stadium der Rekurrenz erreicht. Man bezeichnet als Rekurrenz das symptomlose Wiederauftreten von infektiösen Herpes-Partikeln in der Peripherie (s. S. 480 u. 483).

Treten bei der Reaktivierung der persistenten Herpes-Infektion klinische Symptome auf, so spricht man von Rekrudeszenz oder gleichsinnig vom Rezidiv. Die Rekurrenz tritt häufiger auf als die Rekrudeszenz. Bei immundefizienten und immunsupprimierten Personen kann die Reaktivierung des Virus und seine Ausscheidung mit oder ohne klinische Symptome erfolgen. Rezidive sind bei manchen Menschen häufig, bei anderen selten; bei der Hälfte der Virusträger treten keinerlei Rezidive auf. Bei häufigen Rezidiven an der gleichen Stelle kann sich nach längerer Zeit eine Störung der Sensibilität infolge Ausfalls von Neuronen ergeben.

Die Rolle von Immuneffektoren in der Pathogenese. Vor dem Eintritt in die Epithelzellen der Haut (s.o.) ist das Virus kurze Zeit (im Experiment) durch Antikörper neutralisierbar. Sobald es sich aber erst in den Epithelzellen repliziert, induziert es Mikrofusionen zwischen benachbarten Zellen und breitet sich über Zellverbindungen aus. $\mathrm{Zu}$ erst treten im Epithel Chemokine auf, die CD4-Zellen anlocken und IFN- $\gamma$ produzieren. Die weitere Ausbreitung der lokalen Infektion in den Bläschen kann jetzt durch das Austreten von Antikörpern und zellulären Elementen (ADCC und ZTL) blokkiert werden. Bei T-Zell-Defekten gibt es andererseits große Ulzera der Haut, z. B. bei AIDS (s. S. 609).

Das HSV ist ein Schulbeispiel für die immunologische Verfremdung der Zellmembranen durch Virus-kodierte Glykoproteine. Diese werden membranständig und haben das Vermögen, IgG über dessen Fc-Stück zu binden. Auf diese Weise kann sich die befallene Zelle gegen die zytolytische Wirkung von T-Lymphozyten schützen. Das Glykoprotein C bindet die C3b-Komponente des Komplements und schützt die infizierte Zelle somit vor der C-Lyse.

Infektionen durch HSV2. Die Primärinfektion erfolgt bei HSV 2 meist über die Genitalorgane. Oft werden Kopfschmerzen und Nackensteifigkeit beobachtet. Die HSV 2 bedingte Meningitis kann primär und als Rezidiv entstehen. Ein beträchtlicher Anteil der Meningitiden verläuft ohne Auftreten 
eines Haut-Rezidivs. Die Fazialis-Lähmung (Bell's palsy) wird z.T. durch HSV 2 hervorgerufen.

Enzephalitis. Die Enzephalitis wird fast immer durch HSV 1 verursacht. Sie befällt die temporalen, orbitoparietalen Gebiete des ZNS und wird als nekrotisierende Enzephalitis manifest. Unbehandelt sterben etwa $70 \%$ der Erkrankten; der Rest überlebt mit neurologischen Abnormitäten. Der Grund für die Lokalisation sind möglicherweise HSV-empfängliche Astrozyten des primären Neurons des Bulbus olfactorius („empfängliches Fenster“). Die Fasern des Bulbus olfactorius sind mit den Regionen des limbischen Systems im Parietallappen verbunden. Man schätzt in etwa 1/3 der Fälle, daß diese zusätzliche Infektion mit Propagation über den N. olfactorius die Ursache ist. In anderen Fällen sind Exazerbationen selbst die Ursache der Enzephalitis; man vermutet ein vom Trigeminus-Ganglion ausgehendes Wandern des Virus oder die Aktivierung von bereits im ZNS vorhandener HSV-DNS.

HSV-Keratitis. Es ist bislang nicht sicher, ob eine rezidivierende HSV-Keratitis die Folge einer primären Kornealinfektion ist; sie könnte auch im Ganglion auf weitere Neuronen überspringen, die die Kornea versorgen. Zwar sprechen Tierversuche für die erste Annahme, sie geben aber auch Hinweise dafür, daß das HSV oder sein Genom in der Peripherie, z. B. auf der Haut oder der Kornea persistieren kann. Auch beim Menschen gibt es neuerdings solche Befunde.

Die Fähigkeit des HSV, sich vom Epithel der Kornea in das Stroma auszubreiten, ist durch „Virulenzgene" bedingt. Dies gilt auch für das Vordringen des HSV vom Spinalganglion ins Rückenmark oder in das ZNS (Neuroinvasivität, Neurovirulenz). Während die Keratitis dendritica durch das HSV selbst verursacht wird, stehen ursächlich Chemokine und immunpathologische sowie Autoimmunitäts-Prozesse bei der Keratitis disciformis des Stromas im Vordergrund (Abb., s. S. 689).

Herpes neonatorum. Die „Herpes-Sepsis“ der Neugeborenen ist wahrscheinlich die Folge einer ungenügenden Funktion der dendritischen Zellen und Makrophagen (IL-12-Mangel?, TH-2-Reaktivität!). Mütterliche Antikörper verleihen einen gewissen Schutz vor der Infektion und Erkrankung. Meist sind es Infektionen mit HSV-2, die schwerer verlaufen als mit HSV-1 und sich weniger gut behandeln lassen.

\section{Klinik}

Bei einem Großteil der HSV-bedingten Erkrankungen dominiert Bläschenbildung auf der Haut und den Schleimhäuten (Mund, Genitale). Hinzu gesellen sich Erscheinungen am Auge, am peripheren und zentralen Nervensystem, an den inneren Organen und im Gastrointestinaltrakt.

Grundsätzlich muß zwischen Primärerkrankungen und Rezidiven unterschieden werden; die letzteren werden auch als Rekrudeszenz bezeichnet. Die Inkubationsperiode beträgt bei der Primärinfektion 2-12 Tage (im Mittel sechs Tage).

\section{Primärerkrankungen}

Ein Großteil der Primärerkrankungen durch Herpes-Viren sind Kinderkrankheiten. Obwohl etwa 90\% der Herpes-Infektionen symptomlos bleiben, sieht man die manifeste Primärerkrankung durch Typ 1 relativ häufig, da praktisch alle Kinder infiziert werden. Demgegenüber tritt die Primärerkrankung bei Erwachsenen wegen der relativen Seltenheit der hier in Betracht kommenden Infektionen mit Typ 2 in den Hintergrund.

Gingivostomatitis herpetica. Die Gingivostomatitis herpetica ist eine mit Bläschenbildung einhergehende Entzündung der Mundschleimhaut und des Zahnfleisches im Bereich der vorderen Mundhöhle. Die Bläschen mazerieren und ulzerieren leicht und zeigen dann einen blutigen Grund. Die Primärinfektion kann sich als Rhinitis, als Tonsillitis oder als Pharyngitis mit Lymphknotenschwellungen und Fieber manifestieren. Zur Differentialdiagnose müssen die Herpangina und Stomatitiden anderer Genese (Stomatitis aphthosa, Agranulozytose) in Betracht gezogen werden (Abb., s. S. 688).

Vulvovaginitis herpetica. Es kommt zu einẹr Entzündung des weiblichen Genitale einschließlich der Zervix mit weißen, scharf abgegrenzten plaqueartigen Herden. Die Herde erinnern an Aphthen. Auch am Penis gibt es Bläschenbildungen. Die Affektionen kommen bei Jugendlichen und Erwachsenen meist nach Infektion mit dem HSV 2 vor $(90 \%)$. Liegt bereits eine orale HSV 1-Infektion vor, so verläuft eine genitale Primärinfektion i. allg. etwas leichter. Nur etwa $20-40 \%$ aller genitalen HSV-2-primär-Infektionen sind apparent. 
Keratokonjunktivitis herpetica. Es entsteht eine Hornhauttrübung mit Bläschenbildung auf der Kornea und auf der Bindehaut. Auf der Kornea kann es $\mathrm{zu}$ verschiedenartig geformten dendritischen Ulzera kommen; die Infektion kann auch in die Tiefe vordringen, bereitet aber keine Schmerzen (Abb., s. S. 689).

Ekzema herpeticum. In Hautgebieten mit atopischen Ekzem-Effloreszenzen breitet sich die sonst lokal verbleibende bläschenförmige Herpes-Effloreszenz diffus aus und ergreift ausgedehnte Hautbezirke. Bei der Abheilung bilden sich dicke Krusten. Es ist eine bedrohliche Erkrankung: Gabe von Aciclovir (Abb., s. S. 688).

Meningitis und Meningoenzephalitis. Die primäre Herpes-Meningitis wird durch den Typ 2 verursacht. Sie ist gutartig, zeigt eine anfängliche Vermehrung der Neutrophilen; später finden sich nur noch Lymphozyten im Liquor. Dagegen ist die primäre, durch HSV 1 verursachte Meningoenzephalitis herpetica eine ernste Krankheit, die tödlich ausgehen kann; Häufigkeit $2,3 \times 10^{6} / \mathrm{Jahr}$. Sie bildet klinisch die allgemeinen Symptome einer Enzephalitis aus (Erbrechen, Krämpfe, Bewußtseinstrübung, Fieber, Kopfschmerzen, Koma, Lähmungen).

Generalisierter Herpes der Neugeborenen (Herpes neonatorum). Die Infektion durch HSV 2 (selten Typ 1) erfolgt meist im Geburtskanal; selten ist die Infektion nosokomial bedingt (Vater, Säuglingsschwester). Besonders gefährdet sind frühgeborene Kinder. Es gibt drei Formen:

- Bläschen auf der Haut, im Munde und am Auge;

- Enzephalomyelitis;

- Generalisierte „Herpessepsis“ mit Splenomegalie, Ikterus, Bläschen, Enzephalomyelitis; oft auch ohne Bläschen. Sie entwickelt sich z.T. aus der erstgenannten Form.

Oft sind Herpesläsionen im Bereich des Genitale der Mutter zu finden, die Infektionen erfolgen aber in etwa $70 \%$ ohne erkennbare Bläschen. Übertragungen treten auch dann auf, wenn in der Vorgeschichte (Partner!) kein Anhalt für eine symptomatische Genitalinfektion vorhanden ist. Das Risiko für die Übertragung des HSV auf das Neugeborene beträgt bei einem Primärherpes etwa 50\%, weil der Immunapparat noch nicht stimuliert ist, bei einem Rezidiv aber (apparent oder inapparent) nur etwa 5\%.

Der Herpes neonatorum führt unbehandelt in $80 \%$ zum Tode, Infektionen mit dem Typ 2 haben eine schlechtere Prognose als die mit dem Typ 1. Glücklicherweise ist die Krankheit selten (ein Fall auf 3000-12000 Geburten).

Seltene Erkrankungen. Seltenere Formen der primären Herpesinfektion sind Bläschenbildungen am Stamm oder an den Fingern, z. B. bei Schwestern und Krankenpflegern sowie Ringkämpfern (herpetic whitlow, herpetisches Panaritium). Selten ist auch die Hepatitis mit oder ohne Immundefekt (ACG!), die Ösophagitis und der Befall des Duodenums. Bei Homosexuellen beobachtet man eine Herpes-Proktitis und eine Herpes-Urethritis.

Primärinfektionen in der Frühschwangerschaft sind wegen der hohen Durchseuchung selten, deswegen treten nur ganz selten Embryopathien auf.

\section{Rezidive}

Auslösende Momente für Rezidive sind: Fieberhafte Infekte, Sonnenbrand, Röntgenbestrahlung, Menstruation, akute Gastritis. Die Bezeichnung "Schreckblase" deutet auch auf die Möglichkeit hin, eine Herpes-Exazerbation durch psychische Einwirkungen auszulösen.

Herpes simplex. Meist tritt die Exazerbation als Herpes simplex „recidivans" auf. Es treten - meistens an Übergangsstellen zwischen Haut und Schleimhaut - juckende Papeln auf, die sich schnell zu prallen Bläschen entwickeln (Abb., s. S. 688). Die Bläschen sind $1-3 \mathrm{~mm}$ groß und haben einen klaren Inhalt. Sie heilen unter Krustenbildung ab. Betroffen ist die Nasolabialgegend (Herpes labialis, Herpes facialis) und zunehmend häufiger der Genitalbereich (Herpes genitalis). Oftmals werden beim Rezidiv Kopfschmerzen, Fieber und lokale Lymphknotenschwellungen sowie Meningismus beobachtet. Sehr schwer verlaufen Rezidive mit Generalisation bei AIDS-Patienten. Genitale Infektionen rezidivieren bei ihnen häufiger als orale.

Herpes-Keratitis. Eine weitere Manifestation ist die Herpes-Keratitis. Diese ist wegen der Bläschenbildung und der Korneatrübung leicht zu erkennen; die Bläschen können ulzerieren. Die Krankheit ist langwierig und dauert oftmals einige Monate. Die Prognose ist nicht immer gut, weil der Entzündungsprozeß in das Stroma der Kornea vordringen kann und bei häufiger Wiederholung bleibende Trübungen der Hornhaut auftreten. Schmerzen werden nicht verspürt. 
Herpes-Meningitis. Als ernste Form der Exazerbation kann auch eine Herpes-Meningitis auftreten. Sie bietet das gleiche Krankheitsbild wie die primäre Herpes-Meningitis, meist durch HSV 2 verursacht.

Polyneuritis. Eine Polyneuritis (Guillain-BarréSyndrom) kommt wahrscheinlich ebenso im Gefolge von Rezidiven vor.

\section{Immunität}

Im Verlaufe einer primären HSV-Infektion entstehen zunächst IgM-Antikörper. Sie treten wenige Tage nach der Erkrankung auf. Die Glykoproteine des HSV spielen dabei eine wichtige Rolle. Sie reagieren weitgehend typenüberkreuzend.

Nach einer Primärinfektion entstehen neutralisierende und komplementbindende Antikörper der Klasse IgG sowie IgA-Antikörper. Die IgG-Antikörper lassen sich lebenslang nachweisen. Ihr Titer im Serum (KBR) ist weitgehend stabil; man nimmt an, daß wiederholte Boosterungen durch Rekurrenzen oder Rekrudeszenzen auftreten. Größere Titerschwankungen lassen sich jedoch kaum beobachten. IgM-Antikörper treten während eines Rezidivs nur sehr selten auf. Im Gegensatz zu den Verhältnissen bei HSV sinken die Antikörper (KBR) nach primären VZV-Infektionen im Laufe der Jahre ab; bei einem Zoster lassen sich in diesem Fall aber kräftige Titersteigerungen feststellen.

Zelluläre Immunreaktionen (ADCC, CD4- und CD-8-Lymphozyten sowie die Helferzell-abhängige Antikörperbildung) spielen die wichtigste Rolle bei der Limitierung der HSV-Infektion in den Organen und den Schleimhäuten. IgA-Antikörper-Anstiege bzw. hohe Titer werden sowohl nach genitalen Primärinfektionen mit HSV 2 als auch nach Rekurrenzen oder Rekrudeszenzen regelmäßig beobachtet, während die IgA-Antikörper nach Rekurrenzen mit HSV 1 kaum ansteigen.

\section{Klinische Differentialdiagnose}

In die klinische Differentialdiagnose zwischen primärem und rezidivierendem Herpes sind folgende Überlegungen mit einzubeziehen:

- Die extragenitale Primärinfektion kommt praktisch nur bei kleinen Kindern vor. Bei Erwachsenen tritt der orale Herpes nur als Exazerbation auf.
- Die genitale Primärinfektion tritt vornehmlich nach dem 15. Lebensjahr auf. Auch hier gibt es Rezidive.

\section{Diagnose der Herpes-Enzephalitis}

Die Herpes-Enzephalitis wird durch Elektro-Enzephalogramm, Computer-Tomogramm, NMR-Spektrum sowie evozierte Potentiale diagnostiziert. Die Diagnostik der Wahl ist die PCR im Liquor.

Die wichtigsten Symptome sind Kopfschmerzen, Fieber, Somnolenz, Sprachschwierigkeiten und Lähmungen. Tritt Bewußtlosigkeit (Koma) hinzu, so sind die Wirkungsmöglichkeiten der Chemotherapie gering.

\section{Labordiagnose}

Die Labordiagnose der HSV-Infektionen umfaßt Virusisolierung aus den Bläschen und Antikörpernachweis. Bei Primärinfektionen läßt sich HSV in Blutmonozyten nachweisen.

\section{Isolierung des HSV}

Die Isolierung des HSV wird in Zellkulturen vorgenommen. Als Untersuchungsmaterial dienen Rachenspülwasser, Rachenabstriche, Bronchiallavage, Liquor, Tränenflüssigkeit und Bläschenflüssigkeit; bei Autopsien entnimmt man Gewebeproben aus Gehirn und Leber. Typisch sind die nukleären Einschlußkörperchen in der Zellkultur oder im Gewebe. Der endgültige Nachweis erfolgt durch Neutralisation mit bekannten Seren. Die Typisierung des Virus gelingt im ELISA mit typenspezifischen, monoklonalen Antikörpern auf der festen Phase. Bei Knochenmarktransplantierten ist die Isolierung des HSV aus Rachenabstrichen zur Beurteilung der Immunitätslage wichtig. Methode der Wahl ist die PCR.

\section{Serologische Diagnose}

Die serologische Diagnose erfaßt im Neutralisationstest, in der KBR und im ELISA Antikörper der Klasse IgM, IgG und IgA. Nur deutliche Titeranstiege dürfen verwertet werden; sie kommen fast nur bei Erstinfektionen vor. Hinweise auf vorliegende genitale HSV 2-Infektionen sollen sich durch hohe IgAAntikörper erbringen lassen. Eine Differenzierung der HSV 1- und 2-Antikörper ist bisher nicht routinemäßig möglich, sie gelingt jedoch bei der Verwendung der Glykoproteine $\mathrm{G}$ oder $\mathrm{C}$ als Antigen.

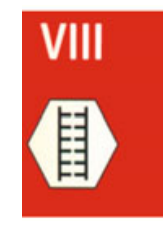




\section{Liquordiagnose}

Bei der Diagnose der Herpes-Enzephalitis gelingt der Nachweis des Virus im Liquor nur durch die PCR.

Serologisch versucht man, lokal gebildete IgGAntikörper im Liquor nachzuweisen: Der Liquor wird isoelektrisch fokusiert und auf eine Folie mit Antigenen (affinitäts-) geblottet. Die gebundenen Antikörper werden nach dem ELISA-Prinzip nachgewiesen.

\section{Therapie}

Mit der Behandlung ist bereits bei Verdacht auf eine HSV-Enzephalitis zu beginnen.

Die Folgen einer HSV-Enzephalitis lassen sich durch rechtzeitigen Beginn der Behandlung deutlich abschwächen, dabei ist vorzugsweise Acycloguanosin (ACG, Aciclovir) angezeigt. Auch die meist tödliche Herpes-Sepsis der Neugeborenen und das Ekzema herpeticum läßt sich durch Acycloguanosin behandeln; die HSV 1-infizierten Kinder haben nach der Behandlung eine bessere Prognose als HSV 2-infizierte.

Die Keratitis herpetica kann lokal mit Trifluormethylthymidin (TFT) oder mit Acycloguanosin behandelt werden. Keinesfalls darf Kortison im frühen Stadium angewandt werden; es ist nur bei bestimmten tiefliegenden Prozessen indiziert (K. disciformis).

Schwere Primär- und häufige Rezidiv-Erkrankungen (z.B. bei AIDS) werden oral durch ACG, Valaciclovir oder Famciclovir behandelt, lokal kann Penciclovir-Creme (Cidofovir, "Vectavir") oder $\mathrm{ZnSO}_{4}$-Gel benutzt werden. Bei ACG-Resistenz oder bei HSV-2-Infektionen kommt auch eine topische Behandlung mit Foscarnet in Betracht.

\section{Prävention}

Allgemeine hygienische Maßnahmen. Nosokomiale Infektionen in Krankenhausabteilungen für Neugeborene und für Immunsupprimierte sollten sich durch allgemeine Hygiene vermeiden lassen. Auf entsprechende Fürsorge haben auch Leukämiekranke und Zytostatika-behandelte Patienten Anspruch. Schließlich sollten auch Ekzemträger vor Herpes-Infektionen geschützt werden (Eczema herpeticum).
Maßnahmen unter der Geburt. In der Geburtshilfe ist $u$.U. eine gezielte Prophylaxe notwendig: Zeigt eine Schwangere die Zeichen einer primären oder rezidivierenden genitalen Herpeserkrankung (in Form der Vulvovaginitis herpetica), so ist die Schnittentbindung angezeigt. Das Neugeborene kann durch die Gabe von Gamma-Globulin zusätzlich Schutz erfahren; besonders indiziert ist diese Maßnahme dann, wenn ein frühgeborenes Kind auf natürlichem Weg zur Welt gekommen ist und die Mutter Herpesbläschen zeigt: Zusätzliche Gabe von Acicloguanosin an das Neugeborene.

Schutzimpfung. Die bisher angebotenen Impfstoffe zur Verhütung von Primärinfektionen oder von HSV-Rezidiven sind im Sinne eines spezifischen Immunschutzes wirkungslos; sie lösen allenfalls Plazebo-Effekte aus.

Chemoprophylaxe. Eine Chemoprophylaxe von rezidivierenden Genitalinfektionen läßt sich längerfristig durch orale Gaben von Acicloguanosin oder besser von Valaciclovir betreiben. Das in den Ganglien befindliche Virus wird aber nicht eliminiert. Alle Herpeseffloreszenzen (HSV 1 und 2) können frühzeitig mit einer der genannten Substanzen behandelt werden.

Meldepflicht. Enzephalomyelitis.

\section{Anhang}

Erythema exsudativum multiforme. Dieses Exanthem in typischer klinischer Ausprägung tritt oft nach HSV-, seltener nach VZV-Rezidiven auf. Häufig wird es sonst nach Infektionen mit Mycoplasma pneumoniae, Adeno-Viren, EBV und Mycobacterium tuberculosis beobachtet. Es soll etwa 10 Tage nach den Virusrezidiven auftreten, man vermutet eine Überempfindlichkeitsreaktion; das Virus läßt sich jedoch nicht nachweisen. Die rechtzeitige Behandlung des Rezidivs mit Acicloguanosin verhindert das Auftreten. 


\section{ZUSAMMENFASSUNG: Herpes-simplex-Virus}

Virus. Doppelstrang-DNS-Virus aus Ikosaeder-Kapsid mit Spike-besetzter Hülle. Leicht züchtbar, Replikation in drei Phasen. Zwei Typen: Oral (HSV1) und genital (HSV2). Nach UV-Bestrahlung transformierend.

Vorkommen. Artspezifische Viren, weltweit.

Epidemiologie. HSV 1: Durchseuchung fast $100 \%$; etwa $10 \%$ apparente Primärinfektionen; HSV2: Genitale Durchseuchung geringer, beginnt mit Intimverkehr (Risikogruppen!), nur etwa $20-40 \%$ apparent.

Übertragung. Übertragung durch Kuß, Geschlechtsverkehr, durch Verletzungen am Finger, bei Geburt. Virus in Speichel, Genitalsekreten, Bläschen.

Pathogenese. Orale und genitale Primärinfektion - Wanderung zu sensorischen Spinalganglien, Latenz, Reaktivierung durch Streß, UV-Strahlen; Rekurrenz in der Peripherie bzw. apparente Rekrudeszenz mit Bläschenrezidiv. Persistenz von DNS im ZNS.
Klinik. Gingivostomatitis herpetica, Vulvovaginitis herpetica, Keratokonjunktivitis, Eczema herpeticum, Meningitis, Meningoenzephalitis, Herpes neonatorum. Rezidivierend als Herpes labialis bzw. genitalis. Rezidive auch bei Keratokonjunktivitis. Bei Immundefekten Gefahr der Generalisation. Erythema exsudativum multiforme als Folgekrankheit.

Immunität. Rezidive trotz humoraler Antikörper und zellvermittelter Immunaktivität (,Immunologisches Herpes-Paradoxon“).

Labordiagnose. Bei Primärinfektion KBR und IgM-, IgG-ELISA, Virusisolierung. Bei Rezidiven nur selten IgM-Reaktion und kaum Titerbewegungen. Enzephalitis: PCR mit Liquor.

Therapie. Acicloguanosin, u.a.; bei BläschenEruptionen auch prophylaktisch, bei Enzephalitis bereits bei Verdacht. Oral: Valaciclovir oder Famciclovir.

Prävention. Screening von Frauen vor Geburt auf HSV im Genitale zur Verhinderung des Herpes neonatorum. Orale Gabe von ValylACG.

Meldepflicht. Enzephalitis.

\subsection{Varizellen-Zoster-Virus}

Das Varizellen-Zoster-Virus (VZV) ruft die Windpocken (Varizellen) hervor. Nach der Primärinfektion verbleibt das VZV in den Spinalganglien. Bei Reaktivierung: Zoster (Gürtelrose). Das Virus ist serologisch und biologisch einheitlich. Die ätiologische Einheitlichkeit beider Krankheitsformen wurde 1931 durch Übertragung des „Zoster-Virus" auf empfängliche Kinder bewiesen; die Empfänger erkrankten an Windpocken. Das VZV kommt nur beim Menschen vor.

\subsubsection{Beschreibung}

\section{Morphologie und Genom}

Das VZV ist ein typisches Herpes-Virus. Die REAnalyse (s. S. 522) ergibt deutliche Unterschiede zwischen dem VZV und den übrigen Herpes-Viren, das Genom enthält $125 \mathrm{kbp}$.

\section{Züchtung}

In vitro ist das Virus nur schwer züchtbar: Man benötigt dazu menschliche Embryonalzellen. In der Zellkultur und den Vesikeln der Haut produziert es typische, im Zellkern lokalisierte Einschlußkörperchen. 


\subsubsection{Rolle als Krankheitserreger}

\section{Epidemiologie}

Der weitaus größte Teil der Kinder macht die Windpocken bis zum 15. Lebensjahr durch, die Infektion verläuft stets apparent. Eine primäre Empfänglichkeit ist stets vorhanden: Die Infektion besitzt eine hohe Kontagiosität. Das Ansteckungsmaximum liegt bei 2- bis 6jährigen Kindern, bereits junge Erwachsene sind $\mathrm{zu}>95 \%$ seropositiv. Varizellen treten endemisch-epidemisch auf; hierbei sind der Winter und das Frühjahr die Haupterkrankungszeiten.

\section{Übertragung}

Die Infektion erfolgt von Mensch zu Mensch als Tröpfcheninfektion oder durch direkten Kontakt. Virus-Emittent ist der akut an Varizellen Erkrankte. Oftmals sind der Zoster der Eltern oder Großeltern eine Ansteckungsquelle für die Kinder und Enkel. Varizellen sind wahrscheinlich die kontagiöseste Krankheit, die wir kennen: Die Übertragung von infektiösem Virus durch Luftzug über verschiedene Räume hinweg („fliegender Infekt") ist verschiedentlich beobachtet worden; die Bezeichnung "Windpocken" spiegelt diese Beobachtung wider. Die Kontagiosität der Varizellen ist größer als diejenige der Pocken. Der Infizierte wird 1-2 Tage vor Ausbruch der Erkrankung kontagiös und scheidet dann für etwa eine Woche das Virus massiv aus. Die Kontagiosität erlischt erst mit dem völligen Abheilen des Exanthems, d.h. mit dem Abfall der Borken. Man kennt auch exogene Reinfektionen, die einen Zoster auslösen.

\section{Pathogenese}

Das Virus wird nicht eliminiert, sondern persistiert nach der Primärinfektion lebenslang und kann später Rezidive hervorrufen. Unter diesen ist die sporadisch als Zoster auftretende Neuritis der Erwachsenen (Zoster, Gürtelrose) die wichtigste Erscheinungsform. Die Latenz des VZV ist ein Analogon zur Latenz des HSV.

Eintrittspforten sind der Nasenrachenraum und die Konjunktiven. Das Virus gelangt von der Eintrittspforte in einer virämischen Phase auf dem Blutweg in die Haut und in die Schleimhäute; dort verursacht es das typische Exanthem und Enanthem.
Wahrscheinlich gelangt das Virus während der akuten Erkrankung von der Haut neurogen in die Spinalganglien: Es läßt sich in den Neuronen und der Glia nachweisen. Besiedelt werden die sensorischen Ganglien entlang der Wirbelsäule bzw. die Ganglien der Gehirnnerven. Im Gegensatz zum HSV persistiert das VZV-Genom wahrscheinlich in den Neuronen und den Glia-Satellitenzellen, wobei die Transkription mehrerer Genregionen erfolgt; das Genom läßt sich durch Hybridisierung nachweisen. Das latente Virus vermehrt sich nach der Reaktivierung in Gliazellen und Neuronen und zerstört - im Gegensatz zum HSV - einen größeren Teil des Ganglions. Die Entzündung im Verein mit Narbenbildungen kann lange Monate andauern und starke postzosterische Schmerzen $(5-10 \%$ aller Zosterfälle) auslösen.

\section{Klinik}

Die Inkubationszeit beträgt 2-3 Wochen. Danach bilden sich zunächst kleine Papeln und dann Streichholzkopf-große, einzeln stehende, nicht-gekammerte Bläschen mit anfänglich wäßerig-klarem, später trübem Inhalt, die große Mengen an Virus enthalten. Die Bläschen der Haut und auf der Zunge (Abb., s. S. 689) sind von einem roten Saum umgeben; sie jucken und werden von Patienten oft zerkratzt. In späteren Stadien zeigen die unverletzten und größeren Bläschen eine zentrale Delle. Die Bläschen entstehen in Schüben; d.h. nicht gleichzeitig: Man findet auf der Haut nebeneinander die verschiedenen Entwicklungsstadien der Effloreszenz von der Papel bis zur Borke („Sternenhimmel“) (Abb., s. S. 689). Einzelne Bläschen können nach Verletzung durch Kratzen bakteriell superinfiziert werden und vereitern. Dann entstehen kreisrunde Narben von etwa 2-3 mm Durchmesser.

Die Infektion verläuft stets manifest, aber häufig afebril. Der Verlauf ist häufig so milde, daß die übrigen Symptome nicht beachtet werden („Spielplatz-Varizellen“). Bei Erwachsenen und Schwangeren verlaufen die Varizellen dagegen oft schwer und hämorrhagisch, z.T. mit Pneumonie.

Komplikationen. In seltenen Fällen entstehen als Komplikationen der Varizellen eine VZV-Otitis, eine Pneumonie oder eine Nephritis. Als schwerwiegende Weiterung imponiert die Meningoenzephalitis, meist als Zerebellitis mit Ataxie. Sie heilt aber meist ohne Folgen aus. Selten ist eine Polyradikuloneuritis vom Typ Guillain-Barré. Eine schwere Neurodermitis kann durch VZV infiziert werden: ACG! 
Bei Kortison-behandelten Kindern und Erwachsenen, bei Leukämiepatienten, bei immunsupprimierten Transplantat-Empfängern und bei AIDSKranken verläuft die Krankheit oft bösartig-generalisiert im Sinne einer hämorrhagischen Allgemeininfektion. Die hierbei auftretenden VZVPneumonien (Schwangerschaft!) sind gefürchtet. Bei immunsupprimierten oder -defekten Patienten (M. Hodgkin, HIV, Leukämien, Knochenmarktransplantierten) tritt in 30-50\% ein schwerer Zoster mit einer Letaliät von $3-5 \%$ auf

Eine Varizellenerkrankung von Graviden tritt wegen der frühzeitigen, hohen Durchseuchung nur in $0,1-0,7 \%$ auf, die Übertragung auf den Embryo erfolgt in $25 \%$, das Risiko für die Embryopathie (hypoplastische Gliedmaßen, Hautläsionen, ZNSund Augenschäden) beträgt bis zur 13. SSW $<1 \%$, in der 13.-20. SSW $2 \%$ und ist danach negativ. Gegen Ende der Schwangerschaft auftretende Primärinfektionen der Mutter können das Kind in utero infizieren (Risiko 20\% für perinatale Varizellen, die Letalität beträgt dabei $20 \%$ ). Es kann dann mit Narben oder Bläschen geboren werden.

Herpes Zoster (Gürtelrose). Nach Abheilung der Varizellen bleibt eine mit der Viruslatenz verbundene lebenslange Immunität bestehen. Das latente Virus kann bei Nachlassen der Immunität Rezidive verursachen. Diese entwickeln sich meist ohne erkennbare Ursache; in einzelnen Fällen kann man dafür Kachexien, Tumoren, Abwehrinsuffizienz etwa durch Leukämie (5-10\% aller Fälle) oder durch zytostatische Therapie - verantwortlich machen. Die Rezidive verlaufen, durch die noch bestehende Teilimmunität bedingt, nicht als generalisiertes Exanthem, sondern als lokal begrenzte Neuroradikulitis mit Bläschen (Zoster, Gürtelrose). In aller Regel treten die Rezidive entlang den Austrittsstellen eines Nerven in der Haut auf, die beim Trigeminus-Befall im Gesicht, als Zoster ophthalmicus oder oticus am Auge bzw. am Ohr, bei Befall von Interkostalnerven als Gürtelrose entsprechend dem Innervationssegment eines Nerven auftritt (Abb., s. S. 689). Für den Zoster kommen überwiegend ältere Kinder, Erwachsene und Senioren in Betracht. Bei stärker reduzierter Immunitätslage (Kortison!) kann ein generalisierter Herpes Zoster mit Pneumonie auftreten (Lebensgefahr!) (s. S. 609). Heftige "postherpetische“ Schmerzen sind bei Senioren häufig. Man kennt auch periphere Fazialislähmungen „sine herpete“.

\section{Immunität}

Im Verlauf der Varizellen-Infektion entstehen IgMund dann IgG-Antikörper, die sich im ELISA oder in der KBR nachweisen lassen. IgG-ELISA-Antikörper persistieren lebenslang, komplementbindende Antikörper verschwinden einige Jahre nach der Infektion. Durch eine Exazerbation in Form des Zosters erfolgt ein sehr deutlicher „Booster“ der Antikörperbildung mit IgM-Reaktion. Bestimmend für den Schutz ist die T-Zell-vermittelte Immunität. Je höher der Lymphozyten-Stimulationsindex ist, desto geringer ist die Zoster-Gefahr.

\section{Labordiagnose}

Die klinische Diagnose bereitet i. allg. keine Schwierigkeiten. Die Virusisolierung ist nicht üblich. Für die affirmative Varizellendiagnose dient der Antikörpernachweis. Er wird mit der KBR oder besser mit einem IgM- und IgG-ELISA vorgenommen. Für epidemiologische Untersuchungen wird der IgG-ELISA eingesetzt. Bei pränatal infizierten Kindern lassen sich nie IgM-Antikörper nachweisen. Die Plazenta zeigt keine Hinweise auf eine VZV-Infektion (Ggs. Röteln, ZMV).

\section{Therapie}

Zwei Krankheitsbilder bedürfen der antiviralen Therapie: Der Zoster und die schweren Varizellen-Komplikationen der Immunsupprimierten. I. allg. verabreicht man systemisch hohe Dosen von Acicloguanosin (ACG) oder oral Brivudin (BvdU) in Kombination mit "ZIG“ (Zoster-Immun-Globulin). Famciclovir und BvdU wirken deutlich besser beim Zoster als ACG. Zoster und Postzosterneuralgien werden frühzeitig mit Valaciclovir, Famciclovir oder Brivudin behandelt. Beim Vorliegen einer Immundefizienz ist die Behandlung dringlich. Bei einem leichten Zoster ohne Schmerzen erübrigt sich eine Therapie. Beim Auftreten von Varizellen bis 5 Tage vor der Geburt ZIG für Mutter und Kind; treten diese bis 2-4 Tage nach der Geburt auf, sollten Mutter und Kind Acicloguanosin sowie das Kind ZIG erhalten. Eine Pneumonie in der $>20$. SSW erfordert vom Tage des Exanthems ab ACG hochdosiert oral oder i.v.

\section{Prävention}

Allgemeine Maßnahmen. Als gezielte Maßnahme der Hygiene empfiehlt sich die Testung aller Säug- 
lingsschwestern u.a. ärztlichen Personal auf das Vorhandensein von Antikörpern gegen das VZV zur Verhinderung von Infektion und Übertragung. Varizellenkranke Kinder müssen isoliert oder ggf. aus der Klinik entlassen werden.

Immunglobulin-Prophylaxe bei Schwangeren. Der Nachweis einer frischen (IgM-positiven) VZVInfektion in der Frühschwangerschaft ist keine Indikation $\mathrm{zu}$ einer Interruption, da nur 1-2\% der Schwangeren mit einer primären VZV-Infektion Schäden beim Kind zeigen. Die gesund geborenen Kinder sollten jedoch serologisch kontrolliert und hinsichtlich ihrer geistigen Entwicklung beobachtet werden. Um das Risiko möglichst ganz auszuschalten, betreibt man die spezifische Prophylaxe mit Immunglobulin: Ist eine seronegative Schwangere mit einem Varizellen-Kranken in Kontakt gekommen, ist so schnell wie möglich nach der Exposition die Verabfolgung von VZV-Immunglobulin („ZIG“) angezeigt. Dies gilt für die gesamte Dauer der Gravidität. Das Immunglobulin soll dem Kind eine Varizellen-Erkrankung ersparen. Der Antikör- perpegel muß kontrolliert werden, ob die Infektion auch tatsächlich verhindert wurde.

Erfolgt eine Exposition gegen Ende der Schwangerschaft oder perinatal ( -5 Tage bis $+2-4$ Tage), so ist die Gabe von ZIG so schnell wie möglich erforderlich; dies gilt auch für Neugeborene von Müttern mit perinatalen Varizellen.

Schutzimpfung. Es wird eine generelle VZV-Impfung angestrebt (mit MMR kombiniert). Die Vakzine ist bei gesunden und bei immundefizienten Kindern sicher (Konversionsrate 80\%) und gut wirksam. Das Impfvirus wird latent und kann nach Jahren als leichter Zoster in Erscheinung treten. Bei 5\% der Impflinge treten wenige Bläschen auf (sehr geringe Kontagiosität). Wichtig ist sie bei Neurodermitikern. Sie wird empfohlen bei Kindern mit Immundefekten und deren Familien sowie vor Graviditäten von Seronegativen.

Meldepflicht. Meldepflicht besteht bei Erkrankungen in größeren Gemeinschaften und bei Enzephalitis.

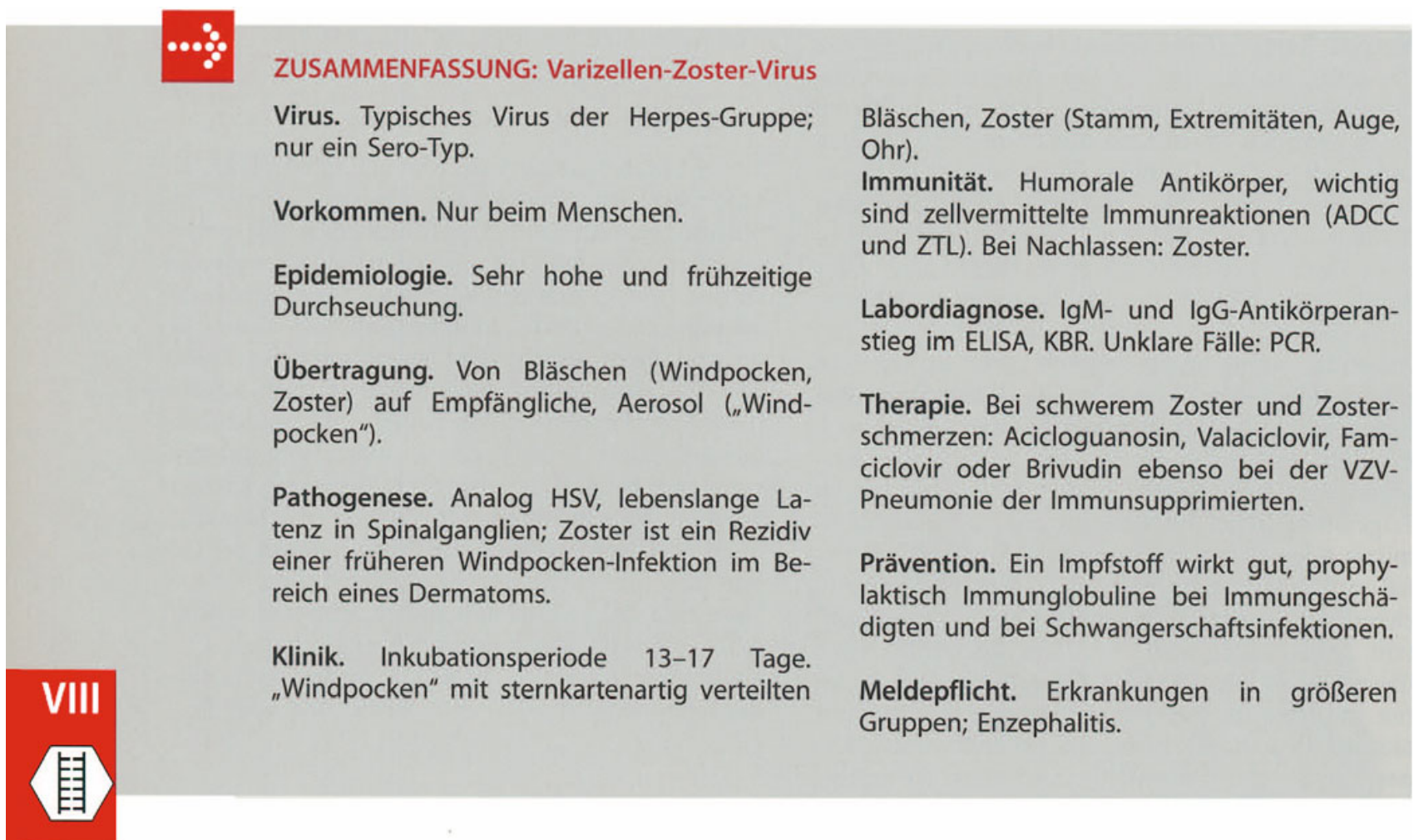




\subsection{Virus der Zytomegalie}

Der Pathologe Ribbert hat 1881 auf große Zellen mit Einschlußkörperchen in den Speicheldrüsen hingewiesen. Goodpasture prägte 1921 die Bezeichnung Zytomegalie. Für den Menschen ist nur das humane Zytomegalie-Virus (ZMV) (SpeicheldrüsenvirusKrankheit) pathogen; es erzeugt Embryopathien, Mononukleoseähnliche Krankheitsbilder und bei AIDS Chorioretinitis, ulzeröse Kolitis, Gastritis sowie Pneumonie und Enzephalitis. Das ZMV ist daher bei Immundefekten (AIDS und Transplantationen) von groBer Bedeutung. Das ZMV geht in Latenz und wird intermittierend ausgeschieden.

\subsubsection{Beschreibung}

\section{Morphologie und Genom}

Das serologisch einheitliche menschliche Zytomegalie-Virus ist ein typisches Virus der Herpesgruppe. Seine DNS umfaßt $235 \mathrm{kbp}$. Die vier Genotypen (Glykoprotein B) determinieren den Tropismus des ZMV (Lymphozyten, Knochenmark etc.).

Das Partikel enthält 4 Moleküle RNS.

\section{Züchtung}

Es vermehrt sich nur in menschlichen Fibroblasten (Lunge, Vorhaut), die Replikation erfolgt langsam. Die Synthese der Proteine des ZMV wird in einer Sequenz von drei Stufen vom Genom abgelesen.

\subsubsection{Rolle als Krankheitserreger}

\section{Epidemiologie}

Die Infektion kann horizontal nach der Geburt, aber vertikal vor der Geburt erfolgen.

Die Ansteckung hat bis zum 35. Lebensjahr etwa $50-80 \%$ der Menschen erfaßt. Die Durchseuchungsrate variiert jedoch je nach dem Lebensstandard bzw. dem sozialen Status; in Deutschland sind $40-70 \%$ der Bevölkerung infiziert.

Im Gegensatz zu den Verhältnissen bei Masern und bei Röteln findet man sogar auf entlegenen Inseln mit geringer Bevölkerungszahl ständig ZMV-Infektionen.

\section{Übertragung}

Die Übertragung erfolgt als Tröpfcheninfektion über den Respirationstrakt und bei engem Kontakt als Schmierinfektion und beim Stillen. Die Übertragung kann außerdem als iatrogene oder nosokomiale Infektion, z.B. auf Kinderstationen und schließlich auch durch Geschlechtsverkehr (Mehrfachinfektionen!), erfolgen.

Eine Primärinfektion kann auch durch Bluttransfusionen oder durch transplantierte Organe erfolgen. Die Ausscheidung erfolgt oftmals monate- und jahrelang mit variabler Stärke, die Ausscheidungsfrequenz und Stärke nimmt bei einer Gravidität zu.

Als postnatale Infektionsquellen kommen v.a. gesunde Kleinkinder, Kinder und Jugendliche in Betracht. Innerhalb eines halben Jahres infizieren sich 50\% aller Familienangehörigen, wenn ein Mitglied das Virus in die Familie hineingetragen hat.

Bei Neugeborenen wird das intrauterin übertragene Virus in 0,3-2,5\% mit dem Urin ausgeschieden; bei Kindern bis zu 5 Jahren ist die Ausscheidungsquote mit $10-30 \%$ besonders hoch; im Alter zwischen 5-15 Jahren liegt die Ausscheidungsquote bei $10-20 \%$, bei Erwachsenen bei $0-2,5 \%$. AuBer im Urin und im Speichel findet sich das Virus auch im Sperma, in den Zervixsekreten, in der Muttermilch (Reaktivierung!) und in der Tränenflüssigkeit. Bei Immungeschädigten ist das ZMV auch im Stuhl gefunden worden. 90\% aller immunsupprimierten Personen scheiden das ZMV mit dem Urin aus.

\section{Pathogenese}

Primäre Replikation. Die primäre Virusreplikation erfolgt vermutlich in den Epithelzellen des Oropharynx. Man hat Virus-DNS auch in den Leukozyten der Tonsillen festgestellt. Im Kern der infizierten Zelle stellt man „eulenaugenartige“ Einschlußkörperchen fest.

Ausbreitung. Im Organismus breitet sich der Erreger der Zytomegalie hämatogen als intrazelluläres Virus in viele Organe aus (Leukovirämie). Hierbei befindet sich das Virus in Granulozyten, Monozyten, T-Lymphozyten und zirkulierenden Endothel-Zellen, aber nicht in B-Zellen.

Persistenz und latente Infektion des Virus. Das ZMV führt bei Kindern und jungen Menschen zu Infektionen, die in der Regel inapparent verlaufen. 
Alle Infektionen gehen in Latenz über: Sie bewirken lebenslanges Virusträgertum, Reaktivierungen sind häufig (Persistenz).

Hauptpersistenzorte sind Speicheldrüsen, Lunge, Brustdrüsen und Nieren. Das Virus kommt vorzugsweise in den Epithelien vor, welche die Ausführungsgänge der Speicheldrüsen („Speicheldrüsen-Virus") auskleiden, niemals aber in Bindegewebszellen. In der Niere befindet sich das Virus in den Zellen der Tubuli sowie ebenso latent persistierend in Monozyten, Gefäßendothelien sowie im Knochenmark. Ein Drittel der Seropositiven hat ZMV-DNS im Knochenmark. Bei Autopsien werden oft Zytomegalie-Einschlußkörperchen (Speicheldrüsen, Nieren) als Folge der persistierenden Infektion festgestellt.

Je schwerer die Infektion verläuft, desto mehr Organe sind betroffen. Beim Neugeborenen sind zahlreiche Organsysteme befallen. Bei Jugendlichen oder Erwachsenen treten eher organtypische Infektionen auf.

Status der DNS in der Latenz. Ein typisches Latenzstadium in Zellen der myeloischen Reihe und der Lunge (Maus) erscheint gesichert, das latente Genom wird stufenweise reaktiviert (Maus). Bezüglich der Persistenz erfolgt vermutlich eine langsame Replikation mit einem primären Zellschaden, die Zelle stirbt dann vermutlich nach einiger Zeit $\mathrm{ab}$ (Einschlußkörperchen). Die Infektion geht vorher auf andere Zellen über. Das Virus besitzt zelltransformierende Eigenschaften, wenn es nach UV-Inaktivierung auf Zellen verimpft wird; es ist gelungen, eine zelltransformierende Region auf dem Virusgenom zu identifizieren. Das Protein bindet an p53 und steigert die Zellteilungsrate.

Pathologische Auswirkungen der Infektion. Schwerwiegende Auswirkungen der Infektion treten bei Neugeborenen nach intrauteriner Infektion auf: Die Zytomegalie ist z.Z. die häufigste Ursache von embryo-fetalen Schädigungen; sie rangiert vor den Röteln und vor der Toxoplasmose. Bei Immundefekten ist die Zytomegalie gefürchtet (s.u.).

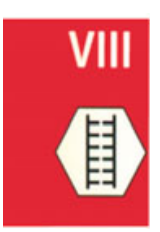

\section{Klinik}

Die vielfältigen Infektionsmöglichkeiten des Menschen mit dem ZMV machen eine Einteilung der klinischen Bilder nach dem Lebensalter erforderlich. Grundsätzlich unterscheidet man Primärinfektionen einerseits und Reaktivierungen einer persistent-latenten Infektion andererseits. Beide Situationen unterscheiden sich im Hinblick auf die Dauer der Virusausscheidung. Nach der Primärinfektion dauert die Virusausscheidung länger als nach Rezidiven.

Die Inkubationszeit bei der Primärinfektion schwankt zwischen 4 und 12 Wochen. Ihre Dauer wird durch die Infektionsdosis und den Immunitätszustand des Infizierten bedingt, bei Reaktivierungen ist sie kürzer.

Kinder, Jugendliche, Erwachsene. Bei Kindern, Jugendlichen und Erwachsenen verlaufen nur etwa $1 \%$ der primären ZMV-Infektionen apparent.

Die Symptomatik läßt sich als Mononukleoseähnliches Syndrom (EBV-negativ) mit Fieber, leichter Hepatitis, allgemeinem Krankheitsgefühl und atypischer Lymphozytose charakterisieren. Im Unterschied zur EBV-Infektion ist die Tonsillitis und die Lymphadenopathie im Halsbereich seltener.

Die Infektion kann zusätzlich mit einer interstitiellen Virus-Pneumonie einhergehen, v.a. bei Kleinkindern. Die Pneumonie ist durch Husten, Atemnot und inspiratorische Einziehungen des Thorax gekennzeichnet. Seltenere Krankheitsbilder sind eine Polyradikulitis (Guillain-Barré), eine hämolytische Anämie, Chorioretinitis und selten Vaskulitis und Purpura. Es wurden auch Fälle mit Gastritis, Ösophagitis, Pankreatitis, ulzerativer Kolitis, Meningoenzephalitis und Perimyokarditis (12\% aller Myokardbiopsien bei dilatativer Myokarditis) festgestellt. Die genannten Erscheinungen können sich über Wochen und Monate erstrecken.

Beim Erwachsenen kommt es zur manifesten Erkrankung meist nur dann, wenn bei allgemeiner Abwehrschwäche die latent-persistierende Infektion reaktiviert wird. In der Praxis muß man besonders nach Transplantationen, Tumoren und AIDS mit einer Reaktivierung rechnen. Die Symptomatik richtet sich nach dem jeweils befallenen Organ.

Intrauterine Infektionen. Diese erfolgen zumeist nach primären Infektionen der Mütter; nur selten entstehen sie durch Reaktivierung einer persistierenden Infektion durch die Schwangerschaft. Aber auch bei intrauteriner Übertragung verläuft ein Teil der Infektionen inapparent; das Virus wird trotzdem von Mutter und Kind ausgeschieden.

Je nach dem Durchseuchungsgrad der Bevölkerung muß man für 1-3\% aller Neugeborenen annehmen, daß sie intrauterin mit dem ZMV infi- 
ziert worden sind. Die Schädigungsrate liegt bei $2-4 \%$ aller Neugeborenen.

Etwa 2-4\% aller seronegativen Schwangeren machen eine primäre Infektion durch, bei etwa $10-20 \%$ der seropositiven Schwangeren wird die latente Infektion reaktiviert, v.a. im 2. und 3. Trimenon. Etwa 20\% aller seropositiven Schwangeren scheiden das Virus während der Schwangerschaft im Zervixsekret aus. Bei Primärinfektionen beträgt die Übertragungsrate auf das Kind $35-50 \%$, bei Reaktivierungen $0,2-2 \%$. Schäden am Embryo treten v. a. bei Infektionen im 1. und 2. Trimenon auf.

Etwa 1\% aller Neugeborenen haben konnatale ZMV-Infektionen (USA; 1990). Von diesen sind 7\% symptomatisch, von ihnen sterben $12 \%$. Die restlichen Kinder haben bleibende Schäden. Zusätzlich treten Spätfolgen (s.o.) bei 15\% der Kinder auf, die anfangs symptomfrei waren. Die Schädigungsrate der Infektionen liegt in der ersten Hälfte der Gravidität bei $40 \%$, später weit niedriger.

Die intrauterin erworbene Infektion zeigt Entwicklungsstörungen und Entzündungsprozesse. Bei der transplazentaren Infektion kann es zur Totgeburt kommen. Beim lebend geborenen kranken Kind findet man Mikrozephalie, Optikusatrophie, Katarakte, intrazerebrale Verkalkungen und geistige Retardierung. Entzündungsprozesse sind Hepatosplenomegalie, thrombozytopenische Purpura, Chorioretinitis, hämolytische Anämie und Ikterus. Leichte Schädigungen machen sich oft erst später bemerkbar; sie treten als Entwicklungsstörungen (Gehör, Sprache) oder als Beeinträchtigung der Motorik auf. Beim Vorliegen einer gesicherten Primärinfektion im ersten Drittel der Gravidität ist ein Abbruch der Schwangerschaft in Erwägung zu ziehen (s. Röteln, S. 575). Wird eine Reaktivierung in späteren Stadien der Schwangerschaft festgestellt, so ist zu empfehlen, das Kind auszutragen. Nach der Geburt sollte das Kind regelmäßig auf etwaige Defekte untersucht werden.

Perinatale Infektionen. Als Infektionsquellen für die perinatalen Übertragungen kommen v.a. die infizierten Geburtswege der Mutter und die Muttermilch in Betracht. Etwa 1/3 aller seropositiven Frauen scheiden das Virus mit der Milch aus. Die Virus-Ausscheidung der Mutter durch den Pharynx und durch den Urin hat dagegen nur eine geringe Bedeutung für die Übertragung.

Die perinatale Infektion bleibt für das Kind selbst meist folgenlos: Nur ganz selten wird bei sonst gesunden Neugeborenen eine Pneumonie (evtl. in Mischinfektion mit Pneumocystis carinii) oder eine Hepatosplenomegalie mit Hepatitis und Thrombozytopenie beobachtet, vor allem bei Frühgeborenen.

Transfusions-Infektionen. Eine Transfusion mit ZMV-positivem Blut („Perfusionssyndrom“) führt bei einem seronegativen Kind zu schweren, häufig tödlichen Erkrankungen, v.a. bei Frühgeborenen. Bei seronegativen Erwachsenen, die durch eine Bluttransfusion infiziert wurden, etwa bei Herzoperationen oder bei Transplantationen, entsteht in etwa einem Viertel aller Fälle ein Mononukleose-artiges Krankheitsbild („Transfusions-Mononukleose"). Heute wird nur noch Blut transfundiert, das dem Serostatus des Patienten entspricht.

Zytomegalie bei Immungeschädigten. Bei Immungeschädigten verläuft die ZMV-Infektion schwerer als bei Normalpersonen. Primärinfektionen verlaufen dabei in jedem Fall schwerer als Reaktivierungen. Als allgemeine Regel gilt: Je stärker die Immunsuppression, desto schwerer der Verlauf der Infektion. Deshalb ist die laufende Beurteilung der Abwehrlage beim Kranken von großer Bedeutung.

Man kontrolliert laufend den Antikörperpegel und die Virusausscheidung. Als Ursache des Immunschadens kommen in Betracht: Immunsuppression bei Transplantationen (Niere, Pankreas, Herz, Leber, Knochenmark), Chemotherapie von Tumoren (Leukämie, Karzinome) und AIDS. Die ZMV-Infektion dieser Patienten bleibt bis zu 2/3 asymptomatisch; in $1 / 3$ der Fälle werden schwere Verläufe (Fieber, Hepatitis, Pneumonie u.a.) beobachtet. Die ZMV-Infektion ist die häufigste opportunistische Infektion bei AIDS. Ein prognostisch schlechtes Zeichen bei AIDS-Patienten ist die Vergesellschaftung der ZMV-Infektion mit Pneumocystis carinii.

Bei immunschwachen Patienten (AIDS) verläuft die ZMV-Infektion mit Fieber, Nachtschweiß, allgemeinem Krankheitsgefühl, Appetitlosigkeit, Muskelschmerzen, Gelenkbeschwerden, Ulzerationen im Gastrointestinaltrakt, Hepatosplenomegalie, Hepatitis, Enzephalopathie, Polyradikulopathie und Chorioretinitis. In $75 \%$ ist die Nebenniere befallen. Als Hauptsymptom tritt die gefürchtete interstitielle ZMV-Pneumonie hinzu. Diese Pneumonie ist bei Empfängern von Knochenmarktransplantaten und bei $20 \%$ der AIDS-Patienten die unmittelbare Todesursache. Die Chorioretinitis fehlt bei Knochenmarktransplantationen oder ist sehr selten. 


\section{Immunität}

Die Infektion mit dem ZMV wird normalerweise durch zellvermittelte und durch humorale Immunreaktionen unter Kontrolle gehalten. Nach einer Primärinfektion entstehen IgM-, IgA- und IgG-Antikörper. Erkrankungen und Virämie bei Reaktivierung erfolgen trotz hoher Titer an neutralisierenden Antikörpern. Bei einer Primärinfektion entstehen zunächst Antikörper gegen Sofortproteine und Frühproteine. Die neutralisierenden Antikörper treten erst 2-5 Monate später auf. Bei Reaktivierungen werden neutralisierende Antikörper sofort gebildet. Gesunde Personen haben ein individualspezifisches Muster von Antikörpern gegen die Epitope der ZMV-Antigene.

Infektionen des Neugeborenen sind ungeachtet der mütterlichen IgG-Antikörper abgeschwächt möglich. Neutralisierende Antikörper gegen Glykoproteine reduzieren den Schweregrad einer ZMVPneumonie, während bei fehlenden Antikörpern oftmals der Tod eintritt.

Für die Induktion der zellvermittelten Immunität sind zunächst Sofortproteine verantwortlich. Infektionen mit dem und Reaktivierungen des ZMV wirken selbst immunsuppressiv, wenn auch in geringerem Grade als bei HIV-Infektionen; dabei ist die Stimulierbarkeit der Lymphozyten durch Mitogene gestört.

Das ZMV kodiert für Proteine, die die Präsentation viraler Oligopeptide für ZTL fast ganz unterbinden, die infizierte Zelle wird durch ZTL nicht mehr erkannt. Ein Fc-Rezeptor-ähnliches Glykoprotein schützt die Zelle vor der Antikörperwirkung, indem es diese am Fc-Stück bindet.

Die Bedeutung der zellvermittelten Immunität für die Kontrolle der Infektionen wird durch die Tatsache bewiesen, daß bei immunsupprimierenden Maßnahmen oft schwere Verläufe festgestellt werden. Die Basis-Resistenz des Organismus, wie z.B. die Makrophagen-Funktion, spielt bei der ZMV-Infektion - im Gegensatz zu den Listerienund den Mykobakterien-Infektionen - nur eine untergeordnete Rolle. Die Verminderung der zellvermittelten Immunität - etwa durch Zytostatika führt zu einer erhöhten Virusausscheidung. Wichtig für die Prognose ist der Lymphozyten-Quotient CD4/CD8; eine Verringerung der CD4-Zellen deutet auf eine Minderung der Immunitätsleistung hin. Bei ZMV-Streuungen infolge Immundefekt sind die TH2-Zellen verringert. Hierzu gehört auch die hormonelle Umstellung während der Gravidität.

Während einer ZMV-Infektion können immunologische Abnormitäten auftreten: Es werden zirkulierende Immunkomplexe, Kälte-Hämagglutinine, Rheumafaktoren, antinukleäre Antikörper, ein positiver Coombstest u. a. beobachtet. Diese Erscheinungen gehen zurück, wenn die Primärinfektion oder die Reaktivierung immunologisch beherrscht wird.

\section{Therapie}

Bei Chorioretinitis, ulzeröser Kolitis und Hepatitis hat sich eine Dauertherapie mit Ganciclovir (DHPG) oder Foscarnet bewährt. Bei längerer Verabreichung besteht die Gefahr der Resistenzentstehung; bei Absetzen der Medikation erfolgen Rezidive; jetzt wird auch Cidofovir (HPMPC) eingesetzt.

Bei Knochenmarktransplantationen gibt man bei Einsetzen der Virämie (PCR) und wenn der pp 65-Antigen-Nachweis positiv wird, Ganciclovir und zusätzlich IgG, um das Auftreten einer Pneumonie zu verhindern. Dies gilt auch, wenn mit der quantitativen PCR in den Blutzellen eine bestimmte DNS-Menge überschritten wird. Bei Chorioretinitis empfehlen sich Foscarnet, Fomivirsen und Ganciclovir intravitreal.

\section{Labordiagnose}

Klinisch läßt sich eine ZMV-Infektion meist nicht diagnostizieren: Man ist auf den Virusnachweis (Isolierung oder PCR) sowie auf den IgM- und IgG-Antikörpernachweis angewiesen.

Die Virusisolierung wird durch die Tatsache erleichtert, daß Materialgewinnung, -versand und -aufbewahrung keine Schwierigkeiten bieten: Das ZMV ist relativ transportlabil; es hält sich aber mehrere Tage lang bei $+4^{\circ} \mathrm{C}$. Bei $-70^{\circ} \mathrm{C}$ ist es sehr lange haltbar, nicht aber bei $-20^{\circ} \mathrm{C}$. Das Virus läßt sich auf diploiden, permanenten menschlichen Zellen (Vorhaut-Zellen) gut züchten, wenn es auf die Zellen zentrifugiert wird. Die Zeitspanne bis zum Auftreten des zytopathischen Effekts kann 3-4 Wochen betragen. Die Anwesenheit des Virus in der Zellkultur kann aber schon nach 1-2 Tagen durch den immunspezifischen Nachweis der Frühantigene erkannt werden (Färbung mit markierten Antikörpern). Wichtig ist die baldige Verimpfung des Probenmaterials, das möglichst steril oder wenigstens keimarm abgenommen werden sollte (Blasenpunktion, Katheter-Urin, Lungenspülwasser, 
Speichel, Genitalsekrete, Amnionflüssigkeit). Im Urin gelingt bei schweren Fällen der Nachweis von Einschlußkörperchen in Nierenepithelzellen. Bei der Beurteilung von Totgeburten spielt die Darstellung der Einschlußkörperchen eine entscheidende Rolle. Bei Autopsien sollte man stets versuchen, das Virus aus geeigneten Organen $\mathrm{zu}$ isolieren und den Antigennachweis zu führen.

Wichtig ist die Verlaufskontrolle der Virusmenge in Urin, Rachenspülwasser und Granulozyten v. a. bei Transplantationspatienten und bei Immunsupprimierten. Bei Knochenmarktransplantierten zeigt die positive PCR in etwa $50 \%$ eine folgende Erkrankung an. Ein positiver Virusnachweis im Urin ist aber nicht gleichbedeutend mit einer Erkrankung; man kann ihn auch nicht zur Unterscheidung zwischen einer Primärinfektion, einer Reinfektion oder einer aktiven Infektion (z.B. nach Knochenmarktransplantation) heranziehen.

Zwecks Diagnose einer aktiven ZMV-Infektion mit Pneumoniegefahr wird getestet:

- ZMV-Ausscheidung im Bronchialsekret und im Speichel.

- Nachweis des pp 65 Antigens in Granulozyten des Blutes durch IFT oder die APAAP-Methode.

- ZMV-DNS oder RNS der $a$-Proteine in Blutmonozyten. PCR jetzt auch quantitativ.

pp 65 ist ein $\gamma$-Protein und befindet sich im Tegument des ZMV. ZNS-Erkrankungen werden durch die PCR und ihre Varianten auf ZMV-DNS im Liquor diagnostiziert. - Die verschiedenen ZMVStämme lassen sich durch Sequenzierung unterscheiden.

Für die Diagnose einer Primärinfektion sind der Nachweis eines Titeranstiegs (ELISA, KBR) und der IgM-Nachweis im Serum der Schwangeren wichtig. Bei einem Verdacht auf die primäre Infektion einer Graviden ist nach Möglichkeit eine Probe von fetalem Blut und Amnionflüssigkeit zu gewinnen und ein kompletter Anti-ZMV-Status zu erstellen und die PCR durchzuführen. Die Unter- suchung der Kombination von IgM-Nachweis im fetalen Blut, ZMV-PCR und Ultraschalldiagnostik liefert z.Z. die besten Ergebnisse. Bei Reaktivierungen kann man häufig den IgM-Nachweis bei der Mutter führen, während die KBR und der ELISA für IgG nur geringe Titerbewegungen zeigen, das IgG ist jedoch hochavide.

\section{Prävention}

Allgemeine hygienische Maßnahmen. Durch die Regeln der Hygiene läßt sich die menschliche Zytomegalie nicht unter Kontrolle bringen.

Vom gegenwärtigen Standpunkt aus erscheint die Auswahl von Blut- bzw. Organspendern für Säuglinge und Knochenmarktransplantationen bezüglich ihrer Seronegativität wichtig. Nach Möglichkeit sollten nur Knochenmarkzellen von Seronegativen übertragen werden.

Schwangerenvorsorge. Im Rahmen der Schwangerschaftsvorsorge sollten alle Frauen auf das Vorhandensein von ZMV-Antikörpern getestet werden (ELISA). Dieser Test sollte obligatorisch werden, bis ein geeigneter Impfstoff vorliegt. $\mathrm{Da}$ die Zahl der seronegativen Frauen mit Gravidität infolge sinkender Durchseuchung zunimmt, steigt die Gefahr einer Primärinfektion mit Embryopathiefolge.

Schutzimpfung. Ein Lebendimpfstoff befindet sich in Erprobung. Zu Bedenken gibt jedoch die Transformationsaktivität des ZMV Anlaß, sowie die Möglichkeit, daß auch das Impfvirus latent wird (s. VZV, S. 640). Man sieht deshalb die Zukunftschancen in einem abgeschwächten ZMV-Lebendimpfstoff, der Reaktivierungen zulassen würde. Immerhin hat ein ZMV-Impfstoff bei Immunsupprimierten gegen Pneumonie geschützt, jedoch nicht gegen eine exogene Reinfektion.

Meldepflicht. Besteht bei Embryopathie. 
ZUSAMMENFASSUNG: Zytomegalie-Virus

Virus. Typisches Herpes-Virus (s. HSV, S. 629), langsame Replikation in einigen Zellarten, nach UV-Bestrahlung transformationsaktiv.

Vorkommen. Zytomegalie-Viren sind artspezifisch.

Epidemiologie. Hohe Durchseuchung bis zum Erwachsenenalter. Ausscheidung durch Kinder für Wochen, Monate und Jahre. Bei Immungeschädigten in $90 \%$ Ausscheidung. Bei Graviden vermehrte Ausscheidung im Genitale. Virus in Muttermilch.

Übertragung. Bei engem Kontakt über Tröpfchen-Kuß-Infektion. latrogen durch Blut und Organe. Nosokomiale Infektionen. Virus im Speichel, Urin, Sperma, Zervix-Sekreten. Übertragung durch Geschlechtsverkehr; intrauterin, perinatal und durch Stillen.

Pathogenese. Typische Einschlußkörperchen in den Kernen und Persistenz/Latenz des Virus in Epithelzellen von Speicheldrüsen, Niere, Lunge u.a. Bei Immunschäden gibt es Reaktivierungen.

Klinik. Einteilung nach dem Lebensalter: Intrauterine Infektion bewirkt Embryopathie, perinatale Infektion meist ohne Folgen.
Transfusion. Transfusionsmononukleose. Immunschäden bewirken Organ-Zytomegalie (Retinitis, Kolitis, Pneumonie u.a.), bei immungesunden Erwachsenen meist inapparent, selten Zytomegalie einzelner Organe. Dilatative Myokarditis (12\%). Die Inkubationsperiode dauert einige Wochen.

Immunität. Lebenslange Immunität durch Antikörper und Lymphozyten, bei Immundefekten Reaktivierung und schwere, generalisierte Erkrankung sowie bakterielle Superinfektionen, diese auch bei Gesunden.

Labordiagnose. IgM- und IgG-ELISA, KBR. Virusnachweis aus Urin, Sekreten u.a. in Zellkulturen („Frühantigene") und pp 65-Antigen in Granulozyten (IFT, ELISA) und PCR.

Therapie. Bei Chorioretinitis, Kolitis, Pneumonie: Ganciclovir (DHPG), Cidofovir (HPMPC), Foscarnet und ggf. IgG.

Prävention. Impfstoff in Entwicklung. Testung von Blut- und Organspendern auf Durchseuchung. Allgemeine Hygiene.

Meldepflicht. Embryopathie.

\subsection{Epstein-Barr-Virus}

Das Epstein-Barr-Virus ist der Erreger der infektiösen Mononukleose (Pfeiffer'sches Drüsenfieber). Bei der Entstehung des Burkitt-Lymphoms, des lympho-epithelialen Nasopharynx-Karzinoms, bestimmter Formen des Hodgkin-Lymphoms sowie von Muskelsarkomen und B-Zelltumoren im ZNS bei AIDS-Patienten ist das EBV der bestimmende ätiologische Faktor. Die Tumor-induzierende Wirkung des EBV wurde durch die Öbertragung auf Affenarten erwiesen; dabei entstehen gutartige proliferative Zustände bis zu oligoklonalen bösartigen Tumoren. Bei Patienten mit Agammaglobulinämie entsteht keine latente Infektion der B-Zellen, weil die Hauptwirtszelle fehlt.

\section{Geschichte}

1889 hat Pfeiffer das nach ihm benannte Pfeiffer'sche Drüsenfieber mit Angina, Lymphknotenschwellungen und gelegentlicher Hepatosplenomegalie beschrieben. Erst 30 Jahre später wurden die atypischen Lymphozyten entdeckt, die dem Krankheitsbild zur Bezeichnung ,infektiöse Mononukleose" verholfen haben. 1932 entdeckten Paul und Bunnell die heterophilen Antikörper. 1964 beobachteten Epstein und Barr in kultivierten BurkittLymphomzellen ein „herpes-ähnliches“ Virus. Schließlich wurde 1968 durch Werner und Gertrude Henle der Beweis erbracht, daß die infektiöse Mononukleose durch das EBV hervorgerufen wird. 


\subsubsection{Beschreibung}

\section{Morphologie und Genom}

Das EBV ist ein typisches Virus der Herpes-Gruppe und enthält eine Doppelstrang-DNS aus $176 \mathrm{kbp}$. Die DNS hat eine Kodierungskapazität für etwa 100 Proteine. Ein Gen kodiert für IL-10. Infizierte Zellen enthalten massenhaft EBERs (d.h. kurze, EBV-kodierte RNS-Moleküle im Kern von B-Zellen).

\section{Proteine}

Wie bei allen Herpes-Viren wird die Synthese der Proteine in drei Stufen kaskadenartig abgerufen. Für die serologische Diagnose der infektiösen Mononukleose, des Burkitt-Lymphoms sowie des Nasopharynx-Karzinoms ist die Verwendung bestimmter Antigene bzw. Antigen-Komplexe von Bedeutung. Man unterscheidet

- die frühen Antigene EA (early antigen),

- die Kernantigene EBNA 1-3 (EBV-nuclear-antigen),

- das Viruskapsidantigen VCA (virus-capsid-antigen) und

- das Membran-Antigen (MA).

EBNA-Antigene und die zwei LMP (Latenz-Membran-Protein-Antigene) sind für die Immortalisierung der Zellen verantwortlich.

\section{Züchtung}

Der Rezeptor für das EBV auf den B-Lymphozyten ist identisch mit dem für das Cd3-Fragment aus dem Komplementsystem. Das Virus läßt sich durch Kokultivierung auf Nabelschnurlymphozyten übertragen. Die B-Zellen werden dabei immortalisiert. In vitro produziert nur ein kleiner Teil der infizierten B-Zellen infektionstüchtige Viruspartikel und erliegt dem ZPE. Die Züchtung des Virus ist deshalb schwierig. Die Virusproduktion läßt sich jedoch induzieren, wenn der Kultur Phorbolester zugefügt werden.

Beim Übergang aus der Latenz in die lytische Form wird aus der zirkulär-episomalen DNS eine lineare DNS. Man nimmt jetzt an, daß beim Switch von Latenz zu Replikation ein "Zebra“ genanntes Gen ein Protein liefert, das die Synthese der frühen Gene anschaltet. Es wirkt dabei als „Transaktivator“.

\section{Einteilung}

Das Epstein-Barr-Virus gehört zur Herpes-Gruppe, ist serologisch einheitlich, umfaßt aber zwei Subtypen, die sich durch ihre tumorbildende Potenz unterscheiden.

\subsubsection{Rolle als Krankheitserreger}

\section{Epidemiologie}

Entsprechend der Übertragung des EBV (s.u.) tritt die Krankheit am häufigsten bei jungen Leuten zwischen 15 und 30 Jahren auf. Bei etwa 50\% der Angesteckten verläuft die Infektion inapparent. Bei Kindern unter fünf Jahren ist Inapparenz die Regel. Der Durchseuchungsgrad ist sehr hoch: Bis zum 30. Lebensjahr ist praktisch die ganze Bevölkerung infiziert worden.

In den unterentwickelten Ländern erfolgt die Durchseuchung mit dem EBV bereits in den ersten 2-5 Lebensjahren. Mit steigendem Lebensstandard verschiebt sich das Durchseuchungsalter zu späteren Lebensjahren hin. In Deutschland ist das Maximum der Durchseuchung etwa im 15.-25. Lebensjahr erreicht. Bei Jugendlichen beginnt die Durchseuchung mit dem Beginn der sexuellen Aktivität.

Die Häufigkeit des Burkitt-Lymphoms wird in Malariagebieten mit 8-10 pro 100000 Personen pro Jahr angegeben; der Tumor tritt vorwiegend bei Kindern auf. Andererseits werden in China pro Jahr mehr als 100000 Fälle von Nasopharynx-Karzinom festgestellt, hier aber vorwiegend bei Personen im Alter von 35-50 Jahren. In diesem Lebensalter ist das endemische Burkitt-Lymphom sehr selten.

\section{Übertragung}

Die Übertragung des nur beim Menschen vorkommenden EBV erfolgt oral, meist durch kontaminierten Speichel, z.B. beim Küssen (CollegeKrankheit, „kissing disease“).

Während und nach der infektiösen Mononukleose scheiden fast alle Patienten das EBV wochen- und monatelang aus. Eine Dauerausscheidung stellt man bei $20-30 \%$ von sonst gesunden Erwachsenen fest. Bei AIDS-Patienten ist die Ausscheidung erhöht. 


\section{Pathogenese}

Die primäre Vermehrung des Virus erfolgt im Epithel der Mundhöhle (Pharyngitis). Nach der Primärinfektion wird das Virus in den Epithelzellen der Ohrspeicheldrüse, der Mundhöhle und der Zunge bei vielen Patienten lebenslang gebildet und ausgeschieden. Der Mensch wird also ein Dauerausscheider. In den Tonsillen werden im Verlauf der akuten Mononukleose B-Lymphozyten infiziert und verbreiten im lytischen Zyklus das EBV in den Organismus (Genitaltrakt u.a.). Die B-Zellen werden polyklonal stimuliert und exprimieren die mRNS für heterophile Antikörper, es gibt ein „immunologisches Chaos“. Da sie außerdem alle virusspezifischen Antigene exprimieren (LMPs, EBNAs), werden sie von ZTL (den großen, atypischen Monozyten) erkannt und lysiert. In der Latenz verhindert das LMP durch Anschaltung des bcl-Gens (u.a.) die Apoptose und damit die Ausrottung der Zellen, so daß immer latent infizierte B-Zellen vorhanden sind (etwa 1 unter 10000 BZellen). Beim Übergang in die Latenz wird die Virussynthese fast völlig abgeschaltet, so daß die ZTL keine Zielantigene finden. In diesem Stadium ist fast nur das EBNA-1 exprimiert, das VirusDNS-Synthese bewirkt.

B-Lymphozyten von seropositiven Personen sind in vitro unbegrenzt fortzüchtbar (d.h. immortalisiert). Einige B-Zellen werden nach und nach lytisch, dabei werden alle EBNAs und die LMPs synthetisiert und Virionen gebildet. EBV blockiert die Antigen-Expression, und durch Bildung von viruskodiertem IL-10 wird die Aktivität der NK-Zellen und der ZTL gehemmt. Das neu gebildete Virus immortalisiert weitere B-Zellen, die beim Durchwandern das Epithel der Mundhöhle reinfizieren. Infizierte B-Lymphozyten verteilen sich in die Organe und sind die Auslöser der Symptomatik, sie fehlen bei der Agammaglobulinämie.

\section{Klinik}

Infektiöse Mononukleose (Pfeiffer'sches Drüsenfieber). Die Inkubationszeit beträgt bei Jugendlichen 10-14 Tage und bei Erwachsenen 4-8 Wochen. Als Symptome treten auf:

- Fieber,

- Angina mit „rauhem Hals“ (Pharyngitis),

- Lymphdrüsenschwellung mit Milztumor,

- Atypische Lymphozyten im Blut.
Die Angina ist oft flächenhaft und führt auf den Tonsillen zu graugelben Belägen und gelegentlich auch zu Ulzera (Abb., s. S. 690). Es kann sich aber auch eine vorwiegend katarrhalische Pharyngitis bilden. Häufig ist ein starker Foetor ex ore vorhanden. Die Lymphknotenschwellungen finden sich zunächst am Hals, dann in der Achsel, in der Leistengegend, aber auch im Hilus. Der Milztumor ist weich; es besteht die Gefahr einer Milzruptur. Im Blutbild findet man typischerweise eine große Zahl von großen, atypischen Lymphoidzellen. Sie werden im Gegensatz zu den segmentkernigen Neutrophilen als „mononukleäre Zellen“ bezeichnet; es handelt sich um aktivierte T-Lymphozyten (CD8-Zellen).

Weitere Erscheinungen der infektiösen Mononukleose sind Hepatitis mit Ikterus, Meningitis, Meningoenzephalitis, Myalgie, Polyneuritis, GuillainBarré-Syndrom, Exantheme, Thrombozytopenie, Myokarditis, Perikarditis, interstitielle Pneumonie und Glomerulonephritis. Die Hepatitis ist relativ häufig das einzige Symptom der Erkrankung. $\mathrm{Ob}$ das EBV eine Embryopathie hervorrufen kann, läßt sich bisher nicht ausschließen. Differentialdiagnostisch ist auch die "Mononukleose" durch das ZMV und die Toxoplasmose in Betracht zu ziehen.

Eine besondere Form der EBV-Infektion ist die Transfusionsmononukleose. Sie wird bei EBV-Seronegativen nach Bluttransfusionen oder Organtransplantationen mit EBV-positivem Material beobachtet (selten).

EBV-Infektionen bei Immunsupprimierten. Im Verlaufe von AIDS ( $<300 \mathrm{CD} 4-Z$ ellen/ $\mu \mathrm{l})$ beobachtet man gehäuft Burkitt-Lymphome, B- und TZell-Lymphome, Zervix-Karzinome sowie die Haarleukoplakie der Zunge („Marker"-Symptom in $24-34 \%$ bei AIDS). Auch bei Transplantatempfängern und bei Kindern mit primären Immundefizienzen oder bei immunsupprimierten Personen beobachtet man progressive, polyklonal-lymphoproliferative Zustände der B-Zellen, die auf das EBV zurückgeführt werden, auch gibt es Myosarkome.

Chronisch aktive EBV-Infektion. Auffallenderweise gibt es bei sonst Gesunden Infektionsverläufe, die sich monatelang hinziehen. Neuerdings glaubt man, eine besondere Verlaufsform der EBV-Infektion abgrenzen zu können: Die „chronisch-aktive EBV-Infektion“. Sie ist durch rezidivierendes Fieber, Splenomegalie, Hepatitis, Viruspneumonie, Lymphknotenschwellungen, Arthralgien infolge In- 
filtration von EBV-haltigen B-Lymphozyten charakterisiert. Serologisch fallen hohe Titer gegen das Kapsid- und Early-Antigen (R(estricted)Form) auf.

X-linked lymphoproliferatives Syndrom. Beim angeborenen Syndrom der Männer beobachtet man häufig schwere Verläufe einer EBV-Infektion, andere Virusinfektionen sind unauffällig. Es kommt zu Hypogammaglobulinämie, zur aplastischen Anämie und zu malignen Lymphomen. Die Sterblichkeit im akuten Stadium beträgt bei diesen Verlaufsformen etwa $70 \%$. Die Immunität gegen das EBV ist zwar normalerweise reguliert, hier liegt jedoch eine mutationsbedingte Überproliferation der T-Zellen vor, die Leberzellnekrosen (u.a.) bewirkt aber die B-Zellproliferation nicht mehr kontrolliert.

EBV-induzierte Tumoren. Nach einer vorhergehenden Infektion mit dem EBV kann es - v.a. in Afrika - zum endemischen Auftreten des BurkittLymphoms kommen. Möglicherweise spielt dabei die schädigende Wirkung der Malaria auf das Immunsystem eine wichtige Rolle.

Das Auftreten des EBV ist mit dem in China weit verbreiteten Nasopharynx-Karzinom (s.u.) eng korreliert, wobei als Kofaktor der häufig in China genossene Salzfisch (Salzverunreinigungen?) in Betracht kommt. Diese beiden Tumorformen sind monoklonal und ein gutes Beispiel für das Zusammenwirken von Viren mit bestimmten Kofaktoren bei der Karzinogenese.

Der Burkitt-Tumor wird als bösartiges Lymphom des Kindesalters vorzugsweise in stark malariaverseuchten Gegenden Afrikas beobachtet; es ist dort der häufigste maligne Tumor. Kinder haben bis zu 1\% Burkitt-Lymphome. Im Tumor läßt sich nur Virus-DNS nachweisen, nach Züchtung in vitro werden auch Kapside gebildet. In den Tumorzellen liegt die DNS episomal in Ringform vor. In den USA und in Europa kommt es sporadisch vor; hier werden vorzugsweise Erwachsene befallen. Bei diesen sporadischen Fällen ist EBV-DNS nur in $20 \%$ vorhanden, die Zellen zeigen aber Translokationen (s.u.).

Heute stellt man sich die Entstehung des afrikanischen Burkitt-Lymphoms folgendermaßen vor: Infolge der Malaria-Infektion proliferieren die BZellen sehr stark. Eine EBV-Infektion verstärkt die Proliferation noch zusätzlich (Immortalisierung). Während bei der Malaria die Proliferation der BLymphozyten polyklonal ist, treten bei den zusätz- lichen Proliferationsreizen durch das EBV - möglicherweise durch Infektion von unreifen B-Zellen fehlerhafte Umlagerungen im Bereich der Immunglobulingene auf, so daß monoklonale Burkitt-Lymphome zustande kommen.

Es kommt hierbei zur reziproken Translokation zwischen dem Chromosom 8 (Träger des c-mycOnkogens) und dem Chromosom 14, 2 oder 22; (Träger der Gen-Garnitur für H-, K- und L-Ketten) der B-Zellen. Man kann diese Ereignisse als „zytogenetische Unglücksfälle" bezeichnen. Hierdurch gerät das c-myc-Onkogen unter den Einfluß der transkriptions- und translationsaktiven Gengruppierung im Chromosom $14(2,22)$. Als Folge steigt die Expression des c-myc-Onkogens und damit die Zahl der Zellteilungen. Dies führt außerdem zu einer Intensivierung der Expression von EBV-spezifischen Membran-Antigenen; gleichzeitig wird das Expressionsmuster der MHC-Antigene und der interzellulären Adhäsionsmoleküle reduziert.

Das Nasopharynx-Karzinom ist ein lympho-epithelialer Tumor; er wird vorwiegend bei der chinesischen Bevölkerung Südostasiens beobachtet. Seine Inzidenz beträgt weltweit $0,3 / 100000 / J a h r$. In China wird eine jährliche Fallzahl von etwa 100000 angegeben. In der Bundesrepublik Deutschland sind $4 \%$ aller bösartigen Tumoren im HNO-Bereich Nasopharynx-Karzinome (Schmincke-Tumor).

Im Nasopharynx-Karzinom enthalten nur die epithelialen Tumorzellen EBV-DNS, nicht aber die Lymphozyten. Das EBV wirkt bei der Tumorentstehung als "Initiator" (s. S. 501). Das LMP ist ein konstitutiv aktiver "Rezeptor" und induziert die Bildung von Oberflächenproteinen (CD-Antigene) und blockiert indirekt die Apoptose.

Beide Tumorformen entstehen in ihrer epidemischen Form durch das Zusammenwirken des EBV mit anderen Zellschädigungen. B-Lymphozyten des Burkitt-Tumors, die Epithelzellen des NasopharynxKarzinoms sowie die Reed-Sternberg-Zellen des Hodgkin-Lymphoms (=B-Zellen) enthalten die EBV-DNS in episomal-zirkulärer Form, jedoch keine Kapside. Auch Karzinome der Speicheldrüsen und der Mundhöhle führt man auf das EBV zurück.

B-lymphoproliferatives Syndrom. Kinder mit angeborenen oder Erwachsene mit erworbenen Störungen des zellulären Immunsystems (AIDS, Transplantationen) können das B-lymphoproliferative Syndrom entwickeln. Auch verschiedene Formen des Morbus Hodgkin werden durch das EBV hervorgerufen. 


\section{Immunität}

Die verschiedenen Antigene des EBV stimulieren den humoralen und den zellulären Immunapparat. Die Besonderheiten der Antikörper-Produktion (heterophile Antikörper u.a.) kommen durch die polyklonale Stimulation der B-Zellen mit dem EBV zustande. Viele EBNA-positive Zellen sezernieren Immunglobuline, deren Spezifität aber weitgehend unbekannt ist.

Antikörper gegen die Antigene des EBV treten in einer typischen Reihenfolge auf. Zu Beginn der klinischen Erkrankung sind meistens schon IgMAntikörper nachweisbar (Tabelle 14.1, Abb. 14.2).

\section{Labordiagnose}

Allgemeines. Die Züchtung des EBV ist für die Diagnose nicht gebräuchlich, der Paul-Bunnell-Test ist durch empfindlichere Verfahren ersetzt worden. Wichtig sind für eine Diagnose das Differentialblutbild und die Teste für Transaminasen. Im Gewebe lassen sich infizierte Zellen gut durch die Anwesenheit der EBER-RNS (analog LATs) nachweisen (In-situ-Hybridisierung).

Henle-Test. Als wichtigstes Nachweisverfahren für Antikörper gegen das EBV muß der Henle-Test angesehen werden. Durch die Wahl entsprechender Antiseren kann er zum Nachweis von IgM-, IgAoder IgG-Antikörpern herangezogen werden.

Tabelle 14.1. Antikörper-Entwicklung bei der infektiösen Mononukleose

\begin{tabular}{|c|c|c|c|c|c|c|c|c|}
\hline Infektionsstatus & $\begin{array}{l}\text { Anti-EBV- } \\
\text { VCA } \\
(\lg G)\end{array}$ & $\begin{array}{l}\text { Anti-EBV- } \\
\text { VCA } \\
\text { (IgM) }\end{array}$ & $\begin{array}{l}\text { Anti-EBV- } \\
\text { VCA } \\
(\lg A)\end{array}$ & $\begin{array}{l}\text { Anti-EBV- } \\
\text { EA } \\
(\lg G)\end{array}$ & $\begin{array}{l}\text { Anti-EBNA- } \\
(\lg M)\end{array}$ & $\begin{array}{l}\text { Anti- } \\
\text { (lgG) } \\
1\end{array}$ & $\begin{array}{l}\text { EBNA- } \\
2\end{array}$ & $\begin{array}{l}\text { Anti-MA- } \\
(\lg G)\end{array}$ \\
\hline $\begin{array}{l}\text { Durchseuchungstiter ( } 90 \% \text { der erwachs. } \\
\text { Bevölkerung) }\end{array}$ & + & - & - & - & - & + & - & + \\
\hline Frische Infektion & ++ & + & $(+)$ & + & + spät & - & + & + \\
\hline Protrahiert verlaufende Infektion & + & $+1-$ & - & $++^{a}$ & - & + & - & + \\
\hline $\begin{array}{l}\text { Reaktivierung bei geschwächter } \\
\text { Immunitätslage }\end{array}$ & + & $(+)$ & - & + & - & + & - & + \\
\hline Burkitt-Lymphom & ++ & - & & + & - & + & - & + \\
\hline Karzinom des Nasopharynx & ++ & & ++ & ++ & & & & \\
\hline
\end{tabular}

${ }^{a}$ R-Form des EA (nicht D-Form)

VCA Virus-Kapsid-Antigen, EA Early-Antigen, MA Membran-Antigen, EBNA Epstein-Barr-nuclear-antigen.

Antikörpertiter

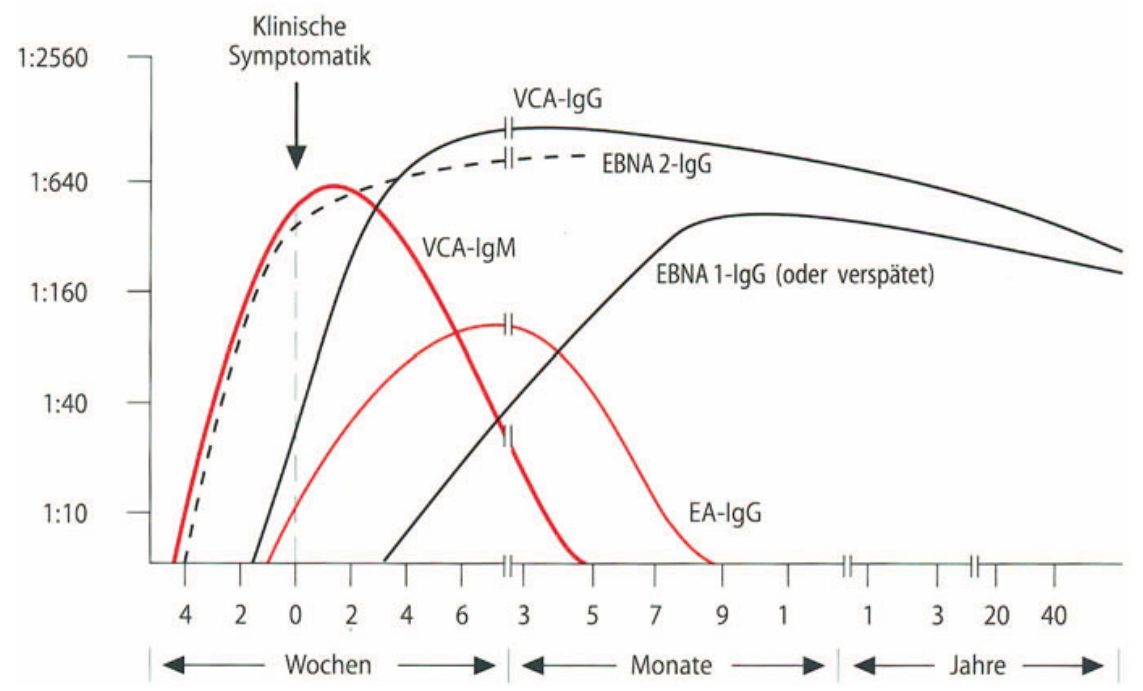

Abb. 14.2. Ablauf einer EBVInfektion: Es ist das Auftreten der VCA-(Viruskapsid), EBNA 1und 2 sowie EA-Antikörper dargestellt 
Als Henle-Test bezeichnet man einen SandwichFluoreszenz-Test mit dem Serum des Kranken oder des Rekonvaleszenten; als Antigen dienen die Antigene des Epstein-Barr-Virus. Kapsidantigene befinden sich in 1-10\% der Zellen aus lymphoblastoiden Linien. Man gewinnt die Ausgangszellen aus Burkitt-Tumoren, führt sie über längere Zeit in vitro fort und streicht sie schließlich auf dem Objektträger aus: Das gleiche Kapsidmaterial kommt auch in Lymphozyten von MononukleoseKranken vor, sofern die Zellen in vitro kultiviert worden sind und mehrere Generationen durchlaufen haben (Tabelle 14.1).

Viele Zellinien verlieren nach längerer Züchtung in vitro die Fähigkeit, EBV zu produzieren. Sie enthalten aber noch ringförmige DNS als Episom und produzieren auch noch virale Antigene; diese sind im Kern (EBNA, EA) oder auf der Zellmembran (MA) lokalisiert. Durch geeignete Verfahren lassen sich diese Antigene induzieren.

Antikörper gegen das EBNA 2 lassen sich ebenso wie gering avide IgG-Antikörper gegen das VCA frühzeitig nachweisen. EBNA 1-Antikörper entstehen zuletzt. Zur Diagnose einer chronischen Form der Mononukleose hat sich das EA im Kern in seiner R-Form (restricted) bewährt, während es sonst diffus (D-Form) im Kern verteilt ist.

Ein wichtiger Prospektiv-Marker für das Entstehen des Burkitt-Lymphoms und des NasopharynxKarzinoms ist die Bestimmung der Antikörper gegen das Kapsid- und das Early-Antigen. Beim Burkitt-Tumor sind IgG und beim zweiten IgA prospektiv erhöht. Zwar sind bei verschiedenen Malignomen der weißen Blutzellen, bei Immunsupprimierten, bei alten Personen und in der Gravidität die Ak gegen die EA und das Kapsid-Antigen auch erhöht; die Titer erreichen aber selten die hohen Werte, wie sie bei den EBV-assoziierten Tumorformen festgestellt werden.

\section{Therapie, Prävention}

Die Therapie einer EBV-Infektion kann bisher nur symptomatisch erfolgen. Für die chronisch aktive EBV-Infektion sind Interleukin 2 und hohe Dosen von Aciclovir in der Erprobung. Die Haarleukoplakie der Zunge spricht gut auf ACG an (s. S. 609). Macrolide als Immunsuppressoren hemmen die BZellproliferation und damit die Entstehung von Lymphomproliferationen (1-10\% aller Patienten) nach Transplantationen.
Schutzimpfung. Eine Impfung gegen EBV steht noch nicht zur Verfügung; sie ist jedoch in hohem Maße wünschenswert. Dabei geht es weniger um die Verhütung der infektiösen Mononukleose als um die Verhütung EBV-assoziierten Tumorarten.

Im Vergleich $\mathrm{zu}$ der angestrebten Herpes-Impfung ist das Ziel der EBV-Impfung einfacher: Während das Ziel eines Herpes-simplex-Impfstoffes in der Verhinderung der Primärinfektion und in der Milderung der Rezidive liegt, soll sich der EBVImpfstoff nur gegen die Primärinfektion richten. Ein Hybrid-Impfstoff (Vaccinia-Virus mit einem EBV-Glykoprotein) wird gegenwärtig am Menschen geprüft.

Tabelle 14.2. Tumorbildung durch EBV

\begin{tabular}{|c|c|}
\hline Tumor & Assoziation mit EBV (\%) \\
\hline $\begin{array}{l}\text { Burkittlymphom (BL) } \\
\text { - Endemisch in Afrika } \\
\text { - Nichtendemisch }\end{array}$ & $\begin{array}{l}100 \\
15-85\end{array}$ \\
\hline $\begin{array}{l}\text { Hodgkin-Lymphom (HD) } \\
\text { - Gemischter Zelltyp } \\
\text { - Nodulär, sklerotisierend } \\
\text { - Lymphozytenarm } \\
\text { - Lymphozytenreich }\end{array}$ & $\begin{array}{l}32-96 \\
10-50 \\
- \\
-\end{array}$ \\
\hline $\begin{array}{l}\text { T-Zell-Lymphome (Non HD) } \\
\text { - T-Zell-Lymphozytose } \\
\text { - T-Zell-Lymphom, Nasalbereich } \\
\text { - T-Zell-Lymphom } \\
\text { (angioimmunoblastisch, } \\
\text { Lymphadenopathie-ähnlich) }\end{array}$ & $\begin{array}{l}40-100 \\
\text { (alle ohne Unterschied) }\end{array}$ \\
\hline $\begin{array}{l}\text { B-Zell-Lymphome (Non HD) } \\
\text { - Plasmozytische Hyperplasie } \\
\text { - Polymorphe Hyperplasie } \\
\text { Polyklonales B-Zell-Lymphom } \\
\text { - Immunoblastisches Lymphom }\end{array}$ & $\begin{array}{l}- \\
- \\
70-100\end{array}$ \\
\hline NK-Zell-Lymphom (Nasal) & - \\
\hline Gliomyosarkom & - \\
\hline $\begin{array}{l}\text { Nasopharynxkarzinom (NPC) } \\
\text { - Hochrisikogebiet } \\
\text { - Rest der Welt" }\end{array}$ & $\begin{array}{l}100 \\
100\end{array}$ \\
\hline $\begin{array}{l}\text { Magen-Karzinom } \\
\text { Japan } 6,7 \%+\end{array}$ & $\begin{array}{l}\text { EBER-1 + } \\
\text { EBNA-1 + Monoklonal }\end{array}$ \\
\hline
\end{tabular}

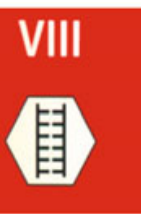




\section{ZUSAMMENFASSUNG: Epstein-Barr-Virus}

Virus. Typisches Herpes-Virus, infiziert Epithelien und B-Lymphozyten; schlecht züchtbar; immortalisiert B-Lymphozyten, das Virus wird dabei latent, ist aktivierbar mit lytischem Zyklus. Replikation in drei Phasen.

Vorkommen. Beim Menschen weltweit.

Epidemiologie. Durchseuchung hoch, abhängig vom hygienischen Standard.

Übertragung. Durch Kuß („kissing disease“), Speichel infektiös, lebenslange Ausscheidung.

Pathogenese. Primäre Infektion von Epithelzellen im Nasenrachenraum, in Tonsillen von Hauptzielzellen, den B-Lymphozyten. Epithelzellen scheiden das Virus lebenslang aus. Das EBV ist der Auslöser von Burkitt-Lym- phom, Nasopharynx-Karzinom und einigen Formen des Hodgkin-Lymphoms sowie von Lymphoproliferationen (s. Tab. 19.2).

Klinik. Infektiöse Mononukleose mit Fieber, Lymphknotenschwellungen mit Milztumor, "buntem" Blutbild, Angina, häufig Hepatitis, Meningitis, Exanthem u.a. Inkubationsperiode 20-50 Tage.

Immunität. Dauerhafte Immunität durch ZTL, Antikörper gegen Kapsid, EBNA, Early- u. Membranantigene.

Labordiagnose. Henle-Test: IFT (IgM und IgG) gegen VCA-, EA-, EBNA-Antigene zur Verlaufsbestimmung der Erkrankung.

Therapie. Symptomatisch. ACG bei Haarleukoplakie.

Prophylaxe. Impfstoff wird entwickelt.

\subsection{Humane Herpes-Viren 6, 7 und 8 (HHV 6, 7 und 8)}

\section{Einleitung}

Nach dem Auftreten der AIDS-Pandemie und der Isolierung des HIV 1 und 2 durch Montagnier und Gallo wurde wegen vieler Unklarheiten der Pathogenese von AIDS nach krankheitsfördernden Kofaktoren gefahndet. 1986 gelang es der Arbeitsgruppe von Gallo, ein bisher unbekanntes Virus zu isolieren; es fand sich bei AIDS-Patienten und bei Personen mit Sarkom, Leukämie und Lymphom. Der gemeinsame Nenner des Auftretens dieses Virus schien ein Schaden des Immunsystems $\mathrm{zu}$ sein. 1988 wurde dann in Japan ein ähnliches Virus aus den Blutlymphozyten von Kindern mit Exanthema subitum isoliert und auf Grund seiner Eigenschaften als HHV 6 bezeichnet. 1990 wurde bei der Züchtung von nicht beimpften CD4-Zellen eines Gesunden ein weiteres zytopathogenes Agens quasi ein blinder Passagier - isoliert. Es wurde als zur Gruppe der Herpes-Viren gehörig erkannt und HHV 7 benannt.
Kaposi-Sarkome (K.S.) traten bis 1980 sporadisch im Bereich des Mittelmeeres bei Senioren und Juden in Osteuropa auf oder wurden endemisch in Zentralafrika bei jüngeren Personen beobachtet. Nach dem Auftreten von AIDS wurde das K.S. bei $20-30 \%$ von AIDS-Kranken, also jüngeren Personen, festgestellt; es wird jetzt als AIDS-definierende Krankheit angesprochen (s. S. 610).

Chang und Moore gelang es 1994 mit der PCR, im K.S. und in B-Zell-Lymphomen des Abdomens eine Virus-DNS nachzuweisen, die ebenfalls zur Gruppe der Herpes-Viren gehörig erkannt wurde. Man schreibt sie jetzt dem K.S.-assoziierten HHV $8 \mathrm{zu}$.

\section{Einteilung}

Die Isolate des HHV 6 lassen sich in die Subtypen $A$ und $B$ einteilen (Tabelle 14.2). Sie gehören ebenso wie das HHV $7 \mathrm{zu}$ den $\beta$-Herpes-Viren. Durch RE-Analysen, die PCR und serologisch lassen sie sich voneinander abgrenzen. Das beim K.S. nachgewiesene Agens wird als HHV 8 bezeichnet; auf Grund der Eigenschaften seiner DNS gehört es zu den $\gamma$-Herpes-Viren. Rhesusaffen beherbergen ein analoges Virus. 
Tabelle 14.3. Eigenschaften von HHV 6 (A und B), 7 und 8

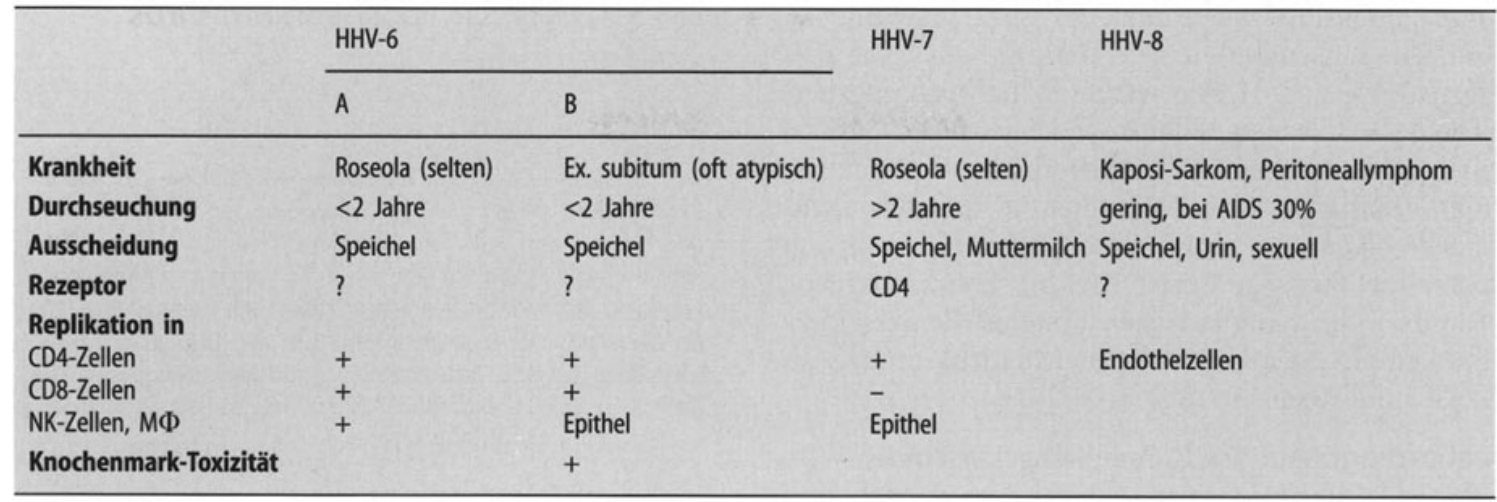

\subsubsection{Humanes Herpes-Virus 6}

Das HHV6B ist der Erreger des Exanthema subitum oder der Roseola infantum. Es wird auch für krankheitsbegleitende Fieberkrämpfe verantwortlich gemacht. Bei Reaktivierungen infolge von Schäden des Immunsystems steigt die Ausscheidung. Das HHV6A ließ sich bisher nicht einem bestimmten Krankheitsbild zuordnen. Beide Viren bleiben nach der Primärinfektion latent und persistierend im Organismus und können reaktiviert werden. Allerdings lassen sich der Reaktivierung noch keine pathogenetischen Folgen zuschreiben.

\section{Beschreibung}

Morphologie und Genom. Als typische HerpesViren enthalten HHV 6A und B eine DoppelstrangDNS mit etwa 160-170 kbp.

Züchtung. Kernpunkt für die Züchtung ist die Stimulierung von Nabelschnurlymphozyten mit IL-2 und Mitogenen. Auf diese Weise gelingt die Übertragung auf CD4-Zellen durch Kokultivierung; dabei wird in den latent infizierten Spenderzellen des Menschen das Virus reaktiviert und kann auf die frischen Zellen übergehen. Die Integration erfolgt in das Chromosom 17, nahe den Telomeren, der Karyotyp soll instabilisiert werden; der Mechanismus der Reaktivierung ist unbekannt.

Die Kapside entstehen im Kern und erhalten dort das Tegument; in den Membransystemen der Zelle erfolgt die Montage zum reifen Virus. Die
Viren lassen sich auf CD4-Zellen übertragen und erzeugen einen zytopathischen Effekt vom Typ der Zellfusion. Einschlußkörperchen lassen sich im Kern und Zytoplasma nachweisen. Es werden Integration, Immortalisierung und Latenz beobachtet. In vivo läßt sich das Virus reaktivieren (Tabelle 14.3). Im Epithel der Speicheldrüsen persistiert das HHV6 und 7 mit Replikation.

\section{Rolle als Krankheitserreger}

Übertragung und Epidemiologie. Die Durchseuchung mit dem HHV-6A und B beginnt mit dem Verschwinden der mütterlichen Antikörper 5-6 Monate nach der Geburt, also viel früher als mit dem EBV. Bald danach steigt die Durchseuchung drastisch an. Die Übertragung erfolgt durch Speichel und Aerosole sowie durch engen Kontakt mit der Mutter. In der akuten Phase läßt sich das Virus in Blutmonozyten, im Speichel und Stuhl nachweisen. Die Erkrankung ist also vorzugsweise die Folge von Infektionen im Säuglings- und Kleinkindesalter. Im Alter von 2 Jahren sind etwa $50 \%$, im Alter von fünf Jahren $80 \%$ der Kinder oder mehr durchseucht. Bei Erwachsenen wurden 85-100\% Antikörperträger festgestellt. Bei Seropositiven kann HHV6-DNS aus Blutzellen isoliert werden. Bei seronegativen Graviden hat man im Falle von Infektionen konnatale Infektionen festgestellt. Bei Erwachsenen wird das Virus mit der PCR im Speichel und Zervixsekret nachgewiesen.

Klinik. Das HHV6B ist der Erreger des Drei-TageFiebers (Exanthema subitum oder Roseola infantum). Das Exanthem tritt gegen Ende der Fieberphase auf. Man kennt auch Fälle ohne Exanthem 
nur mit Fieber und inapparente Verläufe sowie eine „infektiöse Mononukleose“ bei Jugendlichen und Erwachsenen. Die Erkrankung heilt ohne Folgezustände aus. HHV 6 wurde in Entmarkungsherden der Multiplen Sklerose nachgewiesen. HHV 6 ist auch für Enzephalitis, Fieberkrämpfe, Pneumonie, Meningitis, Lymphadenopathie und Knochenmarkschäden verantwortlich. Schließlich bringt man das Virus in Beziehung zur Entstehung von Tumoren des lymphatischen Systems. Es persistiert im Lymphsystem, in den Speicheldrüsen und im ZNS. Inkubationsperiode 7-14 Tage.

Labordiagnose. Bei Immunmangelzuständen wird das HHV 6B reaktiviert: 1-3 Monate danach machen sich Fieber, Exantheme, Pneumonie und Enzephalitis bemerkbar. Antikörper der Klassen IgM und IgG im Gefolge einer Infektion lassen sich in einem Immunfluoreszenztest auf infizierten $\mathrm{T}$ Lymphozyten nachweisen (s. Henle-Test). Der Test wird empfindlicher, wenn auf den Antikörper Komplement gegeben wird und ein Fluoreszeinmarkiertes Antikomplement verwendet wird (AntiKomplement-Immunfluoreszenz, ACIF). Es existiert auch ein ELISA. Im Blutbild sind Granulozyten und Lymphozyten vermindert. Bei Fieberkrämpfen wurde HHV6B-DNS mittels PCR im Liquor nachgewiesen. Reaktivierungen gehen mit einer IgM-Reaktion einher. Therapie: Ganciclovir.

\subsubsection{Humanes Herpes-Virus 7}

Das HHV 7 ist „in search of disease“; es wurde gelegentlich bei Exanthema subitum, z. T. mit Hepatitis und Enzephalitis nachgewiesen. Auch Mononukleose-ähnliche Krankheitsbilder und unklare Fieberzustände sind sehr selten. Bei Immundefekten gibt es oft Reaktivierungen. Seine DNS enthält 145 kbp. Der zytopathische Effekt, die Züchtung des Virus in CD4-Zellen und die Isolierung aus Monozyten des peripheren Blutes gleichen dem des HHV 6. Die Durchseuchung steigt später als beim HHV 6 an. Einige Eigenschaften von HHV 6A und B sowie HHV 7 sind vergleichsweise in Tabelle 14.3 zusammengefaßt.

Die Übertragung des HHV 7 beginnt nach derjenigen mit HHV 6, also nach dem 2. Lebensjahr, und erreicht bei 11-13jährigen $60 \%$, bei Erwachsenen $80-90 \%$. Die Übertragung erfolgt durch den Speichel (PCR: $95 \%$ positiv).

\subsubsection{HHV 8, Kaposi-Sarkom-Virus}

Auf dem langen Wege zur Aufklärung der Ätiologie des KaposiSarkoms (K.S.) gelang 1994 die Entdeckung von "herpesähnlicher DNS" im K.S. von AIDS-Patienten; die DNS dieses $\gamma$-Herpes-Virus enthält etwa $250 \mathrm{kbp}$. Sie läßt sich in K.S.-Zellen von AIDS-Patienten sowie im endemischen afrikanischen und mediterranen K.S. der älteren Männer nachweisen. HHV 8 ist der Hauptfaktor bei der Entstehung des K.S., Nebenfaktoren sind Immunmangel und das Tat-Protein. Beim endemischen K.S. wirkt die Malaria als Kofaktor. Das Genom enthält 4 Onkogene.

\section{Rolle als Krankheitserreger}

Übertragung und Epidemiologie. Die Übertragung des HHV 8 erfolgt offenbar sexuell, bei den meisten Hämophilen und bei Kindern mit AIDS ist es dagegen nicht nachweisbar; AIDS-Kranke haben bis zu 30\% K.S.-Antikörper. Antikörper lassen sich bei K.S.-Trägern in 90-100\% nachweisen. Bei Gesunden wurden in England 0-3\%, in den USA $0-5 \%$ Seropositive entdeckt. Insgesamt ist die Durchseuchung mit dem HHV 8 viel geringer als mit dem EBV; in Afrika wird HHV 8-DNS bereits in der Kindheit im Blut festgestellt, dementsprechend ist die Durchseuchung hoch (30-100\%). Auch im Sputum und in Rachenabstrichen wird es nachgewiesen, wahrscheinlich erfolgt präpubertär die Übertragung durch Speichel. Es findet sich häufiger bei Männern als bei Frauen. Etwa 4\% der Blutspender sollen seropositiv sein (USA). Insgesamt ähnelt die Epidemiologie der des HSV 2.

Pathogenese. In den B-Zellen und den Monozyten des peripheren Blutes ist HHV 8 oder seine DNS bei Patienten mit K.S. nachweisbar. Tritt es bei HIV-positiven Patienten im peripheren Blut auf, läßt sich ein K.S. vorhersagen. Auch bei Immunsupprimierten mit Transplantationen wird es gefunden. Sein Nachweis auch in B-Zell-Lymphomen des Abdomens sowie in Angiosarkomen war überraschend. Das Genom enthält die Information für ein zellzyklusregulierendes Protein (Cyclin-Dähnlich), für Zytokine (IL-6 und -8) und ein Apoptose-blockierendes Gen („bcl-like“). Insgesamt enthält es 18 (von 83!) aus der Zelle „gestohlene" Gene (Chemokine, Komplement-Rezep- 
tor, sowie fünf Gene, die die Synthese von Interferon abschalten). Beim Gesunden wird der Latenzstatus immunologisch streng kontrolliert. In den K.S.-Zellen ist das Virus latent und episomal, in den monozytoiden Zellen ist die Replikation permissiv mit Lyse der Zellen.

Kaposi-Sarkom. Der Tumor besteht aus spindelzellartigen Elementen, die sich von Endothel-Zellen, Fibroblasten oder monozytoiden Zellen ableiten. Das K.S. tritt auf der Haut, den Schleimhäuten, in Organen und im Lymphgewebe multizentrisch auf und ist monoklonal. Weitere HHV 8-bedingte Tumorformen sind die Castleman-Krankheit und Körperhöhlen-Lymphome der B-Zellen.
Labordiagnose. Das HHV 8 ließ sich anfangs nur durch die PCR nachweisen. 1996 ist die Züchtung des Virus in verschiedenen Zellarten (ZPE+) gelungen. Zum Antikörpernachweis verwendet man einen IFT oder ELISA für lytische Antigene und einen "latency associated nuclear antigen"-Test (LANA, analog EBNA); die Teste sind noch nicht ausgereift. Man kennt jetzt drei Varianten des Virus.

Therapie. Es gibt Anhaltspunkte, daß die Anwendung von IFN $\alpha / \beta$ oder von Foscarnet Verkleinerung der K.S. bewirken, Nukleosidanaloge (Ganciclovir und Ciclofovir) sowie Protease-Inhibitoren eliminieren HHV 8 aus dem Blut.

\section{ZUSAMMENFASSUNG: HHV 6 und 7}

Virus. Typische Herpes-Viren. Züchtung der Viren durch Kokultivierung auf NabelschnurCD4-Lymphozyten.

Vorkommen und Übertragung. Nur beim Menschen, Übertragung durch engen Kontakt (Speichel) und Aerosole.

Epidemiologie. Beginn der Durchseuchung im 6. Lebensmonat nach Verschwinden der mütterlichen Antikörper. Hohe Durchseuchung nach zwei Jahren.

Pathogenese. Wahrscheinlich Latenz in Lymphozyten.

Klinik. Drei-Tage-Fieber (Exanthema subitum), Mononukleose-ähnliches Krankheits- bild, Fieberkrämpfe, Pneumonie (?) und Enzephalitis. Inkubationsperiode 3-15 Tage. Möglicherweise Tumoren des lymphatischen Systems. Bei HHV6A und HHV7 noch keine Krankheit sicher nachgewiesen.

Immunität. Wahrscheinlich lebenslang mit inapparenten Reaktivierungen.

Labordiagnose. Routinediagnostik (IFT, ELISA). Virusisolierung durch Kokultivierung. PCR im Liquor. DD: Exanthematische Viruserkrankungen, Arzneimittel-Exantheme, ZMV.

Therapie. Eine spezifische Therapie gibt es nicht.

Prävention. Keine.

\section{ZUSAMMENFASSUNG: HHV 8}

Herpes-Virus DNS mit 250 kbp im KaposiSarkom, polyklonal-monoklonaler, multizentrischer Tumor aus endothelartigen Zellen meist bei Immungeschädigten. Übertragung durch Sexualverkehr. PCR für DNS-Nachweis, IFT, ELISA und LANA-Test für Antikörper.
18 von 83 HHV 8-Genen stammen ursprünglich aus der Zelle: Komplexer Transformationsprozeß. 


\section{Virushepatitis}

D. FALKe, G. Gerken

\section{EINLEITUNG}

Die Erreger der virusbedingten Hepatitis gehören in verschiedene Gruppen von Viren. Nach der Entdeckung der Erreger der Hepatitis A und B blieben NonA/NonB-Hepatitiden zurück. Inzwischen wurden weitere Hepatitis-Viren nachgewiesen oder postuliert $[C, D, E, G$ und TTV]. Die Durchseuchung mit den Viren ist hoch. Die Krankheiten bestehen in akuten und z.T. chronischen Verlaufsformen. Folgekrankheiten sind Leberzirrhose und Leberzellkarzinom. Wichtig ist, daß bei der Hepatitis B, C und D Mutantenbildung bei chronischen Verläufen die Art des Krankheitsbildes beeinflussen.

\section{1 Übersicht}

\section{Definition}

Als Virushepatitis wird unter Ausschluß der Gelbfieber-Hepatitis ein Krankheitsbild bezeichnet, bei dem sich aufgrund einer Infektion mit „hepatotropen" Viren ein Krankheitsprozeß entwickelt, der sich primär auf die Leber beschränkt und nur sekundär andere Organsysteme in Mitleidenschaft zieht.

\section{Epidemiologie}

Die verschiedenen Formen der Virushepatitis sind weltweit verbreitet; in Deutschland gehört die Virushepatitis $\mathrm{zu}$ den wichtigsten Infektionskrankheiten. Auch in der Häufigkeitsstatistik der Virusinfektionen ist ihre Stellung prominent: Sieht man von den exanthematischen Viruskrankheiten (Masern, Röteln u.a.) und den Viruskrankheiten des Respirationstraktes ab, so erweist sich die VirusHepatitis als die häufigste Viruskrankheit. Sie steht in der Statistik der infektiös bedingten Berufskrankheiten nach der Tuberkulose an zweiter Stelle. Ihre Auswirkungen auf die Volksgesundheit sind ebenso gravierend wie die durch sie bedingten wirtschaftlichen Folgen. Deshalb stellt die Virushepatitis z.Z. neben AIDS das wichtigste Seuchenproblem dar. In den Entwicklungsländern mit endemisch auftretender Hepatitis B und C ist diese Infektion der wichtigste Faktor für die Entstehung des Leberkarzinoms; man zählt das HBV und HCV deshalb zu den krebserzeugenden Viren. Nach Entwicklung der Diagnosemöglichkeit für HAV und HBV blieben Hepatitiserkrankungen zurück, die man als NonA/NonB-Hepatitis bezeichnete. Die meisten dieser Hepatitiden (85-90\%) lassen sich auf das HCV zurückführen, der Rest beinhaltet HEV; das HGV und TTV sind asymptomatisch.

\section{Formen der Hepatitis}

Aufgrund des jeweils typischen Übertragungsmodus und der Inkubationszeit kann man bei der Virushepatitis trotz Befall eines einzigen Organs, nämlich der Leber, drei Krankheitsformen unterscheiden. Jede Hepatitisform zeigt neben der unterschiedlichen Ätiologie und Klinik ein typisches pathologisches Gewebebild (nekrotisierende Leberparenchym-Erkrankung).

Der größte Teil der akuten und inapparenten Hepatitisinfektionen heilt folgenlos aus. Bei einem kleineren Teil entsteht ein lebenslanges Trägertum. Das Trägertum kann ohne Dauerschäden der Leber vorkommen; in anderen Fällen tritt bei chronischen Verläufen als Spätfolge eine Zirrhose auf, aus der sich ein primäres Leberkarzinom entwikkeln kann (HBV, HCV). Man kennt auch fulminant tödlich verlaufende Erkrankungen.

Man unterscheidet folgende Prozesse:

- Übergang in ein symptomloses Trägertum.

- Übergang in eine chronische Hepatitis. Diese kann als milder, nicht aggressiver Prozeß verlaufen (chronisch-persistierende, wenig replizierende Hepatitis); sie tritt aber auch als chro- 
nisch-aktive Hepatitis (sog. stark replikativ-aggressiver Histotyp) in Erscheinung. Die chronisch-persistierende Hepatitis hat eine gute Prognose, während die chronisch stark replikative Hepatitis zur Selbstperpetuierung neigt und in der Mehrzahl der Fälle zu Leberzirrhose und zu Karzinom führt.

- Direkter Übergang in eine Zirrhose innerhalb von Monaten.

\section{Leitsymptome und -befunde der akuten Hepatitis}

Ikterus, Juckreiz, Übelkeit, Appetitlosigkeit, Oberbauchschmerzen bzw. Hepatomegalie, Splenomegalie, Lymphknotenschwellungen, Arthralgie u.a.

\section{Differentialdiagnose}

Die Differentialdiagnose eines akuten HepatitisFalles umfaßt den Nachweis des HAV, des HBV, des HDV, des HCV und HEV, des HGV und TTV. Hierher gehören auch bakterielle Infektionen, ZMV, EBV und HSV bzw. die entsprechenden Antikörper; bei ihnen sind jedoch andere Begleitsymptome vorhanden. Auch werden die Transaminasen bestimmt und Biopsien gewonnen.

Meldepflicht. Verdacht, Erkrankung, Tod, Erregernachweis der akuten Hepatitis.

\subsection{Hepatitis A-Virus (HAV)}

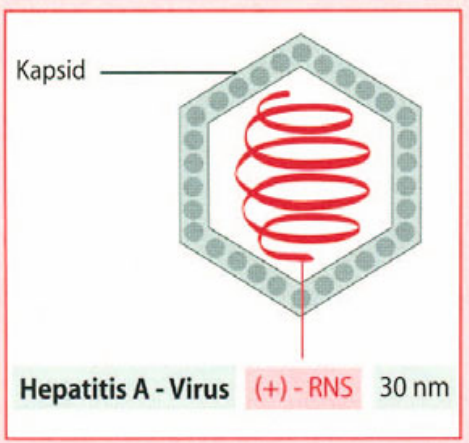

Das HAV ist der Erreger der "infektiösen" epidemischen Gelbsucht wobei viele asymptomatische Verläufe vorkommen. In den Entwicklungsländern ist sie häufig.

Das Virus wurde 1973 durch Immun-Elektronenmikroskopie im Stuhl von Patienten entdeckt. Das Virus ist ein Vertreter der Picorna-Viren. Das Hepatitis A-Virus wurde deshalb früher als Entero-Virus 72 bezeichnet, es ist serologisch einheitlich.

\subsubsection{Beschreibung}

\section{Genom}

Das Virion besitzt eine (+)-Strang-RNS mit einem kovalent gebundenen Protein am 5'-Ende. Das Genom enthält $8,0 \mathrm{~kb}$.

\section{Morphologie}

Das Kapsid (Durchmesser $27 \mathrm{~nm}$ ) besteht aus Kapsomeren, die jeweils vier Proteine enthalten.

\section{Züchtung}

In bestimmten Zellinien vermehrt es sich, ohne einen ZPE hervorzurufen. Das Hepatitis-A-Virus läßt sich auf Affen (Marmosets und Schimpansen) übertragen.

\section{Resistenz gegen äußere Einflüsse}

Das HAV bleibt unter durchschnittlichen Umweltbedingungen außerhalb des Menschen mehr als vier Wochen infektiös.

Das Virus ist ätherstabil und etwas hitzestabiler als die übrigen Picorna-Viren: Es wird erst durch fünfminütiges Erhitzen auf $100^{\circ} \mathrm{C}$ zerstört, es übersteht $30 \mathrm{~min}$ bei $60^{\circ} \mathrm{C}$ (Tabelle 15.1).

\subsubsection{Rolle als Krankheitserreger}

\section{Epidemiologie}

In den Entwicklungsländern ist die Durchseuchung sehr stark ausgeprägt; die Infektionen erfolgen im frühen Kindesalter; in dieser Entwicklungsperiode verlaufen die Infektionen meist asymptomatisch. Man rechnet mit etwa 25000 apparenten Infektionen pro Jahr in Deutschland, auch lassen sich sporadische Krankheitsfälle nach Auslandsreisen feststellen. Die Durchseuchung bei Kindern und Jugendlichen bis $\mathrm{zu} 20$ Jahren ist insgesamt gering.

\section{Übertragung}

Verunreinigte Lebensmittel (Muscheln, Salat etc.) und v.a. Trinkwasser sind die wichtigsten Anstek- 
Tabelle 15.1. Die Hepatitis-Viren und ihre Eigenschaften

\begin{tabular}{|c|c|c|c|c|c|c|c|}
\hline \multirow[t]{2}{*}{ Eigenschaft } & \multicolumn{7}{|l|}{ Hepatitis } \\
\hline & A & B & D & $\mathrm{C}$ & $E$ & G & TTV \\
\hline Erreger & HAV & $\mathrm{HBV}$ & HDV & $\mathrm{HCV}$ & HEV & HGV & TTV \\
\hline Nukleinsäure & RNS(+) & DNS + - & RNS(-) & RNS(+) & RNS(+) & RNS(+) & DNS (-) \\
\hline Genom (kb) & 7,8 & $3,2 \mathrm{kbp}$ & 1,7 & 9,4 & 7,5 & 9,4 & $3,8 \mathrm{~kb}$ \\
\hline Durchmesser (nm) & 28 & 42 & 36 & $60-70$ & 34 & $?$ & $?$ \\
\hline Hülle & - & + & $+(\mathrm{HBV})$ & + & - & + & - \\
\hline Virusfamilie & Picorna & Hepadna & Virusoid & Flavi & ${ }_{\text {"Hepatitis E" }}$ & Flavi & Circino \\
\hline Züchtung in vitro & + & $(+)$ & - & $(+)$ & - & - & - \\
\hline Stabilität $-20^{\circ} \mathrm{C}$ & + & + & $?$ & $?$ & sehr gering & $?$ & $?$ \\
\hline Stabilität $60^{\circ} \mathrm{C} / 1 \mathrm{~h}$ & stabil & stabil & fast inaktiv & fast inaktiv & $?$ & ? & $?$ \\
\hline Stabilität $100^{\circ} \mathrm{C} / 20^{\prime}$ & inaktiviert & inaktiviert & inaktiviert & inaktiviert & ? & $?$ & $?$ \\
\hline
\end{tabular}

kungsquellen. Eine Übertragung durch Aerosole ist nicht festgestellt worden.

Man hat größere Epidemien beobachtet, die durch verunreinigtes Trinkwasser entstanden sind, v. a. in Kriegs- und Notzeiten oder bei Naturkatastrophen. In Kinderheimen, Lagern und dergleichen erfolgt die Ausbreitung fäkal-oral schnell. Durch mit Abwässern verunreinigte Schwimmbäder oder Teiche können Explosiv-Epidemien zustandekommen. Durch Bluttransfusionen wird das HAV nur in Ausnahmefällen übertragen. Man hat Hepatitis A-Fälle jetzt auch vermehrt bei Drogensüchtigen festgestellt.

\section{Pathogenese}

Man nimmt an, daß das Virus nach einer fäkaloralen Übertragung in den Magen-Darmtrakt gelangt. Bisher hat sich kein Hinweis auf eine Replikation im Epithel des Intestinums finden lassen. Das HAV gelangt wahrscheinlich über eine kurzdauernde Virämie in die Leber. Nach einer anderen Hypothese soll der Transport in die Leber durch Lymphozyten erfolgen. Die Leberzellen und Kupffer-Zellen enthalten viel Antigen. HAV-Antigen wird aber auch in der Milz und in den Lymphknoten beobachtet. Die Virusvermehrung kann für sich allein keine Zellschädigung bewirken. Der Zellschaden bei der Hepatitis A ist indirekt: Er wird durch zytotoxische Lymphozyten verursacht. Das im Stuhl erscheinende Virus stammt aus den Gallenwegen; es wird bereits 14 Tage vor dem Auftreten des Ikterus nachweisbar. Auf dem Höhepunkt der Ausscheidung enthält der Stuhl et- wa $10^{9}$ Viren pro Gramm. Bereits vor Beginn der Erkrankung geht die Virus-Ausscheidung drastisch zurück. Man vermutet, daß bereits in dieser Phase IgA-Antikörper auf der Schleimhaut erscheinen und die Ausscheidung von infektiösem Virus reduzieren. Bereits zu Beginn der klinischen Erkrankung lassen sich im Serum IgM-Antikörper nachweisen. IgM- und IgG-Antikörper wirken Virusneutralisierend (Abb. 15.1).

Zellinfiltrate sind vorwiegend portal und periportal zu finden, es sind meist CD8-Zellen. Die Schädigung der Hepatozyten erfolgt unter dem Bild einer herdförmigen Nekrose. Die Herde liegen in der Umgebung der Zellinfiltrate, aber auch im Zentrum der Läppchen. Bei Kindern sind die Läsionen viel weniger ausgeprägt als bei Erwachsenen.

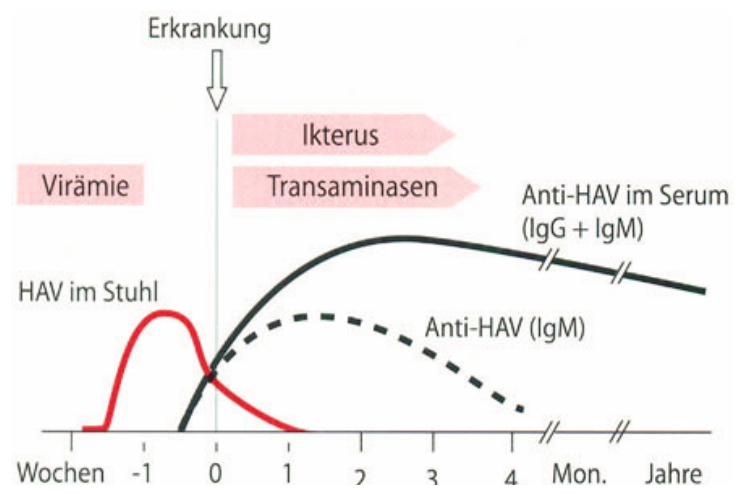

Abb. 15.1. Ablauf einer Hepatitis A-Infektion. Vor Beginn der Erkrankung tritt das HAV im Stuhl auf, zu Beginn der Erkrankung sind bereits IgM-Antikörper nachweisbar 


\section{Klinik}

Die Inkubationsperiode beträgt 2-6 Wochen. Die klinischen Symptome gleichen denen der Hepatitis B. Der Ausbruch ist abrupt, aber leicht; Fieber wird häufiger als bei Hepatitis B beobachtet. Die Infektionen verlaufen bei Kindern meist anikterisch; bei Erwachsenen wird der Ikterus häufiger beobachtet. Es gibt nur wenige schwer verlaufende Fälle. 15\% aller klinisch-ikterischen Fälle verlaufen protrahiert, z.T. mit Cholestase. Die Letalität beträgt $0,1-0,2 \%$ der hospitalisierten (!) Fälle. Es entstehen keine Virusträger; als Folgezustand kann eine Autoimmun-Hepatitis zustandekommen.

\section{Immunität}

Das Überstehen der Hepatitis A hinterläßt eine lebenslange Immunität. Spätfolgen (wie bei Hepatitis B) gibt es nicht. Selten werden Autoantikörper gebildet (ANA, ASGPR; s. S. 676).

\section{Labordiagnose}

Im Stuhl läßt sich das Virus bereits 14 Tage vor der klinischen Erkrankung mit dem Antigen-ELISA feststellen. Die Nachweisrate für das Virus sinkt bei Beginn der klinischen Erkrankung je- doch stark ab. Die Diagnose erfolgt durch einen Antikörper-ELISA und die Bestimmung der Transaminasen. Bereits zu Beginn der Erkrankung lassen sich IgM-Antikörper nachweisen; der Befund bleibt für etwa 3-4 Monate positiv. Frühzeitig sind auch bereits IgG-Antikörper vorhanden. Der Virusnachweis gelingt durch die PCR (nicht Routine).

\section{Prävention}

Allgemeine Hygiene-Maßnahmen. Der beste Weg zur Verhütung der Hepatitis $A$ ist eine gute Allgemeinhygiene. In Hospitälern haben sich unter guten hygienischen Bedingungen keine Sekundärfälle feststellen lassen. Deshalb erscheinen strenge Isolierungsmaßnahmen kaum lohnend, zumal die Virusausscheidung zum Zeitpunkt der Hospitalisierung bereits reduziert ist.

Prophylaxe. Ein Totimpfstoff aus menschlichen diploiden Zellen ist sehr gut wirksam. Bei Risikogruppen und vor Tropenreisen ist eine Impfung mit einem Totimpfstoff sehr zu empfehlen, die Konversionsrate ist sehr hoch.

Ein Impfschutz kann durch Schnellimmunisierung in zwei Wochen erzielt werden, eine Auffrischung ist nach ca. 10 Jahren erforderlich.

\section{ZUSAMMENFASSUNG: Hepatitis A}

Virus. Das (+)-Strang-RNS-Virus gehört zu den Picorna-Viren. Nur ein Serotyp. Ätherstabil, in der Außenwelt sehr haltbar.

Vorkommen. Sehr weit verbreitet. Bei gutem Hygienestandard verschwindet das Virus aus der Bevölkerung (Industrieländer).

Epidemiologie. Hohe Durchseuchung in den Entwicklungsländern, häufig asymptomatisch, vorzugsweise bei Kindern.

Übertragung. Schmutz-Schmier-Infektion, durch Lebensmittel und Trinkwasser sowie im Freibad.

Pathogenese. Nach oraler Infektion durch eine Virämie in die Leber. Das Stuhlvirus stammt aus den Gallenwegen. Das Virus selbst wirkt nicht zytolytisch, ZTL zerstören die Leberzellen.
Immunität. Die Infektion erzeugt eine lebenslange Immunität, wahrscheinlich inapparente Booster-Infektionen.

Klinik. Inkubationsperiode 2-6 Wochen. Fieber, Ikterus, Hepatitis, viele subikterische Fälle, sehr selten Todesfälle, keine Zirrhosen, kein Leberkarzinom, kein Trägerstatus.

Labordiagnose. Virusausscheidung bereits 10-14 Tage vor Erkrankung, nimmt vor Krankheitsbeginn schnell ab: Antigen-ELISA, IgM- und IgG-Antikörper, Transaminasen.

Therapie. Keine spezifische Therapie.

Prävention. Allgemein-hygienische Maßnahmen. Aktive Impfung vor Tropenreisen: Totimpfstoff, sehr gute Konversionsrate.

Meldepflicht. Verdacht, Erkrankung, Tod, Erregernachweis. 


\subsection{Hepatitis B-Virus (HBV)}

Das Virus ruft die Hepatitis B hervor. Diese Hepatitis wird auch als "Serumhepatitis", "Transfusionshepatitis", "Fixer-Hepatitis" oder "Hippie-Hepatitis" bezeichnet. Sie kann in chronische Verlaufsformen einmünden und zur Leberzirrhose und zu Leberkarzinom führen. - Das HBV wird zu den Hepadna-Viren gerechnet. Viren dieser Gruppe finden sich auch bei Schimpansen, Waldmurmeltieren und Enten. Auf der Erde gibt es 300 Mio HBV-Träger.

Der Impfstoff mit dem HBsAg verhindert Erkrankung, Zirrhose und Leberzellkarzinom.

\section{Geschichte}

Bereits 1885 wurde von Lürmann eine „IkterusEpidemie" beschrieben, die im Gefolge einer Pokken-Impfaktion aufgetreten war. Rückschauend lassen sich diese Fälle und auch des „Salvarsan“-Ikterus der Syphilitiker auf eine Übertragung des Hepatitis-B-Virus zurückführen. Vorkommnisse dieser Art legten bereits frühzeitig den Gedanken nahe, in menschlichen Seren befinde sich ein infektiöses Agens, das Hepatitis verursache. 1938 wurde klar, daß durch die Anwendung von Masern-Rekonvaleszenten-Serum eine infektiöse Hepatitis entsteht: Der „homologe Serum-Ikterus“. Diese Er- kenntnis wurde auf die Hepatitis-Fälle übertragen, die nach Bluttransfusionen ebenso auftraten wie nach ärztlichen Eingriffen mit ungenügend sterilisierten Geräten. 1963 entdeckte dann Blumberg in den Seren der Ureinwohner Australiens ein Antigen, das mit den Seren von multitransfundierten Hämophilen präzipitierte, das sog. „Australia“-Antigen; es wurde später in HBs-Antigen umbenannt. 1970 wurde die Bezeichnung Hepatitis B eingeführt.

\subsubsection{Beschreibung}

\section{Genom}

Das HBV enthält eine Doppelstrang-DNS, bestehend aus einem kompletten (-)- und einem inkompletten (+)-Strang. Am 5'-Ende des (-)Strangs sitzt ein kovalent gebundenes Protein, das als Primer für die Synthese dieses Strangs benötigt wird. Der Gegenstrang ( + ) ist am 3'-Ende inkomplett (Abb. 15.2). Man unterscheidet vier Gene: HBs-, Polymerase-, Core- (C-) und HBx-Gen.

\section{Morphologie}

DANE-Partikel. Das HBV wird in seiner infektiösen Form als DANE-Partikel bezeichnet (Durchmesser $42 \mathrm{~nm}$ ). Es besteht aus einem Nukleokap-
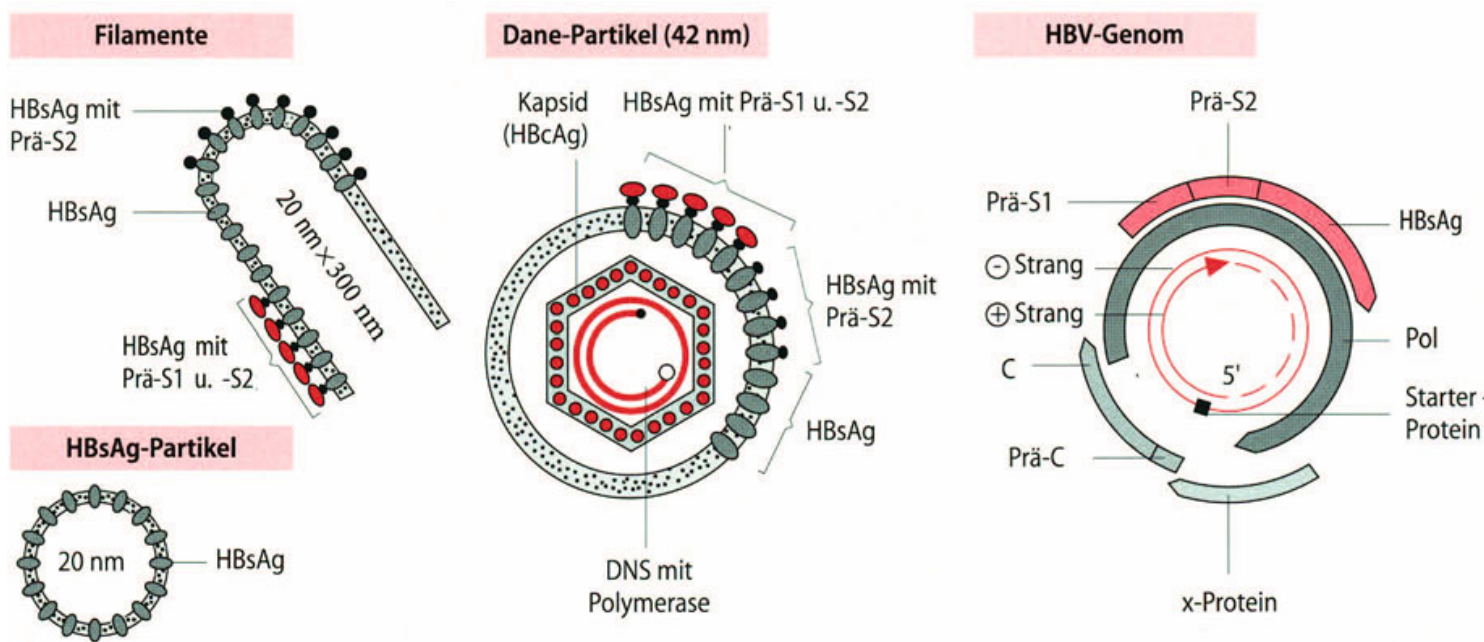

Abb. 15.2. DANE-Partikel, HBsAg und filamentöse Formen des Hepatitis B-Virus, sowie das Genom mit den Pol-, Core-, X- und HBs-Genen. Aus dem Core-Gen entsteht das HBCAg für das Kapsid und das lösliche HBeAg. Das HBs-Gen umfaßt Prä-S1, Prä-S2 und das HBsAg 
sid aus Hepatitis B-Core-Antigen ( $\mathrm{HBcAg}$ ) sowie der lipidhaltigen Hülle mit dem Surface-Antigen (HBsAg). Im Kapsid befindet sich eine doppelsträngige DNS und eine Polymerase mit den Eigenschaften einer reversen Transkriptase. Außerdem beobachtet man im Blut Infizierter noch rundliche, $22 \mathrm{~nm}$ messende, nicht infektiöse Partikel sowie filamentöse Formen $(20 \times 200 \mathrm{~nm})$; beide bestehen aus HBsAg. Das HBeAg ist ein lösliches Protein, das aus der Zelle sezerniert wird und im Serum auftritt (Abb. 15.3).

HBs-Antigen. Das HBsAg ist das immunisierende Antigen. Es wird im Zytoplasma gebildet und läßt sich dort durch fluoreszierende Antikörper nachweisen. In der Leber wird es im Überschuß gebildet und in das Blut sezerniert. Ein typischer Virusträger (s. S. 666) hat etwa $10^{8}$ DANE-Partikel, $10^{9}$ Filamente und $10^{13}$ HBsAg-Partikel pro $\mathrm{ml}$ im Blut. Das Determinantenmuster des HBsAg ist komplex. Jeder Komplex trägt die immunisierende Komponente „a“. Andere Komponenten werden mit den Buchstaben d, w, y, r, q bezeichnet; sie kommen in Kombination vor, wie z.B. ayw, adr, ayr und adw. Diese Formeln bezeichnen Markerantigene für die Feinepidemiologie. Das Gen des Gesamt-HBs-Antigens besitzt drei aneinandergereihte Abschnitte: Prä-S1, Prä-S2 und HBs. Sie werden zu einem großen, einem mittleren und kleinem HBsAg translatiert. DANE-Partikel und Filamente enthalten neben HBsAg auch das große und mittlere, die $20 \mathrm{~nm}$ HBs-Partikel aber nur das kleine HBsAg.

HBe-Antigen. Das HBeAg läßt sich durch den IFT im Kern der Zelle und in der Zellmembran demonstrieren. Das HBeAg läßt sich ebenso wie das HBsAg, die DNS-Polymerase und Virus-DNS im Serum nachweisen. HBeAg und DNS sind wichtige Marker für die Infektiosität des Serums bzw. des Patienten. Fehlt das HBeAg im Serum beim Vorhandensein von HBV-DNS und Anti-HBe, können Mutationen in der Regulator-Region des HBc-Gens die Ursache dieser besonderen Marker-Konstellation sein (s.u.) oder das HBeAg ist eliminiert.

HBc-Antigen. HBcAg läßt sich in den Kernen von Leberbiopsiematerial durch den IFT nachweisen. Im Serum wird $\mathrm{HBcAg}$ nicht gefunden. $\mathrm{HBcAg}$ und $\mathrm{HBeAg}$ weisen keine serologischen Kreuzreaktivitäten auf, besitzen aber gemeinsame Epitope für ZTL.

Das gesamte $\mathrm{HBc}-\mathrm{Gen}$ besteht aus der PräC-Region am $\mathrm{NH}_{2}$-Terminus und dem Struktur-HBc-
Gen. Wird nur ein Teil des Prä-Core am $\mathrm{NH}_{2}$-Terminus abgespalten, so entsteht das membranständige $\mathrm{HBeAg}$ (p 23); erfolgt auch am $\mathrm{COOH}$-Terminus eine Abspaltung, liegt das sezernierte $\mathrm{HBeAg}$ ( $p$ 18/20) vor. Tritt im Präcore-Bereich eine Mutation auf, so kann eine HBeAg-negative, aber HBVDNS-positive fulminante Hepatitis entstehen.

$\mathrm{HBx}$-Protein. Das $\mathrm{HBx}-\mathrm{Gen}$ ist eine Proteinkinase und wirkt als „Transaktivator“ (s. S. 598) für virale und zelluläre Promotoren, es beeinflußt dabei verschiedene Signalwege; die Wirkung ist zelltypisch, aber nicht artspezifisch. So verstärkt es die Replikation des HBV nur in der Leberzelle und sensibilisiert Zellen für die Apoptose oder hemmt diese. Seine Mitwirkung bei der Entstehung des primären Leberzellkarzinoms wird durch einen Einfluß auf die Proteinkinase $\mathrm{C}$ und die Bindung an das p 53 zurückgeführt.

\section{Replikation}

Nach der Bindung des Prä-S1 an einen noch nicht definierten Rezeptor (Annexin?) wird das Virus durch Endozytose aufgenommen (Abb. 15.3). Nach dem Uncoating erfolgt im Kern die Komplettierung des unvollständigen (+)-DNS-Stranges durch die Viruspolymerase. Dann bilden sich ringförmige Nukleosomen sowie verknäuelte Superhelices. Die Transkription durch eine Zellpolymerase wird an dem (-)-Strang vorgenommen. Dabei entsteht informative (+)-RNS, die in zwei Formen auftritt. In linearen Abschnitten (2,1 und 2,4 kb) dient sie als mRNS für die Translation, in Ringform (3,5 $\mathrm{kb})$ als (+)-Prägenom. Die Ringform kommt durch etwa 200 RNS-Basen zustande, die sich am 3'- und 5 -Ende überlappen.

Im Zytoplasma lagert sich das Prägenom mit der neugebildeten reversen Transkriptase und neusynthetisiertem Kapsid-Protein (HBcAg) zu Kapsiden zusammen. Das Prägenom wird in DNS umgesetzt und nach der reversen Transkription sofort abgebaut. Erst dann erfolgt die Synthese des meist inkompletten DNS(+)-Stranges. Als Enzym dient die DNS-Polymerase des HBV. Im endoplasmatischen Retikulum und im Golgiapparat erhält das Kapsid seine Hülle und wird durch Exozytose ebenso wie das $\mathrm{HBeAG}$ freigesetzt. Eine Integration an beliebiger Stelle im Zellgenom ist als zytogenetischer Unglücksfall anzusehen: Sie ist nicht Voraussetzung für die Replikation. In den Hepatozyten von chronisch Infizierten findet man inte- 


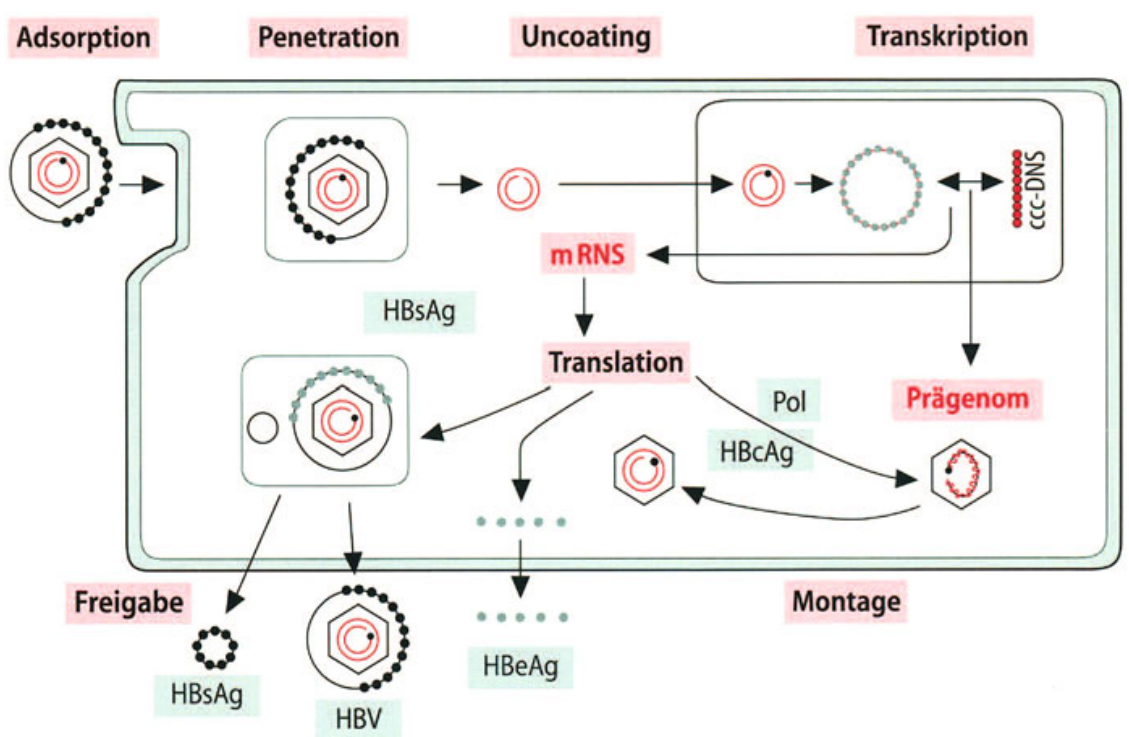

Abb. 15.3. Die Replikation des HBV. Adsorption, Aufnahme durch Endozytose, Komplettierung des (+)-DNS-Strangs, Entstehen des "closed supercoiled circle" (ccc) und von ringförmigen Nukleosomen.

grierte, aber defekte Virus-DNS. Im floriden Stadium liegt die DNS episomal frei in der Zelle vor.

\section{Züchtung}

Das HBV läßt sich routinemäßig noch nicht züchten. In Schimpansen erzeugt es eine Hepatitis B.

\section{Resistenz}

Das Virus ist relativ stabil, auch gegen Ätherbehandlung. Es übersteht z.B. eine 30-minütige Behandlung bei $50^{\circ} \mathrm{C}$, eine einstündige Behandlung bei $60^{\circ} \mathrm{C}$ und wird erst nach 10 stündiger Behandlung bei dieser Temperatur inaktiviert. Bei $100^{\circ} \mathrm{C}$ ist es nach 20 min inaktiv (Tabelle 15.1, s. S. 658).

\subsubsection{Rolle als Krankheitserreger}

\section{Epidemiologie}

Man schätzt, daß etwa 300 Mio Menschen an einer chronischen Hepatitis B erkrankt sind. In Deutschland gibt es etwa 50000 Infektionen pro Jahr.
Transkription des Prägenoms sowie der mRNS und Translation, Montage und Freigabe von DANE-Partikeln, $\mathrm{HBsAg}$ und $\mathrm{HbeAg}$

Die Verbreitung ist weltweit. In den USA sind 0,1-0,5\% der Bevölkerung chronische Träger; die Durchseuchung in den Entwicklungsländern beträgt $10-40 \%$. In Griechenland z. B. liegt die Zahl der HBsAg-Träger bei $5 \%$, die Zahl der Träger von anti-HBc bei $20-50 \%$. In Deutschland sind weniger als 0,5\% HBsAg-positiv. In einer gesunden Population junger Erwachsener in Deutschland sind Antikörper gegen das $\mathrm{HBcAg}$ in $2-4 \% \mathrm{zu}$ finden. Diese Antikörper stellen einen verläßlicheren Indikator für eine früher erfolgte Durchseuchung dar als Antikörper gegen das HBsAg. In Taiwan spielt die perinatale Infektion für die Durchseuchung eine bedeutende Rolle. Dieser Übertragungsweg ist in Ostasien besonders häufig.

Bei bestimmten Risikogruppen (Homosexuelle, Prostituierte, i.v. Drogensüchtige und Personen mit häufig wechselnden Geschlechtspartnern) ist die Durchseuchung ebenfalls hoch. Heterosexueller Intimverkehr ist im übrigen ein wichtiger Übertragungsmodus. AIDS-Patienten sind $\mathrm{zu}$ fast $100 \%$ durchseucht. Die perinatale Infektion in Ostasien erfolgt wahrscheinlich kurz vor, unter oder nach der Geburt. Perinatal infizierte Kinder haben deshalb bei der Geburt nur in $6 \%$ HBsAg im Serum, einen Monat später in $90 \%$. Das Risiko der Übertragung auf das Kind ist bei HBs- und HBeAgpositiven Müttern sehr hoch (85\%). Auch HBsAg- 
positive, aber HBeAg-negative Mütter infizieren ihre Kinder (6\%). In Deutschland schätzt man 550 Risikogeburten pro Jahr. Die Infektion trifft dabei auf einen immunologisch unreifen Organismus, so daß wahrscheinlich durch eine "high-dose“ Toleranz infolge Anergie eine chronische Infektion entsteht. Immer noch stellt die Hepatitis B eine häufige Nosokomial-Infektion dar. Besonders gefährdet sind Mitarbeiter auf Dialyse- und Intensiv-Stationen, ärztliches und zahnärztliches Personal, Laborpersonal sowie Familienangehörige von HBsAg-positiven Personen. Übertragungen sind u.a. durch die Benutzung gemeinsamer Zahnbürsten möglich.

Durch die vorgeschriebene Untersuchung der Blutkonserven ist die HBV-Transfusionshepatitis stark zurückgegangen. Im Diagnostiklabor muß jede Blutprobe als kontagiös angesehen werden. Eingetrocknete Blutproben haben sich mehr als eine Woche lang als infektiös erwiesen. Die Übertragung durch blutsaugende Insekten (Mücken und Wanzen) ist eher unwahrscheinlich. Eine Übertragung durch Aerosole ist extrem selten; Spritzer HBsAg-haltigen Blutes in die Augen haben Infektionen bewirkt.

\section{Übertragung}

Die Übertragung der Hepatitis B erfolgt v.a. durch kontaminiertes Blut bzw. Blutprodukte. Unter experimentellen Bedingungen kann die Übertragung von $1 \times 10^{-8} \mathrm{ml}$ virushaltigen Blutes zu einer Infektion führen. Außerdem sind Sperma und ZervixSekret sowie Speichel und Tränenflüssigkeit virushaltig, so daß HBV oral und sexuell übertragen werden kann. Besonders wichtig ist die MutterKind Übertragung („perinatal"). Eine Übertragung kommt v.a. durch ungenügend sterilisierte Instrumente (Kanülen, Spritzen, Endoskope) oder durch Tätowierungs- und Ohrstichgeräte zustande.

\section{Pathogenese}

Die Hepatitis B eine Krankheit, bei der die Immunreaktion das bestimmende pathogenetische Element darstellt. Der überwiegende Teil der Infektionen verläuft inapparent, wird also immunologisch frühzeitig beherrscht; bei den apparenten Verläufen hingegen zerstört das Immunsystem nach Ablauf der Inkubationsperiode zunächst die eigenen Leberzellen, erst dann erfolgt die komplette Elimination des HBV durch ZTL. Vorwiegend virusspezifisches $\mathrm{HBc}$ - und $\mathrm{HBeAg}$ wird in der Zellmembran exprimiert, das das Zielantigen für die immunreaktiven T-Lymphozyten darstellt. Besonders häufig werden chronische Verläufe bei Kindern nach perinataler Infektion beobachtet, deren Immunapparat das Virus nicht eliminieren kann (s. S. 666, s. a. Abb. 15.5). Das HBeAg findet sich sogar schon bei Neugeborenen im Blut, wenn die Mütter HBeAg-positiv sind. Bei Immunmangelzuständen erfolgen oftmals Reaktivierungen einer chronischen Hepatitis B, weil ZTL den Prozeß nicht mehr kontrollieren. Hauptgrund der chronischen Hepatitis ist eine Unterfunktion der ZTL und T-Helferzellen, deren spezifische Stimulierbarkeit gestört und deren Zahl reduziert ist. Verantwortlich scheint ein Mangel an IL-12 infolge einer virusbedingten Schädigung der dendritischen Zellen zu sein. Das HBV wurde außer in Leberzellen auch in Pankreas-Zellen sowie in Makrophagen und Lymphozyten nachgewiesen. Man weiß jetzt, daß in diesen Zellen das HBV exprimiert wird.

Im Verlauf der akuten HB entstehen Antikörper gegen $\mathrm{HBc}, \mathrm{HBe}$ sowie gegen die Polymerase und gegen das $\mathrm{x}$-Protein. Zunächst erscheinen AntiPrä-S1 und Anti-Prä-S2. Anti-HBe und Anti-HBc treten ebenso frühzeitig auf, während HBs-Antikörper erst viel später erscheinen (Abb. 15.4). Bei Patienten, die eine chronische Hepatitis B entwikkeln, bleiben beide Antigene im Blut nachweisbar. Prä-S1- und Prä-S2-Antikörper sind wahrscheinlich neutralisierend und liefern auch B- und TZellepitope der Virushülle. Die ZTL sind vorwiegend gegen $\mathrm{HBe}-$ und $\mathrm{HBcAg}$ gerichtet. Das ZTL stimulierende IFN- $\gamma$ kann nur in Anwesenheit von IL-12 gebildet werden; das $\mathrm{HBeAg}$ wirkt immunsuppressiv.

Pathogenetische Bedeutung kommt den im Serum nachgewiesenen HBsAg/Ak-Komplexen (und $\mathrm{HBeAg} / \mathrm{Ak}) \mathrm{zu}$. Sie sind für die Periarteriitis nodosa, die Glomerulonephritis und die Kryoglobulinämie verantwortlich, vielleicht auch für die gelegentlich beobachteten Gelenkbeschwerden sowie für Exantheme. Das HBV verursacht keine Embryopathien.

Pathohistologisch sind die sinusoidalen Zellen aktiviert; man findet reichlich Lymphozyten. Die Zellzerstörungen sind über das gesamte Leberläppchen verteilt. In schweren Fällen findet man zusätzlich eine ausgeprägte Zerstörung der zentrolobulären Areale. Die Lymphozyten findet man oftmals im ganzen Läppchen in enger Nachbarschaft mit den Leberzellen. 


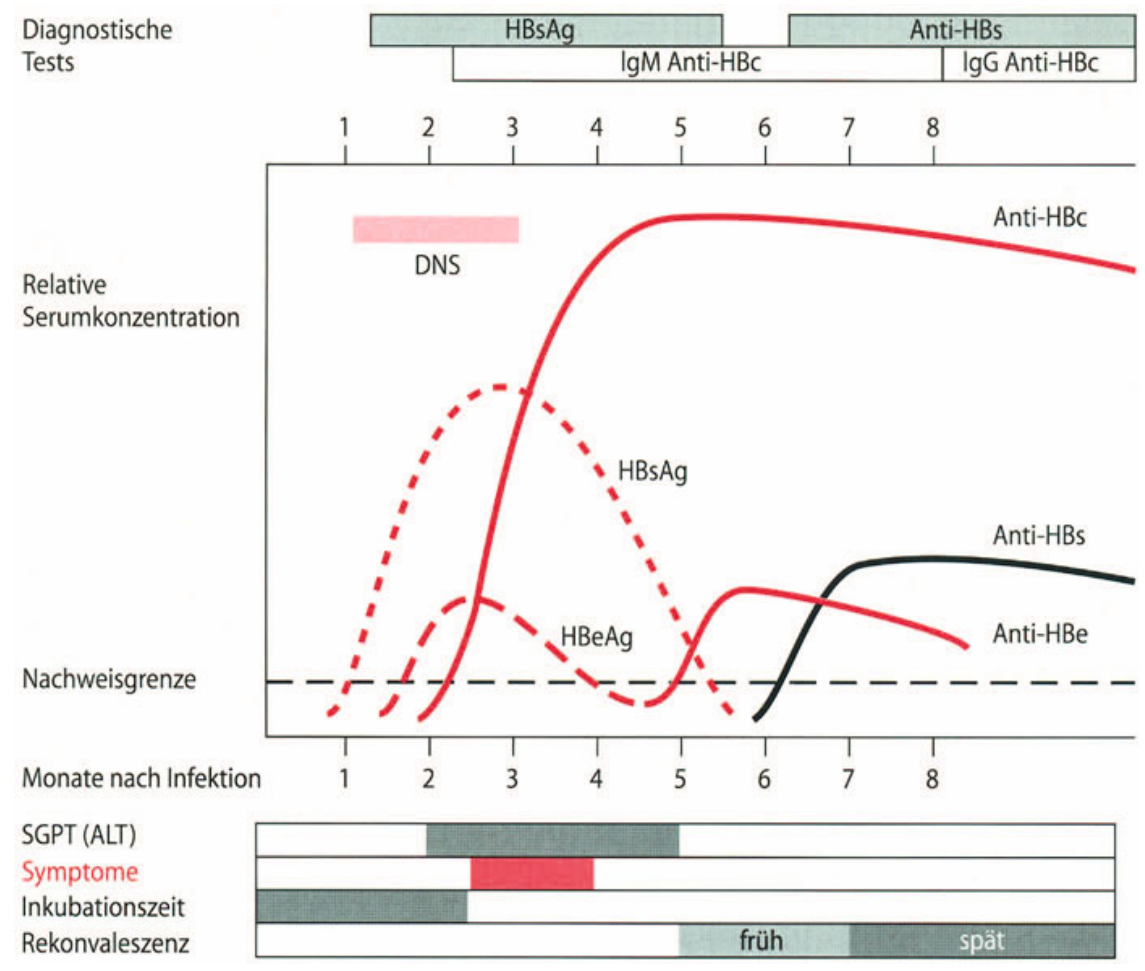

Abb. 15.4. Ablauf einer Infektion mit dem HBV. Auftreten der DNS, der Ag-Marker, der Antikörper sowie Symptome und Transaminasen

\section{Klinik}

Die akute Phase der Hepatitis durch HBV entwikkelt sich nach einer Inkubationsperiode von 2-6 Monaten (Abb. 15.4). Die Dauer der Inkubationsperiode hängt von der Infektionsdosis ab: Je höher die Dosis an HBV, desto kürzer ist die Inkubationsperiode und umgekehrt. Gegen Ende der Inkubationsperiode, aber noch im präikterischen $\mathrm{Zu}$ stand, stellt sich Krankheitsgefühl ein, es entwikkeln sich Abneigung gegen Speisen, Schwindel, Erbrechen und Abdominalbeschwerden. Bei etwa 10$20 \%$ der Patienten kommt es in diesem Stadium zu Erscheinungen, die auf die Krankheit hinweisen: Fieber, Exantheme und rheumatoide Gelenkbeschwerden, Panzytopenie, Myalgien und Guillain-Barré-Syndrom. Zwei bis 14 Tage später wird der Ikterus bemerkt; die Leber ist dann fest und vergrößert. Die Patienten fühlen sich in diesem Stadium jedoch besser. Bei langdauernder Gelbsucht entwickelt sich eine Cholestase, verbunden mit Pruritus. Die Rekonvaleszenzphase kann Wochen dauern. Je jünger die Personen sind, desto leichter ist der Verlauf. Mutationen im Präcore-Be- reich des $\mathrm{HBc}-\mathrm{Gens}$ werden oft bei fulminanten Verläufen beobachtet.

\section{Differentialdiagnose}

Eine ikterische oder anikterische Begleit-Hepatitis kann bei zahlreichen Infektionskrankheiten auftreten. Typisch ist die Leberbeteiligung für den Morbus Weil, für die konnatale Syphilis, für Hämorrhagische Fieber und das Gelbfieber; eine Hepatitis kann aber auch bei Infektionen mit Picorna-Viren, Viren der Herpesgruppe, bei Bruzellosen, Rickettsiosen und bei der Malaria vorkommen, wichtig ist auch die toxische und die Autoimmun-Hepatitis.

\section{Immunität}

Das zelluläre Immunsystem dürfte die Hauptlast bei der Beherrschung der HBV-Infektion tragen; hierfür spricht, daß nach der Infektion von Neugeborenen häufig chronische Verläufe auftreten. Man kann deshalb folgern, daß eine partielle „high-dose“-Toleranz durch große Mengen an Vi- 
rusantigen für chronische Verläufe verantwortlich ist.

\section{Labordiagnose}

Eine bedeutsame Rolle für die Diagnose (Tabelle 15.2) und Prognose der akuten und chronischen Hepatitis spielen die verschiedenen Antigene, die im Serum auftauchen oder in Biopsie-Material nachgewiesen werden können, desgleichen die entsprechenden Antikörper und die Transaminasen; die Interferontherapie wird durch die PCR kontrolliert.

Bereits in der zweiten Hälfte der Inkubationsperiode läßt sich $\mathrm{HBsAg}$ mit Prä-S1- und -S2-Ag im Serum feststellen. Dies gilt auch für HBeAg, DNS, die virale DNS-Polymerase und für die elektronenmikroskopisch nachweisbaren DANE-Partikel. Das wichtigste Zeichen für den Beginn der Ausheilung ist das Absinken der HBs- und der HBe-Menge im Serum, spätestens 10-14 Tage nach Beginn der Erkrankung. Innerhalb von 8-12 Wochen sinkt die DNS unter die Nachweisgrenze.

Wenn nur Anti-HBc positiv ist, sollte auch Anti-HBc-IgM und Anti-HBs bestimmt werden. Wenn HBsAg positiv ist, empfiehlt sich eine Bestimmung von HBeAg und, wenn möglich, der HBV-DNS. Zur Kontrolle des Verlaufes werden diese Parameter mehrmals bestimmt. Chronische Verlaufsformen werden in Abständen von sechs Monaten kontrolliert. Bei gesunden $\mathrm{HBsAg-Trägern} \mathrm{genügt}$ im Prinzip eine Untersuchung, im Falle einer Im- munsuppression muß jedoch mit Reaktivierungen gerechnet werden. Die Durchseuchung mit dem $\mathrm{HBV}$ wird anhand der $\mathrm{HBc}$-Antikörper festgestellt.

\section{Akute Infektion}

Bei einer akuten Infektion tauchen frühzeitig IgMund dann auch IgG-Ak gegen das HBcAg auf. Anti-HBc-IgM lassen sich bis etwa sechs Monate nach einer akuten Hepatitis B nachweisen. Zwischen dem Verschwinden des HBe-Antigens und dem Auftreten des Anti-HBe klafft öfter eine zeitliche Lücke. Dies gilt in viel stärker ausgeprägter Weise für das HBsAg/Anti-HBs-System. In jüngster Zeit hat man im Serum von Patienten Antikörper gegen das $\mathrm{x}$-Protein und gegen die DNS-Polymerase festgestellt. Das HBV kann auch nach der Ausheilung lebenslang im Organismus verbleiben; transplantierte Lebern werden erneut infiziert.

\section{Chronische Hepatitis}

Bei der chronischen Hepatitis persistiert das HBsAg mehr als 6 Monate. Die Persistenz kann Jahre oder das ganze Leben lang andauern. 10\% der sonst gesunden Erwachsenen mit akuter Hepatitis B werden chronisch, bei Kleinkindern sind es $50 \%$ und bei perinataler Infektion 90\% (meist asymptomatisch, aber erhöhte Transaminasen, Abb. 15.5). Bei etwa $60 \%$ der Patienten mit chronischer Hepatitis fehlen anamnestische Angaben über eine akute Hepatitis B. Ein direkter Übergang

Tabelle 15.2. Labordiagnose von HBV-Infektionen

\begin{tabular}{|c|c|c|c|c|c|c|c|c|c|}
\hline Krankheitsstadium & $\mathrm{HBsAg}$ & $\mathrm{HBeAg}$ & $\begin{array}{l}\text { Polymerase/ } \\
\text { DNS }\end{array}$ & $\begin{array}{l}\text { Anti- } \\
\text { HBs }\end{array}$ & $\begin{array}{l}\text { Anti- } \\
\text { HBC-IgM }\end{array}$ & $\begin{array}{l}\text { Anti- } \\
\text { HBC-IgG }\end{array}$ & $\begin{array}{l}\text { Anti- } \\
\text { HBe }\end{array}$ & $\begin{array}{l}\text { Infektiosität } \\
\text { des Blutes }\end{array}$ & Besonderheiten \\
\hline Inkubationsperiode & + & $+1-$ & $+1-$ & - & - & - & - & ++ & \\
\hline Akute Hepatitis & + & + & + & - & + & - & - & ++ & \\
\hline $\begin{array}{l}\text { Rekonvaleszenz: } \\
\text { früh } \\
\text { spät }\end{array}$ & $\begin{array}{l}+ \\
-\end{array}$ & $\begin{array}{ll}- \\
-\end{array}$ & $\begin{array}{ll}- \\
-\end{array}$ & $\begin{array}{l}- \\
+\end{array}$ & $\begin{array}{l}+ \\
-\end{array}$ & $\begin{array}{l}+/- \\
+\end{array}$ & $\begin{array}{l}+1- \\
+\end{array}$ & $\begin{array}{l}(+) \\
-\end{array}$ & \\
\hline Jahre nach Erkrankung & - & - & - & $+1-$ & - & + & - & - & $\begin{array}{l}\text { Anti-HBC sicherster Marker } \\
\text { für Durchseuchung }\end{array}$ \\
\hline Chronisch aktive Hepatitis & ++ & + & + & - & + & + & - & ++ & Hochinfektiös \\
\hline Chronisch aktive Hepatitis & + & $+1-$ & - & - & + & + & $-1+$ & + & Mäßig infektiös \\
\hline „Relaps" & + & $+1-$ & + & - & - & + & $-1+$ & + & Infektiös \\
\hline Persistierende Hepatitis & + & - & - & - & - & + & $+1-$ & + & Gering infektiös \\
\hline HBsAg-Träger & + & - & - & - & - & + & - & $(+)$ & Wenig infektiös "gesund" \\
\hline Nach Impfung & - & - & - & + & - & - & - & - & \\
\hline
\end{tabular}




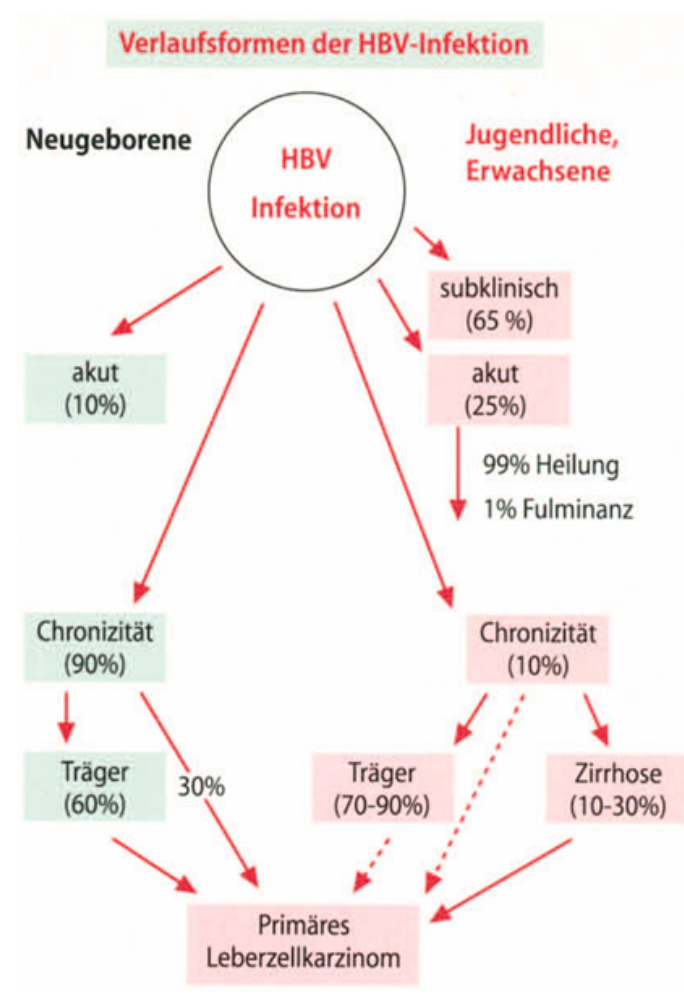

Abb. 15.5. Verlaufsformen der HBV-Infektion. Die Infektion von Neugeborenen wird in $90 \%$, diejenige von Kindern im Vorschulalter zu $50 \%$, bei Jugendlichen und Erwachsenen in $10 \%$ chronisch. Aus den chronischen Formen kann ein primäres Leberzellkarzinom entstehen

in die chronische Infektion wird oft bei perinatal infizierten Neugeborenen und bei immungeschädigten Personen beobachtet (Toleranz?). Man schätzt 6-7 inapparente Infektionen auf einen klinischen Verlaufsfall. Todesfälle werden vorwiegend durch die chronischen Formen hervorgerufen, in $1 \%$ verläuft die akute $\mathrm{HB}$ fulminant tödlich.

\section{Träger}

Der gesunde Träger ist durch das Vorhandensein von $\mathrm{HBsAg}$, Anti-HBc-IgG sowie durch weitgehend normale histologische Befunde gekennzeichnet. Der Gehalt des Serums an HBsAg ist gering (bis $10-20 \mu \mathrm{g} / \mathrm{ml}$ ), jedoch können in $2 / 3$ der Fälle Spuren von HBV-DNS im Blut nachgewiesen werden. Das Risiko für ein PLK (s. S. 667) ist ebenfalls erhöht.

\section{Chronisch-persistierende und chronisch aktive Hepatitis}

Wichtig ist die Unterscheidung zwischen der chronisch-persistierenden und der chronisch-replikativen Hepatitis: Beide Formen der Hepatitis lassen sich vom "gesunden“ oder asymptomatischen Trägerstatus durch den histologischen Befund bei der Biopsie und durch die Transaminasenpegel unterscheiden. Während im Serum des gesunden Trägers wenig HBsAg und keine erhöhten Transaminasen vorhanden sind, werden bei anderen Verlaufsformen bis $\mathrm{zu} 500 \mu \mathrm{g} / \mathrm{ml} \mathrm{HBsAg}$ im Serum und hohe Transaminasenwerte beobachtet. Die Persistenz von HBeAg, von DNS und von DANEPartikeln spricht für eine chronisch-aktive Form. HBeAg kann bei dieser Form verschwinden. Dies ist prognostisch ein gutes Zeichen: Spontanheilungsrate $1-5 \%$ pro Jahr. Histologisch läßt sich vorübergehend oft eine verstärkte entzündliche Aktivität nachweisen; die HBV-DNS geht dabei allmählich im Serum zurück. Ist die Entzündung abgeklungen, so fehlt die DNS. Es gibt jedoch Fälle, bei denen trotz Auftretens von Anti-HBe eine Reaktivierung der HBV-DNS-Synthese erfolgt ( $\mathrm{Ta}-$ belle 15.2).

\section{Transaminasen}

Die Transaminasenkonzentration im Serum (SGOT, SGPT) ist ein guter Gradmesser für das Ausmaß der jeweiligen Leberzellzerstörung. Bei niedrigen Werten findet sich histologisch (Biopsie) das Bild eines gesunden HBsAg-Trägers oder eine inaktive Fibrose oder aber eine Zirrhose.

\section{Therapie}

Zur Prophylaxe müssen hochtitrige HB-Immunglobulin-Präparate (HBIG), z. B. bei Lebertransplantationen und bei Neugeborenen verwendet werden. Als Chemotherapeutika sind Famciclovir und Lamivudin mit Interferon kombiniert in der Erprobung; chronisch-replikative Verlaufsformen werden mit Erfolg (25\%) mit Interferon $a 2$ und Lamivudin behandelt oder erhalten Lamivudin, ein Zytokin und HBsAg therapeutisch.

\section{Prävention}

Überprüfung der Blutspender. Die wichtigste Maßnahme zur Verhinderung der Übertragung ist 
die Überprüfung aller Blutspender auf HBsAg (Tabelle 7.14, S. 528); auch auf peinlich genaue Sterilisation aller ärztlichen Instrumente ist $\mathrm{zu}$ achten. Insbesondere sollte die Übertragung des HBV durch Blutreste an Kanülen etc. durch entsprechende Vorsichtsmaßnahmen verhindert werden. Bei Verletzungen von Seronegativen mit Kontakt von HBV-haltigem Blut muß sofort aktiv und passiv geimpft werden u.z. innerhalb von 6-12 Stunden (s. S. $999 \mathrm{ff}$ ).

Schutzimpfung. Seit einigen Jahren ist die aktive Immunisierung mit einem Totimpfstoff möglich. Das Impfantigen besteht aus gentechnologisch hergestelltem HBs-Antigen. Drei Dosen, meist im Abstand von null und sechs Wochen sowie sechs Monaten erzeugen einen fast $100 \%$ igen Schutz. Der Impferfolg sollte kontrolliert werden; bei niedrigem Anti-HBs $(\leqslant 10 \mathrm{U})$ ist eine alsbaldige Auffrischung angezeigt, ansonsten wird entsprechend den erzielten Impftitern verfahren. Bei Kontakt mit virushaltigem Blut: s. o.!

Nach der Geburt eines Kindes, dessen Mutter HBsAg-positiv ist, ist innerhalb von 12 Stunden eine passive Immunisierung angezeigt, außerdem ist die dreimalige aktive Immunisierung des Kindes erforderlich (0-1-6 Monate). Auf diese Weise läßt sich das Angehen einer Infektion (s.o.) und damit lebenslanges Trägertum verhindern. Die Untersuchung der schwangeren Frau auf HBsAg gehört daher zur Mutterschaftsvorsorge; sie sollte auf jeden Fall bei Müttern aus Endemiegebieten und Risikogruppen vorgenommen werden. Frühere Studien mit dem HB-Impfstoff haben gezeigt, daß die passiv-aktive Impfung auch nach bereits erfolgter Exposition wirksam ist. Es gibt "non-responder“ nach 3maliger Impfung bei 5-10\% aller Geimpften, bei Dialysepatienten sind es etwa $40 \%$. Die Ansprechrate läßt sich steigern, wenn die Dosis erhöht wird, oder besser, wenn der Impfstoff intradermal injiziert wird, das HBsAg gelangt auf diese Weise besser an die dendritischen Zellen. Es gibt auch Anhaltspunkte dafür, daß die Zahl der Nonresponder nach Injektion eines Impfstoffes mit Prä S1 und 2 gesenkt wird. Ursächlich vermutet man, daß bestimmte HLA-Typen für diese Erscheinung verantwortlich sind. Es sollte jedoch beachtet werden, daß sich die Berichte über Escape-Mutanten nach der HBsAg-Impfung mehren.

\section{Das HBV und das primäre Leberzellkarzinom}

Das primäre Leberzellkarzinom (PLK) macht in Westeuropa und den USA etwa 2-3\% aller Karzinome aus. Bei Männern ist das Risiko größer als bei Frauen. In Teilen von Afrika, Südostasien, in Alaska und den Mittelmeerländern stellt dieses Karzinom jedoch $20-40 \%$ aller Krebsfälle. Seit langem bereits hat man die posthepatitische Leberzirrhose in Beziehung zum PLK gebracht, das etwa 10-20 Jahre nach der HBV-Infektion auftritt. In Japan bekommen 23\% aller Patienten mit posthepatitischen Zirrhosen ein PLK. In Taiwan wurde gezeigt, daß das Risiko, ein PLK zu bekommen, bei HBsAg-positiven Personen $300 \mathrm{mal}$ größer ist als bei Normalpersonen. Die geographische Verteilung des PLK deckt sich weitgehend mit der Verteilung der persistierenden HBV-Infektionen. Man schätzt, daß weltweit 250000 Personen pro Jahr ein PLK bekommen.

Im PLK ist die DNS des HBV in das Zellgenom integriert. Dies ist ein wichtiger Hinweis auf die besondere Beziehung der HBV-Infektion zum Auftreten des PLK. Zumeist ist das Virus-Genom deletiert, invertiert, rearrangiert oder verdoppelt. In den monoklonalen Zellen der primären Leberzellkarzinome wird fast immer $\mathrm{HBsAg}$, relativ häufig $\mathrm{HBxAg}$, aber nur selten $\mathrm{HBcAg}$ exprimiert. Für die transformierende Wirkung des HBV ist $u$.a. das $\mathrm{x}$ Gen verantwortlich, das Reparaturmechanismen ausschaltet. Das HBx-Gen löst hierdurch mutative Wirkungen am Zellgenom aus und schaltet auf diese Weise Suppressorgene aus. Aflatoxine wirken auf das Zellgenom ebenso mutationsauslösend. Die Promotoren des HBsAg wirken transformierend. Auch der Integrationsprozeß des HBV-Genoms selbst löst mutative Wirkungen am Zellgenom aus und schaltet wahrscheinlich Suppressorgene (s. S. 502) aus. Insgesamt nimmt die Entstehungsweise des PLK verschiedene Wege.

Die HBV-Infektion ist der wichtigste Risikofaktor für die Entstehung des PLK. In bezug auf alle Krebserkrankungen folgt die HBV-Infektion sofort auf den Risikofaktor Rauchen. Die PLK sind monoklonal (s. EBV und Burkitt-Lymphom), die Zellen wachsen in der nu/nu-Maus (ohne T-Zellen) zu einem Tumor aus. Der affirmative Beweis für die Beteiligung des HBV an der Entstehung des PLK ist der Rückgang desselben nach Massenimpfungen. Dies zeichnet sich in Taiwan tatsächlich bereits $a b$. 
Virus. DANE-(42 nm), HBsAg-Partikel und fadenförmiges HBsAg. Vertreter der HepadnaViren mit ringförmiger Doppelstrang-DNS in Kapsid mit Hülle. Im Partikel DNS-Polymerase, $\mathrm{HBs}$ - und $\mathrm{HBC}$-Antigen. $\mathrm{HBeAg}$ nur im Serum. Züchtung bisher nicht möglich; $\mathrm{HBs}$ besteht aus Determinanten $a, d, w, y, r, q$.

Vorkommen. Weltweit verbreitet nur beim Menschen; bei Tieren verwandte HepadnaViren.

Epidemiologie. Durchseuchung in Griechenland, Asien, Taiwan, Afrika sehr hoch. 300 Mio chronische HBV-Patienten, 300fach gröBeres Risiko für primäres Leberkarzinom bei chronischer Hepatitis B; hohe Durchseuchung bei i.v. Drogenabhängigen, Homosexuellen, Prostituierten.

Übertragung. Durch kontagiöses Blut und Blutprodukte, ungenügend sterilisierte ärztliche Geräte (Spritzen, Kanülen etc.), Geschlechtsverkehr. Sperma, Sekrete sind virushaltig, ebenso Speichel und Tränenflüssigkeit; Zeichen für Infektiosität des Blutes ist HBeAg, HBV-DNS und HBsAg. Perinatale Übertragung.

Pathogenese. Infektion der Leber auf dem Blutweg. Die Immunreaktion des Organismus löst das Krankheitsgeschehen aus. Chronische Verläufe v.a. bei perinatal infizierten Kindern oder bei Defekt der Interferonbildung. $\mathrm{HBC}$ und $\mathrm{HBe}$ sind Zielantigene für ZTL. Immunkomplexbildung ( $\mathrm{HBsAg} / \mathrm{Ak}$ ) bewirkt Periarteriitis nodosa u.a.

Klinik. Inkubationsperiode 2-6 Monate, 2/3 inapparenter Verlauf. 10\% der Erwachsenen werden chronisch. Zunächst unklare Abdomi- nalbeschwerden, dann Fieber, Gelenkbeschwerden. Exantheme und Ikterus. Wochenlanger Verlauf. Übergang in chronische Hepatitis mit aktivem oder persistierendem Verlauf. Bei Verschwinden von $\mathrm{HBeAg}$ und Polymerase sowie HBV-DNS-Übergang in persistierende Hepatitis. Außerdem sind asymptomatische Träger (mit HBsAg im Serum) und HBV-Mutantenträger möglich.

Immunität. Eine durchgemachte Hepatitis B hinterläßt lebenslange Immunität, akute IgMund IgG-Antikörper gegen $\mathrm{HBs}, \mathrm{HBe}$ und $\mathrm{HBC}$ (Polymerase u.a.). Schützende Antikörper $\mathrm{HBs}$, zur Bestimmung der Durchseuchung HBc-Antikörper.

Labordiagnose. Nachweis je nach Stadium und Form der Erkrankung: Antigene HBs, $\mathrm{HBe}, \mathrm{HBV}-\mathrm{DNS}$ sowie IgM oder IgG gegen $\mathrm{HBs}, \mathrm{HBe}$ und $\mathrm{HBC}$. Differentialdiagnose: $\mathrm{He}-$ patitis A, C, D, TTV und E, Gelbfieber, M. Weil, ZMV, EBV, HSV, Brucellosen, Rickettsiosen und Malaria. Pathohistologie, Transaminasen. Blutproben testen!

Therapie. Symptomatisch. Einzelne chronische Formen: Interferon- $a 2$. In der klinischen Prüfung befindet sich Famciclovir und Lamivudin mit Interferon sowie IL-2.

Prävention. Impfung, Prüfung der Blutproben etc., Sterilität der ärztlichen Geräte, $\mathrm{Hy}$ gienemaßnahmen bei Trägern.

Expositionsprophylaxe. Bei Perinatalinfektionen und Verletzungen: HBIG und aktive Impfung (0-1-6 Monate).

Meldepflicht. Verdacht, Erkrankung, Tod. Erregernachweis. 


\subsection{Hepatitis DELTA-Virus (HDV)}

Das Virus der Hepatitis D ist ein defektes RNS-Virus. Es benötigt für seine Replikation ein Helfer-Virus in Gestalt des HBV, das letztere liefert die Hülle mit dem Prä S1 und 2 sowie dem $\mathrm{HBsAg}$ für das HDV-Kapsid.

Die Hepatitis D kann nur dann auftreten, wenn bereits eine Hepatitis B vorliegt oder wenn die Infektion mit dem HBV und HDV gleichzeitig erfolgt. Das HDV verstärkt die Hepatitis-Situation.

Die Impfung mit dem HBsAg schützt gegen das HDV.
brid"-Virus: Sein Kapsid und die RNS stammen vom HDV; die Hülle wird jedoch vom HBV geliefert.

Die verfügbaren Antiseren reagieren mit 2 Proteinen $(24 \mathrm{kDa}$ und $27 \mathrm{kDa}$ ). Beide Proteine befinden sich im Kapsid, das $24 \mathrm{kDa}$-Protein bindet sich an RNS. Beide Proteine werden vom Antigenom kodiert. Das gemeinsame Präkursorprotein besitzt ein M.G. von $68 \mathrm{kDa}$.

\section{Züchtung}

Es ist bisher nicht gelungen, das HDV zu züchten. Es ist übertragbar auf Schimpansen und Waldmurmeltiere mit endogener Hepatitis B. Das HDV repliziert sich in den infizierten Leberzellen außerordentlich stark.

\section{Geschichte}

1977 wurde in den Leberzellen von Patienten mit Hepatitis B ein neues Antigen durch Rizzetto entdeckt, das als $\delta$-Antigen bezeichnet wurde. Das gleiche Antigen wurde später als Bestandteil von „kompletten“ Viruspartikeln identifiziert.

Das D-Antigen wurde stets nur im Serum solcher Patienten festgestellt, die mit dem HBV infiziert waren. Es lag nahe, ein defektes Virus zu postulieren, welches auf die Zulieferung von Hüllmaterial durch ein Helfer-Virus (HBV) angewiesen ist: Versuche mit Schimpansen haben dies bestätigt.

\subsubsection{Beschreibung des Virus}

\section{Genom}

Die Nukleinsäure dieses Virus ist eine (-)-StrangRNS mit 1678 Nukleotiden. Die RNS gleicht derjenigen von Virusoiden. Sie liegt als stäbchenförmiger Ring vor, es gibt eine genomische und eine antigenomische Form. Im Virion kommt nur die erste Form vor. Ihre Replikation erfolgt nach dem rolling circle Modell. Die Replikation erfolgt durch eine Wirtszellpolymerase. Man kennt bisher drei Genotypen, sie sind serologisch aber identisch.

\section{Morphologie}

Die Viren haben einen Durchmesser von $36 \mathrm{~nm}$; sie reagieren mit einem HBsAg-spezifischen Antiserum. Das Viruspartikel ist ein pathogenes „Hy-

\subsubsection{Rolle als Krankheitserreger}

\section{Epidemiologie}

In Süditalien, in Zentralafrika und im vorderen Orient sowie bei i.v. Drogenabhängigen ist die Infektion weit häufiger als in Mitteleuropa; die Durchseuchung bei HBsAg-Trägern beträgt in den genannten Gegenden bis zu 90\%. Dagegen liegt sie in Norditalien bei $5,5 \%$, in den USA bei $7 \%$ und in Deutschland weit unter 1\%. Die i.v. Drogenabhängigen in Deutschland sind zu $40 \%$ durchseucht. Zeichen einer HDV-Infektion findet man bei $0,4 \%$ der Dialysepatienten, bei $1,7 \%$ der chronisch HBVKranken, aber kaum je bei akut HBV-Kranken. Als Hauptinfektionsquelle müssen in Deutschland die Drogenabhängigen angesehen werden.

\section{Übertragung}

Sie erfolgt ähnlich wie bei der Hepatitis B. Eine Übertragung durch Intimkontakt ist nicht selten. Das HDV wird wie das HBV auch perinatal übertragen. HIV-Infizierte und Drogenabhängige sind oft mit dem HDV infiziert. Die Blutproben für Transfusionszwecke müssen nur auf das Vorkommen von HBV geprüft sein, nicht aber auf HDVAntikörper.

\section{Pathogenese}

Das HDV ist vermutlich direkt zytopathogen. Inapparenz oder milder Verlauf der Infektion korreliert 
zu geringer Durchseuchung der HDV-positiven Personen, Chronizität und schwerer Verlauf zu hoher Durchseuchung. Je schwerer der Verlauf, desto häufiger findet man Mutanten. Offenbar gibt es auch asymptomatische Verläufe. In Biopsiematerial läßt sich das HDV-Antigen im Kern von Leberzellen feststellen. Eine Superinfektion mit HDV bei bestehender HBV-Infektion bewirkt sehr schwere Läsionen mit Überwiegen der Viruszytotoxizität gegenüber Lymphozytotoxizität. Eine primäre Doppelinfektion mit HBV und HDV bewirkt dagegen relativ geringe Läsionen, verglichen mit dem Gewebsbild bei der Superinfektion.

\section{Klinik}

Die HDV-Erkrankung beginnt akut mit Krankheitsgefühl, Appetitlosigkeit und Druck im rechten Oberbauch; dann tritt Gelbsucht auf. Patienten mit einer Primär-Doppelinfektion „HDV plus HBV“ weisen oft eine chronisch-aktive Hepatitis und Zirrhose auf; sie sterben eher als Patienten mit einer alleinigen HBV-Infektion. Bei Doppelinfektionen ist das Krankheitsgeschehen besonders schwer, heilt aber meistens aus, wenn es nicht zur Lebernekrose kommt (Fulminanz). Bei besonders schweren Verläufen der Hepatitis $B$ muß an eine unerkannte zusätzliche HDV-Infektion gedacht werden, von denen $5-10 \%$ chronisch werden. Hinweise darauf kann die Anamnese liefern (Drogensüchtige, Homosexuelle, Prostituierte). Superinfektionen von HBsAg-Trägern mit dem HDV verursachen eine Phase mit akuter Hepatitis und relativ kurzer Inkubationsperiode und bewirken oft chronisch-aktive Verläufe der HDV-Infektion (bis zu 70-90\%) mit Zirrhose und häufig fulminantem Verlauf; die HBV-DNS-Menge wird reduziert, es erfolgt eine zeitweise Konversion von $\mathrm{HBsAg}$ positiv zu $\mathrm{HBsAg}$ negativ (Abb. 15.6). Fulminanz ist beim HDV $10 \times$ häufiger zu beobachten als bei HBV und HCV,

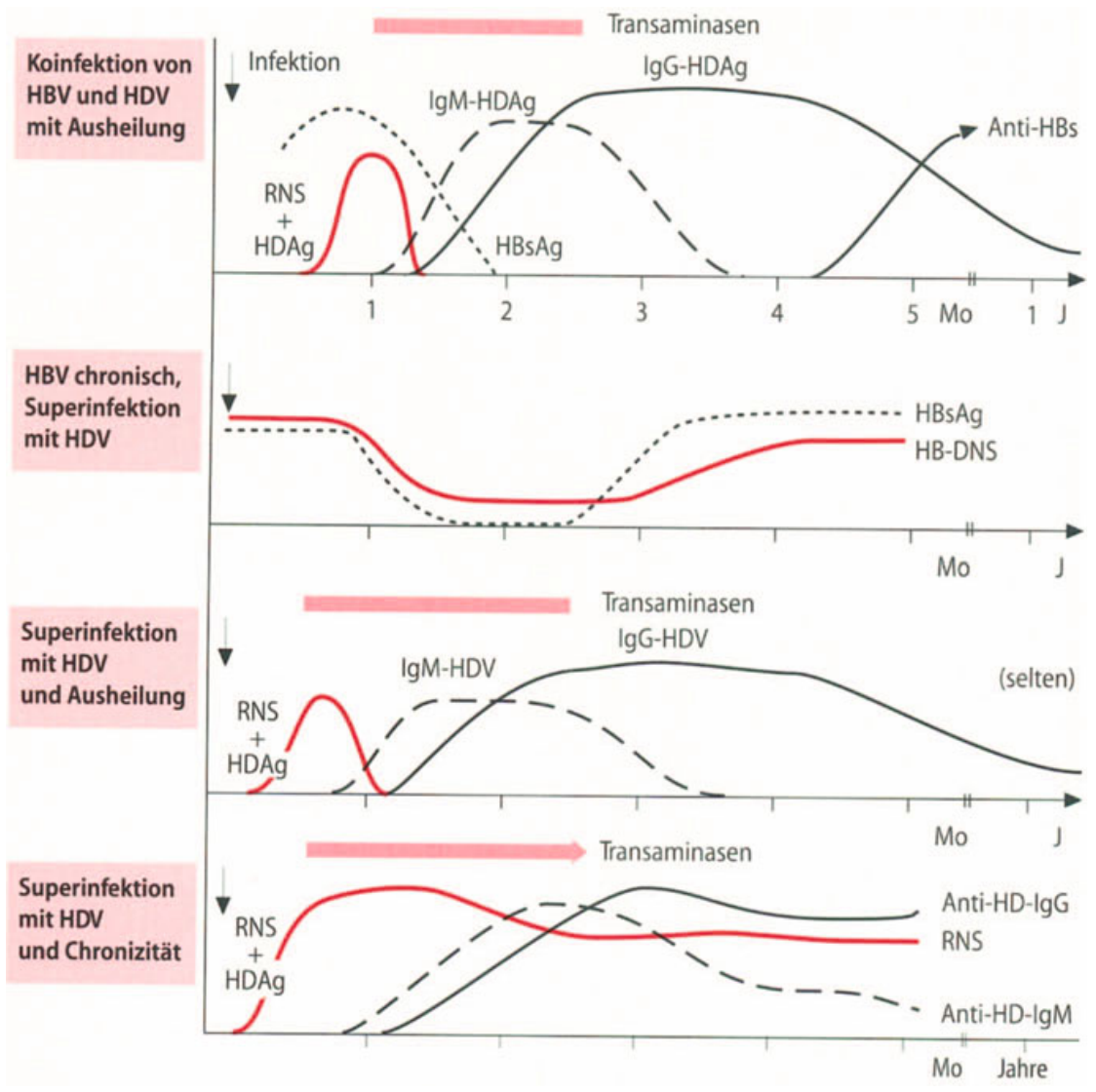

Abb. 15.6. Koinfektionen mit HBV und HDV bzw. Superinfektion mit HDV. Es ist Ausheilung und Chronizität dargestellt 
sie ist durch zusätzliche Zeichen einer Enzephalopathie charakterisiert. Die Inkubationsperiode der Hepatitis D beträgt 2-6 Monate.

\section{Immunität}

Eine Immunität gegen HBV (durch natürliche Infektion oder durch Totimpfstoff erworben) schützt gegen die Infektion mit HBV, aber auch gegen HDV. Im Verlauf einer akuten, selbstlimitierenden HDVInfektion treten virusspezifische IgM- und IgG-Antikörper auf; geht hingegen die akute in eine chronische Infektion über, persistieren die Anti-HDV-IgG mit hohen Werten. Außerdem können Autoantikörper gegen Mitochondrien (AMA) auftreten.

\section{Labordiagnose}

Mit einem ELISA lassen sich IgM-Ak gegen eine frische HDV-Hepatitis noch bis etwa 6-8 Wochen nach Beginn der Erkrankung nachweisen. Zur Abrundung der Diagnose ist aber auch der Nachweis der HBV-Marker zu fordern. Nach einer abgelaufenen D-Hepatitis läßt sich HDV-spezifisches IgG lebenslang in geringer Menge feststellen; hingegen bleibt bei chronischen HDV-Infektionen das AntiHDV-IgG hoch positiv.

Die Persistenz der HDV-Infektion läßt sich noch besser durch den Nachweis der HDV-RNS im
Serum zeigen (PCR), die Transaminasen sind oft erhöht. Mit dem IFT ist im biopsierten Lebergewebe der HDV-Antigennachweis möglich. Im Serum kann man das HDV-Antigen durch das Immunoblot-Verfahren nachweisen; dies gilt auch für Leberextrakte aus Biopsiematerial.

Die Untersuchung auf Anti-HBc-IgM erlaubt die Entscheidung, ob bei bestehender HBV-Infektion eine Superinfektion mit HDV vorliegt, oder ob es sich um eine von Anfang an bestehende Doppelinfektion mit beiden Viren handelt. Im erstgenannten Fall fehlt das Anti-HBc-IgM, im zweiten Fall ist es stark positiv.

\section{Therapie}

IFN- $\alpha 2$ wirkt dauerhaft nur in $10 \%$ der Fälle. Die Anwendung von Lamivudin und IL-2 befindet sich im Versuchsstadium.

\section{Prävention}

Zur Verhütung spielt die Erkennung und Aussonderung von HBV-positiven Blutspendern die größte Rolle. Die Prophylaxe erfordert die gleichen Maßnahmen wie bei der Hepatitis B. Die Umweltresistenz des HDV gleicht der des HBV. Postexpositionell wird eine aktive und passive Impfung gegen die Hepatitis B empfohlen.

\section{ZUSAMMENFASSUNG: Hepatitis D}

Virus. Defektes RNS-Virus (36 nm) mit Genom und Antigenom, als Helfer wirkt HBV, dessen HBsAg als Hülle. Ähnlichkeit der RNS zu den Virusoiden. RNS in Ringform.

Vorkommen. In Süditalien und Rumänien weit verbreitet, ebenso Zentralafrika, Orient, nördliches Südamerika.

Epidemiologie. In den gleichen Regionen und gleiche Risikogruppen wie bei HBV.

Übertragung. Analog wie HBV: Entweder zugleich mit HBV als Primärinfektion oder als Superinfektion; selten durch Intimkontakt.

Pathogenese. HD-Ag im Kern von Leberzellen nachweisbar. RNS und Antikörper im Blut.
Klinik. Asymptomatische und leichte Verläu$\mathrm{fe}$, Superinfektion von chronischer HB verursacht akuten Schub und Fulminanz; Doppelinfektion mit HBV und HDV: Schweres Krankheitsbild mit Übergang in chronisch aktive Hepatitis und Zirrhose.

Immunität. Die Immunität gegen HBV schützt gegen HDV.

Labordiagnose. Im ELISA Ag- und Antikörper-Nachweis. PCR. Biopsie.

Therapie. IFN- $a .2$ nur wenig wirksam.

Prävention. s. Hepatitis B.

Meldepflicht. Verdacht, Erkrankung, Tod, Erregernachweis. 


\subsection{Hepatitis C-Virus (HCV)}

Nachdem HAV und HBV entdeckt waren, blieben immer noch viele sog. NonA/NonB-Hepatitisfälle zurück. 1989 wurde dann das HCV entdeckt. Es ist der Erreger einer leicht verlaufenden Hepatiübergehen kann. Auf der Erde gibt es 400-600 Mio HCV-Träger.

Seit 1999 läßt sich das HCV nach einem komplizierten Verfahren züchten. tis, die aber oft chronisch wird und in Zirrhose und Leberzellkrebs

\section{Morphologie}

Das Virus besitzt einen Durchmesser von 60-70 nm. Es besteht aus einem Kapsid und trägt eine Hülle mit Spikes; es ist noch nicht sicher dargestellt worden. Vom Genom wird ein Vorläuferprotein mit etwa 3000 Aminosäuren gebildet, das durch Proteasen des HCV in Struktur- und Nichtstrukturproteine gespalten wird.

\section{Züchtung}

Das HCV läßt sich auf Schimpansen übertragen und in vitro züchten. Bester Nachweis: RT-PCR mit Typenbestimmung.

\subsubsection{Rolle als Krankheitserreger}

\section{Epidemiologie und Übertragung}

heitssymptome mit Transaminasenerhöhung beobachtet wurden. Da die herkömmlichen Verfahren zum Virusnachweis jedoch keine Resultate erbrachten, wurde zwecks Isolierung einer komplementären DNS aus dem Plasma eines frisch infizierten Schimpansen Nukleinsäure isoliert und verarbeitet. Dann wurde nach DNS-Klonen gefahndet, die in Expressionssystemen ein Antigen produzierten, das mit den Seren von menschlichen Rekonvaleszenten und chronisch Infizierten mit Non A/Non B-Hepatitis im ELISA reagierten. Die entsprechende cDNS wurde sequenziert und das Virus schließlich als neues Genus der Flaviviridae identifiziert. Antikörper gegen dieses Virus wurden bei Patienten in aller Welt festgestellt.

\subsubsection{Beschreibung des Virus}

\section{Genom}

Das Virus besitzt eine (+)-Einzelstrang-RNS mit 9,4 kb. Sie enthält am 5'-Ende eine nicht-kodierende Region, gefolgt vom Kapsid- und zwei Hüll-Genen sowie fünf Nichtstrukturgenen (Polymerase, Protease u. a.). Die Replikation erfolgt im Zytoplasma. Man kennt jetzt 12 Genotypen mit jeweils weiteren Varianten, die im Verlauf der chronischen Infektionen entstanden sind.
Die Epidemiologie ähnelt der des HBV in vieler Hinsicht (Tabelle 15.3). Risikogruppen sind i.v. Drogenabhängige, Dialysepatienten, Homosexuelle, Insassen von Gefängnissen. HCV-Träger sind weit verbreitet: In Deutschland sind etwa $0,6 \%$, in den USA 1,5-4,4\% der Gesamtbevölkerung seropositiv, in Europa etwa $10 \%$ aller Dialysepatienten. In Deutschland werden pro Jahr etwa 20000-50000 frische HCV-Infektionen beobachtet.

Als Infektionsquelle kommen v.a. Blutspender aus sozial niedrigen Schichten sowie (meist i.v.-) Drogenabhängige in Betracht. Wahrscheinlich wird das Virus auch durch Intimkontakt (v.a. bei AIDS) und kleine Hautverletzungen übertragen; es wurde im Sperma festgestellt. Es gibt eine perinatale Übertragung von der Mutter auf den Säugling $(<5 \%)$, inapparente Familieninfektionen sind nicht selten.

\section{Pathogenese}

Das HCV läßt sich im Serum und in Blutlymphozyten (v.a. B-Zellen) nachweisen, zu Beginn der akuten Infektion erfolgt eine Schädigung des Knochenmarks. In Blut, Speichel und Urin findet sich RNS des HCV. In der Leber wird eine diffuse, periportale Zerstörung der Leberzellen mit geringem Periportal-Infiltrat festgestellt, man findet eine abundante Verfettung und portal Pseudolymphfollikel. Man vermutet, daß der Zellschaden immunpathogenetisch ausgelöst wird. Ein TNF- $\alpha$-Polymorphismus 
Tabelle 15.3. Wichtige Merkmale der Hepatitiden

\begin{tabular}{|c|c|c|c|c|c|c|c|}
\hline \multirow[t]{2}{*}{ Eigenschaft } & \multicolumn{7}{|l|}{ Hepatitis } \\
\hline & A & B & D & C & $E$ & G & TTV \\
\hline Ink.-periode & 2-6 Wochen & 2-6 Monate & 2-6 Monate & 2-10 Wochen & 6 Wochen $(2-8)$ & $?$ & $?$ \\
\hline Übertragung & $\begin{array}{l}\text { Fäkal-oral } \\
\text { (Nahrungsmittel, } \\
\text { Wasser, Stuhl) }\end{array}$ & $\begin{array}{l}\text { Parenteral } \\
\text { Intimverkehr } \\
\text { Perinatal }\end{array}$ & $\begin{array}{l}\text { Parenteral } \\
\text { Intimverkehr (?) } \\
\text { Perinatal }\end{array}$ & $\begin{array}{l}\text { Parenteral } \\
\text { Sexuell } \\
\text { Sporadisch }\end{array}$ & $\begin{array}{l}\text { Fäkal-oral } \\
\text { Trinkwasser }\end{array}$ & $\begin{array}{l}\text { Parenteral } \\
\text { Sexuell }\end{array}$ & $\begin{array}{l}\text { Parenteral } \\
\text { Fäkal-oral } \\
\text { Sexuell (+) }\end{array}$ \\
\hline $\begin{array}{l}\text { Infektiöses } \\
\text { Material }\end{array}$ & Stuhl & $\begin{array}{l}\text { Blut und Blut- } \\
\text { produkte, Spei- } \\
\text { chel, Sperma, } \\
\text { Exsudate }\end{array}$ & $\begin{array}{l}\text { Blut und Blut- } \\
\text { produkte, Spei- } \\
\text { chel, Exsudate }\end{array}$ & $\begin{array}{l}\text { Blut und Blutpro- } \\
\text { dukte, Speichel, } \\
\text { Sperma, Exsudate }\end{array}$ & $\begin{array}{l}\text { Stuhl, } \\
\text { Trinkwasser }\end{array}$ & $\begin{array}{l}\text { Blut und } \\
\text { Blutprodukte }\end{array}$ & $\begin{array}{l}\text { Blut } \\
\text { Stuhl }\end{array}$ \\
\hline Verlauf & Kurz, gutartig & $\begin{array}{l}\text { Schwer } \\
\text { Chronizität } \\
\text { Leberzirrhose }\end{array}$ & $\begin{array}{l}\text { Schwerer als HB } \\
\text { "Akute Schübe" } \\
\text { Leberkarzinom }\end{array}$ & $\begin{array}{l}\text { Leichter als HB } \\
\text { Chronizität } \\
\text { einer Hepatitis B } \\
\text { Leberkarzinom }\end{array}$ & $\begin{array}{l}\text { Gutartig } \\
\text { Kurz } \\
\text { Zirrhose }\end{array}$ & Fraglich & $?$ \\
\hline Auftreten & $\begin{array}{l}\text { Endemisch } \\
\text { Epidemisch }\end{array}$ & $\begin{array}{l}\text { Risikogruppen } \\
\text { Endemisch } \\
\text { Sporadisch } \\
\text { Lokal-epidemisch }\end{array}$ & $\begin{array}{l}\text { Risikogruppen } \\
\text { Endemisch } \\
\text { Sporadisch } \\
\text { h }\end{array}$ & $\begin{array}{l}\text { Endemisch } \\
\text { Sporadisch } \\
\text { Risikogruppen }\end{array}$ & $\begin{array}{l}\text { Epidemisch } \\
\text { Sporadisch }\end{array}$ & $\begin{array}{l}\text { Sporadisch } \\
\text { Endemisch } \\
\text { Risikogruppen }\end{array}$ & Endemisch \\
\hline Prophylaxe & $\begin{array}{l}\text { Hepatitis A-IgG } \\
\text { Aktive Impfung }\end{array}$ & $\begin{array}{l}\text { Hepatitis B-IgG } \\
\text { Aktive Impfung }\end{array}$ & $\begin{array}{l}\text { Hepatitis B-IgG } \\
\text { Aktive Impfung }\end{array}$ & $?$ & $?$ & $?$ & $\begin{array}{l}? \\
+\end{array}$ \\
\hline Inapparenz & etwa $50 \%$ & $60-80 \%$ & + & $\begin{array}{l}\text { Sporadisch } 10-50 \% \\
\text { Posttransfusional } \\
60 \%\end{array}$ & & + & \\
\hline Chronizität & - & $10 \%$ & $60-80 \%$ & etwa $60-80 \%$ & - & persistent & $+?$ \\
\hline Fulminanz & $\begin{array}{l}0,6 \% \text { von } \\
\text { Hospitalisierten }\end{array}$ & $\begin{array}{l}\text { Wildtyp } 1 \% \\
\text { Mutanten } 30 \%\end{array}$ & $\begin{array}{l}\text { Koinfektion } \\
1-2 \% \\
\text { Superinfektion } \\
\text { bis } 50 \%\end{array}$ & $<1 \%$ & $\begin{array}{l}\text { Männer } 2-3 \% \\
\text { Gravide } 22 \%\end{array}$ & $+(?)$ & $+?$ \\
\hline
\end{tabular}

soll mit einer chronisch-replikativen Hepatitis C korreliert sein. Auffallendes Kennzeichen der Biopsie ist eine Aktivierung der Sinusoidal-Rand-Zellen. Die Hauptlast der Viruselimination tragen CD8-Zellen. $20-40 \%$ heilen aus, $60-80 \%$ aller HCV-Infektionen werden chronisch, $20 \%$ von ihnen gehen in eine chronisch aktive Hepatitis mit Zirrhose über. Das Risiko für die Entstehung eines PLK ist stark erhöht.

Es sind 12 Genotypen mit weiteren Subtypen des HCV bekannt. Superinfektionen mit dem HAV verlaufen sehr schwer: Schutzimpfungen!

\section{Klinik}

Die Inkubationsperiode beträgt 2-20 Wochen. Der apparente Verlauf der Hepatitis C ist meist leichter als bei anderen Hepatitiden und wird nur bei $5 \%$ der Infizierten beobachtet. Die akute Hepatitis C kann voll ausheilen (15\%), es gibt aber auch fulmi- nante Verläufe. Eine chronische Hepatitis C entwickelt sich mild und schleichend auch ohne erhöhte Transaminasen in ca. 60-80\% aller Infizierten. Rezidive der Erkrankung sind häufig, auch gibt es Superinfektionen mit HCV (Abb. 15.7).

\section{Immunität}

Im Verlaufe der Erkrankung entwickeln sich IgMund IgG-Antikörper; auch ZTL gegen infizierte Leberzellen wurden nachgewiesen. Im Serum treten Immunkomplexe auf; trotz Anwesenheit von Antikörpern persistiert bei chronischen Fällen die Virämie (RT-PCR für RNS!), die Transaminasen sind jedoch meist nicht erhöht. Es ist vorläufig unbekannt, ob passiv verabfolgtes IgG einen Schutz verleiht. Häufig sind Kryoglobulinämie und verschiedene Spezifitäten von Autoantikörpern. Diabetes vom Typ I, Polyarteriitis nodosa und Thrombozytopenie sieht man als Folgen einer HCV-Infektion 

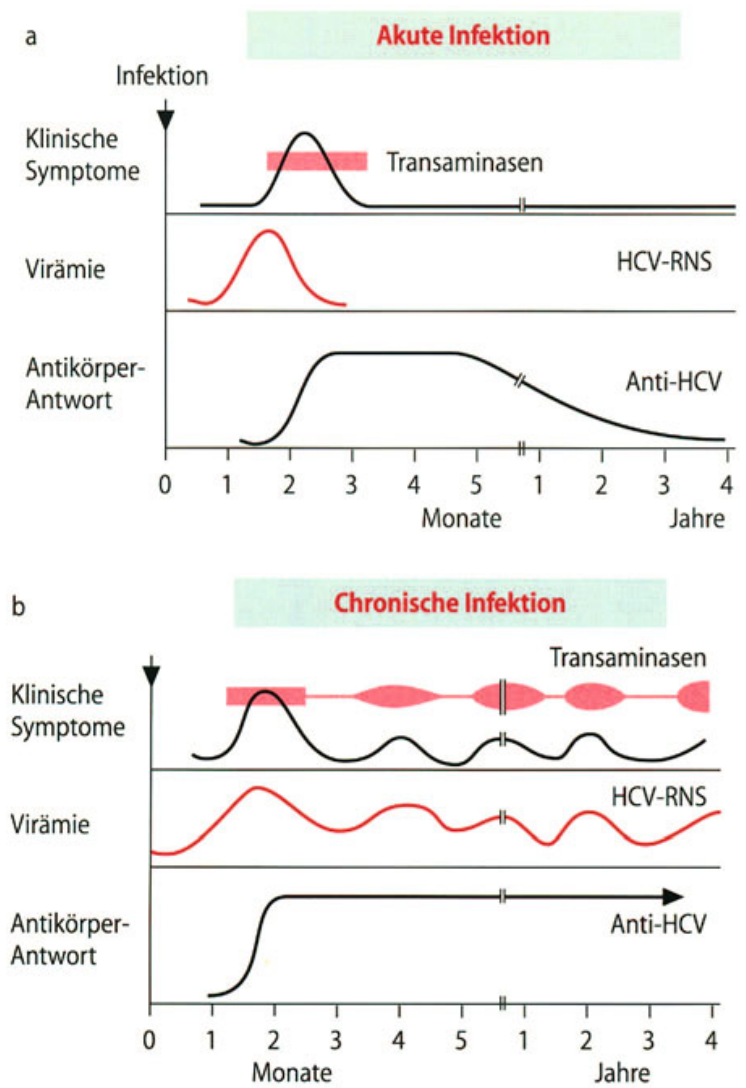

Abb. 15.7. Ablauf der akuten und chronischen HCV-Infektion. Als Marker sind HCV-RNS, Anti-HCV und Transaminasen dargestellt an. Rheumafaktoren lassen sich in $70 \%$ nachweisen.

\section{Labordiagnose}

Die Diagnose der Erkrankung wird durch einen IgG-ELISA gegen Struktur- und Nichtstruktur-Antigene (C 100, C 33 und C 22) gestellt, auch IgM läßt sich nachweisen. Die RNS läßt sich im Serum mit der PCR nachweisen. Bei Schwangeren aus Risikogruppen sollte die PCR angestellt werden! Transaminasenwerte geben den Krankheitsverlauf weniger gut an als die PCR.

\section{Resistenz, Prävention und Therapie}

Das HCV ist empfindlich gegenüber Formalin, Hitze und Chloroform. Wichtig ist die Prüfung von Blut für Transfusionszwecke auf Antikörper im ELISA und der Nachweis der RNS mit der PCR. Bei Patienten aus Risikogruppen (Dialysepatienten) ist wegen der Übertragungsgefahr sorgfältige Hygiene zu beachten. Der besonders häufig vorkommende Subtyp 1b ist relativ resistent gegen die Wirkung von IFN $a 2$, das in $20 \%$ v. a. beim Vorliegen des Subtyps 2 eine Ausheilung erbringt. Standard ist die Therapie mit Ribavirin und Interferon. Indikation für die Therapie ist die Leberbiopsie; das Ansprechen und der Therapieerfolg wird durch Biopsie und HCV-Viruslastbestimmung geprüft.

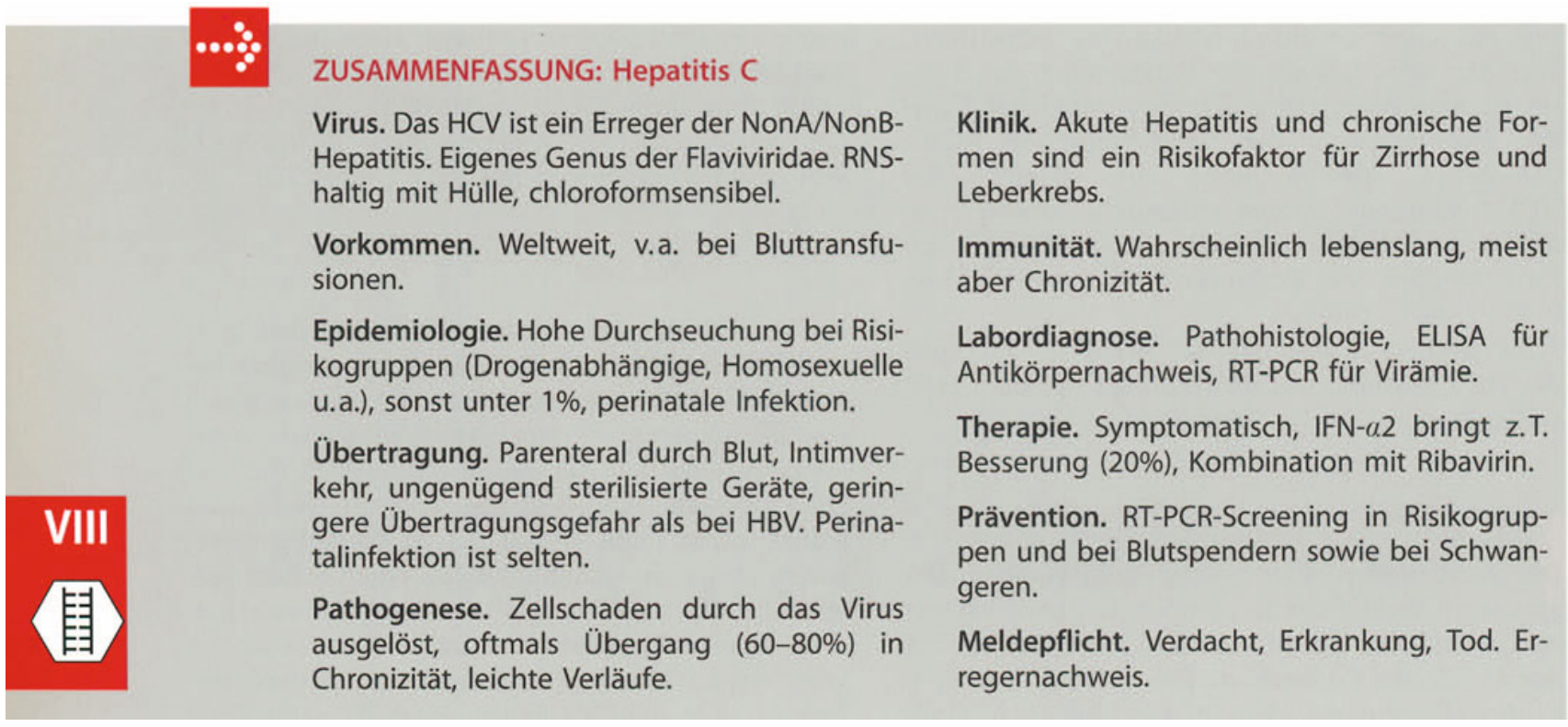




\subsection{Hepatitis E-Virus (HEV)}

Das HEV besitzt einen Durchmesser von etwa 27$34 \mathrm{~nm}(7,5 \mathrm{~kb},(+)$-Strang-RNS, ohne Hülle, drei Ableserahmen, nicht-kodierende Region) und bildet ein eigenes Genus. Es ist sehr stabil und wurde in großen Epidemien auf dem indischen Subkontinent, ferner in Mexiko und Afrika beobachtet, Antikörper werden aber auch in den Industrieländern (1-2\%) nachgewiesen. Die Übertragung erfolgt durch verunreinigtes Trinkwasser. Die Inkubationsperiode beträgt 18-64 Tage. Die Erkrankungen treten vorwiegend bei Jugendlichen und Erwachsenen auf. Neben dem Hauptsymptom (Gelbsucht) wird weniger häufig Anorexie, Hepatomegalie, Fieber, Erbrechen und Schmerzen beobachtet, der Verlauf ist schwerer als bei HAV. Infektionen durch HAV, HBV, HCV und durch HDV lassen sich epidemiologisch und serologisch oder durch die PCR ausschließen. Die Infektion wird auch auf Familienangehörige übertragen. Auffallend ist, daß die Krankheit bei graviden Frauen im 3. Trimenon einen sehr schweren Verlauf nimmt; die Letalität der Frauen betrug hier etwa 20\%. Häufig erfolgt die Übertragung von der Mutter perinatal auf das Kind bei hoher Sterblichkeit der Kinder. Chronische Fälle gibt es nicht (Tabelle 15.3, s. S. 673), jedoch Reinfektionen. Es gibt einen IgM- und IgG-ELISA für die Diagnostik. Die Virämie dauert 2-3 Wochen. Pathologisch-anatomisch bewirkt das HEV Einzel- oder fleckförmige Leberzellnekrosen, die Läsionen ähneln der bei der Hepatitis A: Portale und periportale Zerstörungen, viele aktivierte Kupffer- und NK-Zellen werden beobachtet, im Gegensatz zur Hepatitis A aber weniger Lymphozyten. HEV-Antigene finden sich im Zytoplasma. Das HEV läßt sich auf Schimpansen und Rhesusaffen sowie Ratten übertragen, bei Schweinen gibt es nahe Verwandte (Zoonose?).

\section{ZUSAMMENFASSUNG: Hepatitis E}

Virus. Das HEV ist ein „Hepatitis E-like Virus“ mit einer (+)-Strang-RNS in einem IkosaederKapsid; Kapsomere wie Tassen nach außen gerichtet.

Vorkommen. Epidemisch und endemisch in Asien, Südamerika und Afrika. Selten in Deutschland.

Übertragung. Schmutz- und Schmierinfektion, Trinkwasser, Lebensmittel (?). Übertragung auch auf Familienangehörige.
Pathogenese. Bei Infektion von Graviden oft tödliche Verläufe (20\%).

Klinik. I.allg. leichter Verlauf, Inkubationsperiode 18-64 Tage. Keine Chronizität.

Labordiagnose. ELISA oder PCR, hierzulande sehr selten.

Meldepflicht. Verdacht, Erkrankung, Tod. Erregernachweis.

\subsection{Hepatitis G-Virus (HGV)}

Auch nach der Entdeckung des HCV blieben noch Non-A-E-Hepatitiserkrankungen zurück: $3 \%$ der akuten und $17 \%$ der chronischen Hepatitiden in den USA ließen sich keinem dieser Viren zuordnen. Bereits 1971 war ein Virus von einem infizierten Chirurgen (GB) auf Tamarin-Affen übertragen worden. Das aufbewahrte Material ließ sich auch noch 1995 weiterpassagieren, wobei sich drei Viren, nämlich GB-A, -B und $-\mathrm{C}$ abgrenzen ließen.
Im Gegensatz zum HCV war die Pathogenität für Schimpansen gering. Auch aus Patienten mit NonA-E-Hepatitis konnte 1996 direkt ein neues Virus isoliert werden: das HGV. Es ist nahezu identisch mit dem HGB-C-Virus.

Es handelt sich um ein (+)-RNS-Strang-Virus, das zur Flavi-Gruppe gezählt wird. Das Genom enthält $9,4 \mathrm{~kb}$, an Proteinen sind eine Helikase, zwei Proteasen und die Polymerase identifiziert. Es ist mit dem HCV relativ nah verwandt.

Die Übertragung erfolgt durch Bluttransfusionen und sexuell, dabei enthält das Sperma das HGV. Mit 
der RT-PCR wurde es bei Blutspendern in 1-2\% der Fälle, bei Hämodialysepatienten in 3-4\% und bei Drogenabhängigen in $35-50 \%$ nachgewiesen; auch kommt es oft mit HCV gemeinsam vor. Offenbar persistiert das HGV im Organismus ohne Krankheitserscheinungen. Man vermutet, daß es aplasti- sche Anämien erzeugen kann und vielleicht fulminante Verläufe verursacht. Vorläufig läßt es sich nur durch die RT-PCR nachweisen. Es kann auch von der Mutter auf das Neugeborene übertragen werden (60\%). Antikörper (und ZTL?) bewirken die Elimination des Virus und wirken schützend.

\section{ZUSAMMENFASSUNG: Hepatitis G}

Virus. Das HGV gehört als eigenes Genus zu den Flavi-Viren. Es besteht aus (+)-StrangRNS in einem Ikosaeder-Kapsid mit Hülle. Ätherempfindlich.

Vorkommen. Beim Menschen weltweit verbreitet, weniger als $1-2 \%$ infiziert.

Übertragung. Durch Bluttransfusionen und bei i.v. Drogenabhängigen, oft sexuell; es wird oft mit HCV und seltener mit HIV übertragen.
Pathogenese. Leichter Verlauf, keine Transaminasenerhöhungen.

Klinik. Bisher keine Erkrankungen beobachtet. Virus persistiert bis zu 10 Jahren oder länger im Blut.

Labordiagnose. RT-PCR, Antikörperteste sind unzuverlässig.

Meldepflicht. Keine.

\subsection{TT-Virus (TTV)}

1997 wurde ein neues Hepatitis-Virus entdeckt, das TTV (nach den Initialen des Patienten). Es handelt sich um ein Einzelstrang-DNS-Virus mit negativer Polarität ohne Hülle mit etwa $3,8 \mathrm{~kb}$ und 2 ORF; die DNS liegt in Ringform vor (Circino-Virus). Man kennt viele Genotypen, dies erschwert die Diagnostik mit der PCR. Es wird durch Bluttransfusionen übertragen, mit dem Stuhl ausgeschieden und wahrscheinlich fäkal-oral übertragen. Die Virämie dauert Monate und Jahre. Bei Blutspendern findet es sich zu 14\% im Blut (PCR), bei Patienten im Endstadium von Lebererkrankungen bis zu $55 \%$, auch in der Muttermilch soll es vorkommen. Bei akuten und chronischen Infektionen sind die Transaminasen auch längerfristig erhöht. Im Gallensaft tritt es in 10-100fach höherer Konzentration auf als im Serum. Die lange Dauer der Virämie (Jahre) könnte auf einen Immundefekt hindeuten. Wahrscheinlich repliziert es sich in der Leber, ob es eine Hepatitis auslöst, ist eher ungewiß. - Auch jetzt kennt man die Ätiologie nicht aller Virushepatitiden: Man erwartet ein weiteres Virus.

\section{9 „Autoimmun-Hepatitis"}

Außer den Virus-Hepatitiden A, B, C, D, E und G sowie TTV gibt es Hepatitis-Fälle, bei denen ätiologisch kein Virus angenommen werden kann. Wie bei vielen Virusinfektionen gibt es auch bei der Hepatitis im Anschluß an die primäre Virusphase sekundäre, „autoaggressiv“ bedingte Phasen.

"Autoimmun"-Hepatitisfälle sind gekennzeichnet durch Hypergammaglobulinämie, Präponderanz bei Frauen, oftmaliges Vorkommen von HLA$A 1,-D R 3$ und -DR4 sowie -B8 sowie durch verschiedene Autoantikörper. Zur Charakterisierung dieser Hepatitis untersucht man das Spektrum der Autoantikörper: Antikörper gegen Nukleinsäuren (ANA), glatte Muskulatur (SMA), Leber, Niere, Mikrosomen (LKM), lösliches Leberantigen (SLA), Asialoglykoproteinrezeptor (ASGPR) und gegen Mitochondrien (AMA).

Die Unterscheidung zwischen autoimmunen und viralen Formen ist wichtig: Die autoimmune Form ist einer immunsuppressiven Therapie zugänglich, während es bei den viralen Hepatitiden bei immunsuppressiver Therapie zu einer Verschlechterung kommt. 


\section{EINLEITUNG}

Die Pocken waren die seit Jahrtausenden am meisten gefürchtete Krankheit des Menschen. Jenner hat um 1800 die Impfung gegen die Pocken ausgearbeitet und eingeführt. Durch ein gezieltes Impfprogramm der WHO wurde diese Krankheit 1977 ausgerottet. Heute spielen nur noch das Molluscum contagiosum (Moll. cont.) und einige tierpathogene Spezies der PockenViren eine Rolle.

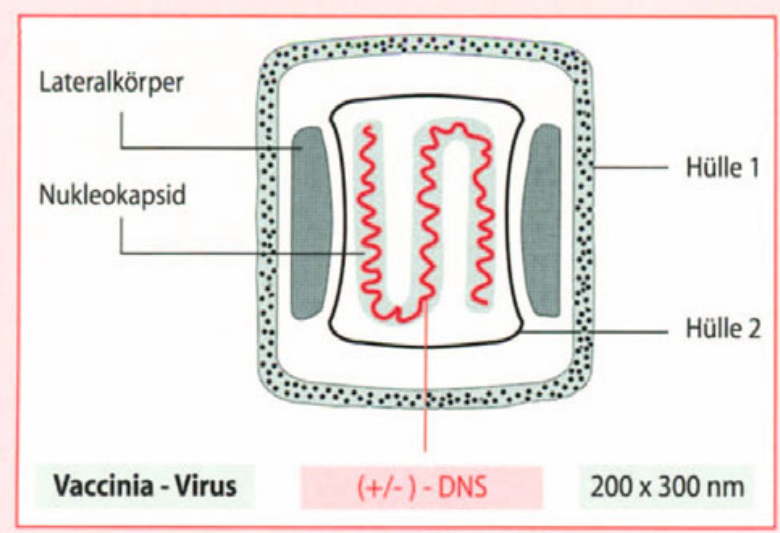

\subsection{Die Gruppe der Pocken-Viren}

Man faßt unter der Bezeichnung „Pocken-Viren“ eine Familie von großen Doppelstrang-DNS-Viren (130-375 kbp) mit komplexer Struktur zusammen. Sie treten als Erreger von Krankheiten bei Mensch und Tier auf.

Die Pocken-Gruppe gliedert sich nach dem jeweiligen Wirtsspektrum ihrer Glieder in Untergruppen. Hiervon sind nur drei für die Humanmedizin bedeutsam; die übrigen Erreger kommen bei Tieren vor und werden nur selten auf den Menschen übertragen.

\section{Genus Orthopox-Viren}

- Menschenpocken-Virus (Mensch); Variola vera;

- Vaccinia-Virus (Rind, Mensch, s. S. 679);

- Kuhpocken-Virus (Rind, Mensch, Nagetierreservoir);
- Mäusepocken-Virus (Affen, Mensch) Squirrelreservoir? u.a. (s. S. 680).

Genus Parapox-Viren. Das Melkerknoten-Virus ist für den Menschen pathogen: Es erzeugt die Melkerknoten-Krankheit. Das Orf-Virus erzeugt papulo-vesikuläre Läsionen am Finger.

Weitere Pocken-Viren. Hierzu gehören zahlreiche für den Menschen apathogene Viren, z. B. die Geflügelpocken, das Myxom-Virus des Kaninchens und die Schweinepocken-Viren. Weitere Subgruppen sind die Tana- und Yabapocken-Viren (Genus Yatapocken) der Affen sowie das Virus des Molluscum contagiosum.

\subsection{Molluscum contagiosum}

Das Molluscum contagiosum (Dellwarze) ist eine Infektionskrankheit des Menschen, es führt zu gutartigen, proliferativen Hauttumoren. Es wurde 1814 zum ersten Mal beschrieben. 1941 wurde der Erreger erstmals experimentell von Mensch zu Mensch übertragen. Das Genom des Virus enthält etwa 160 Gene. 


\section{Beschreibung}

Morphologie. Die Morphologie des Virus entspricht dem der Pocken-Viren.

Einteilung. Da die Züchtung des Virus in vitro bisher nicht gelungen ist, basiert die Typeneinteilung auf der Restriktionsenzymanalyse: Drei Genotypen. Genus Molluscipoxvirus.

\section{Rolle als Krankheitserreger}

Epidemiologie. Das Molluscum contagiosum tritt bei Kindern zumeist vereinzelt auf, man hat jedoch auch kleine Epidemien in Kindergärten und Schulen beobachtet.

Übertragung. Die Infektion wird direkt von Mensch zu Mensch weitergegeben, erfolgt aber auch indirekt; so wurde bei Besuchern von Schwimmbädern gehäuft Molluscum contagiosum festgestellt.

Pathogenese. Das Molluscum contagiosum ist auf die Haut beschränkt. Die Knötchen enthalten große Mengen an Virus. Die epithelialen Veränderungen sind "Epitheliosen", keine Adenome oder Epitheliome. Sie entstehen durch Proliferation der basalen Schichten (Akanthom) des Plattenepithels und weisen zentral eine Vertiefung auf, aus der sich zerfallende Epithelmassen entleeren. Die Basalmembran wird nicht durchbrochen, die Basalzellen nehmen aber an den Proliferationsvorgängen teil. Das Virus repliziert sich - wie alle Pokken-Viren - im Zytoplasma, die Einschlußkörper- chen entsprechen den Syntheseorten. Bestimmte Proteine des M.c. binden IL-18 und verhindern auf diese Weise die Stimulierung des Immunsystems durch Mangel an IFN- $\gamma$, deswegen auch die lange Dauer der Effloreszenzen. Andere Proteine verhindern die Apoptose. Je weniger CD4-Zellen vorhanden sind, desto häufiger ist das M.c.

Klinik. Das Molluscum contagiosum tritt nach einer Inkubationszeit von wenigen Wochen im Gesicht, aber auch am Hals, an den Armen, am Rükken und an den Genitalien in Form von Knötchen auf. Die Hauttumoren sind fleischfarbig; sie stellen sich als perlenartige, feste und genabelte Knötchen dar. Oftmals sind auch die Augenlider befallen; dabei werden eine Konjunktivitis und eine Keratitis beobachtet. Die Knötchen vergrößern sich nur sehr langsam; sie wachsen im Verlauf von Monaten, verschwinden dann aber meist spontan (zelluläre Immunreaktion) (Abb. S. 690). Bei AIDS-Patienten finden sich verstreut über die Körperoberfläche Anhäufungen von Dellwarzen. Mit einem IgG-ELISA haben sich Antikörper gegen das M.c.Virus nachweisen lassen. Die Antikörper zeigen eine mit steigendem Alter ansteigende Durchseuchung an; liegen Dellwarzen vor, lassen sich bis zu 70\% Antikörper feststellen.

Therapie. Zumeist lassen sich die Knötchen mit dem scharfen Löffel entfernen. Anwendung von flüssigem $\mathrm{N}_{2}$, Jodlösungen oder Cantharidin. Laserbehandlung. Cidofovir-Gel, Imiquimod-Gel lokal.

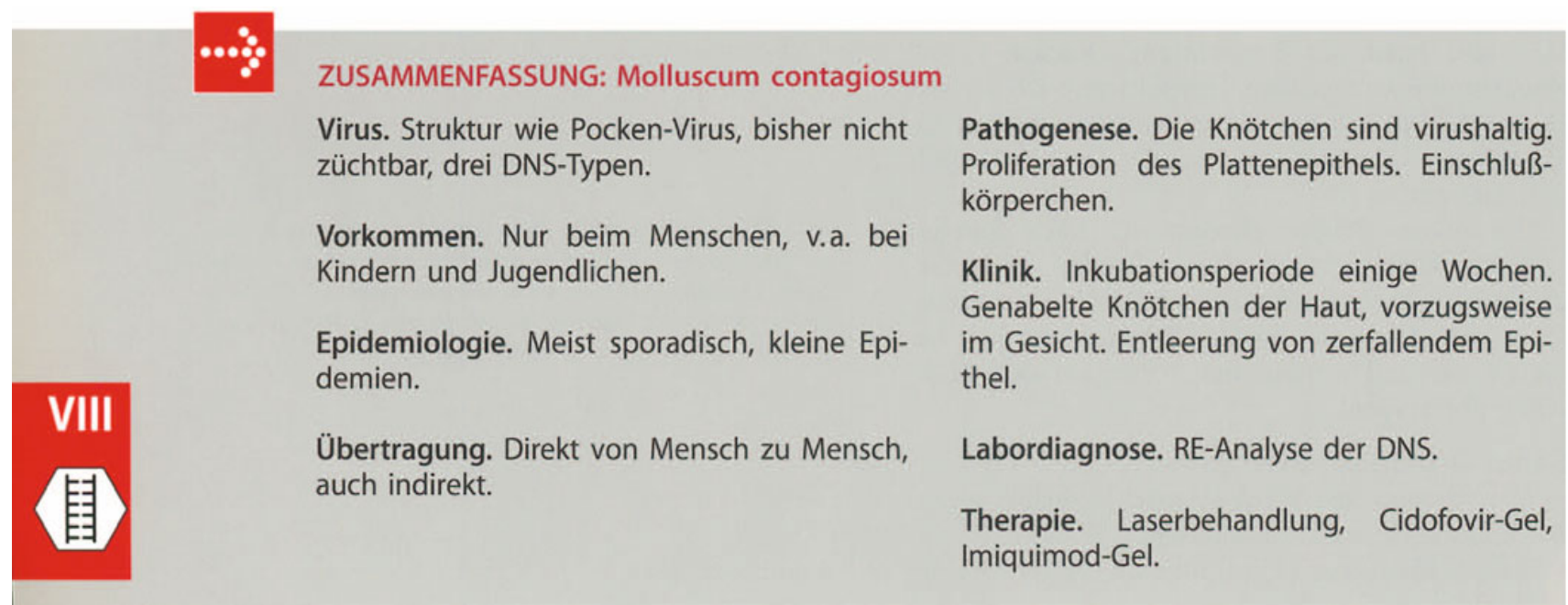




\subsection{Pocken- und Vaccinia-Virus}

Das Pocken-Virus ist für den Menschen hochvirulent und als Erreger der Pocken (Blattern, Variola major, Variola vera, „smallpox") bekannt: Es kommt nur beim Menschen vor. Im Gegensatz dazu ist das Vaccinia-Virus für den Menschen nur schwach virulent; es diente als Impfvirus gegen die echten Pocken. Heute dient das Vaccinia-Virus in stark attenuierter Form als Vektor für den Einbau von Virus- oder Tumorantigenen.

\section{Geschichte}

Die Pocken sind als endemisch auftretende Seuche bis ins 19. Jahrhundert hinein eine der am meisten gefürchteten Krankheiten gewesen. Sie waren bis in die Mitte des 19. Jahrhunderts eine Hauptursache für das Stagnieren der Bevölkerungszahl in Europa trotz hoher Geburtenziffer. Die nach dem 2. Weltkrieg registrierten Infektketten waren von eingeschleppten Einzelfällen ausgegangen: v.a. vom Luftverkehr. Seit 1977 sind die Pocken durch weltweite Impfprogramme ausgerottet. Dies ist das erste Beispiel für die gezielte Eliminierung einer seuchenhaften Infektionskrankheit.

\subsubsection{Beschreibung des Virus}

\section{Morphologie}

Pocken-Viren sind quaderförmig gebaut $(100 \times 200 \times 300 \mathrm{~nm})$. Die Doppelstrang-DNS des Virions ist in ein fadenförmiges Kapsid eingebaut. Es trägt zwei ineinanderliegende Hüllen und dazwischen zwei Polkörperchen in Gestalt von je einer „Polscheibe“.

\section{Vermehrungszyklus}

Der Vermehrungszyklus der Pocken-Viren ist am Beispiel des Vaccinia-Virus studiert worden. Die für die allgemeine Virologie grundlegenden Erkenntnisse über Adsorption, Penetration, Uncoating, Enzyminduktion, Bausteinsynthese und Mon- tage sind zum großen Teil am Modell des Vaccinia-Virus gewonnen worden. Die Vermehrung der Pocken-Viren erfolgt an Synthesezentren im Zytoplasma. Das Vaccinia-Virion enthält eine viruskodierte DNS-abhängige RNS-Polymerase u.a. Enzyme; die Virus-DNS enthält außerdem Gene, deren Produkte als Wachstumsfaktor für Epithelzellen wirken oder die Komplementkaskade hemmen. Das Vaccinia-Virus verhindert durch Expression eines IL-1-Inhibitors die Entstehung von Fieber im Gegensatz zur Variola vera-Virusinfektion, die mit hohem Fieber einhergeht.

Charakteristisch für die Morphologie der vom Vaccinia- und vom Variola-Virus befallenen Zelle sind die Guarnieri'schen Einschlußkörperchen. Sie färben sich im Zytoplasma als basische Gebilde gut an. Sie enthalten Ansammlungen aus reifen und unreifen Viruspartikeln.

\section{Resistenz gegen äußere Einflüsse}

Die Pocken-Viren sind außerordentlich resistent gegen Austrocknung und können sowohl durch Staub als auch durch Tröpfchen über mehrere Meter hinweg übertragen werden.

Züchtung ist möglich im lebenden Tier, im bebrüteten Hühnerei und in der Zellkultur.

\subsubsection{Rolle als Krankheitserreger}

\section{Übertragung}

Das Virusreservoir für die echen Pocken sind ausschließlich kranke Menschen; gesunde Träger sind nicht bekannt. Die Kontagiosität beginnt mit dem Auftreten des Rachenkatarrhs und hört mit dem Abheilen der verschorften Pusteln auf. Die Übertragung erfolgt in der ersten Krankheitsperiode durch Tröpfcheninfektion vom Rachen aus und durch Einatmen von eingetrocknetem Pustelmaterial. Nach Erscheinen der Pusteln und Krusten ist die Haut des Kranken und dessen Bettwäsche kontagiös. Eintrittspforte ist der Nasenrachenraum.

\section{Klinik}

Die Inkubationszeit beträgt ca. zwei Wochen (1213 Tage). Man beobachtet bei Beginn der klinischen Erscheinungen schweres Krankheitsgefühl, hohes Fieber und heftige Kreuzschmerzen sowie 
einen Rachenkatarrh. In diesem Stadium ist der Kranke hochinfektiös. Nach 1-5 Tagen sinkt das Fieber $a b$ und steigt nach einem Intervall von etwa einem Tag wieder an (biphasischer Fiebertyp). $\mathrm{Zu}-$ gleich treten Hauteffloreszenzen auf. Die Lymphknoten sind vergrößert. Bevorzugt sind die Extremitäten und das Gesicht, während der Stamm weniger befallen ist. Das Exanthem besteht anfangs aus roten Flecken, die sich zu Knötchen umbilden: Diese werden in virushaltige Bläschen umgewandelt, die sich bald eintrüben, sodann eintrocknen und schließlich verschorfen. Nach der Abheilung bleibt eine Narbe zurück. Vom Auftreten der ersten Krankheitserscheinungen bis zum Abfallen der Krusten vergehen 4-6 Wochen. Die Letalität beträgt 20-30\%. - Infektionen mit dem VacciniaVirus beim Vorliegen von zellulären Immundefekten bewirken lokale Nekrosen.

\section{Immunität}

Nach einer durchgemachten Pocken-Erkrankung bleibt eine langdauernde Immunität zurück. Der Schutz wird durch zytotoxische Lymphozyten hervorgerufen; „nebenbei“ entstehen Antikörper.

\section{Prävention}

Edward Jenner hat 1790/96 erstmals Schweinepokkenmaterial auf seinen fast einjährigen Erstgeborenen und später Kuhpockenmaterial von einer infizierten Melkerin auf James Phipps übertragen. Als Impfstoff, als Vakzine, diente seit der Mitte des vorigen Jahrhunderts eine Suspension von Vaccinia-Virus mit einem festgelegten Virusgehalt. Das Impfverfahren bot jedoch für den einzelnen Impfling nur für etwa 1-2 Jahre sicheren Schutz. Der relative Schutz war mit 10-15 Jahren zu veranschlagen. Meldepflicht von Verdacht, Erkrankung und Tod bei echten Pocken. Erregernachweis.

\subsection{Anhang}

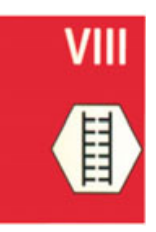

\section{Gibt es ein natürliches Reservoir für Pocken-Virus?}

Die Ausrottung der Pocken (Variola major) beim Menschen wirft die Frage auf, ob es bei in freier Wildbahn lebenden Tieren Verwandte des PockenVirus gibt, die gelegentlich auf den Menschen übertreten und zum Ausgangspunkt einer Epide- mie werden könnten. Ein solches Ereignis hätte verheerende Folgen, weil es auf eine immunologisch völlig ungeschützte Weltbevölkerung treffen würde.

In der Tat existieren bei wildlebenden Affen „Monkeypox“-Viren, die gelegentlich auf den Menschen übertreten. Die Infektion des Menschen durch verschiedenartige Affen-Viren ist also kein ungewöhnliches Ereignis. In Zaire hat man z.B. von 1980-1985 282 Patienten mit Pockenerkrankungen durch das Monkeypox-Virus festgestellt. 1996 folgten weitere Erkrankungen. Weitere Fälle wurden seit 1970 in Liberia, Nigeria, Sierra Leone und an der Elfenbeinküste festgestellt. Serologisch erwies es sich als nahe verwandt mit dem Vaccinia-Virus. In Ländern mit dieser Zoonose gibt es seither spezielle Überwachungsdienste.

Das Krankheitsbild des auf den Menschen übertragenen Monkeypox-Virus ist dem der echten Pocken sehr ähnlich. Nur eine sehr frühzeitig auftretende Lymphadenopathie erlaubt die Abgrenzung gegen die echten Pocken und die Windpokken. Lymphknotenschwellungen traten bei ungeimpften Personen in $84 \%$ auf, bei vakzinierten Personen in 53\%. Bei vakzinierten Personen verlief die Krankheit viel leichter. Die Prognose war abhängig vom Schweregrad der Komplikationen. Unter den vakzinierten Personen traten keine Todesfälle auf, bei den nicht vakzinierten Erwachsenen betrug die Mortalität 11\%, bei Kindern $15 \%$.

In Deutschland sind in den letzten Jahren verschiedentlich „Kuhpocken"-Erkrankungen vorgekommen, v.a. scheinen Katzen die Überträger zu sein. Tatsächlich sind wildlebende kleine Nagetiere der Ursprung dieser "Kuhpocken-ähnlichen“ Viren, von denen sie auf Kamele, Rinder, Büffel, Elefanten, Katzen etc. und selten auf den Menschen im Sinne von Endgliedern der Infektkette übergehen. Hier können sie bei Immunschwachen lebensbedrohliche Krankheiten hervorrufen. Mit dem Absinken des Impfschutzes gegen die echten Pokken - und damit auch gegen diese Tierpocken der Orthopoxgruppe - ist daher mit einem vermehrten Auftreten dieser Infektionen zu rechnen. Die Büffelpocken in Indien sind eine Subspezies des Vaccinia-Virus; sie werden gelegentlich von Mensch $\mathrm{zu}$ Mensch weitergegeben.

Eine sehr wichtige Frage ist es, ob die Möglichkeit besteht, daß sich aus diesem (oder einem anderen) Virus ein für den Menschen hochpathogenes Virus wie das Variola-Virus entwickeln kann. Dafür gibt es bisher nur wenig Anhaltspunkte. Im 
Gegensatz zu den echten Pocken werden diese Viren nur selten an Familienangehörige und andere Personen weitergegeben; es hat sich jedoch gezeigt, daß bei den neuen Ausbrüchen die Affenpocken wesentlich häufiger von Mensch $\mathrm{zu}$ Mensch weitergegeben werden als früher beobachtet. Variola minor (=Alastrim) ist eine wenig pathogene, aber stabile Einheit des Variola-vera-Virus.
Heute befürchtet man die Verwendung des Pokken-Virus im Rahmen eines Bioterrorismus und setzt die lange unterbrochene Suche nach Chemotherapeutika fort. Cidofovir schützt Mäuse vor Kuhpocken-Infektionen. - Die Arbeiten mit dem Variola-vera-Virus und den Monkeypox-Viren erfolgen im Hochsicherheitslabor.

\section{ZUSAMMENFASSUNG: Pocken-Virus}

Virus. Doppelstrang-DNS-Virus mit helikalem Kapsid und zwei Hüllen.

Vorkommen. Früher weltweit, jetzt ausgerottet.

Epidemiologie. Alle Infizierten erkranken. Durch gezielte Schutzimpfung ausgerottet.

Übertragung. Tröpfcheninfektion, Staubinfektion, Virus ist sehr resistent.

Pathogenese. Replikation im Nasenrachenraum, zweiphasische, systemische Ausbreitung; hämatogen, "Pocken" auf der Haut.

Klinik. Inkubationsperiode 12-13 Tage: Variola vera. Schwere, fieberhafte Erkrankung mit knötchen-/bläschenförmigem Exanthem. Variolois als abgeschwächter Verlauf bei Teilimmunität (nach V. vera oder Impfung), dabei gefürchtete Ausscheidung des Virus.
Immunität. Nach Variola vera einige Jahre, dann partiell. Nach Impfung dauert der absolute Schutz nur 1-2 Jahre. Bei zellulärem Immundefekt: Nekrotisierende Entzündung als Impfkomplikation.

Labordiagnose. Partikelnachweis im EM. Züchtung in Zellkultur, im bebrüteten Hühnerei und auf der Chorioallantois-Membran.

Therapie. Symptomatisch. Chemotherapeutika?

Prävention. Schutzimpfung mit Vaccinia-Virus, dies gilt auch für die Kontrolle von Affenpocken-Erkrankungen und ebenso für gentechnologische Arbeiten mit dem Vaccinia-Virus. Die allgemeine Pflicht zur Pockenschutzimpfung ist aufgehoben.

Meldepflicht. Verdacht, Erkrankung und Tod. Erregernachweis. 


\section{7 Seltene, subakute oder chronische Virus- und Prion-Krankheiten (,slow virus diseases")}

D. FALKE, J. BOHL

\section{EINLEITUNG}

"Slow virus diseases" (SVD) sind Erkrankungen verschiedener Ätiologie, die sich durch eine sehr lange Inkubationsperiode und einen überaus langsamen Verlauf des Krankheitsprozesses von anderen Viruskrankheiten unterscheiden.

Einige subakut oder langsam progredient bzw. chronisch verlaufende Infektionskrankheiten des ZNS sind auf konventionelle Viren zurückzuführen, z. B. die SSPE auf das Masern-Virus und die PML auf das JC-Virus.

Zu den "Slow virus diseases" werden auch die Prion-Krankheiten gezählt. Ihre Auslösemechanismen unterscheiden sich grundsätzlich von den Infektionen durch Viren: Die übertragenen Eiweißmoleküle vermehren sich nicht selbst; sie induzieren vielmehr nur durch Umfaltung die vermehrte Bildung von Prion-Proteinen des Wirtsorganismus "subviral particles". Auf diese Weise wird das Immunsystem unterlaufen.

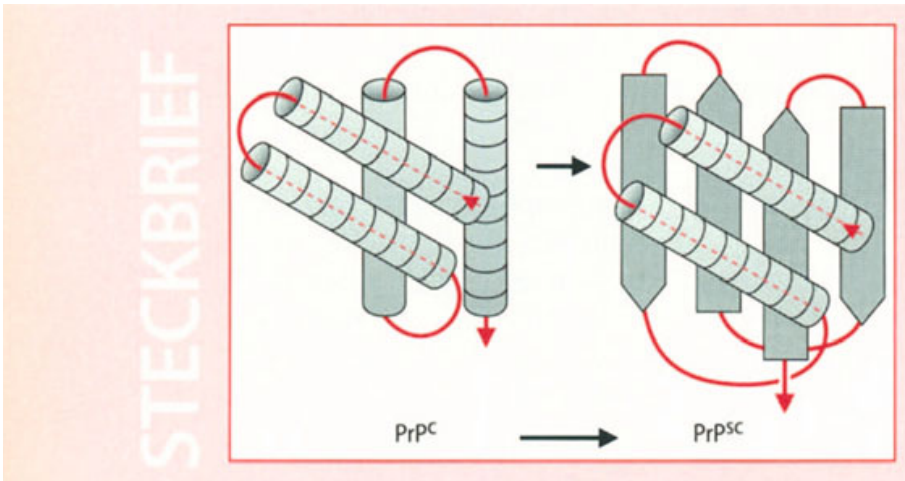

\subsection{Allgemeines}

Die Masern-Virus-Infektion führt gelegentlich $\mathrm{zu}$ einem langsam progredienten enzephalitischen Krankheitsbild, welches SSPE genannt wird: Subakute Sklerosierende Panenzephalitis (s. S. 561). Eine zweite Masern-Virus-Enzephalitis der chronischen Art stellt die Masern-Virus-Einschlußkörperchen-Enzephalitis (MIBE) dar, welche vorwiegend bei Immundefekten beobachtet wurde. Als Ursache der Progressiven Multifokalen Leukoenzephalopathie (PML) wirkt das JC-Virus (s. S. 622). Auch die AIDS-Enzephalopathie, welche oft ein dementielles Krankheitsbild erzeugt, ist als Folge der chronischen HIV-Infektion aufzufassen. Ob und auf welche Weise bei der Entstehung einer Multiplen Sklerose (MS) oder einer amyotrophen Lateralsklerose (ALS) eine Virus-Infektion beteiligt sein könnte, ist noch unklar. Auch bei chronischen psychischen Erkrankungen im weitesten Sinn wird eine chronische Borna-Virus-Infektion als auslösender Faktor diskutiert.

$\mathrm{Zu}$ den SVD im engeren Sinne, zu den humanen Prion-Krankheiten, werden $z$. Z. gerechnet:

- Creutzfeldt-Jakob-Krankheit (CJK),

- Gerstmann-Sträussler-Scheinker-Syndrom (GSS),

- Kuru, eine Krankheit der Eingeborenen auf Neu-Guinea,

- tödliche Schlaflosigkeit (FFI: Fatale Familiäre Insomnie),

sowie bei Tieren:

- Scrapie, die Traber-Krankheit der Schafe und Ziegen,

- Rinderwahnsinn („mad cow disease“) oder auch BSE genannt (Bovine Spongiforme Enzephalopathie),

- vergleichbare Erkrankungen bei anderen Huftieren, bei Katzenartigen (Feliden) und vielleicht sogar auch bei Vögeln (Strauße in England).

Erläuterung: z.B. steht D178N für eine Mutation in Position 178 von D (Asparaginsäure) in $\mathrm{N}$ (Asparagin). 


\subsection{Prion-Krankheiten}

\section{Kuru}

Eine seit 1900 bei einem Eingeborenenstamm auf Neu-Guinea (Stamm der Fore) endemisch auftretende Krankheit wurde von jenen „Kuru“ genannt (d.h. „trembling with cold fear": also Zittern in kalter Furcht). Die Krankheit wurde offensichtlich bei rituellen Trauerzeremonien, welche mit kannibalistischen Praktiken einhergingen, auf andere Stammesmitglieder übertragen. Nach einer Inkubationszeit von mindestens vier Jahren traten Ataxien auf sowie Tremor, Verhaltensanomalien und schließlich Kachexie und Demenz. Die KuruKrankheit konnte experimentell auf Schimpansen und auch auf andere Affenspezies übertragen werden. Nachdem diese Art von „Kannibalismus“ eingestellt wurde, nahm die Zahl der Neuerkrankungen kontinuierlich $\mathrm{ab}$ und die Krankheit konnte bis heute fast verschwinden.

\section{Creutzfeldt-Jakob-Krankheit (CJK)}

Das klinische Krankheitsbild der CJK wird gekennzeichnet durch einen raschen zur Demenz führenden zerebralen Prozeß, welcher oft mit einer zerebellären Symptomatik (Ataxie), einem Myoklonus und Pyramidenzeichen einhergeht. Die Krankheit tritt meist im höheren Lebensalter, im 30.-85. Jahr, auf und führt in etwa 9-18 Monaten zum Tode. Sie kann auf Primaten und viele Säugetiere experimentell übertragen werden.

Auch iatrogene Übertragungen auf andere $\mathrm{Pa}$ tienten sind beschrieben worden, z. B. nach Hornhauttransplantationen, durch Verpflanzung von lyophilisierter Dura mater und v.a. durch Wachstumshormonpräparate, gewonnen aus Hypophysen von Leichen. Die Prävalenz der CJK beträgt etwa $1 \times 10^{-6} / \mathrm{Jahr}$. Sie kommt in vier Varianten vor:

- Sie kann sporadisch entstehen (85\%).

- Sie tritt als hereditäre Krankheit gehäuft in Familien auf, welche bestimmte Mutationen auf dem Prion-Gen im 20. Chromosom haben, z. B. D178N, E200K, V210I (15\%).

- Die Krankheit kann erworben werden durch iatrogene Übertragung oder akzidentelle Inokulation von kontaminiertem Material.

- Die neue Variante der CJK (vCJK), in Aminosäure 129 ist sie homozygot für Methionin.

\section{Gerstmann-Sträussler-Scheinker-} Syndrom (GSS)

Das GSS-Syndrom ist eine seltene, familiär auftretende, chronische, degenerative Erkrankung des ZNS, welche mit ataktischen Störungen einhergeht und schließlich in eine Demenz mündet. Die Prävalenz beträgt $1 \times 10^{-8}$ pro Jahr. Im Prion-Gen auf dem 20. Chromosom wurden mehrere Mutationen bei den verschiedenen Familien gefunden: P102L, P105L, A117V, Y145Stop, V180I, F198S und Q217R.

\section{Familiäre Fatale Insomnie (FFI)}

Das klinische Bild der FFI ist durch Schlaflosigkeit, Unfähigkeit $\mathrm{zu}$ essen sowie auch durch Ataxien, Myoklonien und Pyramidenbahndegeneration gekennzeichnet. Auch bei dieser seltenen Krankheit ist eine Mutation auf dem kurzen Arm des 20. Chromosoms nachgewiesen worden (D178N), zusätzlich besteht Homozygotie im M129M.

\section{Scrapie}

Die Scrapie der Schafe kann auf Mäuse und Hamster übertragen werden und manifestiert sich durch Zuckungen, Kratzen sowie schließlich Paralyse und Tod der Tiere nach 1-4jähriger Inkubationszeit. Sie ist seit 250 Jahren bekannt.

\section{Bovine Spongiforme Enzephalopathie (BSE)}

Seit 1986 wurde in England in zunehmendem Maße eine übertragbare spongiforme Enzephalopathie (TSE: Transmissible Spongiforme Enzephalopathy) bei Rindern beobachtet: BSE (Bovine Spongiforme Enzephalopathie). Diese Epidemie des „Rinderwahnsinns" ist vermutlich durch die Verfütterung von mit Scrapie infiziertem Schaffleisch in Form von Fleischmehl an Rinder ausgelöst worden. BSE konnte bisher sowohl akzidentell als auch experimentell auf viele andere Spezies übertragen werden. Orale (?) Aufnahme von Rindermaterial durch den Menschen ist die Ursache der neuen Variante der CJK (vCJK). Zur Eindämmung der Seuche wurden in England 2,7 Mio Rinder verbrannt. Auf dem Höhepunkt erkrankten etwa 200000 Rinder pro Jahr, jetzt sind es noch etwa 2000. 


\subsubsection{Prion-Protein}

Prion-Krankheiten sind im Tierreich weit verbreitet. Spontane Prion-Krankheiten gibt es bei Menschen, Schafen, vielleicht auch bei Rindern (BSE). Alle Prion-Krankheiten, sowohl die sporadischen als auch die hereditären sowie die iatrogen entstandenen lassen sich experimentell auf andere Spezies übertragen, meist auf Nager, aber nur, wenn diese Tiere ein eigenes Prion-Protein-Gen besitzen.

\section{Erreger und Pathogenese}

Der Erreger aller dieser Krankheitsformen ist das Prion-Protein (PrP); ob es Nukleinsäure enthält, ist unwahrscheinlich. Es ist sehr resistent gegen UV-Bestrahlung sowie Hitze und Formalinbehandlung. Das M.G. des $\operatorname{PrP}^{c}$ beträgt $33-35 \mathrm{kDa}$. Das $\operatorname{PrP}^{c}$ besteht aus vier $a$-Helices, das $\operatorname{PrP}^{\text {sc }}$ aus zwei $a$-Helices und vier $\beta$-Faltblättern (vereinfachtes Modell). Das $\operatorname{PrP}^{c}$ der Zelle läßt sich in der Membran von normalen Neuronen nachweisen. Es besitzt 254 Aminosäuren, und sein Gen ist beim Menschen auf dem Chromosom 20 lokalisiert. Das $\operatorname{PrP}^{c}$ besitzt eine große Ähnlichkeit mit dem Aktivator für den Azetylcholin-Rezeptor; sein Rezeptor ist der Lamininpräkursor (?). Im ZNS von kranken Organismen wird das $\operatorname{PrP}^{\text {sc }}$ (von Scrapie) nachgewiesen, das in "ausgefällter" Form als "Amyloid“ außerhalb der Zelle abgelagert ist. Amyloid - in unterschiedlichem Ausmaß entstanden - ist pathognomonisch für alle Prion-Krankheiten (Farbtafel S. 690). Im Gegensatz zum $\operatorname{PrP}^{c}$ ist das $\operatorname{PrP}{ }^{s c}$ infolge der Konformationsänderung des Moleküls proteaseresistent und unlöslich. Unterschiedliche Grade der Resistenz beruhen auf der differierenden Struktur der PrP ${ }^{\mathrm{sc}}$-Moleküle infolge der unterschiedlichen Wirkung der Mutationen auf die Proteinstruktur.

Erbliche Formen der CJK und des GSS zeigen bestimmte Mutationen des PrP-Gens. Der Grad der Umfaltbarkeit des PrP-Moleküls bestimmt auch die Inkubationsperiode, den Verlauf und die Pathohistologie der CJK, u.z. sowohl beim Menschen als auch im Tier. Spontane Umfaltungen des $\operatorname{PrP}^{\mathrm{c}}$ sind die Ursache der sporadischen CJK.

Wird ein $\operatorname{Pr}^{\text {sc }}$ übertragen, so bewirkt es quasi autokatalytisch mit Hilfe von Chaperonen die Umformung des bereits vorhandenen, normalen $\operatorname{PrP}^{c}$ des Menschen in die krankheitserzeugende $\mathrm{PrP}^{\mathrm{sc}}$ -
Form. In „Knock-out“-Mäusen für das PrP-Gen entsteht nach der Infektion keine Erkrankung, weil das $\operatorname{Pr} P^{c}$ fehlt. Antikörper gegen das $\operatorname{PrP}$ treten nicht auf, Entzündungszeichen werden nicht beobachtet, Hauptmerkmal ist die spongiöse Degeneration des ZNS, die durch Vakuolisierung und apoptotischen Zerfall der Neuronen sowie Mikrogliaund Astrozyten-Poliferation zustande kommt. Man unterscheidet histologisch verschiedene Formen. Die neue Variante der CJK (vCJK) ist bisher bei 50 Patienten beobachtet worden. Diese neue Variante der $\mathrm{CJK}$ ist durch frühzeitigen Beginn ( $\mathrm{ab}$ 12 Jahre), langsamen Verlauf und herdförmige Verteilung von vakuolisierten Neuronen mit starker Ablagerung von Amyloid in der Umgebung gekennzeichnet. Die Einheitlichkeit von BSE der Rinder und der neuen Variante der CJK wird nahegelegt durch das Vorkommen von drei unterschiedlich glykosilierten Formen des $\mathrm{PrP}^{\mathrm{sc}}$ nach Auftrennung im Gel (Westernblot, M.G. 27-30 kDa). Die Übertragung von BSE- und von vCJK-Material auf verschiedene Tierspezies hat Krankheit und identische Bandenmuster des $\operatorname{PrP}^{\mathrm{sc}}$ ergeben. Man vermutet, daß die Vermehrung von Zytokinen (TNF$a$, IL-1 u.a.) in den befallenen Zellen pathogenetisch wichtig ist. Das PrP selbst kann neurotoxisch wirken und Apoptose auslösen. Die Wanderung des $\operatorname{PrP}^{\mathrm{sc}}$ von der Peripherie (z.B. vom Magendarm-Trakt) in das ZNS erfolgt mit Beteiligung des lymphatischen Systems, wobei dendritische Zellen, B- und T-Zellen erforderlich sind.

\section{Diagnose, Prophylaxe und Resistenz}

Mit monoklonalen Antikörpern läßt sich im Gewebe das krankheitsspezifische $\operatorname{PrP}^{\mathrm{sc}}$ darstellen. Das vCJK-Material breitet sich in viele Gewebe aus (Tonsillen, Appendix) und läßt sich zu diagnostischen Zwecken nachweisen. Im Liquor ist die neuronenspezifische Enolase erhöht. Im EEG finden sich 3-Phasen-Komplexe, und mit der PositronenTomographie läßt sich ein lokaler Hypometabolismus nachweisen. An Surrogatmarkern im Liquor kennt man das Tau-Protein, das $\mathrm{S} 100-$ und das 143-3-Protein ( $M G 30 \mathrm{kDa}$ ). In 5-7\% sprechen sie auch bei Enzephalitis, M. Alzheimer u. a. an. Erhitzung für $120 \mathrm{~min}$ auf $200^{\circ} \mathrm{C}$ zerstört die Infektiosität sicher. 


\subsection{Marburg- und Ebola-Virus}

Marburg- und Ebola-Virus werden zu den Filo-Viren gezählt. Sie erzeugen schwere, oft tödlich verlaufende Hämorrhagische Fieber. Beide Viren wurden durch spektakuläre Krankheitsausbrüche bekannt.

1967 traten in Marburg, Frankfurt und Belgrad schwere Erkrankungen bei Tierpflegern von Grünaffen (Cercopithecus aethiops) aus Uganda auf; von 38 erkrankten Personen starben sieben. 1976 wurden in Zaire ähnliche Symptome beobachtet: Ebola-Virus; die Mortalität lag bei 89\%. 1989 bekamen 14\% von gesund gebliebenen Tierpflegern, die respiratorisch kranke Makaken (Macaca mulotta) von den Philippinen betreuten, Antikörper gegen das Reston-Virus (USA). 1994 wurde eine Ethnologin krank, die einen gestorbenen Schimpansen seziert hatte.

Das Marburg-Virus wurde 1967 von Slenczka und Siegert in Marburg isoliert und von Peters elektronenmikroskopisch dargestellt: Es ist ein fadenförmiges Gebilde von $80 \times 1000 \mathrm{~nm}$, bestehend aus helikalem Kapsid, Matrixprotein und Hülle mit Spikes. Das Genom besteht aus (-)-Strang-RNS und enthält $19,1 \mathrm{~kb}$.

Die Übertragung erfolgt durch engen Kontakt (Blutspritzer, Verletzungen, Hautkontakt). Das Erregerreservoir in Afrika ist noch nicht bekannt (Fledermäuse?), das beim Menschen asymptomatische Reston-Virus stammt von Makaken aus Ostasien. Alle drei Isolate (Marburg-, Ebola- und Reston-Virus) sind mehr oder weniger serologisch verwandt, die Erreger sind offenbar weit verbreitet. Auch bestehen starke Virulenzunterschiede. In der Milz, den Lymphknoten, der Leber und der Lunge befindet sich bereits frühzeitig viel Virus. In den Geweben, vor allem in der Leber, finden sich fokale Nekroseherde, aber nur wenig Entzündungszellen. Erst spät im Verlauf treten Hämorrhagien im Gastrointestinaltrakt, im Mund und in den serösen Häuten auf. Hämorrhagien finden sich darüber hinaus in vielen Organen, einschließlich des ZNS. Infizierte Endothelien und Makrophagen setzen viel TNF $a$ frei. IFN $a / \beta / \gamma$ ist stark reduziert. Klinisch wichtig ist ein schweres SchockSyndrom.

Die Inkubationsperiode beträgt sieben Tage. Die Symptome sind Schüttelfrost, Muskelschmerzen, Exanthem, Erbrechen, Blutungen, Hypotension und Apathie. Antikörper lassen sich im IFT sowie im Westernblot nachweisen, im Gewebe gelingt der Antigennachweis durch Immunhistologie, im Blut der Virusnachweis durch das EM. Die Isolierung und Züchtung in Affennierenzellen ist möglich. In Monozyten wird die RNS durch die RT-PCR nachgewiesen. Therapie: Keine. Im Mäuseversuch schützen Antikörper vor der Infektion. Meldepflicht bei Verdacht, Erkrankung und Tod. Erregernachweis, Hochsicherheitslabor!

Differentialdiagnose. S. 527.

\subsection{Guillain-Barré-Syndrom (GBS)}

Das Guillain-Barré-Syndrom ist eine meist akut auftretende entzündliche demyelinisierende Erkrankung des peripheren Nervensystems. Diese Auto-Immunerkrankung manifestiert sich etwa 1 bis 2 Wochen nach Infektion mit EBV, ZMV, Influenza oder (seltener) durch HSV oder auch HIV. Die schwersten Formen entstehen nach Infektion mit Campylobacter jejuni (s. S. 304). Möglicherweise kommt es im Verlauf dieser Erkrankungen $\mathrm{zu}$ einer Auto-Immunisierung gegen Bestandteile des peripheren Myelins, wodurch eine Polyradikulitis, Polyganglionitis und eine Polyneuritis zustande kommt. Im schlimmsten Fall resultiert eine rasch aufsteigende Paralyse: Landry'sche Paralyse (erstmals beschrieben 1859) mit vollständiger Tetraplegie. Die Erkrankung kann sich klinisch auch als Bell'sche Paralyse (Fazialis-Lähmung) oder als Paraplegie manifestieren. Das zentrale Nervensystem bleibt hierbei immer unversehrt.

Pathohistologisch sieht man im peripheren Nervensystem perivaskuläre Ödeme, lymphomonozytäre, z.T. perivaskuläre Infiltrate und Entmarkungen. In den Nervenscheiden des Biopsie-Materials läßt sich polyklonales IgM und IgG nachweisen. Die Isolierung des auslösenden Virus (ZMV, HSV u. a.) gelingt meist nicht; durch serologischen Ausschluß der in Betracht kommenden Viren, gelegentlich auch durch IgM-Nachweis, läßt sich gegebenenfalls auf ein Virus als spezifische Ursache schließen. Influenza- (u. a.) Impfungen besitzen allenfalls ein Risiko von 1 Fall auf $10^{6}$ Impfungen, wahrscheinlich nur bei Patienten mit GBS oder Polyneuropathien. HBsAg-, die jetzigen InfluenzaImpfstoffe sowie Masernimpfungen lösen kein GBS aus. Therapie: Austauschtransfusion. 


\subsection{Borna-Krankheit}

Die Borna'sche Krankheit der Pferde ist seit dem 17. Jahrhundert bekannt. Der Name geht auf das seuchenhafte Auftreten Ende des 19. Jahrhunderts um die Stadt Borna bei Leipzig zurück. Die Symptome der Enzephalomyelitis sind Hyperästhesien, Schluckstörungen, Schlafsucht oder Aggression und Ataxie; dann folgen Lethargie, Lähmungen und Koma, so daß nach 2-3 Wochen der Tod eintritt.

Beim prädisponierten Menschen werden im Verlauf von Infektionen mit dem Borna-Disease-Virus Zusammenhänge mit psychiatrischen Erkrankungen, vor allem endogenen Depressionen, vermutet.

Das Virus enthält eine (-)-Strang-RNS mit 8,9 kb, sein Durchmesser beträgt etwa $90 \mathrm{~nm}$ (Ikosaeder mit Hülle). In der Zellkultur läßt es sich zwar züchten, erzeugt aber keinen ZPE. Im ZNS der befallenen Tiere ist vor allem das limbische System befallen. Pathognomonisch sind die Joest-Degen'schen Einschlußkörperchen in den Neuronen. Zum Nachweis von Virusmarkern und Antikörpern im Serum oder Liquor eignet sich ein IFT, ein ELISA oder ein Westernblot. In Blutmonozyten sind Virusmarker vor allem über die PCR nachgewiesen worden. Kürzlich wurden auch Isolate von psychiatrischen Patienten und dem Gehirn eines Schizophrenie-Patienten gewonnen. Die Beziehungen der Borna-Viren der Tiere zu den menschlichen Erkrankungen bzw. deren Isolate sind offen.

\subsection{Multiple Sklerose}

Die Ätiologie der Multiplen Sklerose (MS) ist ungeklärt. Man betrachtet sie u.a. als eine durch Viren induzierte sekundäre Autoimmunkrankheit, möglicherweise mit einem genetischen Hintergrund. Die genetische Disposition betrifft vor allem Menschen mit der HLA-Kombination HLA-A3 und -B7, am häufigsten assoziiert mit -Dw2 und -DRw2. Die bisher vorliegenden Erhebungen haben ein epidemiologisches Verhalten ergeben, das an die Verhältnisse bei der Polio erinnert. Die Prävalenz steigt mit der geographischen Breite nordwärts (ab $40^{\circ}$ Nord) und auch mit dem Lebensstandard. Wahrscheinlich wird die Krankheit in den ersten 15 Lebensjahren erworben und manifestiert sich erst nach einer mehr oder weniger langen Latenzperiode. Offensichtlich fungieren bestimmte Bestandteile des zentralen Myelins (z.B. das basische Myelin-Protein, Glykolipide und Cerebroside) als Antigene, initiiert durch eine Virusinfektion. Es könnte sich um Masern-Viren handeln, oder auch Paramyxo-Viren, Retro-Viren oder das HHV 6. RNA von Masern-Viren und von Parainfluenza-Viren konnte in einigen MS-Fällen im ZNS nachgewiesen werden; jedoch muß dies nicht ursächlich mit der Entmarkungskrankheit verbunden sein. Jüngere Beobachtungen favorisieren das HHV 6 als auslösenden Faktor. IgM-Antikörper gegen das p38/41 treten bei Patienten mit chronischem schubförmigen Verlauf gehäuft auf. Bei drei von sieben Patienten mit aktiven MS-Läsionen und akuten Entmarkungen konnten Strukturproteine des HHV 6 nachgewiesen werden. Diese Beobachtungen hätten weitreichende Bedeutung, da sich neue Krankheitsschübe chemotherapeutisch durch die Gabe von Acicloguanosin verhindern ließen. Therapeutisch wird u. a. IFN $\beta$ gegen die MS eingesetzt.

Der klinische Verlauf und pathologisch-anatomische Befunde zeigen mehrere Erscheinungsformen der Multiplen Sklerose: chronische MS, akute MS, Neuromyelitis optica, konzentrische Sklerose u.a. Am häufigsten ist die chronische Verlaufsform der MS, die meist in Schüben zu immer massiveren neurologischen Ausfallerscheinungen führt.

Bei der Neuromyelitis optica stehen Entmarkungsprozesse im Vordergrund. Auch die chronische MS beginnt zuweilen mit einer Sehnervenerkrankung. Die konzentrische Sklerose ist ein seltenes Krankheitsbild.

Neuropathologisch-anatomische Veränderungen bei der chronischen MS sind multiple Entmarkungsherde im Großhirn, im Hirnstamm, im Kleinhirn und vor allem auch im Rückenmark. Diese Entmarkungsherde kommen jedoch auch im Bereich der grauen Substanz vor. Der immunologisch initiierte Entzündungsprozeß führt zunächst $\mathrm{zu}$ einer Zerstörung der Myelinscheiden; jedoch führt er auch zu einer axonalen Schädigung bis zu einer vollständigen Zerstörung des Gewebes.

Die autoimmunologische Encephalomyelitis disseminata bewirkt nur eine Zerstörung des zentralen Myelins, peripheres Myelin wird hierbei nicht angegriffen. - Differentialdiagnostisch ist an ein zerebrales Tumorleiden zu denken.

In akuten Krankheitsphasen kommen außer Makrophagen und lymphoiden Zellen auch Granulozyten vor; in chronischen Episoden überwiegen lympho-plasmazelluläre Infiltrate. Im Bereich alter abgeheilter Entmarkungsherde ist eine deutliche reaktive Vermehrung faserbildender Astrozyten zu finden (daher der Name: Multiple Sklerose). 

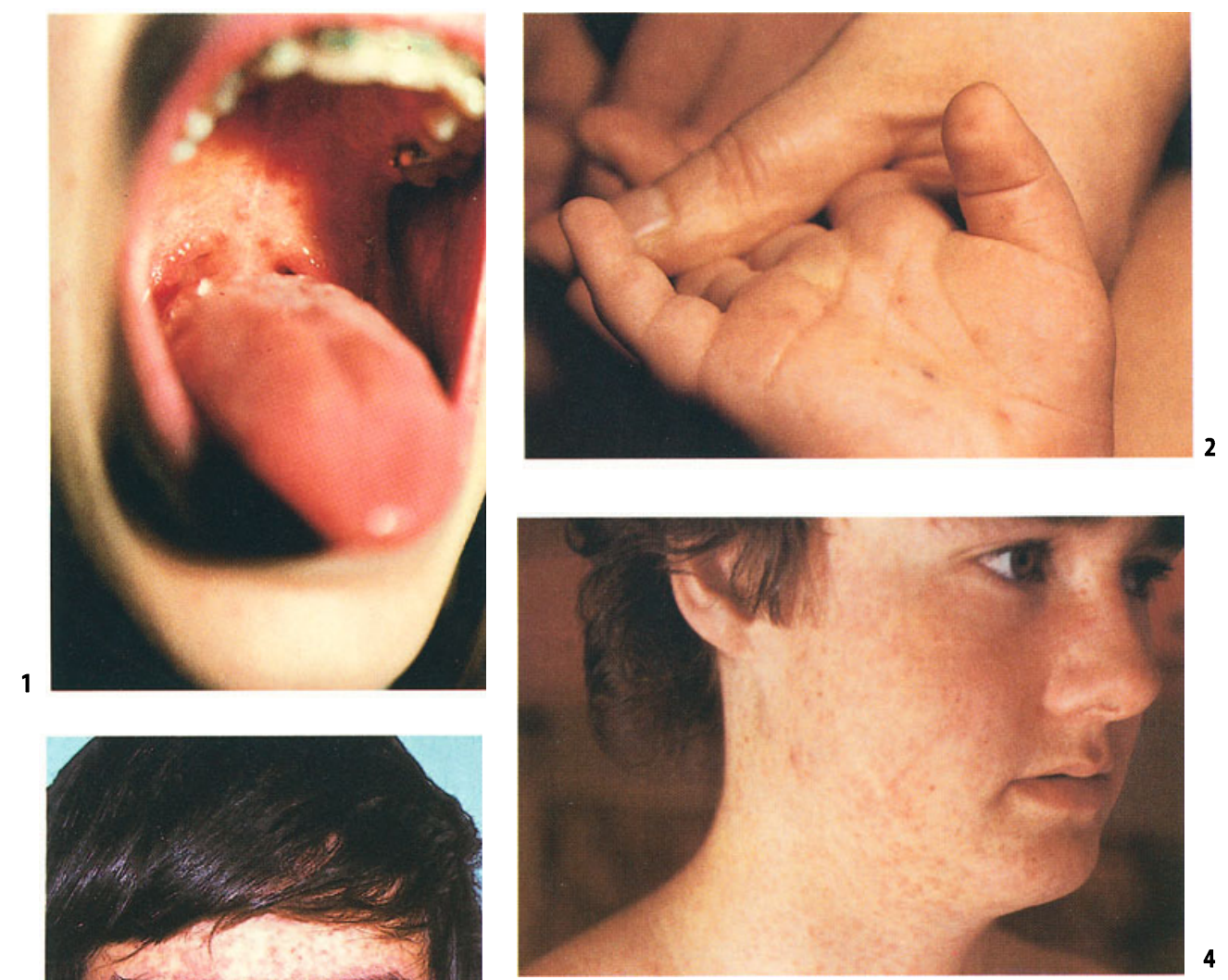

3
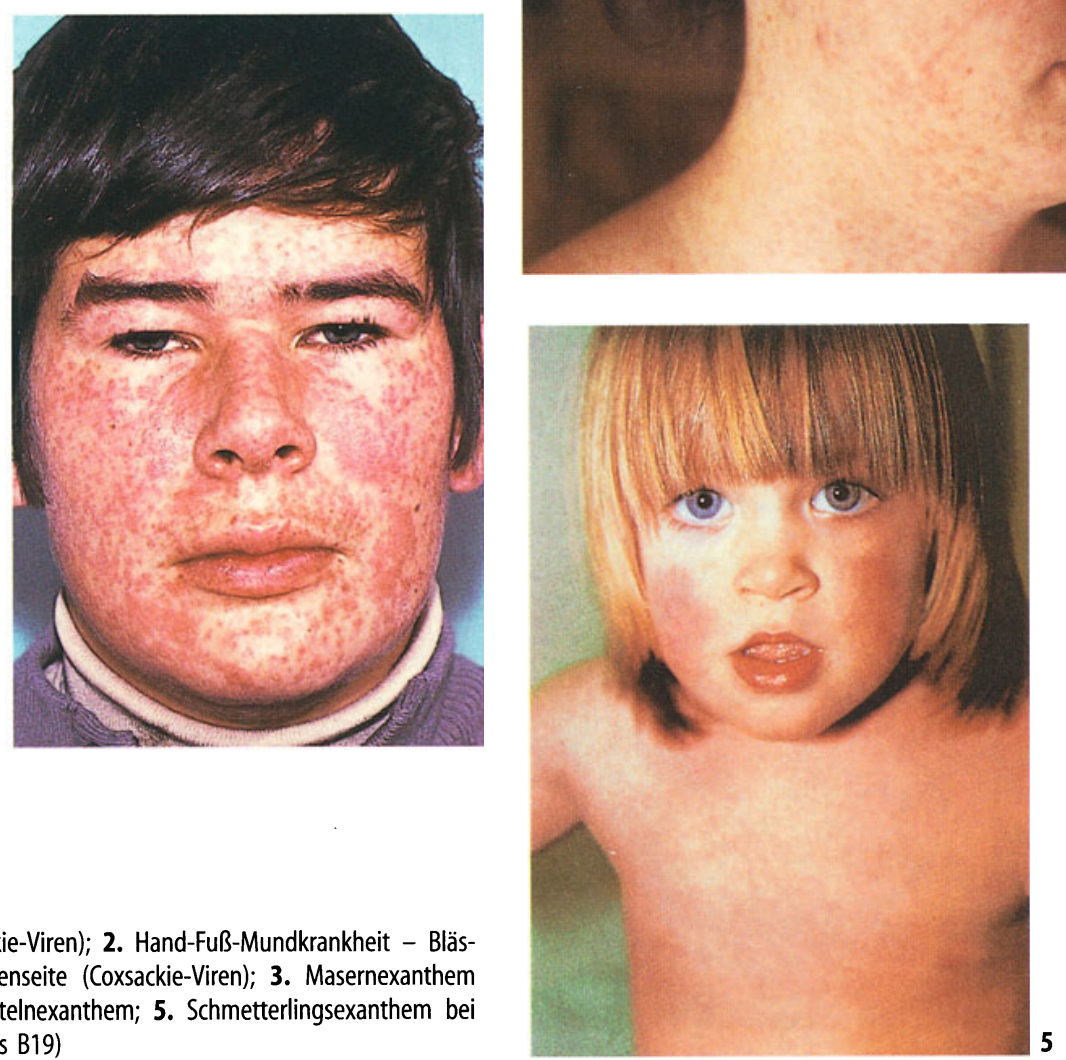

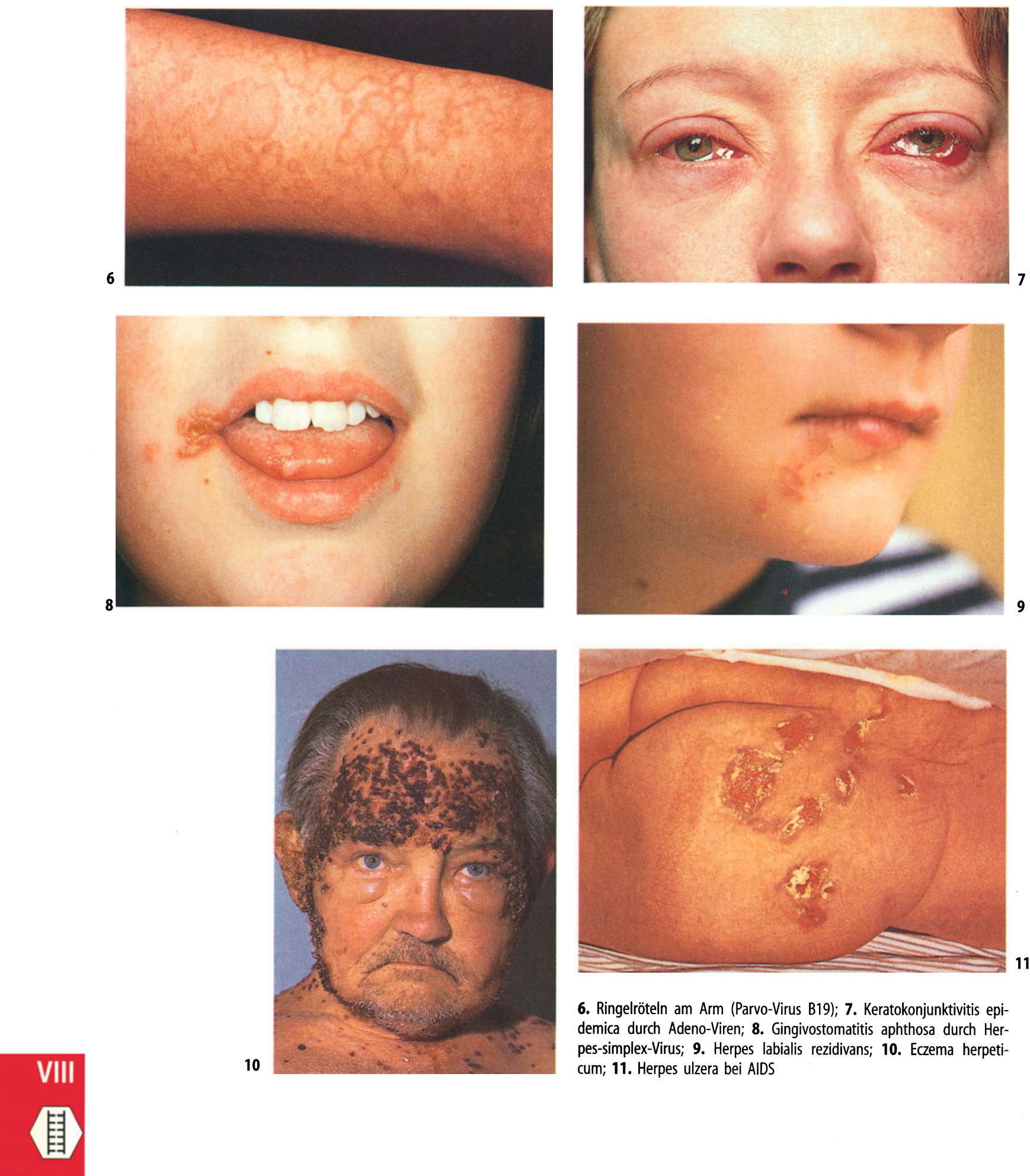

6. Ringelröteln am Arm (Parvo-Virus B19); 7. Keratokonjunktivitis epidemica durch Adeno-Viren; 8. Gingivostomatitis aphthosa durch Herpes-simplex-Virus; 9. Herpes labialis rezidivans; 10. Eczema herpeticum; 11. Herpes ulzera bei AIDS 

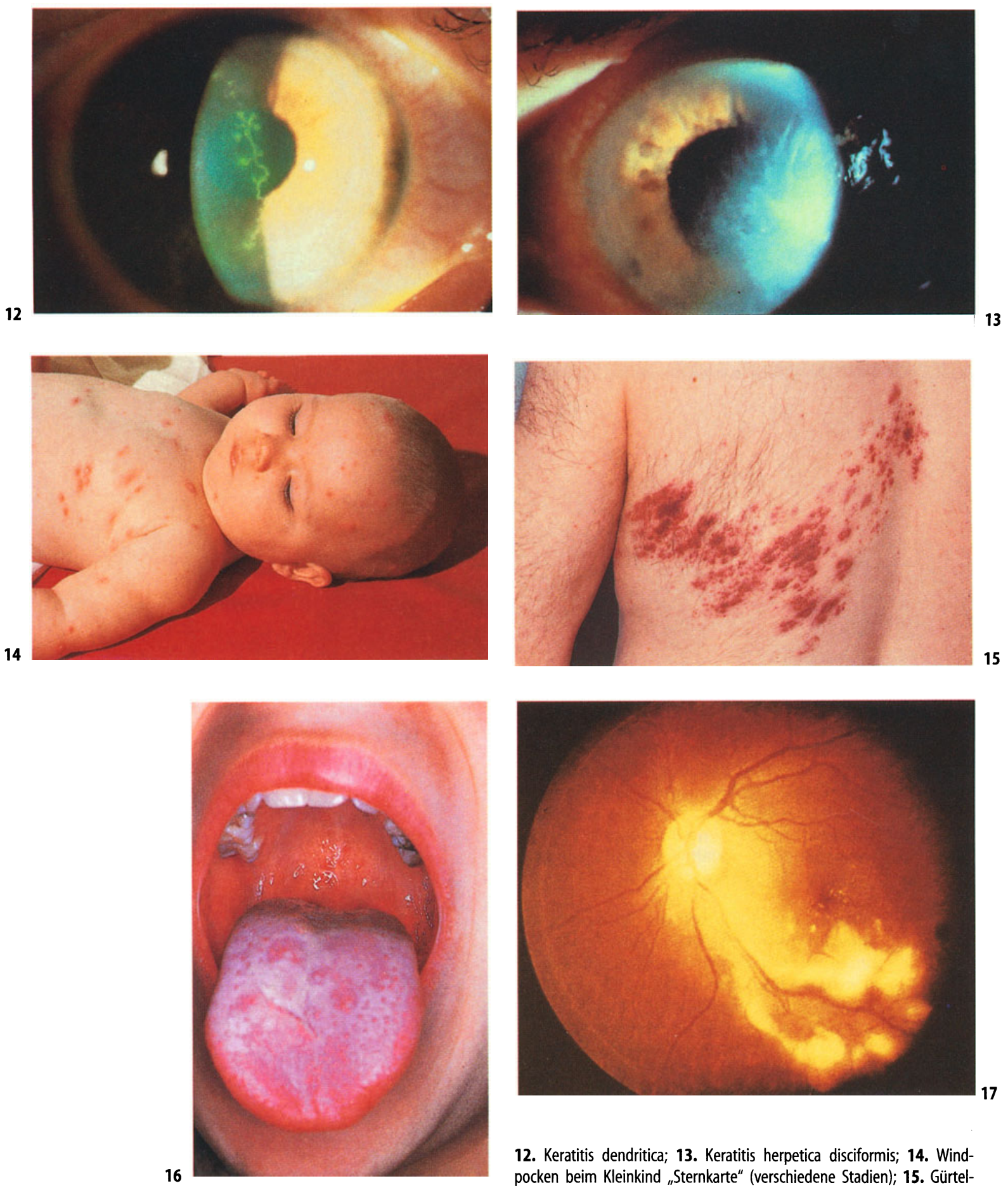

12. Keratitis dendritica; 13. Keratitis herpetica disciformis; 14. Windpocken beim Kleinkind "Sternkarte" (verschiedene Stadien); 15. Gürtelrose am Rücken; 16. Windpockenbläschen auf Zunge und am weichen Gaumen; 17. Chorioretinitis bei AIDS durch Zytomegalie-Virus 

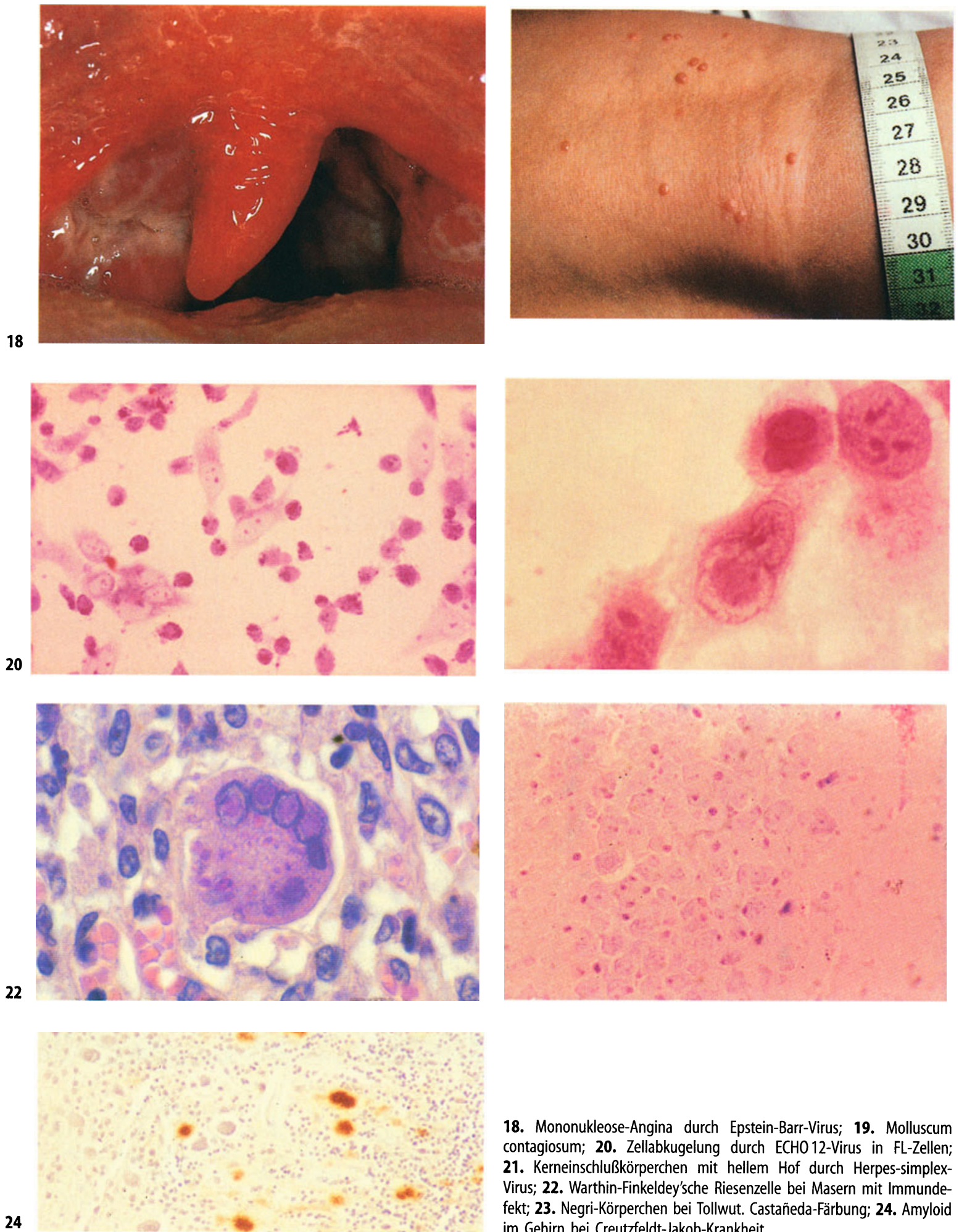

18. Mononukleose-Angina durch Epstein-Barr-Virus; 19. Molluscum contagiosum; 20. Zellabkugelung durch ECHO 12-Virus in FL-Zellen; 21. Kerneinschlußkörperchen mit hellem Hof durch Herpes-simplexVirus; 22. Warthin-Finkeldey'sche Riesenzelle bei Masern mit Immundefekt; 23. Negri-Körperchen bei Tollwut. Castañeda-Färbung; 24. Amyloid im Gehirn bei Creutzfeldt-Jakob-Krankheit 